\title{
Osteoporosis in inflammatory Bowel disease : epidemiological, pathophysiological and clinical studies
}

Citation for published version (APA):

Schoon, E. J. (2001). Osteoporosis in inflammatory Bowel disease : epidemiological, pathophysiological and clinical studies. [Doctoral Thesis, Maastricht University]. Universitaire Pers Maastricht. https://doi.org/10.26481/dis.20011116es

Document status and date:

Published: 01/01/2001

DOI:

10.26481/dis.20011116es

Document Version:

Publisher's PDF, also known as Version of record

\section{Please check the document version of this publication:}

- A submitted manuscript is the version of the article upon submission and before peer-review. There can be important differences between the submitted version and the official published version of record.

People interested in the research are advised to contact the author for the final version of the publication, or visit the DOI to the publisher's website.

- The final author version and the galley proof are versions of the publication after peer review.

- The final published version features the final layout of the paper including the volume, issue and page numbers.

Link to publication

\footnotetext{
General rights rights.

- You may freely distribute the URL identifying the publication in the public portal. please follow below link for the End User Agreement:

www.umlib.nl/taverne-license

Take down policy

If you believe that this document breaches copyright please contact us at:

repository@maastrichtuniversity.nl

providing details and we will investigate your claim.
}

Copyright and moral rights for the publications made accessible in the public portal are retained by the authors and/or other copyright owners and it is a condition of accessing publications that users recognise and abide by the legal requirements associated with these

- Users may download and print one copy of any publication from the public portal for the purpose of private study or research.

- You may not further distribute the material or use it for any profit-making activity or commercial gain

If the publication is distributed under the terms of Article $25 \mathrm{fa}$ of the Dutch Copyright Act, indicated by the "Taverne" license above, 


\section{Osteoporosis in Inflammatory Bowel Disease}

Epidemiological, Pathophysiological and Clinical Studies 
(6) Erik Jan Schoon, Maastricht 2001

15BN 9052783276

cover: "Marlstone from Limburg" photography: EJ Schoon design: Datawyse

Scientific studies in this thesis were supported by an educational grant from Astrazeneca, the Netherlands.

Printing of this thesis was financially supported by AstraZeneca, the Netherlands. Additional financial support by Astra Zeneca Sweden, Byk, MSD. Tramedico, Ferring, Eli Lilly, Procter \& Gamble, Aventis, Janssen-Cilag and Schering-Plough was gratefully acknowledged. 


\title{
Osteoporosis in Inflammatory Bowel Disease
}

\author{
Epidemiological, Pathophysiological \\ and Clinical Studies
}

PROEFSCHRIFT

ter verkrijging van de graad van doctor aan de Universiteit Maastricht, op gezag van de Rector Magnificus,

Prof. dr. A.C. Nieuwenhuijzen Kruseman, volgens het besluit van het College van Decanen, in het openbaar te verdedigen

op vrijdag 16 november 2001 om 12.00 uur

door

Erik Jan Schoon

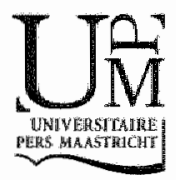




\section{Promotor}

Prof. dr. R.W. Stockbrügger

\section{Co-promotores}

Dr. R-J.M. Brummer

Dr. M.G.V.M. Russel

\section{Beoordelingscommissie}

Prof. dr. E.F.M. Wouters (voorzitter)

Prof. dr. G. Bianchi Porro (University of Milan, Italy')

Prof. dr. S.B. Hanauer (University of Chicago, USA)

Prof. dr. J.M.J.P. van der Linden

Prof. dr. P.B. Soeters 
Let us not forget

how fragile we are .......

Sting

Aan mijn ouders

Gabrielle,

Folkert, Veerle en Karlijn 



\section{Contents}

Abbreviations: 8

Chapter $1 \quad$ Introduction 9

Chapter $2 \quad$ Osteoporosis in IBD: a review 15

Chapter 3 The prevalence of osteoporosis in Crohn's disease:

a population-based study in the Netherlands

Chapter $4 \quad$ Clinical determinants of bone mineral density in

Crohm's disease

Chapter $5 \quad$ Bone minerall density in patients with recently diagnosed $I B D$

Chapter $6 \quad$ Low serum and bone vitamin $K$ status in patients with long-standing Crohn's disease: another pathogenetic factor of osteoporosis in Crohn's disease?

Chapter 7 Abnormal bone turnover in longstanding Crohn's disease in remission

Chapter $8 \quad$ Osteoporosis and spontaneous vertebral fractures in Crohn's disease: size of the problem and risk. factor analysis in a large European study population

Chapter $9 \quad$ General discussion

Chapter 10 Summary

Chapter 11 Samenvatting

Chapter 12 Metabole botziekten bij chronische inflammatoire darmziekten (ziekte van Crohn en colitis ulcerosa)

Dankwoord

Curriculum Vitae 


\section{Abbreviations}

\begin{tabular}{|c|c|}
\hline 5-ASA & $=5$-amino-salicylic acid \\
\hline BAP & $=$ bone specific alkaline phosphatase \\
\hline BMD & $=$ bone mineral density \\
\hline BMI & $=$ body mass index \\
\hline $\mathrm{CD}$ & $=$ Crohn's disease \\
\hline CDAl & $=$ Crohn's disease activity index \\
\hline $\mathrm{Cl}$ & $=$ confidence interval \\
\hline CTX & = collagen type | C-terminal crosslinks \\
\hline DXA & $=$ dual eneirgy $X$-ray absorptiometry \\
\hline DPD & $=$ deoxypyridinaline \\
\hline $\mathbb{F N}$ & = femoral neck \\
\hline Gla & = gamma-carboxyglutamate \\
\hline Glu & $=$ glutamic acid \\
\hline $\mathrm{HBC}$ & $=$ hydroxyapatite binding capacity \\
\hline$\| B D$ & $=$ inflammatory bowel disease \\
\hline $1 G F-1$ & $=$ insulin like growth factor 1 \\
\hline L.S & = lumbar spine \\
\hline MGP & $=$ matrix Gla proteins \\
\hline PTH & $=$ parathyroid hormone \\
\hline OC & $=$ osteocalcin \\
\hline$O C_{\text {mound }}$ & = bound osteocalcin (carboxylated) \\
\hline$O C_{\text {riger }}$ & = free osteocalcin (undercarboxylated) \\
\hline$O C_{\text {TOYAL }}$ & $=$ total osteocalcin \\
\hline $\mathrm{QCT}$ & = quantitative computer tomography \\
\hline SD & $=$ standard deviation \\
\hline SPA & = single photon absorptiometry \\
\hline $\mathrm{TB}$ & $=$ total body \\
\hline UC & $=$ ulcerattive colitis \\
\hline WHO & = World Health Organization \\
\hline
\end{tabular}




\section{Introduction}




\section{Introduction}

Inflammatory bowel disease was first described 300 years aga, but it was 32 years after the first report by Burril Bernard Crohn, in 1932, recognizing terminal ileitis as a clinical entity, that bone problems were described as a potential complication "2. In 1964, Edwards and Truelove described radiologically assessed osteoporosis in 9 of $624(1.4 \%)$ patients with Ulcerative colitis and they stated that: "...this must be regarded as an underestimate of its true frequency which would only be determined by systematic studies".

In 1976 Genant et al. reported impaired skeletal growth and mineralization in 54 adolescent and adult patients with inflammatory bowel disease by qualitative and quantitative radiological techniques which consisted of conventional röntgenography, photon absorptiometry, and radiographic morphometry".

In 1987 Compston et al. published a cross-sectional study on 75 patients with inflammatory bowel disease (IBD) using single photon absorptiometry of the forearm and computer tomography scanning (CT) of the vertebrae ${ }^{5}$.

In the 1990's dual energy X-ray absorptiometry (DXA) became available, as a safe and easy method to assess bone mineral density (BMD), and the number and size of the studies increased subsequently. Pigot et al. described the first cross-sectional study using DXA in a group of patients with both ulcerative colitis (UC) and Crohn's disease (CD) ${ }^{6}$. After this several studies were published, which will be discussed in more detail in the next chapter.

In the last decades an increasing number of treatment options for IBD became available and were implemented in daily practice. Nowadays, the life expectancy of IBD patients is comparable to that of the background population ${ }^{7,8}$. This might be the reason that patients and clinicians are compielled to focus on the long-term complications and the quality of life in IBD.

In a recent study performed in the Netherlands (1991-1994), an incidence rate for $C D$ was found of 6.9 per 100.000 inhabitants per year and 10.0 for UC, respectively". That study was the start of the South-Limburg IBD registration, which was also the base of a number of the investigations which are described in the present thesis.

Early attention to the problem of bone disease could mean a long-term benefit for the patient as the age profile in $C D$ shows a peak incidence between 15 and 30 years, with a female preponderance.

In 1998, the Dutch Health Council advised against a general population screening for osteoporosis but recommended a case-finding strategy ${ }^{10}$. For prevention of the late complications of osteoporosis, particularly bone fractures, IBD patients seem an excellent example of a group in which screening would be useful.

Many questions regarding the clinicall management of metabolic bone disease in IBD remain unanswered: "Who is at risk? Why? And: What shall we do about it?" it There is a lack of evidence-based knowledgle in this field of metabolic bone disease. Hopefully, the studies described in this thesis will contribute to an increasing basal knowledge of this complication for clinicians and will offer benefit to the patients by preventing debilitating fractures. 


\section{References}

1. Inflammatory bowel disears. In: Kirstrer JB and Shorter RG, eds. 4 ed. 1995:327.

2. Crohn BB, Ginzberg L, Oppenhemer GD. Regional lleitis: A pathologic and chical entity. $1 \mathrm{~A}$ M A $1932,99-1323-1329$.

3. Eumards $\mathrm{F}_{3}$ Truelove $5 \mathrm{C}$. The course and prognosis of Ulcerative colitis. Gut 1964:5:1:-22.

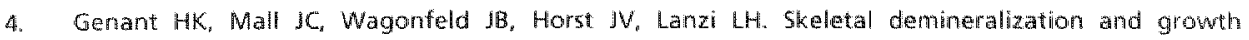
retardation in intlanmatory bowel disease. Invest Radiol 4976:11:541 549 .

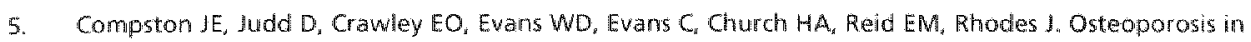
patients whin inflammatory bowel disease. Gut $1987,28: 410415$.

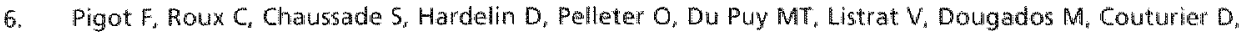
Amor B. Low bone mineral density in patients with inflammatory bowel disease. Dig Dis SCh $1992 ; 37: 1396-1403$.

7. Farrokhyar F, Swarbrick ET, Grace RH, Hellier MD, Gent AE, invine EI. Low monality in ulcerative colitis and Crohn's disease in three regional centers in England. Am J Gastroenterol 2001:96:501-507.

8. Witte J, Shivananda 5, tennard-Jones JE, Beftramä M, Politi B, Bonanomi A, Tsianos EV, Mouzas I. Schulz TB, Monteiro E, Clofent I, Odes 5, Limonard CB, Stockbrugger RW, Russel MG. Disease outcome in inflammatory bowel disease: mortally, morbidify and therapeutic management of a $796 \%$ person inception cohort in the European Collaborative Study on Inflammatory Bowel Disease (ECIBD). Scand J Gastroenterol 2000;35:1272-1277.

9. Russel MG, Dorant E, Volovics A, Brummer RA, Pop P. Muris WW, Bos LP. Limonard CB, Stockbrugger RW. High incidence of inflammatory bowel disease in The Netherlands: results of a prospectwe study. The South Limburg $\| B D$ Study Group. Dis Collon Rectum 1998:41:33-40.

10. Prevention of osteoporosis related fractures. Health Counsel: osteoporosis commission. 1908. Health: Counsel of the Netherlands.

11. Sachar $D_{n}$ Personal communication. 



\section{Outline of the thesis}

Chapter 2 reviews the current knowledge on the relation between IBD and metabolic bone disease.

In chapter 3 the results are presented regarding the prevalence of osteoporosis and osteopenia in Crohn's disease of a well-defined population-based cohort from the IBD South-Limburg study area.

In chapter 4 clinical determinants of bone mineral density are discussed in a population-based cohort of patients with Crohn's disease. Many potential risk factors for low bone mineral density have been taken into consideration and analysed by linear regression.

A study investigating whether bone mineral density in patients with IBD is already low at diagnosis is described in chapter 5. Bone mineral density measurement of recentily diagnosed patients with Crohn's disease and ulcerative colitis is measured and compared to age and gender matched population controls. Bone minera! density of patients with Crohn's disease and ulcerative colitis are compared, in this respect. Determinants for bone mineral density at diagnosis are assessed.

In chapter 6 vitamin $\mathrm{K}$ status in serum and bone of patients with long-standing Crohn's disease in remission is assessed. The level of circulating uncarboxylated osteocalcin, as a marker for vitamin $\mathrm{K}$ status of bone, is correlated with bone mineral density and is presented as a novel risk factor for osteopenia in Crohn's disease.

In chapter 7 the pathophysiologic process of bone turnover is described in a homogeneous group of patients with long-standing Crohn's disease in clinical remission by using biochemical markers.

In chapter $\mathbf{8}$ describes the baseline data of an European multi-centre intervention study in which the prevalence and risk factors of osteoporosis in Crohn's disease are considered. This is the first study in which results are described on systematical radiographic assessment of vertebral fractures in patients with Crohn's disease.

In chapter 9 the results of above mentioned studies are discussed in the context of current literature. An opinion is given on future developments.

In chapter 10 a summary is given of the studies in this thesis.

Chapter 11 is a summary in Dutch.

Chapter 12 is a review in Dutch. 



\section{Osteoporosis in IBD: a review}

EJ Schoon, BHR Wolffenbuttel, RW Stockbrügger

Published in part in:

Drugs of Today 1999;35(Suppl.A):17-28 And in:

Maladies inflammatoires chroniques de I'intestin/lnflammatory Bowel Disease.

R Modigliani ed. John Libbey Eurotext, Paris 2000 
16. Chapter 2

\section{Abstract}

The association between inflammatory bowel disease (IBD) and metabollc bone disease has been known for some decades. When dualenergy $X$-ray absorptiometry (DxA) became avaliable, the number and the size of studies on this subject increased The reported prewalence of decreased bone mass varies from $27 \%$ to $77 \%$, depending on patient selection, method of bone density measurement and definitions used. Osteoporosis is defined as a systemic skeletal disease characterized by low bone mass and microarchitectural deterioration of bone tissue, with an ncrease in bone fragility and fracture risk, osteopenia is the predinical condition of osteoporosis, The pathogenesis of bone loss In IBD is probably multifactorial and nvolves maldiglestion and malabsorption with vitamin $\mathrm{D}$-deficiency and calcium deficiency, sex hom mone deflciency, smoking, disease activity, and conticosteroid use, in several studies, bone mineral density in patients with Crohn's disease is similar to bone mineral density in patients with ulcerative colitis, but others have indicated that low boine mineral density is preferentially a feature of Crohn's disease. In Crohn's disease moire risk factors for the pathogenesis of bone loss are present than in ulcerative colitis. The use of corticosteroids and the disease process in IBD are supposed to have a central role in the negative effects on bone metabolism. Many studies support the negative effect of corticosteroids on bone mineral density, but there are also controversial data Corticosteroids are effective in the treatment of $\mathrm{BDD}$. However they cause a negative calcium balance reduce bone formation, they increase bone resorption, and suppress the gonadal sterold production. Furthermore, it has been demonstrated that pro inflammatory cytokines directly influence osteoblast and osteodast function. Osteoblast and osteoclast function can be measured by biochemical markers of bone turnover, such as bone-specific alkaline phosphatase, osteocalcin, deoxypyridinoline and collagen type 1 degradation products. With these methods some studies find no significant changes, while others find a disturbed remodelling due to impaired bone formation, horeased bone resorption, or both. Clinical risk individual patient, and therors of actual bone mass in the susceptibility for steroids. Therefors, to be an individual measuring bone mineral density should be low and such a long-term corticosteroid performed in every patient in whom first series of children werapy can be expected Recently, the vertebral fractures were with Crohn's disease who developed Presently only a fowere reported

osteopenia and osteopos on the prevention and treatment of mentation of calcium and in IBD are avallable, Supplepatients should become a vitamin $\mathrm{D}$ in corticostercid-treated been published on treatment therapy. Recently, a study has disease and the results are bisphosphonates un Crohn's corticosteroids like budesonide may positive. Locally-applied on bone metabolism than prednisoy have a less negative effect be proven. 


\section{Prevalence of osteoporosis in IBD}

The association between bone loss and inflammatory bowel disease (IBD) was first reported in 1964. The reported prevalence was low, as it was based on relatively insensitive criteria, such as fractures and radiological signs of osteoporosis in patients with ulcerative colitis (UC). There was another early report on skeletal abnormalities in IBD by Genant et al." The results indicated that osteopenia and retardation of growth were common in $1 \mathrm{BD}$, particularly in adolescents.

Osteoporosis is a systemic skeletal disease characterized by microarchitectural reduction of bone tissue leading to low bone mass, increased bone fragility and, thereby, increased fracture risk". The preclinical state of osteoporosis is called osteo-penia. Osteoporosis is commonly found as senile or post-menopausal osteoporosis, or as a consequence of chronic disease or medical treatment. Osteomalacia is a defect in mineralization of an essentially normal bone matrix and is called rickets in children. Osteomalacia is mainly a consequence of vitamin D-and calcium-deficiency seen in children or elderly with malnutrition or malabsorption. or in rare cases of vitamin D resistance.

Different methods of bone density measurements can be used such as quantitative computed tomography (QCT), single-photon absorptiometry (SPA), double-photon absorptiometry (DPA) and dual energy X-ray absorptiometry (DXA). DXA is accurate, reproducible and involves very low doses of radiation.

Bone mineral density (BMD) is expressed in standard deviations of means, $T$ - and $Z$ scores, which are compared to reference populations (Table 2.1). One standlard deviation decrease in BMD increases the fracture risk 1.5 to 3 -fold ${ }^{3.4}$.

\section{Table 2.1 Definitions of T and Z-score}

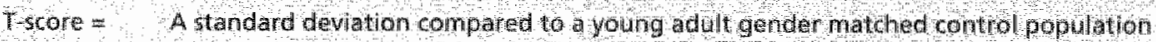

Z-score $=\quad$ A standard deviation compared to age and gender matched control populathon

The WHO-definition for osteoporosis and osteopenia (Table 2.2) was initially designed for post-menopausal bone mineral density but is presently also used for secondary osteoporosis and in males. As there is no commonly accepted definition of osteoporosis expressed in Z-score, the comparison of the present data on the prevalence of osteoporosis can be confusing.

Table 2.2 World Health Organization definitions of osteopena and osteoporosis

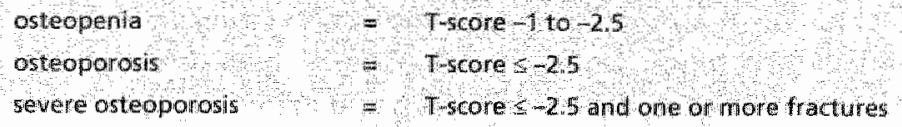


Since 1987, several cross-sectional studies have been published on the prevalence of osteopenia and osteoporosis in $1 \mathrm{BD}^{3.52}$. The reported prevalence of decreased bone mass varies widely from $2.7 \%$ to $77 \%$, and is higher in Crohn's disease (CD) than in UC. These studies, as summarized in Table 2.3, are, in general, studies from referral centers and involve mostly mixed groups of $C D$ as well as UC patients. Several different definitions of osteoporosis and osteopienia, expressed as T-score and/or Zscore, have been used. Apart from the lack of uniformity in these studies, it is obvious that there is a high prevalence of osteopenia and osteoporosis in IBD. Strikingly, no gender-dependent risk for bone loss is found, and in larger studies the hip seems to be more frequently involved in the bone-losing process than the spine. Also, in $1 \mathrm{BD}$, the risk for osteoporosis significantly increases after menopause, as expected from the normal population.

The prevalence of symptomatic fractures was established in six studies. In a study by Compston, 6 of 23 patients $(26 \%)$ with osteoporosis (in this case defined as Zscore $<-2$ ) had radiological evidence of one or more vertebral crush fractures. In two other studies vertebral crush fractures were found in $5 \%$ and $7 \%$. respectively, of the IBD patients. Jahnsen et al. found $3.3 \%$ fractures in CD and 1.6 $\%$ in UC $C^{13}$. Vestergaard et al. reported an increased fracture risk in Crohn's disease but not in UC; in female patients especially, the relative risk was $2.5^{14}$. No increased risk for male patients was found in this study. In a large epidemiological study, the overall relative risk of fracture was $40 \%$ higher in patients with IBD than in population controls ${ }^{15}$. However, both studies were retrospective, BMD was not measured, and $X$-rays of the spine were not performed systematically. Vertebral crush fractures have even been reported in children with $\mathrm{CD}$ using corticosteroids ${ }^{16}$ and, anecdotally, as presenting symptom".

\section{Pathophysiology of osteoporosis in IBD}

Bone is a living tissue in which there is a constant cycle of degradation (resorption) performed by osteoclasts and bone formation by osteoblasts replacing old bone with new bone. This bone turnover should be in balance; otherwise, decreased formation, increased resorption or both lead to bone loss. Osteoblasts and osteoclasts originate from stem cells in the bone marrow and proliferate under a complex influence of growth factors, cytokines, and hormones. Remodelling imbalance can result in osteopenia and osteoporosis. To diagnose osteomalacia histologic examination of bone acquired by biopsy and the presence of unmineralized "osteoid" is necessary.

\section{Histomorphometry}

A study on the histomorphometric changes in bone of 19 osteoporotic patients with IBD showed reduced bone formation at the cellular and tissue level ${ }^{\text {sis }}$. The proportionately greater change in wall width than in resorption cavity was consistent with a negative remodelling balance. None of the patients had osteomalacia as defined by the criteria of increased osteold border width and mineralization lag time, but there was an indication for a mild mineralization defect. 
In an earlier study of patients with small bowel resections, mostly with IBD. 9 of 25 patients had bone changes indicative of osteomalacia". In another study of nine patients selected to be at "high risk" for metabolic bone disease, histologic examination of bone bilopsies showed osteomalacia in six patients and concomitant osteopenia in four ${ }^{20}$. In a study on bone biopsies of 36 unselected CD patients with small-bowel resections, a mean reduced trabecular bone mass was found, but frank signs of osteomalacia were found in only two biopsies".

Table 2.3 Cross-sectional and population based studies on prevalence af osteopenia and osteoporosis in inflammatory bowel disease.

\begin{tabular}{|c|c|c|c|c|}
\hline author & co/UC(n) & method & definition & prevalence $(\%)$ \\
\hline \multirow[t]{3}{*}{ Compston' } & 5211 & SPA & osteoporosis $2 \leq 2$ & Lumbar spine + forearm \\
\hline & & $\mathrm{CT}$ & & $\mathrm{CD} 41$ \\
\hline & & & & UC 14 \\
\hline \multirow[t]{4}{*}{ Tromm } & $52 / 23$ & $\mathrm{Cl}$ & osteopenia $2<-1$ & Lumbar spine (CD) 30 \\
\hline & & & & Lumbar spine (UC) 9 \\
\hline & & & asteoporosis $Z<-2$ & Lumbar spina (CD) 75 \\
\hline & & & & lumbar spine (0Q) 4.4 \\
\hline Abitbols & $34 / 50$ & $D \times A$ & osteoplenila $2 \leq-1$ & Lumbar spine: 43 \\
\hline \multirow[t]{2}{*}{ Silvennoinen } & $78 / 60$ & $\mathrm{D} \times \mathrm{A}$ & osteopenia 2 -1 & lumbar spine: 5,3 \\
\hline & & & & femoral neck 59 \\
\hline \multirow[t]{4}{*}{ Bjarnalsson } & 4435 & DXA & osteopenia $\mathrm{T}$ s & lumbar spine: 54 \\
\hline & & & & femoral neck 77 \\
\hline & & & osteoporosis Ts $>25$ & lambar spine: 18 \\
\hline & & & & femeral neck 29 \\
\hline \multirow[t]{6}{*}{ Schoon } & 1410 & DXA & osteopenia $T \leq-1$ & lumbar spine 22 \\
\hline & & & & temoral neck 41 \\
\hline & & & & total body 27 \\
\hline & & & osteopolosist $\leq-25$ & lumbar spine? \\
\hline & & & & femoral nedk 11 \\
\hline & & & & totial bodys \\
\hline
\end{tabular}

$C O=$ Crohn's disease, UC = ulceratlve colitis, $D X A=$ dual energy $X$ ray absarptiometry, SPA $=$ single photon absorptionetry, $\mathrm{GT}=$ quantitative computed tomograply.

\section{Biochemical markers}

Osteoblast and osteoclast function can be measured by using biochemical markers of bone turnover ${ }^{22}$ (Table 2.4). While these biochemical markers are inadequate predictors of actual bone mass, they do provide information on the bome turnover in the entire skeleton ${ }^{2 *}$. Some studies have found no significant changes using these markers, whille others have found a disturbed remodelling due to impaired bone formation, increased bone resorption, or both. The different outcomes of these studies can partially be explained by differences in patient selection, disease activity and corticosteroid use s, $2,24 \cdot 27_{\text {. }}$ 
Table 24 Blochemical parameters of bone tumover.

bone formation

osteocialcin

bione-spectic alkatine phosphatase

$C$ and N-propeptides of type l collagen bone resorption

hydroxyproline

hydroxylusine glycoside

pyridinium crosslinks of collagen

telopeptides

tartrate resistant acid phosphatase

In a study on bone turnover in patients with $C D$, osteoblast activity, reflected in serum osteocalcin levels, was impaired in patients treated with predrisolone, whereas budesonide in controlled ileal release formulation did not have such an effect. Urinary markers of bone degradation, i.e. pyridinolines and deoxypyridinolines, did not differ between the groups ${ }^{2 \pi}$.

\section{Risk factors for osteoporosis in IBD}

Risk factors contributing to the development of osteoporosis in IBD are in mostly similar to those in other conditions leading to secondary loss of bone mass. However, some are disease-specific or a consequence of treatment and, therefore, need the speciall attention of the physician (gastroenterologist).

\section{Corticosteroids}

Corticosteroid therapy is, in general, the most important cause of secondary osteoporosis. Although corticosteroids are effective in the treatment of patients with $1 B D$, they cause a negative calcium balance by reducing calcium absorption and increasing urinary calcium excretion. They also reduce bone formation increase bone resorption, and suppress gonadal steroid production ${ }^{2 * 30}$. Several studies have reported a negative effect of steroids on BMD in patients with $1 \mathrm{BD}^{5,3, y_{1}, t 3}$. This finding has also been described in other chronic diseases treated with corticosteroids, such as rheumatoild arthritis and obstructive pulmonary disease $^{2}$. Although many studies support the hypothesis of the negative effect of corticosteroids, there are controversial data too. In a study by Bjarnasson et al., mo correlation was found between the BMD of patients who were never treated with corticosteroids and those who had received a maximum lifetime dose of $10 \mathrm{~g}^{6}$. One explanation could be the exclusion of high-risk groups of patients using more than $10 \mathrm{mg} / \mathrm{day}$ prednisolone for 6 weeks before DXA, patients with a lifetime dose exceeding $25 \mathrm{~g}$, and post-menopausal patients.

Although Silvennoinen et al. reported a relatively low prevalence of osteopenia in IBD, a wreak but significant negative correlation between BMD and total lifetime steroid dose was found". Andreassen et al. observed that $C D$ patients who had 
been using steroids had a significantly lower BMD than healthy controls, but that cumulative corticosteroid dose did not correlate with $B \mathrm{BD}^{32}$.

Jahnsen et all. completed a study on BMD involving 60 patients with $C D, 60$ patients with UC and 60 controls ${ }^{13}$. The total steroid dose for CD was significant higher than fore those with UC. BMD was significantly lower in CD patients than in UC patients and in controls. Disease localization, duration of disease, and resection did not significantly influence BMD. In this study, treatment with corticosteroids had a significant negative influence on BMD in CD patients but not in UC patients. An equivalent result was found for the lifetime prednisolone dosage. In a covariate amalysis, corticosteroid use and low body mass index were the most important predictive factors of BMD in the patients with $C D$.

In a longitudinal study in children with $C_{1}$, no difference was found in $B M D$ lbody mass ratio between patients with alternate day corticosteroids and without corticosteroids, over a 2-year follow up ${ }^{33}$.

\section{Disease activity}

Disease activity is supposed to play a significant role in the development of metabolic bone disease in $\triangle B D$, especially in CD. A significantly lower BMD was already found at diagnosis in $C D$ compared to $U C$, indicating that factors other than corticosteroids may be involved". However; in a case-control study on 64 recently diagnosed IBD patients, BMD did not differ from that of age and gendermatched healthy controls ${ }^{14}$. A period of untreated disease of more than 6 months before diagnosis was identified as a risk factor for low BMD in the $\triangle B D$ patient group.

It has been demonstrated that cytokines directly affect bone formation and resorption as they influence the osteoblast and osteoclast function. Particularly proinflammatory cytokines like TNF, IL-1, and IL-6 are supposed to have a pivotal role in this process ${ }^{35,36}$. These cytokines are also important in the inflammatory process in $1 \mathrm{BD}^{37}$. In a recent study serum of pediatric patients with active $\mathrm{CD}$ was injected into rats $^{38}$. Compared to controls, this serum significantly decreased bone dry weight and calcium content, while serum from UC patients had no such effect. These data suggest that proinflammatory cytokines influence bone formation and bone resorption, resulting in bone loss. The exact factors causing bone loss have to be defined by further research ${ }^{3}$. In one study, genetic factors, i.e. the presence of IL-6 allele and the absence of the interleukin 1 receptor antagonist (IL-1 Ira) allele correlated with bone loss in a mixed group of 86 UC and CD patients ${ }^{\text {40 }}$.

\section{Smoking}

Only one study has to date, addressed smoking habits as a risk factor for osteoporosis in $1 \mathrm{BD}^{4}$. The authors found a significant negative effect of smoking on BMD in female IBD patients. No effect on BMD in male IBD patients was found, which was not surprising because almost all male patients in this study smoked. 
22 Chapter 2

\section{Hypogonadism}

Although corticosteroids are supposied to suppress the production of sex hormones, low testosterone levels in male IBD patients have also been described as an independent risk factor for osteoporosis ${ }^{42}$. Total testosterone levels were significantly associated with serum osteocalcin levels as a marker for increased bone formation. This association was independent of age and current steroid use. Female patients receiving high doses of corticosteroids can become amenorrhoic, due to lower estrogen levels. When estrogen protection of bone stops after menopause, bone resorption increases and the rate of bone loss increases, especially in the first years thereafter ${ }^{43,44}$.

\section{Body composition}

Low body mass is a risk factor for osteoporosis in the general population. Several studies show that low body weight is one of the most important risk factors for osteopienia ${ }^{32,43,45}$.

\section{Vitamin D deficiency}

There is a high prevalence of vitamin $D$ deficiency in patients with $C D^{20,46}$. This is caused by small intestinal disease, diarrhea, dietary effects, use of cholestyramin and, possibly, decreased sun exposure. These processes lead to a decrease in calcium absorption and cause a negative calcium balance. Vitamin $D$ status can be measured by 25 -hydroxyvitamin $D$, which best reflects the total body vitamin $D$ stores. Although 25-hydroxyvitamin D levels were llow in $56 \%$ of CD patients in a controlied study, those of 1,25-hydroxyvitamin D, the active metabolite, did not significantly differ from the levels in controls ${ }^{4 ?}$. In this study vitamin D status was independent of nutritional status, disease location, and previous intestinal resections.

Osteomalacia, as a consequence of vitamin D deficiency, is clinically associated with bone pain, bone deformations in children, fractures, muscle weakness, and tetany caused by hypocalcemia in severe cases. Typical radiographic changes are described. These clinical symptoms, elevated parathyroid hormone (PTH), elevated bonespecific alkaline phosphatase, and very low levels of 25 -hydroxyvitamin $D \ll 10$ nmol/1) could indicate the presence of osteomalacia, and a bone biopsy for confirmation should be considered. DXA does not differentiate between osteomalacia and osteoporosis. However, clinical signs of osteomalacia are rare in
$1 \mathrm{BD}^{30}$.

In a study on the relationship between vitamin D, PTH, and BMD in IBD, patients had lower serum levels of 25 -hydroxyvitamin $\mathrm{D}$ than healthy controls, but similar hydroxy-vitamin D and PTH were not associated with BMD. In another study, BMD of all measured areas was significantly lower in patients with increased PTH than in those with normal PTH, except for the lumbar spine ${ }^{\text {t3. }}$. 


\section{Disease duration}

A small number of studies address the issue of time-dependent bone loss and risk factors in IBD. In seven longitudinal studies of IBD patients, different rates of annual bone loss were found. The studies are summarized in Table 2.5. Both studies by Motley et al. describe the same patient population ${ }^{41,50}$. Study populations were generally small, and mixed groups of UC and CD patients were involved. The rate of spinal trabecular bone loss measured by QCT was studied for one year in 70 IBD patients. A mean loss of $3 \%$ was found. BMD of the radius was measured by SPA in 39 IBD patients, with a mean follow up of almost 8 years $^{52}$. The mean rate of annual bone loss was less than $1 \%$ in both sexes. In a smaller study by Ryde et al., in 13 IBD patients, a rapid decrease in total body calcium of $7.8 \%$ per year over a period of 2 years was found (by prompt $\gamma$-neutron activation analysis) ${ }^{53}$. BMD of the lumbar spine decreased $2.5 \%$, and of the radius $2.1 \%$ annually, measured by quantitative computed tomography and single photon absorptiometry, respectively. In a study by Ghosh et al., no bone loss was found over a one-year follow-up period by DXA measurements in 23 IBD patients, 20 of whom received corticosteroids ${ }^{5.4}$. Roux et al. prospectively studied 35 patients with IBD by DXA for a mean fallow-up period of 19 months. Mean annual BMD changes were $-6.2 \%$ and $0.9 \%$ in patients with and without steroids, respectively, which was significantly different. Interestingly, bone loss was not observed in UC patients after colectomy ${ }^{55}$.

In another longitudinall study involving $108 \mathrm{CD}$ patients with bowel resections and a mean follow-up of 5.5 years, bone loss was only demonstrated in the femoral neck and was not related to steroid use or length of the resected smallabowel segment ${ }^{56}$. Schulte at al. found low mean BMD changes over an 18 -month followup period, and no difference with regard to $C D$ or UC was observed ${ }^{57}$. However, a subgroup of patients lost a significant amount of bone, whereas other patients even gained bone mass. Twenty-five percent of the patients were on vitamin D and calcium supplements, but no difference in bone loss was found compared to the group not taking prophylactic drugs.

In conclusion, bone loss was found in five out of seven studies, and in some the rate of bone loss was higher than the expected age-related bone loss, which is about $1 \%$ for pre-menopausal females and $0.5 \%$ for males, after peak bone mass has been achieved. There is a great variation in BMD changes, and evidence for bone gain in a subgroup of patients. 
24 Chapter 2

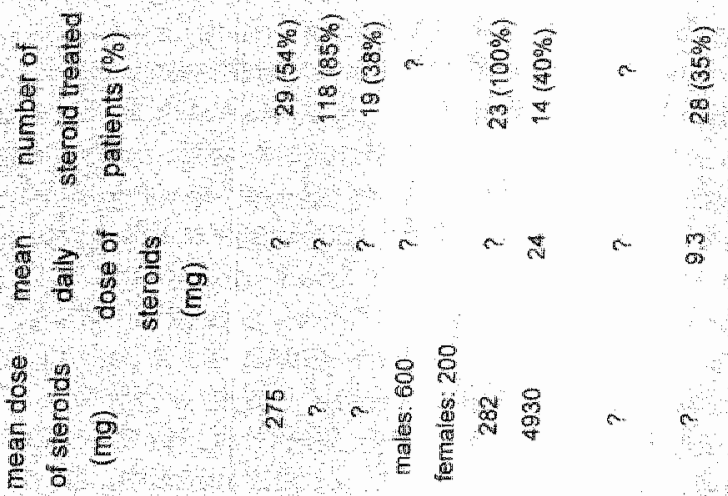

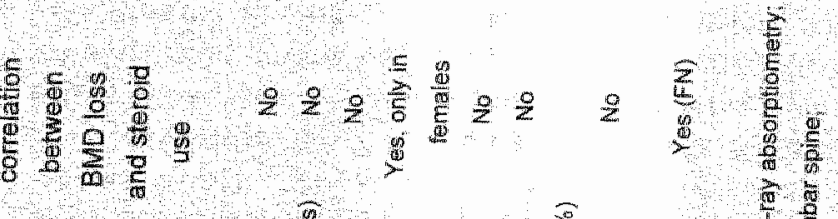

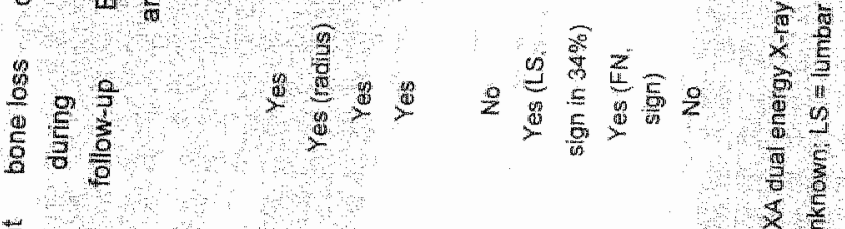

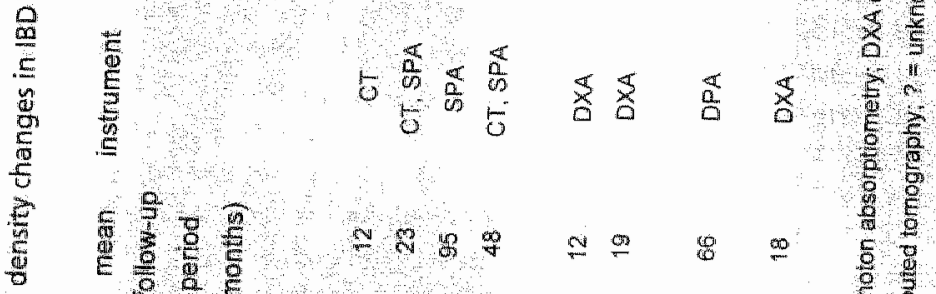

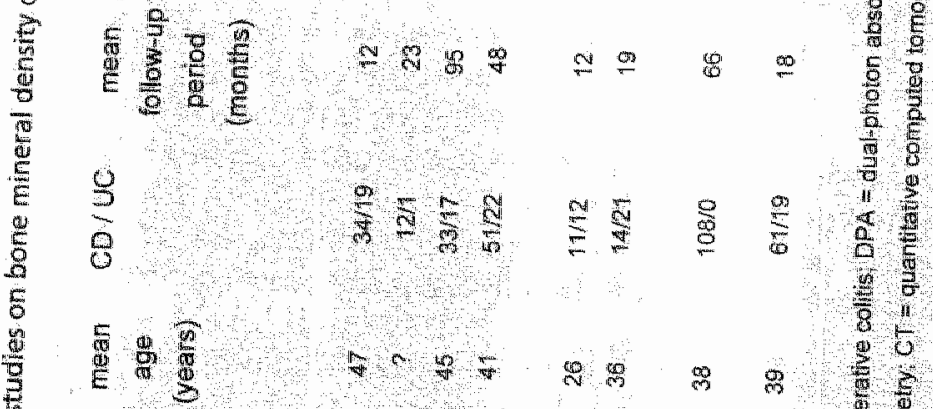

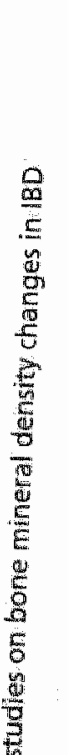

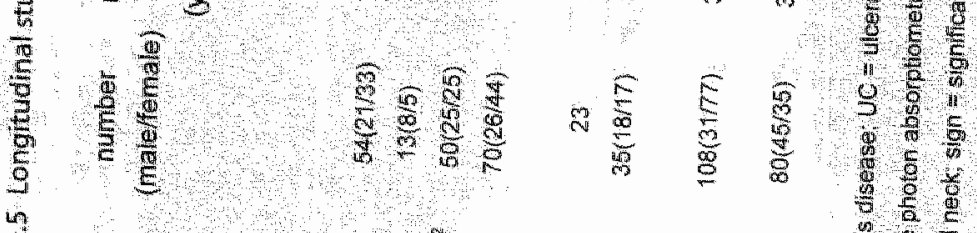

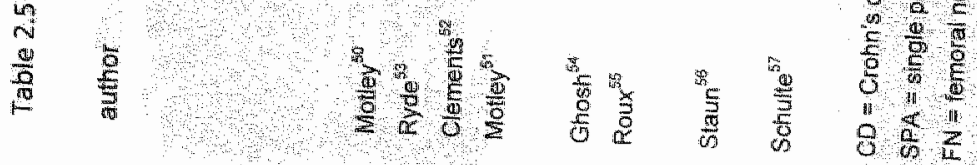




\section{Young age}

Juvenile patients with $C D$ are at a higher risk of developing osteoporosis ${ }^{\text {*. }}$. Children with CD have a higher risk of developing osteopenia than children with UC. Steroid therapy and nutritional status are important determinants of BMD in these patients: Treatment of the underlying $\mathrm{CD}$ can result in marked improvement in bone mineralization ${ }^{60}$. However, many adolescent IBD patients will reach a lower peak bone mass than healthy persons ${ }^{10}$. In the general population, peak bone mass is reached at about the age of thirty. IBD patients, who have a disease onset early in life and achieve lower peak bone mass, may reach the fracture threshold earlier in life. Recently, the first series of five pediatric patients with $C D$ in whom vertebral compression fractures developed as a complication of active disease, steroid treatment, and low BMD was described ${ }^{5 .}$.

\section{Extra-intestinal disease}

Female patients with CD located in the terminal illeum with concomitant sacroiliac joint inflammation had significantly lower BMD than patients with ileitis terminalis Crohn without sacroiliac joint involvement, despite longer disease duration in the contral group $\mathrm{p}^{\mathrm{k}}$. Therefore, a concomitant clinical condition predisposing to osteoporosis may considerably increase the risik for low BMD. This has not been evaluated in male CD patients, and in UC patients yet.

\section{Prevention and treatment of osteoporosis in IBD}

Since therapies that completely restore bone mass lost over years are not available preventive measures should be taken if possible. In general, one is advised to have am adequate dietary intake of vitamin $\mathrm{D}$ and calcium, to stop smoking and excessive use of alcohol, and to exercise. The daily needs of elementary calcium are about $1200 \mathrm{mg}$ for adolescent and adults and $1500 \mathrm{mg}$ for postmenopausal females. Calcium intake below these recommendations are seen more often in IBD patients than in healthy controls, but calcium intake was not associated with BMD in a cross-sectional study ${ }^{62}$. A low-lactose diet is common among IBD patients.

Several therapies for primary and secondary osteoporosis are available: calcium. vitamin D and derivatives, sex hormones, anabolic steroids, calcitonin, fluorides, and bisphosphonates.

Six studies regarding the prevention and treatment of osteoporosis in IBD have been published. These studies are summarized in Table 2.6. Vogelsang et al. reported that vitamin $D$ and calcium substitution over a period of one year prevented bone loss in a group of 75 CD patients ${ }^{63}$. Placebo-treated patients had a significant bone loss (median $7 \%$ ). In an uncontrolled study, estrogen replacement therapy (HRT) was effective in the prevention of bone loss in post-menopausal IBD patients ${ }^{\text {sa }}$. A prospective study on oral calcium supplementation versus placebo in corticosteroid-using IBD patients failed to show a significant benefit after 1 year of treatment ${ }^{65}$. In a small, randomized trial, one year of fluoride therapy significantly improved BMD ${ }^{6 E}$. 
Table 26 , ntervention studies on $B M D$ in $B B D$

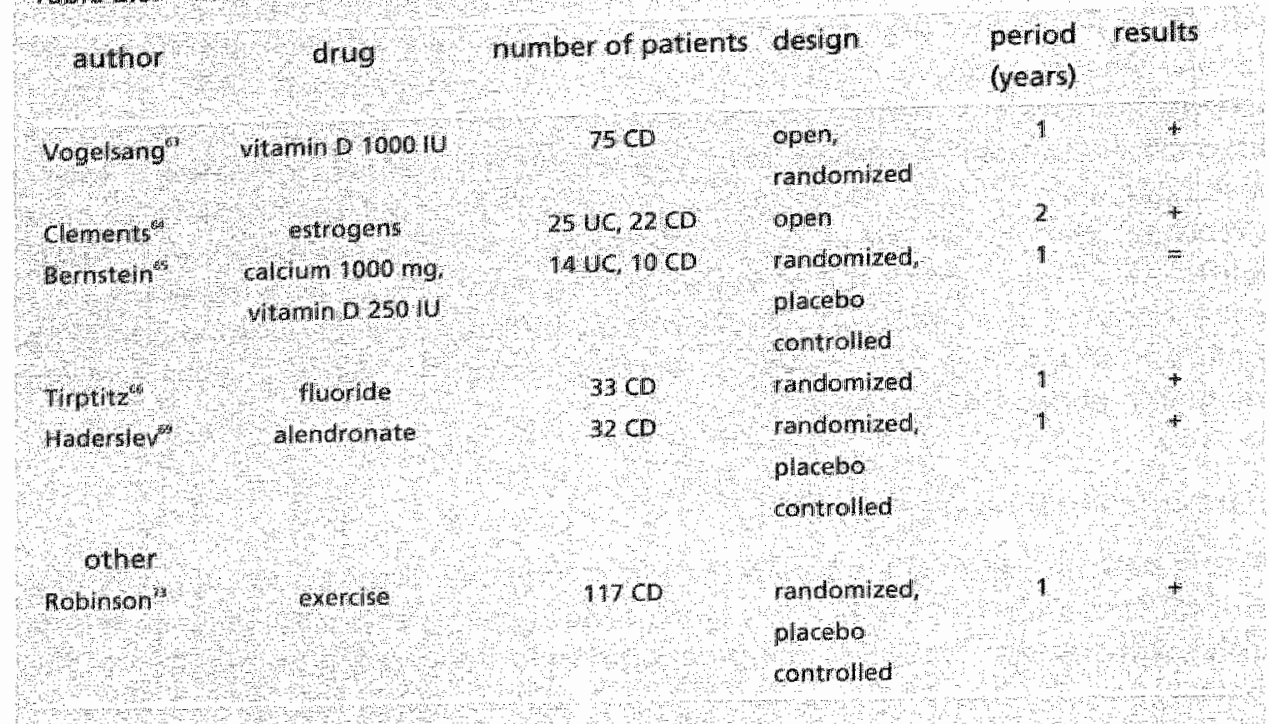

Resuls + oostive, and = unchanged

Given the current evidence, dietary advice concerning the intake of callum and vitamin D should be given to every patient with IBD. Vitamin D and calcium should be supplemented in cases of vitamin D deficiency, steroid use, resection, or chronic use of cholestyramin. In a recent meta-analysis, it was concluded, that all patients started on corticosteroids should receive prophylactic therapy with calcium and vitamin $D^{67}$.

There are only a few studies on treating osteoporosis in IBD with bisphosphonates. Alendronate significantly improved BMD over a period of 48 weeks in corticosteroid-treated patients with several underlying diseases (only $5 \%$ were IBD patients $)^{6 .}$. The underlying disease did not affect the response to alendronate in subgroup analysis, although these data were not shown. Treatment with alendronate significantly improved lumbiar spine BMD in patients with CD compared to placebo controls in a study with a one-year follow-up; however, these patients were in remission ${ }^{\text {. }}$. Biochemical markers of bone turnover decreased significantly in the alendronate group compared to those taking placebo. In another study recently presented as abstract, addition of $30 \mathrm{mg}$ of intravenous parmidronate to vitamin $D$ and calcium, in a randomized controlled trial, was effective after one year of treatment" $t^{7 /}$. As bisphosphonates have been proven to be very effective in the treatment of postmenopausal osteoporosis and in the prevention of corticosteroid-induced osteoporosis in several other diseases, they could be considered for IBD patients receiving long-term corticosteroid therapy, particularly those with low bone density ${ }^{60,72}$. Preventive therapy with antiresorptive agents like bisphosphonates for every corticosteroid-using IBD patient, however, is a subject of debate as there seems to be an individual susceptibility for 
steroids in every patient. Patilents considered for preventive use of bisphosphonates could be selected on the basis of low BMD at the start of corticosteroid therapy. a history of non-traumatic fractures or hawing entered menopause. Another reason for considering treatment with bisphosphonates is the identification as rapid bone losers by serial BMD measurements or by biochemical markers. Osteoporosis (Tscore $\leq-2.5$ ), at any site of measurement or a non-traumatic fracture is an indication for active treatment. In osteopenia (T-score between -1 to -2.5 ) preventive measures should be taken. BMD and the results of treatment should be followed up at intervals of $2-3$ years. It is important to treat the underlying disease optimally and, if necessary, to give corticosteroid therapy as briefly and as low-dosed as possible. "Steroid-saving" therapy like azathioprine should be considered in steroid-dependent patients. Low-impact physical exercise proved to be effective in maintaining BMD in a randomized, controlled trial ${ }^{p_{3}}$.

\section{Discussion}

Although there are different methods for measuring BMD and different definitions of osteoporosis have been used, there is sufficient evidence of a high prevalence and high morbidity of metabolic bone disease, i.e., osteopenia and osteoporosis in $\mathbb{B D}$, especially in $C D$. Little has been published about the endpoint of symptomatic and asymptomatic fractures, and there is no long-term study on fracture risk in IBD. Since there is a very good correlation between BMD measurements with DXA and fracture risk in the general population, this can probably be extrapolated to IBD patients". As a novel diagnostic method of low bone mass, the correlation between hand skin-fold thickness and BMD in patients with CD has recently been described. Mean hand skim-fold thickness was significantly lower in patients with osteoporosis than in patients with normal BMD ${ }^{74}$. However, the association was not strong enough to recommend this method as a diagnostic test for osteoporosis in an individual patient. A study on ultrasound evaluation of the calcaneus in patients with Crohn's disease demonstrated that these patients had reduced broadband ultrasound attenuation compared with an age and gender matched control population ${ }^{75}$. Calcaneal ultrasound was significantly associated with BMD at the hip and the spine, but the correlation was insufficient for use as a screening tool for DXA.

Different findings regarding the significance of corticosteroid effects on BMD in IBD patients can be explained by the multifactorial nature of bone loss, the difficulties of accurate, retrospective calculation of steroid doses used, the heterogeneity of the populations studied, the individual susceptibility of the patients to the damaging effect of steroids, and the confounding effects of disease activity. Patients with $I B D$ are often treated with high initial doses of corticosteroids, tapered to lower levels with the aim of inducing remission. Most bone loss occurs in the first 3 months of corticosteroid use, and there may be a reversible component after stopping steroid therapy. Control of disease activity with appropriate therapy has the highest priority and may even improve bone minerallization. Studies in patients treated with corticosteroids may potentially be 
28 Chapter 2

confounded by the higher use of corticosteroids in patients with a higher disease burden. More knowledge is needed on the interrelationship between several risk factors. This could be obtained in large, preferably population-based, studies on $\mathrm{BMD}$ in IBD. In this context, it is interesting to assess, whether locally active steroids like budesonide have fewer negative effects on bone than prednisolone. This is piresently being investigated in a large, randomized study.

Since patients with IBD are at an increased risk for osteoporosis, bone densitometry should be performed every 2 - 3 years to identify patients in need of treatment and to monitor the effects of interventions to prevent or treat bone $\operatorname{loss}^{75}$. A past history of one or more fragility fractures is a strong risk factor for future fractures, independent of bone density, and should be regarded as an indication for treatment. If bone densitometry is not available, patients should be selected for treatment on the basis of strong risk factors, such as low body weight or malnutrition, post-menopausal status or hypogonadism, corticosteroid therapy, or persistent disease activity ${ }^{37}$. Vitamin $D$ deficiency should be corrected. Patients should have dietary advice on calcium and vitamin $\mathrm{D}$ intake or receive preventive supplementation of calcium and vitamin $D$. To reduce the risk of inadequate calcium intake, unnecessary dietary restrictions, e.g. milk products, should be avoided in these patients.

Since low BMD can already be found at diagnosis in long-term undiagnosed and untreated $C D$, the prevalence of low bone mineral density is higher and an abundance of circulating cytokines may be involved in the demineralization process. There are probably more mechanisms responsible for this condition in CD than in UC. For this reason, CD and UC should not be regarded as the same entity in the study of bone metabolism in IBD.

At present there is a need for more studies on the pathogenesis, prevention, and treatment of osteoporosis in CD as well as in UC. 


\section{References}

1. Edwards. F, Truelove SC. The course and prognosis of ulcerative colitis. Gut 1964:5:1-22.

2. Genant HK, Mall IC, Wagonfeld JB, Horst JW, Lanzi LH. Skelecal demineralizathon and gronvth retardation in inflammatory bowel disease. Invest Radiol 1976; 11(6): 541-549.

3. Consensus development conference: diagnosis, prophylaxis, and treatment of osteoporosis. Am J Med 1993; 9467:646-650.

4. Marshall $\mathrm{D}$, Johnell $\mathrm{O}$. Wedel H. Meta-analysis of how well measures of bone mineral density predict occurrence of osteoporotic fractures. BM.1996; 312(7041): 1254-1259.

5. Abitbol W, Roux C. Chaussade S, Guilemant S, Kolta S, Dougados M et all Metabolic bone assessment in patients with inflammatory bowel disease. Gastroenterology 1995; 108(2):417-422.

6. Bjamason 1. Macpherson A, Mackintosh $C_{x}$ Buxton Thomas M: Forgacs I, Moniz C. Reduced bone density in patients with inflammatory bowel disease. Gut 1997; 40(2):228-233.

7. Compston IE, Judd D, Crawley EO, Evans WD, Evans C, Church HA at. Osteoporosis in patients with inflammatory bownel disease. Gut 1987; 28(4):410-415.

8. Ghosh 5 , Cowen 5 , Hamman W., Ferguson A. Low bome mineral density in Crohn's disease, but not in wlcerative colitis, at diagnosis. Gastroenterology 1994: 107(4): 1031-1039.

9. Pigot $F_{i}$ Roux $C_{4}$ Chaussade 5 , Hardelin $D$, Pelleter $D$, Du Puy MT et al. Low bone mineral dansity in patients with inflammatory bowel disease. Dig Dis Sici 1992: 37(9):1396-1403.

10. Schoon EJ, van Nunen AB, Wouters RS, Stockbrugger RW, Russel MG. Osteopenia and osteoporosis if? Crohn's disease: prevalence in a Dutch population-based cohort. 5cand I Gastroenterol Suppl 2000; $35(232): 43-47$.

11. Silwernoinen $\mathrm{JA}_{\mathrm{A}}$ Kartunen TJ, Niemela SE. Manelius JJ, Lehtola JK. A controlled study of bone mineral dersity in patients with inflammatory bowel disease. Gut 1995; $37(1) ; 71 \times 76$.

12. Tromm A, Rickels K, Huppe D, Wiebe $V$, May B. Osteopenia in chronic inflammatory bowell diseases. Results of a cross- sectional study using quantitatiwe computerized tomography. Leber Magen Darm $1994 ; 24(1): 23-30$.

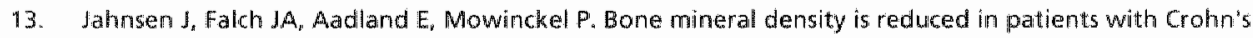
disease but not in pattents with ulcerative collitis: a population based study. Gut 1997; 40(3);313-319.

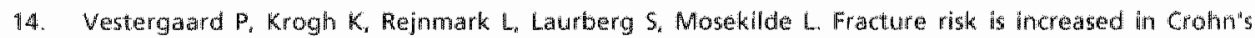
disease, but not in ulcerative colitis. Gut 2000; 46(2):176-181.

15. Biernstein CH. Blanchard JF, Leslie W, Wadd A, YU BN. The incidence of fracture among patients with inflammatory bowel disease. A population-based cohort situdy. Arn mtern Med 2000; 133(10):795799.

16. Semeac El, 5talings, VA, Peck SN, Piccoli DA. Vertebral compression fractures in pediatric patients with Crohn's disease. Gastroenterology 1997; 112(5):1710-1713.

17. Thearle M, Hortick M, Bilezikian IP, Lewy J, Gertner JM, Levine LS et al. Osteoporosis: an unusual presentation of childhood Crohn's disease. J Clin Endocrinol Metab 2000; $85(6) \times 2122-2126$.

18. Croucher $\mathrm{PI}$, Vedi S, Motley RJ, Garrahan NI, Stanton MR, Compston JE. Reduced bone formation in patients with osteoporosis assoclated with inflammatori bowel discase. Osteoporos int 1993; $3(5): 236 \cdot 241$

19. Compston JE, Ayers AB, Horton LW. Tighe IR, Creamer B. Osteomalacia after smallintestinal resection. Laincet 1978; $1(8054): 9 \% 12$.

20. Driscoll RH, Jr. Meredith SC, Sitrin M. Rosenberg UH. Vitamin D deficiency and bone disease hn patients with Crohn's disease. Gastroenterology 1982; 83(6) 1252 1258 .

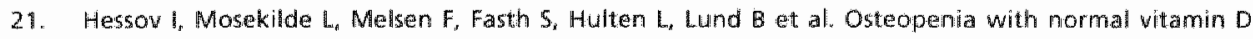
metabolites after small-bowel resection for Crohn's disease. Scand J Gastroenterol 1984; 19(5):691. 696. 
22. Wastell $R$, Bumsolon A. The wallue of biochemical markers of bone turnover in osteoporosis. 1 Rheumatol $1997 ; 2467: 1215-1217$

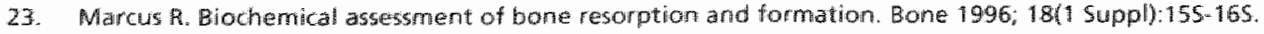

24. Bischoff SC Hermann A. Goke M, Manns MP, won zur MA, Erabant G. Altered bone metabolism in inflammatory bowel disease. Am : Gastroenterol 1997; 92(7):1157-1163.

25. Roux C. Abitbol W. Chaussade 5, Kolta S, Guilemant 5, Dougados M at al. Bone loss in patients with inflammatory bowel digease; a prospective study. Osteoporos tht 1995; 5(3):156-160.

26. Schoon EJ, Geerling BG. Van Dooren IM, Schurgers Ld, Vermeer $C_{\text {, Brumer }}$ B et al. Abnormal bone turnover in long-sitanding Grohn's diseaise in remission. Aliment Pharmacol Ther 2001; 15(6):783-792.

27. Silwennoinen I, Risteli $L_{n}$ Kartumen $t$. Risteli I. Increased degradation of type I collagen in patients whithinflammatory bowel disease. Gut 1996; 38(2):223-228.

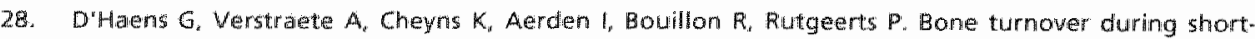
term therapy with methyprednisolone or budesonide in Crohn's disease. Aliment Phamacol Ther $1998 ; 2(5): 419-424$

29. Canalis E. Chrical review 83: Mechanisms of glucocorticoid action in bone: implications to glucocorticoid-induced osteoporosis. J Clin Endocrinol Metab 9996; 811(10):3441-3447.

30. Eastell R. Management of corticosteroid-induced osteoporosis. UK Consensus Group Meeting on Osteoporosis J Intern Med 1995; 237(5) 439-447.

31. Adinoff AD. Hollister JR. Steroidlinduced fractures and bone loss in patients with asthma. M Engl J Med 1983; 309(5):265-268.

32. Andreassen H. Hylander $\mathrm{E}$. Rix M. Gender, age, and body weight are the major predictive factors for bone mineral density in Crohn's disease: a case-control cross-sectional study of 193 patients. Am I Gastroenterol 1999: $94(3): 824-828$.

33. Issemman $\mathbb{R}$ M Atkinson SA, Radoja $C_{x}$ Fraher Lu Longitudinal assessment of growth, mineral metabolism, and bone mass in pediatric Crohn's disease. J Pediatr Gastroenterol Nutr 1993; 17(4):401406 .

34. Schoon EJ. Blok BW, Geerling BJ, Russel MG, Stockbrugger RW, Brummer RJ. Bone mineral density in patients with recently diagnosed inflammatory bowel disease, Gastroenterology 2000; 119(5):1203:1208.

35. Nguyen $L_{n}$ Dewhirst FE, Mauschka PV, Stasherko P. Interleukin-1 beta stimulates bone resorption and inhibits bone formation in wiwo. Lymphokine Cytokine Res 1991: 10(1 -2):15-21.

36. Wallach 5 , Avioli LW, Feimblatt 10 , Carstens $\mathrm{JH}$, Ir. Cytokines and bone metabolism. Calcif Tissue Int $1993 ; 536): 293-296$.

37. Hommes DW, wan Dullemen $H$, Radema $5 A$, Tytgat GN, van Dewenter SI. The role bo cytokines in the pathogenesis of inflammatory intestinat diseases. Ned Tijdschr Geneeskd 1994; 138(49):2427-24:32.

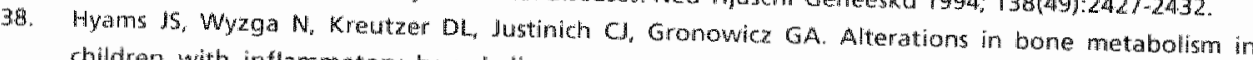
chidren with inflammatory bowel disease: an in witro study. J Pediatr Gastroenterol Nutr 1997 24(3):289-295.

39. Issenman RM. Bomes in Crohn's: cytokines, a missing link? I Pediatr Gastroenterol Nutr 1997 24(3) $361-362$

40. Schute CM, Dignass AU, Goebell H, Roher HD, Schutte KM. Geneth factors dietermine extent of bone loss in inflammatory bowel disease. Gastroenterology 2000; 11944\$:909-920.

41. Silvennoinen HA, Lehtola $\mathrm{JK}$. Niemela SE. Smoking is a risk factor for osteoporosis in women with inflammatory bowel disease. Scand Jastroenterol 1996; 31(4): 367-371.

Robinsion RJ, lqbal 5], al Azzawi F, Abrams $K$. Mayberry JF. Sex hormone status and bione metabolism in men with Crohn's disease. Aliment Pharmacol Ther 1998; 12(1):21-25

43. Delmas $P D$, Hardy $P$, Gatrnero $P$, Dain $M$. Monitoring individual response to hormone replacement therapy with bone markers. Bone 2000; 26(6):553-560. 44. Rogers A, Hannon RA, Eastell R. Biochemical markers as predictors of rates of bone loss after
menopause. Bone Miner Res 2000; $15(7): 1398-1404$. 


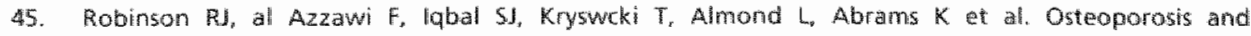
determinaints of bone density in patients with Crolin's disease. Dig Dis So 1998; 43(11):2500-2506.

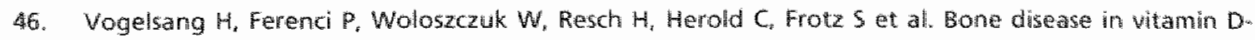
deficient patients with Crohm's disease. Dig Dis 5 ci $1989 ; 34(7): 1094-1099$.

47. Vogelsang $H$, Ferenci P, schilling R, Woloszczuk W, Haschke, W et al. Vitamin D-status in outpatients with Crohn"s disease. Eur J Gastronterol Hepatol 1994:6: 513-517.

48. Siwennoinen 1. Relationships between vitamin $\mathrm{D}$, parathyroid homone and bone mineral density in inflammatory bowel disease. Interin Mted 1996; 239(2):131.137.

49. Andrearsen $H_{\text {, Rix M }}$, Brot $C$, Eskildsen P. Regulators of calcium homeostasis and bone minetal donsity in patients with Crohn's disease. Scand \& Giastroenterol 1998; $33(10): 1087-1093$.

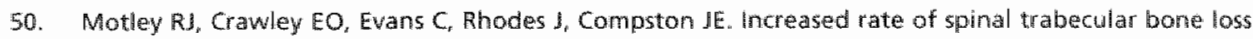
in partents with unflammatory bowel disease. Gut 1988; 29(10):1332-1336.

5i. Motfey R, Clements D. Evans WD Crawtey EO, Evans C, Rhodes I et al. A four-year longhtudinall study of bone loss in patients with inflammatory bowel disease. Bone Miner 1993; 23(2):95-104.

52. Clements D, Motley RJ, Ewans WD. Harries AD, Rhodes J. Coles RJ et all. Longitudinal study of cortical bone loss in patients with inflammatory bowel disease. Scarnd 1 Gastroenterol $1992: 27(12): 1055$-1060.

53. Ryde Sl, Clements D, Evans WD, Motley R, Morgan WD, Evans C et al. Total body calcium in patiants with inflammatory bowel disease: a longitudinal study. Clin Sici (Colch) 1991: 80(4):3191-324.

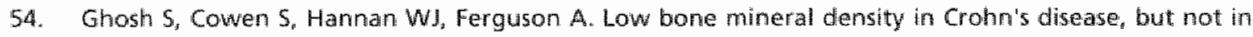
ulcerative colitis at diagnosis. Gastroenterology 1994; 107(4): 1031-1039.

55. Roux C. Abitbol W. Chaussade S, Kolta S, Guillemant S. Dougados $M$ et al. Bone loss in patients with inflammatory bowe disease: a prospective study. Osteoporos Int 1995; 5(3):156-160.

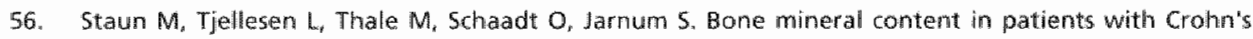
disease. A longitudinal study in patients with bowel resections. Scand J Gastroentero: 1997: $32(3) 226-232$

57. Schulte C, Dignass AU, Mann $K$, Goebell H. Bone loss in patients with inflammatory bowel disease is less than expected: a follow-up study. Scand I Gastroenterol 1999; 34(7):696-702.

58. Boot AM, Bouquet 1 , Krenning EP, de Munck Keizer-Schrama SM. Bone mineral density aind nutritional status in children with chronic inflammatory bowel disease. Gut 1998;42(2):188 194.

59. Gokhale R, Favuls MI, Karrison T, Sutton MMMA Rich B, Kirschner BS. Bone mineral density asses.sment in children with inflammatory bowel disease. Gastroenterology 1998; $114(5): 902-911$.

60. Cowan FJ, Gregory IW, Jenkins HA. Bone mineral diensity in Crohn's disease. Gut 1997; 41 (4):578-579.

61. Teichmann J, Lange U, Stracke H, Dopol W, Klor HU, Federlin K. Rapid spinal trabuecular borue loss in female patients with fleitis terminalis crohn and additional sacrolliac joint inflammation. The umatol Int $1997 ; 17(2): 45-48$.

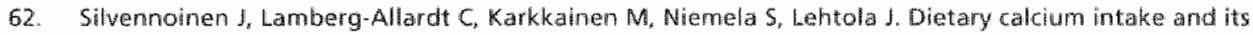
relation to bone mineral density in patients with inflammatory bowel disease. I Intern Med 1996 : $240(5): 285-292$.

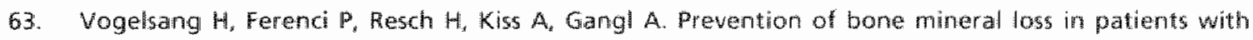
Crohn"s disease by long-term oral vitamin D supplementation. Eur J Gastroenterol Hepatol 1995 : $7(7): 609-614$

64. Clements D, Compron JE, Ewans WD, Rhodes I. Hormone replacenent therapy prevents bone loss in patients with inflammatory bowal disease. Gut 1993; 34(11): 1543.1546.

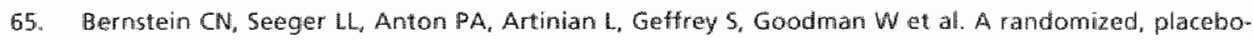
controlled irial of callium supplementation for decreased bone density in corticonteroildusing patients with inflammatory bowel disease: a pilot study. Aliment pharmacol Ther 1996; 10(5);777-786.

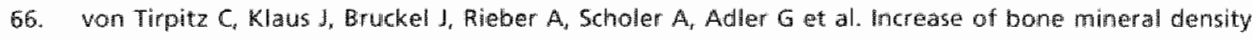
with sodium fluoride in patients wh Crohn's disease. Eur 1 Gastroenterol Hepatol $2000 ; 12(1): 19-24$.

67. Homik J, Suarez-Almazor ME, Shea B, Cranney A, Wells $G$, Tugwell P. Calcium and witamin D for conticosteroid-induced osteoporosis. Cochrane Database 5yst Rev 2000;(2), CD000952. 
32 Chapter 2

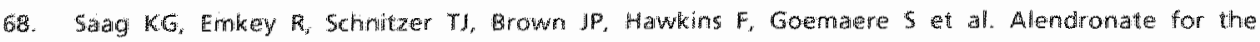
prevertion and treatment of glucaconticidinduced osteoporosis. Glucocorticoidnduced Osteoporosis Intervertion Study Group. N Engi I Med 1998; 339(5):292-299.

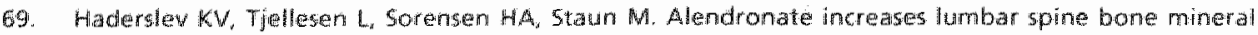
density in patients with Crohn's disease. Gastroenterology 2000; 11903639646.

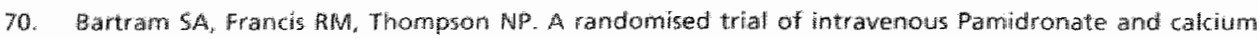
and whamin $D$, in the treatrient of osteoporosis associated with Grohin's disease. Gastroenterology 2001: Supph:A 3982

71. Adachi JD, Bensen WG, erown J, Hanley D, Hodsman A, lossie $R$ et al. Intermittent etidronate therapy 10 prevent conticosteroid induced osteoporasis. N Engl J Med 1997; 337(6):382-387.

72. Homk 3 , Graney A, Shed $B$. Tugwell $P$, Wells $G$, Adachi $R$ et al. Bisphosphonates for steroid induced osteoporosis. Cochrane Database Syst Rev 2000,(2): CDO0 $34 \%$.

73. Robinson RJ, Krzwwicki T. Almorid L, al Azzawi F, Abrams K. lqbal Sl et al. Effect of a low impact exarcise program on bone mineral density in crotin's disease: a randomized controlled trial. Gastroenterology 1998; 11511$): 36-41$.

74. Robinson RJ, al Azawi F, Gbal 5 J, Abrams $K$, Mayberfy lif. The relation of hand skin-fold thickness to bone mimeral dersity in patients with Crohn's disease. Eur $\$$ Gastroenterol Hepatol 1997; 9(10).945 949.

75. Robitison R.J. Carr I, lqbal SI, al Azzawi F, Abrams K, Mayberry JF. Screening for osteoporosis in Crohn's disease. A detailed ewaluation of calcaneal utrasound. Eur 1 Gastroenterol Hepatol 1998; 10(2):137-140.

76. Gluer CC. Monitoring skeletal changes by radiological techmiques. J Bone Miner Res 1999; 14(11):1952-1962.

77. Compston JE. Detection of osteoparosis in patients with inflammatory bowel disease. Eur I Gastromerol Hepatol 1997 ; $9(10) 9311-933$. 


\section{The prevalence of osteoporosis in Crohn's disease: a population-based study in the Netherlands}


34 Chapter 3

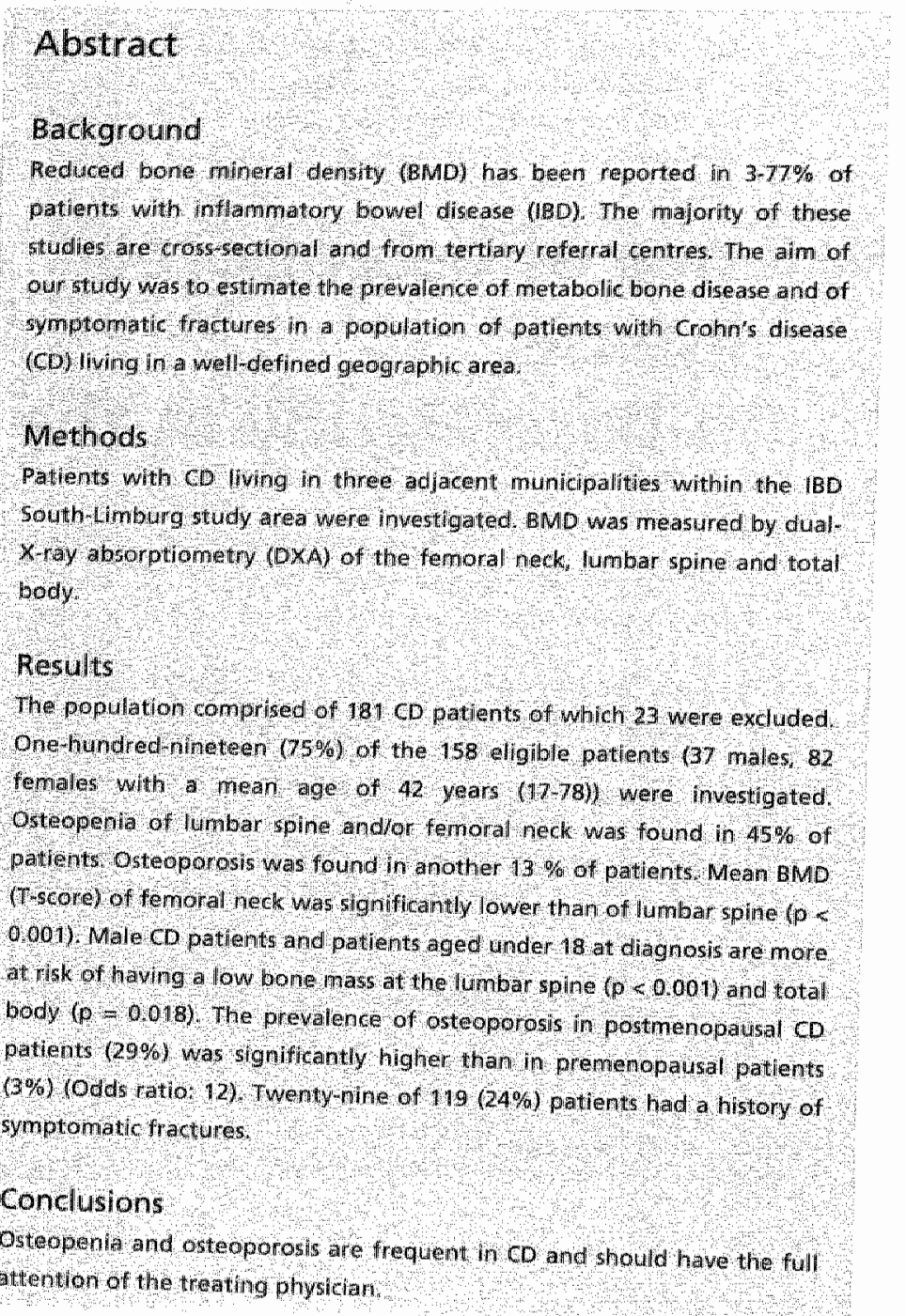




\section{Introduction}

The association between inflammatory bowel disease (IBD) and low bone mineral density (BMD) was first reported in 1964. The reported prevalence was low as it was based on relatively insensitive criteria such as radiological signs of osteoporosis and fractures.

Since the introduction of novel methods of BMD measurement several studies have been published on the prevalence of osteopenia and osteoporosis in $1 \mathrm{BD}$. The reported prevalence of decreased bone mass varies widely $(13-77 \%)$ and is dependent on patient selection, method of BMD measurement and definition of osteoporosis used ${ }^{2.4}$. The studies are usually cross-sectional from tertiary referral centres and mostly mixed groups of Crohn's disease (CD) and ulcerative colitis (UC) patients were reported. Several studies found a significant difference in BMD between $C D$ and UC patients and in one study a significant difference in BMD was found even at diagnosis". Only three studies have been published on BMD reporting $C D$ patients allone ${ }^{1,1.13}$.

Vertebral crush fractures, as a consequence of osteoporosis, are already reported in juvenile patients with $\mathrm{CD}^{14}$. The prevalence of fractures in IBD patients was established in four studies and varied from 5 to $26 \%$ regarding radiologically assessed fractures and from 3.3 to $7 \%$ concerning symptomatic fractures ${ }^{25,6,14}$.

The aim of our study was to estimate the prevalence of metabollic bone disease and of symptomatic fractures in an unselected population of $\mathrm{CD}$ patients living in a well-defined geographic area.

\section{Patients and methods}

Patients with CD living in three adjacent municipalities of the IBD South-Limburg study area in the Netherlands", with a total of 150.891 inhabitants (118.465 in Maastricht, 20.591 in Meerssen, 11.835 in Eijsden), were investigated during the period of January 1996 to July 1997. Crohn's disease was diagnosed on the basis of endoscopical and/or radiological evidence, supported by mucosal biopsies and/or examination of surgical specimen when available. For confirmation of the $C D$ diagnosis the Lennard-Jones criteria were applied". The University Hospital of Maastricht is the only hospital in the city of Maastricht and therefore also serves as the community hospital for the selected area.

The study population comprised of 181 CD patients, all of Caucasian ethnicity, of whom 14 patients were excluded because of pregnancy, renal insufficiency, ankylosing spondylitis (3x), rheumatoid arthritis, pulmonary cancer and change of diagnosis to ulcerative colitis $(7 x)$. Four patients from the $\mathrm{BBD}$ registry had died before inclusion, one patient due to a thrombo-embolic event (possibly related to an exacerbation of $(D)$, three others died of causes unrelated to $C D$. Five patients had moved out of the study area. 
The intention was to investigate each patient attending the outpatient clinic during the study period. One-hundred-nineteen (75\%) of the 158 eligible patients, 37 males and 82 females with a mean age ( \pm SD) of $42( \pm 14$ ) years (range 17-78)) were investigated. Mean duration of disease was $10.5( \pm 8.8)$ years. The disease was located in the small-bowel in 35 patients, in the colon in 10 patients, while 74 patients had both disease localisations. Seventy-three patients had one $(n=42)$ or more $(n=31)$ surgical resections. Patient characteristics are given in Table 3.1.

Thirty-nime patients (14 males, 25 temales) who did not attend the outpatient clinic during the study period could not be included. The mean age of this group of patients was $42( \pm 15)$ and mean duration of disease was $12( \pm 9)$ years.

Table 31 Patient characteristics

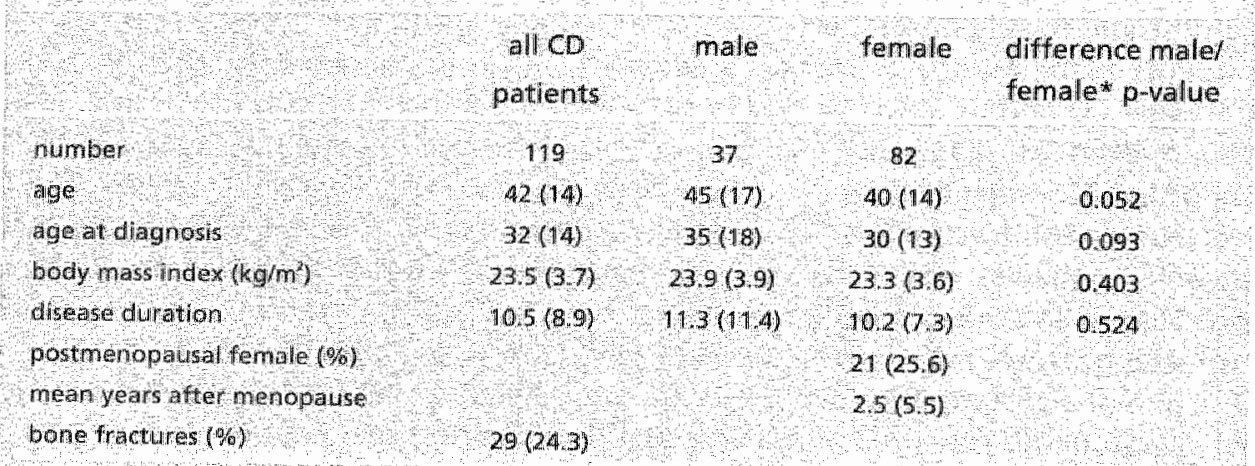

All data are expressed as nean and standard deviation (SD), as numbers and percentage if indicated (\%). Independent $t$ thest

\section{Bone mineral Density}

In all 119 patients, bone mineral density was measured using dual-energy $X$-ray absorptiometry (DXA) (Lunar DPX-L, Lunar software version DPX $-L$ 1.3; Lunar Radiation Corp. Madison, WI $)^{14}$ of lumbar spine $\left(\mathrm{L}_{2} \cdot \mathrm{L}_{4}\right)$ and the femoral neck of the non-dominant hip. DXA of the total body was performed in 61 patients. BMD was expressed in absolute values $\left(\mathrm{g} / \mathrm{cm}^{2}\right)$. T-score (one standard deviation compared to a young adult gender matched reference population), and Z-score (one standard deviation compared to an age and gender matched reference population), respectively. Reference data were based on populations from the United States, United Kingdom, and Northern Europe ${ }^{19-2 !}$. The wariation of mean BMD values among geographical areas contributing to normal data was $1.3 \%$.

The number of patients with osteopenia and osteoporosis was assessed according to the WHO classification ${ }^{2 !}$ in which osteopenia is defined as a T-score between -1 and -2.5 and osteoporosis as T-score $<-2.5$. In addition the Z-score was applied to make the study comparable to previous prevalence studies. In this case an accepted biological concept of pathology was applied as $Z$-score $<-1$ to $<-2$ for osteopenia
and $Z$-score $\leq-2$ for more severe bone disease. 


\section{Fractures and other parameters}

The number of wrist, vertebral, femoral and other spontaneous or traumatic fractures in the past history were assessed by questionnaire. The body mass index $\left(\mathrm{kg} / \mathrm{m}^{2}\right)$ was calculated. Age of onset of $\mathrm{CD}$, disease duration and disease localization were derived from the medical records.

\section{Statistical analysis}

Comparisons of risk factors between male and female patients were performed using a parametric test (independent t-test), otherwise a non-parametric (MannWhitney) was performed. In order to correct for the age difference between male and female $C D$ patients the Z-score was applied in gender specific analysis of BMD. The Pearson's coefficient was used for expression of correlation.

The Statistical Package for the Social Sciences (SPSS 7.5, SPSS inc., Chicago, III) was used for the analysis. A. P value of $\leq 0.05$ was considered statistically significant.

\section{Results}

\section{Prevalence of osteopenia and osteoporosis}

Mean BMD $\left(\mathrm{g} / \mathrm{cm}^{2}\right)$, T- and Z-score of lumbar spine, femoral neck and/or total body of all patients are given in Table 3.2. A highly significant correlation was found between BMD of total body and lumbar spine $(r=0.715, p<0.001)$, total body and femoral neck $(r=0.748, p<0.001)$ and lumbar spine and femoral neck $(r=0.600$, $p<0.001)$. Highly significant correlations were also found for $T$ - and $Z$-scores.

Table 32 Mean bone mineral density (ISD)) at different sites expressed in absolute values $\left(g / \mathrm{cm}^{2}\right), \mathrm{T}$ and Z-score.

\section{BMD}

lumibar spine

Hemoral nack

totalloody
$1,164(0,168)$

$0.892(0167)$

1. $116(0.107)$
Twsore

$-0,2(1,31)$

$-0.96(1,3)$

$-050(1,32)$ 2,sore

$001(124)$

(15) (1)

-027 (10)

Mean BMD of femoral neck expressed in T-score was significantly lower than BMD of lumbar spine and total body (Table 3.2, Figure 3.1). The prevalence of osteopenia and osteoporosis at different sites of measurement is given in Table 3.3. 


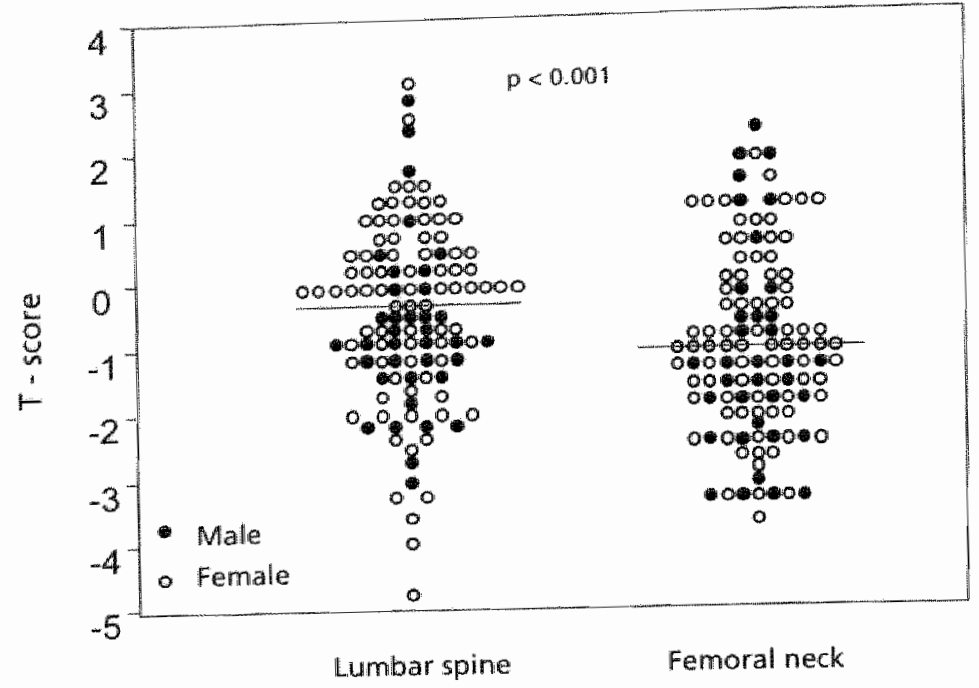

Figure 3.1 T-score of llumbar spine versus femoral neck in 119 patients with Crohn's disease

Table 33 Prevalence (in percentage) of normal bone nass, osteopenia and osteoporosis in 119 patients with crohn's disease defined as T-score (WHO-criteria) and as Z score (blologic variability).

\begin{tabular}{|c|c|c|c|c|c|c|}
\hline & $\begin{array}{c}\text { namal } \\
\mathrm{T} \\
2\end{array}$ & $\begin{array}{c}\text { Tscore } \\
\text { osteopenia } \\
-2.5<\mathrm{T} \leq-1 \\
\%\end{array}$ & $\begin{array}{c}\text { osteoporosis } \\
T S-2 S \\
0 \%\end{array}$ & $\begin{array}{c}\text { normal } \\
2>-1 \\
\\
\end{array}$ & $\begin{array}{l}2<z s-1 \\
\text { low }\end{array}$ & $\begin{array}{l}\text { very low } \\
25-2 \\
\%\end{array}$ \\
\hline Aumber spena & 11 & 22 & 7 & 79 & 16 & 3 \\
\hline tenoralneck & 48 & 41 & 11 & 66 & 25 & 9 \\
\hline latal body & 67 & 27 & 6 & 74 & 21 & 4 \\
\hline $\begin{array}{l}\text { temoral spine or } \\
\text { femonil neck }\end{array}$ & 42 & 45 & 13 & 59 & 28 & 13 \\
\hline
\end{tabular}

\section{Gender}

In the gender specific analysis, the gender difference in BMD of the total body (Zscore) was nearly significant $(p=0.051)$. No difference was found for lumbar spine $(p=0.439)$ or femoral neck $(p=0.768)$, respectively. Risk estimation for having osteoporosis revealed an odds ratio in females of $0.439(95 \% \mathrm{Cl}: 0.170-1.138)$, but this was not statistically significant.

No significant difference in BMD (Z-score) at the lumbar spine, femoral neck or total body was found between pre-and postmenopausal females. The prevalence 
of osteopenia did not differ significantly between postmenopausal and premenopausal women. However, in postmenopausal $C D$ patients the prevalence of osteoporosis $(6 / 21,24 \%)$ was significantly higher than in premenopausal patients $(2 / 61,3 \%)($ Odds ratio $12,95 \% \mathrm{Cl}: 2.2-65.5)$.

\section{Age of disease onset}

Patients with a disease onset under 18 years $(n=12)$ had mean $Z$-scores, that were significantly llower than in patients with CD diagnosed above the age of 18 ( $p<$ 0.011 , with exception of the femoral neck (Table 3.4).

Table 3.4 Mean bone mineral density ( -score) of patients with age at diagnosis below or above 18 years.

\begin{tabular}{|c|c|c|c|}
\hline 2score & $\begin{array}{l}\text { age at diagnosis s } 18 \text { years } \\
\qquad n=12\end{array}$ & $\begin{array}{l}\text { age at diagnosis }>18 \text { years } \\
\qquad n=107\end{array}$ & pyalue \\
\hline lumbar spine & $-107(0,08)$ & $0.12(1.21)$ & 0,000 \\
\hline femonal neck & $112(104)$ & $-046(1) 18)$ & 0.066 \\
\hline total body & $0.86(0.70)^{1}$ & $0,20(1,0 \mathrm{~B}) \times$ & 0.018 \\
\hline
\end{tabular}

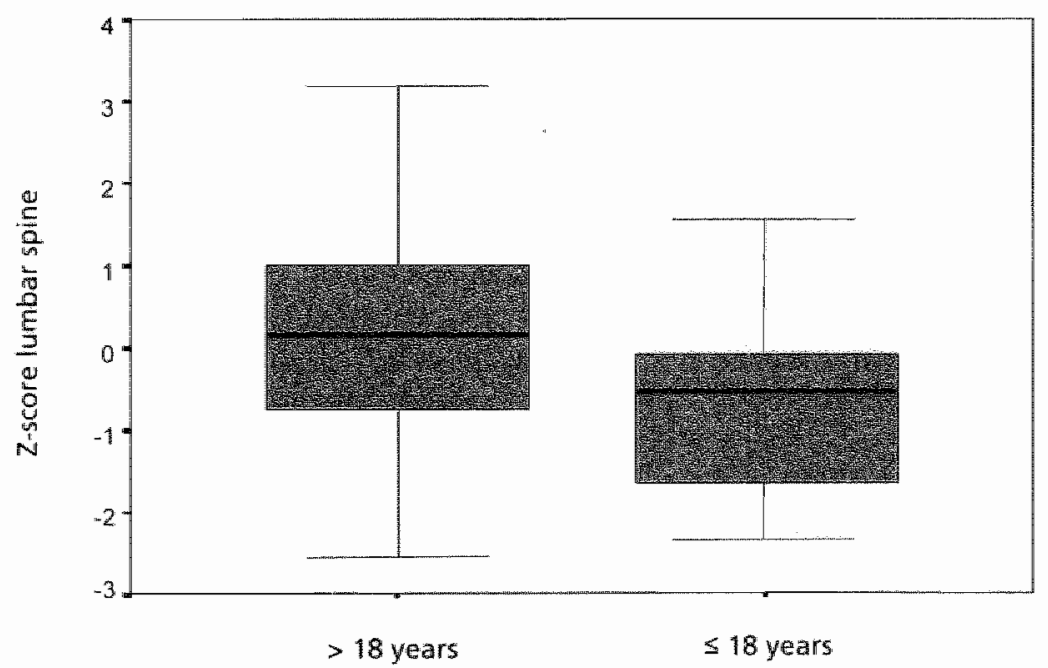

Figure 3.2 Mean bone mineral density ( 2 -score) of the lumbar spine of patients with age at diagnosis below or above 18 years $(p<0.001)$. 
40. Chapter 3

\section{Fractures}

Twenty-nine of the $119(24 \%)$ of patients had a history of symptomatic fractures: 2 hip, 6 wrist and 16 other fractures (clavicle, ribs etc.). Symptomatic vertebral fractures were not reported. Although all mean BMD and T-scores were lower in this group, no significant differences in BMD $\left(\mathrm{g} / \mathrm{cm}^{2}\right)$ or T-scores were found between patients with and without fractures. However, the two patients who had suffered from a hip fracture (both post-menopausal females aged 66 and 72 years), had low BMD of the femoral neck with T-scores of -2.30 and -2.93 , respectively.

\section{Discussion}

A high prevalence of osteopenia and osteoporosis was found in this populationbased study on BMD in patients with CD. Fifty-eight percent of patients in this study had this type of metabolic bone disease. The risk of osteoporosis in $C D$ significantly increased in female patients after menopause as expected from the normal population.

The WHO-definition for osteoporosis and osteopenia was initially designed for post-menopausal decrease of bone mineral density (primary osteoporosis), but is presently also used for secondary osteoporosis and in malles. A T-score $\leq-2.5$ indicates a definitively increased fracture risk. As there is no commonly accepted definition of osteoporosis expressed in Z-score, the comparison of the presently published studies on the prevalence of osteoporosis in IBD can be confusing. The results in Table 3.3 indicate that the use of Z-score gives a good indication of osteoporosis, but may underestimate the presence of osteopenia. It is the osteopenic patient that might benefit from preventive treatment to avoid further deterioration of bone mass.

In this study, which is different from a cross-sectional study performed in a referral centre, mild to severe cases of CD were involved. Twenty-five percent of patients in the pre-defined study area could not be investigated. However, there was no significant difference regarding mean age and duration of disease with the $75 \%$ included patients. The prevalence of osteopenia and osteoporosis could have been lower if all patients had been included considered that these patients had had less severe illness. Disease activity and concurrent use of corticosteroids are thought to be important factors influencing $B M D$ in $C D^{23.75}$.

Fracture history revealed two hip fractures. Considering the significantly lower BMD of the femoral neck in CD, this should possibly be an endpoint in further longterm studies on osteoporosis in CD. The relatively low hip fracture rate could be explained by the fact that osteoporosis is only one factor predisposing to fracture, and in this relatively young group of patients with good mobility and eyesight the tendency to fall is generally low. No X-ray examinations of lumbar-and thoracic spine were performed, as only symptomatic vertebral fractures were considered.

In the overall population, mean BMD (T-score) of the femoral neck was lower than in the lumbar spine. This finding is comparable to the findings in other studies ${ }^{4,25}$. The risk to develop metabolic bone disease did not differ between male and female IBD patients. Both these findings indicate that there is another 
pathophysiologic mechanism responsible for the development of metabolic bone disease in IBD than in corticosteroid-induced or senile osteoporosis conditions in which trabecular bone is more affected than cortical bone ${ }^{27}$. The predominant cortical bone loss could be explained by secondary parahyperthyroidism caused by vitamin D or calcium malabsorption, both common in patients with small bowel resection ${ }^{28}$.

This study demonstrates that disease onset before 18 years of age implicates a higher risk for development of metabolic bone disease. This phenomenon might be explained by the fact that growing and developing bones are more susceptible to the negative effects of disease activity and treatment of Crohn's disease ${ }_{\text {n }}$ and that achievement of an adequate peak bone mass is more difficult ${ }^{29.34}$.

In this large population based cohort on bone mineral density in Crohn's disease a high prevalence of osteopenia and osteoporosis was found. Mean bone mineral density of the femoral neck was significantly lower than in the lumbar spine. A physician taking care of patients with Crohn's disease has to be aware of this potential extra-intestinal complication of Crohn's disease, and probably preventive measures have to be applied. 


\section{References}

1. Edwards F, Truelove 5. The course and prognosis of ulcerative colitis. Gat 1964:5: 1-22.

2. Abitbol $V$, Roux $C$, Chássade S, Guillemant S, Kolta S, Dougados M, Couturier D, Amor B. Metabolic bone assesment in patients with inflammatory bowal disease. Gastroenterology 1995, 108:417-22.

3. Bernstein CN. Seeger LL, Sayre IW, Anton PA, Artinian L, Shanahan F. Decreased bone density in inflammatary bowel disease is related ta conticosteroid use and not disease diagnosis I Bone Miner Res 1995; 10:250-6.

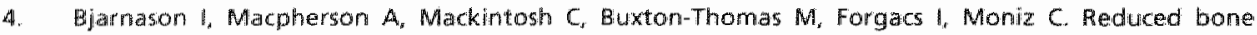
densty in patients with inflammatory bowel disease. Gut 1997;40: 228.33.

5. Compston JE, Judd D, Crawley EO, Evans WD, Evans C, Church HA, Reid EM, Rhodes J. Osteoporosis in patients with inflammatory bowel disease. Gut 1987; 28:410-5.

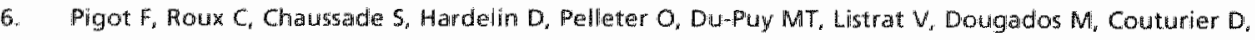
Amor B. Low bone mineral density in patients with inflammatory bowel disease. Dig.Dis.Sci. $1992 ; 37: 1396-403$.

7. Scharla $5 H$, Minne $H W$, Lempert UG, Leidig $G$, Hauber M. Raedsch $\mathbb{R}$, Ziegler $R$. Bone mineral density and calcium regulating hormones in patients with inflammatory bowell disease (Crohn's disease and ulcerative colitis). Exp Clin Endocrinol 1994: 102:44-9.

8. Silvennoinen JA, Kartitunen TJ, Niemela SE, Manelius IJ, Lehtola JK. A controlled study of bone mineral density in patients with inflammatory bowe disease. Gut 1995:37:71-6.

9. Tromm A, Rickels K. Huppe D, Wiebe V, May B. Osteopenial in chronic inflammatory bowel diseases. Results of a crosswectional study using quantitative computerized tamography. Leber. Magen.Darm. $1994: 24: 23 * 30$

10. Ghosh 5 , Cowen 5 , Hannan W. Ferguson A. Low bone mineral density in Crohn"s disease, but not in ulcerative colitis, at diagnosis. Gastroenterology $1994 ; 107: 1031 \times 9$.

11. Robinson R., AlAzzawi $F_{*}$ lqbal Si, Kryswcki T. Almond $L_{*}$ Abrams $K_{*}$ Mayberry JF. Osteoporosis and determimants of bone density in patients with Crohn's disease. Dig.Dis.5ir. 1998;43:2500-6.

12. Andreassen H. Hylander E, Rix M. Gender, age, and body weight are the major predictive factors for bone minerall density in Crohn's disease: a case-control cross-sectional study of 113 patients. Am.J.Gastroenterol. 1999;94:824-8.

13. Vogelsang H, Ferenci P. Woloszcuk W. Resch H, Herold C. Frotz S, Gangl A. Bone disease in vitamin D-defichent patients with Crohn's disease. Dig. Dis. Sci. 1989:34: $1094-9$.

14. Semeao EJ, stallimgs VA. Peck SN, Piccoli DA. Vertabral compression fractures in pediatric patients with Crohn's disease. Gasitroenterology 1997* 112:1710-3:

15. Jahnsen $J$ "Falch $1 A$. Aadland $E$, Mowinchel P. Bone mineral density is reduced in patients with Crohn's disease but not in patients with uhcerative colitis: a population based study. Gut 1997; 40:313-9.

16. Russel MG. Dorant E, Volovics A, Brummer FJ, Pop P, Muris JW, BOs LP, Limonard CB, Stockbrugger RWV. High incidence of inflammatory bowel disease in The Netherlands: results of a prospective study. The South Limburg BBD Study Group. Dis Colon Rectum 1998;41(1):33-40.

17. Lennard-Jones JE. Classification of inflammatory bowel disease. Scand I Gastroenterol Suppl. 1989:170:2-6.

18. Mazess RB, Barden HS, Bisek JP. Hanson J. Dualmenergy x-ray absorptiometry for total-body and regional bone-mineral and soft-tissue composition. Am J Clin Nutr 1990;51(6):1106-12.

19. Mazess RE, Barden HS, Ettinger M, Johnston $C_{4}$ Dawson HB, Baran D, Powell M, Notelovitz M. Spine and femur density using dual-photon absorptiometry in US white women. Bone Miner 1987:2:219.9.

20. Stevenson IC, Lees B, Devenport M. Cust MP. Ganger KF. Determinants of bone density in normal womer: risk factors for future osteoporosis? BMU. 1989;298:9244928. 
21. Kroger H, Heikkinen L, Laitinen K, Kotaniemi A. Duat-energy X.ray absorptiometry in normal women: a cross-sectional study of 717 Finnish volunteds. Osteoporos Int $1992 ; 2(3) ; 135440$.

22. Assessment of fracture risk and its application to screening for postmenopausal osteoporosis. Report of a WHO Study Group. World Health Organ Tech Rep Sier. 1994:843:1-129.

23. Compston JE. Dextection of osteoporosis in patients with inflammatory bowel disease. Eur I Gastroenterol Hepatol 1997:9:931-3.

24. Hyams JS, Wyzga N, Kreutzer DL, Justinich CJ, Gronowicz GA. Alterations in bone metabolism in children with inflammatory bowel disease: an in vitro study. J Pediatr Gastroenterol Nutr 1997; 24:289-195.

25. Issenman RM. Dones in Crohn's: cytokunes, a missing llink? J Pediatr Gastroenterol Nutr 1997. $1997 \% 24: 361-2$

26. Pollak $R D_{\text {, Karmeli }}$, Ellakim $R$, Ackerman $Z$, Tabb $K$, Rachmilewitz D. Femoral neck osteopenia in patients with inflammatory bowel disease. Am.J.Gastroenterol. 1998;93; 1483-90.

27. Clements $D_{*}$ Compsiton $J E$, Evans WD, Rhodes $\AA_{*}$. Homone replacement therapy prevents bone loss in patients with inflammatory bowel disease. Gut 1993;34:1543-6.

28. Andreassen H, Rix MA, Brot C. Eskildsen P. Regulators of calcium homeostasis and bone minerall density in patients with Crohn's disease. Scand. J. Gastroenterol. 1998;33:1087-93.

29. Boot AM, Bouqulet $J$, Krenning EP, die MK. Bone mineral density ard nutritional status in children with chronic inflammatory bowel disease. Gut 1998,42:188-94.

30. Herzog $D_{*}$ Bishop $N$. Gloriew F. Seidman EG. Interpretation of bone mineral density values in pediatric Crohn's disease. Inflammatory Bowel Disseases 1998;4:261-7.

31. Issenman RM, Atkinson SA, Radoja $C_{x}$ fraher L. Longitudinal assessment of growth mineral metabolism, and bone mass in pediatric Crohn's disease. \& Pediatr Gastroenterol Nutr 1993;17:401-66. 



\section{Clinical determinants of bone mineral density in Crohn's disease}

EJ Schoon, $A B$ van Nunen, $P$ Geusens,

RW Stockbrügger。 MGVM Russel 


\section{Abstract}

\section{Background}

A high prevalence of osteopenia and osteoporosis has been reported in Crohn's disease (Co) The pathoglenesis is probably multifactorial but not completely clarified

\section{Aim}

The aim of our study was to establish determinants of osteoporosis in a large populat on based group of patients with $C D$.

\section{Methods}

$419 \mathrm{CO}$ patients vere nuestigated Bone trineral density (BMD) was measured by dual $X$-ray absorptionetry (DXA).

\section{Results}

Linear regression analysis indicated both body weight and femalle gender. as sigrificant positue determinants of $\mathrm{BMD}$, and age as well as a combined use of prednisolorie and azathioprine as negative determimants. In femeles positwe determinanis of aMD were body weight and the use of azathopine Postmenopausal status, use of prednisolone, normal serim magnesium level, and the combinied use of prednisolone and azathioptine, respectively, were negative determinants in males, serum calcium level and body weight were significant positive determinants. whereas age was a negative determinant of $B M D$.

In the linear regression model, the contribution of all significant Invesitigated fisk factors for BMD of lumbar spine, femoral neck and total body a counted for so\% of the variation in BMD.

\section{Condusions}

Patients with CO at risk for low BMo are: male and post menepausal female patients, with low body weight and a history of combined use of prednisolone and azathioprine, normal serum magnesium level and a low serum calcum level, towever climical risk factors are not strong enough preelictors of BMD and do not replace DXA measurements in patients with io 


\section{Introduction}

A high prevalence of osteopenia and osteoporosis has been reported in Crohn's disease ${ }^{1-8}$. The pathogenesis is probably multifactorial, and several risk factors have been stated: corticosteroid $15^{4.5 .9}$, disease activity ${ }^{10.11}$, malnutrition ${ }^{2.12}$ "malabsorption, vitamin D deficiency ${ }^{17}$, smoking ${ }^{14}$ and sex hormone deficiency ${ }^{15}$. Differences in the prevalence and in the risk factors of low bone mineral density (BMD), can be explained by the diversity of populations studied and by the varying methods used to measure BMD. In general, studies have indicated that low BMD is a feature of $C D$ rather than of ulcerative colitis $(U C)^{3,4}$. Osteopenia of the femoral neck is more prevalent than that of the lumbar spine, distinguishing osteoporosis in $C D$ from senile and corticosteroid-induced osteoporosis ${ }^{1,7,16-18}$. We recently described that BMD in newly diagnosed IBD patients was not different from healthy controls, and concluded that low BMD must be a consequence of the disease process and/or the treatment modalities. "With regard to fractures as a consequence of low BMD, an increased fracture risk was reported in Crohn's disease but not in $U C^{20}$ In a large epidemiological study the relative risk of fracture was $40 \%$ higher in patients with IBD than in population controls ${ }^{21}$. Vertebral crush fractures have even been reported in children with $C D$ using corticosteroids ${ }^{22}$, and anecdotally as presenting symptom".

In two large cross-sectional studies, involving only CD patients, low body weight, male sex in addition to current use and cumulative dose of steroids were reported as independent determinants of low BMD in one ${ }^{6}$, and high age, male sex, and low body weight in the other study, respectively'.

The aim of the present study was to identify determinants of low bone mineral density in a large Dutch population-based cohort of patients with Crohn's disease.

\section{Methods}

\section{Patients}

Patients with CD living in three adjacent municipalities of the IBD South-Limburg registry area in the Netherlands, with a total of 150.891 inhabitants (118.465 in Maastricht, 20.591 in Meerssen, and 11.835 in Eijsden), were investigated ${ }^{23}$. Crohn's disease was diagnosed on clinical grounds using endoscopic and/or radiological evidence, supported by mucosal biopsies and/or examination of surgical specimens when available. For confirmation of the $C D$ diagnosis, the Lennard-Jones criteria were applied ${ }^{24}$.

The study population consisted of $181 \mathrm{CD}$ patients, all of Caucasian ethnicity, of whom 14 patients were excluded because of: pregnancy, renal insufficiency, ankylosing spondylitis ( 3 patients) ${ }^{25}$, rheumatoid arthritis, puimonary cancer, and change of diagnosis to ulcerative colitis (7 patients). Four patients from the IBD registry had died before inclusion, one patient due to a thrombo-embolic event (possibly related to an exacerbation of CD), three others due to causes unrelated to $C D$. Five patients had moved out of the study area. 
48. Chapter 4

The intention was to investigate all patients attending the outpatient dinic during the study period. One-hundred-nineteen (75\%) of the 158 eligible patients, 37 males and 82 females with a mean age $( \pm S D)$ of $42( \pm 14)$ years (range 17-78) were investigated. Mean duration of disease was $10.5( \pm 8.8)$ years. The disease was located in the small-bowel in 35 patients, in the colon in 10 patients, while 74 patients had ileo-colonic disease. Seventy-three patients had one $(n=42)$ or several $(n=31)$ surgical resections. Patient characteristics are given in Table 4 .1. Thirty-nine patients (14 males, 25 females) who did not attend the outpatient dinic during the study period were not included. The mean age of these patients was $42( \pm 15)$ years and mean duration of disease was $12( \pm 9)$ years. The Ethics Committee of the University Hospital Maastricht approved the IBD epidemiological study protocol, and all subjects gave their written informed consent before the start of the study.

Table 4. chincal characteristic of 119 patients wilh Crohns disease

\begin{tabular}{|c|c|c|c|c|}
\hline & $\begin{array}{l}\text { all } \mathrm{CD} \\
\text { patlents }\end{array}$ & male & femiale & $\begin{array}{c}\text { difference } \\
\text { maleffemale } \\
\text { p-vallue }\end{array}$ \\
\hline namber & 119 & 37 & 82 & \\
\hline age & $42(14)$ & $45(1)$ & $40(-4)$ & 0.052 \\
\hline age at diagnosis & $32(14)$ & $35(18)$ & $30(13)$ & 0093 \\
\hline body miass index & $235(37)$ & $239(39)$ & $23.3(3.6)$ & 0,403 \\
\hline disease duration & $10.5(8.8)$ & $11.3(11.4)$ & $10.2(73)$ & 0.524 \\
\hline number of admissions & $27(0.1)$ & $28(3.7)$ & $27(2.8)$ & 0,087 \\
\hline number of resections $(\%)$ & & & & \\
\hline one & $43(36)$ & & & \\
\hline more thain ore & $31(26)$ & & & \\
\hline
\end{tabular}

\section{Bone mineral Density}

In all patients bone mineral density was measured using duall-energy X-ray absorptiometry (DXA) (Lunar DPX-L, Lunar software version DPX-L 1.3; Lunar Radiation Corp., Madison, WI) of lumbar spine $\left(L_{F}-L_{A}\right)$ and femoral neck of the nondominant hip. In 61 patients DXA of the total body was also performed. BMD was expressed in absolute values $\left(\mathrm{g} / \mathrm{cm}^{2}\right), r$-score (one standard deviation compared to a young adult gender matched reference population), and Z-score (one standard deviation compared to an age and gender matched reference population). Reference data were based on populations from the US, United Kingdom, and Northern Europe ${ }^{26.28}$. There was a $1.3 \%$ standard deviation of mean BMD values of the populations in various geographical areas contributing to normal data. The proportion of patients with osteopenia and osteoporosis, respectively, was assessed according to the WHO classification in which osteopenia is defined as a T-score between -1 and -2.5 and osteoporosis as a T-score $\leq-2.5^{29}$. The data on the prevalence of osteoporosis and on symptomatic fractures have been presented 
earlier?. The Z-score was used to correct for age differences between groups if applicable.

\section{Parameters}

The cumulative lifetime amount of prednisolone or equivalent used and the previous (for more than three months) or current use of azathioprine, vitamin $\mathbb{D}_{\text {, }}$ and calcium were collected from the medical records. Firom these records also the number of resections, number of hospital admissions, and the presence of lactose intolerance was noted. The current use of alcoholl (g/day) and the cumulative amount of cigarettes smoked during lifetime was calculated in pack-years (one pack-year, being one package of cigarettes smoked daily during one year) were assessed from a patient questionnaire. Family history of osteoporosis was assessed by the same questionnaire and was considered positive if at least one of the firstdegree family members had a clinical history of osteoporosis. Physical activity was assessed using a physical activity index score according to Baecke, which is an 18 points scale involving habitual physical activity (sports and daily physical activity) during childhood ( $<12$ years), young adulthood (12-18 years), and during the previous six months, respectively ${ }^{30}$. The body weight and height were measured to calculate the body mass index $\left(\mathrm{kg} / \mathrm{m}^{2}\right)^{31}$.

\section{Laboratory parameters}

Serum magnesium was measured in the routine laboratory and a reference value of $0.7-1.0 \mathrm{mmol} \mathrm{Mg} / \mathrm{l}$ was applied. Serum calcium $(n=2.1-2.6 \mathrm{mmol} / \mathrm{l})$ was measured in the same laboratory and was corrected for the albumin level $(n=32-42 \mathrm{mg} /$ ) . Serum 25 -hydroxywitamin D concentration was measured by using a ${ }^{125}$ I radioactive immunoassay (RIA, Incstarr Corporation-Stillwater, Minnesota, US) with two different ranges of reference values (summer (June-December): 70-100 nmol/I, winter (January-May): 25-70 nmol/l) ${ }^{32}$. Serum parathyroid hormone was measured by immuno-radiometric assay (IMRA) for which the reference value (for normal calcium level) of 2-6 pmol/l was applied ${ }^{3 .}$. Ninety-one patients agreed to do 72 hours faeces collection, while taking their habitual diet to determine the faecal fat excretion (normal value $\leq 29$ gr/72*hours).

\section{Statistical analysis}

Comparisons of risk factors were performed using a parametric test (independent $t$ test) if a normal distribution was present; otherwise an appropriate non-parametric test (Mann-Whitney U) was used. ANOVA was used for comparison of bone mineral density between groups. The Pearson's coefficient of correlation was used to calculate correlations.

Potential independent risk factors influencing BMD were selected by univariate analysis, these factors, including age and gender, were used in a linear regression analysis to identify independent determinants of $\mathrm{BMD}$ in $\mathrm{CD}$. In the total group of the patients, and in male and female patient groups separately, $R^{2}$-adjusted was calculated to estimate the contribution of all independent variables included in the linear regression model. Two-tailed tests for significance were used in all statistical 
analyses. A p-value of $<0.05$ was considered to be statistically significant. The Statistical Package for the Social Sciences (SPSS 8.1, SPSS inc., Chicago, Ull, USA) was used for the analyses.

\section{Results}

The prevalence of osteopenia and osteoporosis is demonstrated in Table 4.2. Malle CD patients had a significantly lower mean Z-score of the total body compared to females $(-0.58$ and -0.12 , respectively $(\rho=0.05)$ ), whereas no significant gender differences for femoral neck or lumbar spine BMD were found. As the mean age of the malle population was almost significantly higher, the Z-score was applied to correct for age difference.

Table 42. Prevalence (in percentage) of normal bone mass, osteopenia and osteoporosis In 119 patients with Crohn's disease defined as T-score (WHO-criteria).

\begin{tabular}{|c|c|c|c|}
\hline & ${ }_{\text {normal }}>-1$ & osteopenia $-2.5<T \leq-1$ & $\begin{array}{c}\text { osteoporosis } T \leq-2.5 \\
\%\end{array}$ \\
\hline 2 & 71 & 22 & 7 \\
\hline femoral neck & 48 & 41 & 11 \\
\hline rotal body & 67 & 27 & 6 \\
\hline
\end{tabular}

Postmenopausal female patients had a lower BMD $\left(\mathrm{g} / \mathrm{cm}^{2}\right)$ than premenopausal patients, which was significant at the femoral neck $(p=0.037)$, ulsing T-scores at the lumbar spine ( $p=0.024)$. However, comparison of the Z-score demonstrated higher mean values except for the total body Z-score, which was not significantly different, meaning no significant difference compared to the normative DXA controls.

Possible risk factors influencing bone mineral density in $C D$ patients that were studied are given in Table 4.3 .

No correlation was found between severity of metabolic bone disease and disease duration, number of resections and number of hospital admissions. Disease localisation did not significantly influence BMD, T- or Z-scores (Table 4.4). No correlation was found between severity of metabolic bone disease and life-style factors (smoking and previous or current physical activity). Patients with a positive family history of osteoporosis did not have a significant lower bone mass than patient without such antecedents.

Patients with a serum magnesium level below the lowest limit of the applied reference value $(19 \%)$ had a significantly higher $Z$-score at the lumbar spine than patients with a normal serum magnesium level $(p=0.008)$. Serum magnesium correlated significantly with serum calcium level $(r=0.315, p=0.002)$. 
Clinical determinants of osteoporosis in IBD

Table 43 Possible factors influencing bone mineral density in 19 patients with crohm's disease

\begin{tabular}{|c|c|}
\hline & CD patlents \\
\hline corticosteroids use ever $(\%)$ & $\left.69(579)^{\prime}\right)$ \\
\hline Ufe prednisolone dose (mig) & $4749(9010)$ \\
\hline azathioprine use ever ( $\%$ ) & $35(29.4 \%)$ \\
\hline cholestyramin use ever $(\%)$ & $22(18 \%$ \\
\hline curvent calcium supplement & $21(8 \%)$ \\
\hline Gurrent witamin D supplement & $15(13 \%)$ \\
\hline postmenopacsal female $(\%)$ & $20 / 82(24396)$ \\
\hline time from menopause (years) & $25(5.5)$ \\
\hline females use of oral anticontraceptives & $70 / 82(85 \%)$ \\
\hline periods of amenormoea & $12775(16 \%)$ \\
\hline lactose intolerance & $15(2,6 \%)$ \\
\hline physical actwity index & $15,0(27)$ \\
\hline moking, no smoker $(\%)$ & $23 \%$ \\
\hline current $1 \%$ & $47 \%$ \\
\hline previous $(\%)$ & $309 \%$ \\
\hline packet years of smoking & $12.6(128)$ \\
\hline family history of osteoporosis & $10(8 \mathrm{a} \%)$ \\
\hline alkaline phephatase $(10)$ & $894(404)$ \\
\hline serumcalei um (mmoll) & $240(012)$ \\
\hline elevated PTH $>6$ priolin) & $393(3.2 \%)$ \\
\hline serum PTH (pmoll) & $33(1.4)$ \\
\hline low serum magnesum $(<075 \mathrm{mmo} / 1 / 1)$ & $197102(187 \%)$ \\
\hline serum magnesium (mmolly) & $0,79(0,08)$ \\
\hline vitamin D deficiency? & $40 / 11(36 \%)$ \\
\hline Grecal fat exicretion (grm2 hours) & $397(51,7)$ \\
\hline atients with teatorhhoea $>21 \mathrm{gu} /$ & $67791(74 \%)$ \\
\hline
\end{tabular}

Data are represented as mean (standard devition) or as number and percentage if indicated (\%) Two different ranges of reference values (summer (June-December) 70,100 nimoly/, whter Uanuary. May) $25-70$ nimol/l).

Table 4.4. Mean bone mineral density stratified according to disease localization in 119 patients with Crohn's disease.

\begin{tabular}{|c|c|c|c|c|}
\hline lumbar spine $L_{2} L_{\text {, }}$ & $-0.07(1.33)$ & $0,03(136)$ & $0,02(121)$ & 095 \\
\hline femoral neck & $-0,00(123)$ & $-0,15(111)$ & $0.57(1.18)$ & 0.60 \\
\hline al body & $-0.27(1 / 4)$ & $-0.33(0,44)$ & 0.27 (1.09) & 0.99 \\
\hline
\end{tabular}

Stat stical analysis was determined by an analysís of variance (ANOVA) Bone rmineral density 1 expressed as Z-scores (rumber of standard deviations from age and sex-matched mormal values) Mean Z-scores (standard deytation) are shown, ho sigunicant differences we re found. 
At the time of DXA measurement 21 patients were regular users of calcium supplements (median dose 500-1000 mg/day), and 15 were on vitamin D supplementation (median dose 400 IU/day). Patients who had vitamin D deficiency $(36 \%)$ had a lower BMD at the femoral neck $(p=0.044)$, and a significantly lower Tscore of the femoral neck ( $p=0.038$ ) than patients with normal vitamin $D$. Using the Z-score, to correct for age difference between the groups, this difference was absent ( $\mathrm{p}=206$ ). No difference was found for the lumbar spine BMD, T- or Z-scores. Serum parathyroid hormone was ellevated in $3 \%$.

In the total group of patients linear regression analysis demonstrated both body weight and female gender as significant positive determinants of BMD and, age and a combined use of prednisolone and azathioprine as negative determinants (Table 4.5). In females significant positive determinants of BMD were body weight and the use of azathioprine. Postmenopausal status, use of prednisolone, normal serum magnesium level, and the combined use of prednisolone and azathioprine, respectively, were negative determinants (Table 4.6). In males significant positive determinants were corrected serum calcium level and body weight, whereas age was a negative determinant of BMD (Table 4.7).

Table 4.5. Determinants positively or negatively influencing bone mineral density in patients with Crohn's disease $(n=119)$ expressed in bone mineral density (g/an') ar Z-score.

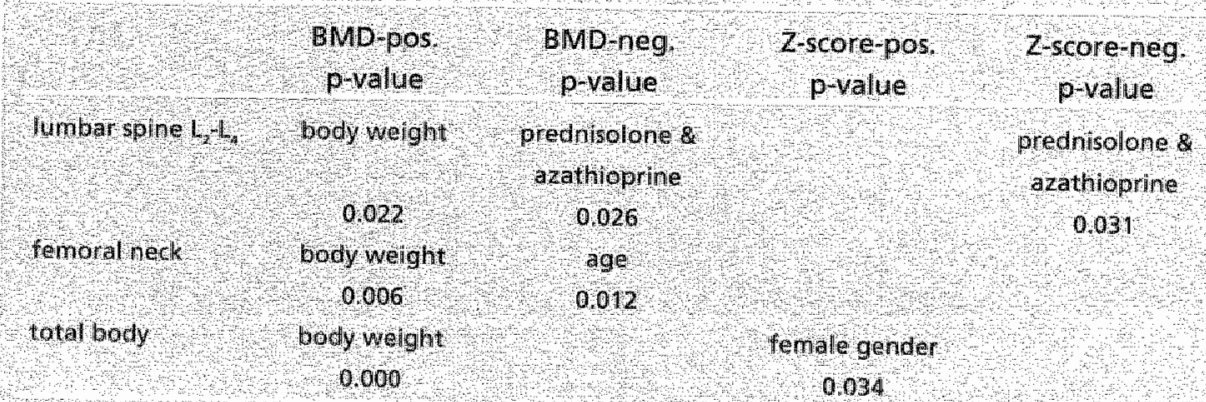

Whigat regresion onalysis. Prednisolone a azalhioprine $=$ previous or current combined use of prednisolone equivalent and azol hoprin

In the linear regression model, the contribution of all significant investigated risk factors for BMD of lumbar spine, femoral neck and total body accounted for $50 \%$ of the variation in BMD. 
Table 4.6. Determinants positively or negatively infuencing bone mineral density in female patients with Crohn's disease $(n=82)$ expressed in bone mineral density $\left(g / \mathrm{cm}^{2}\right)$ and $Z$ sicore.

\begin{tabular}{lll}
\hline \\
\hline
\end{tabular}

Linear regression analysis, Weight $=$ body weight, postmenopausal = postmehopausal stahus, predinisolone \& azathioprine = previous or current combined use of prednisolone equivalent and azathioprine, azathioprine - prevlous or current use of azathioprine aganist no use, nagnesilum = serum magnesium level (mmolin)

Table 47. Determinants of positive and negative effects bone mineral density in male patients with Crohn's disease $(n=37)$ expressed in bone mineral density $(\mathrm{g} / \mathrm{cm})$ and 2 -score

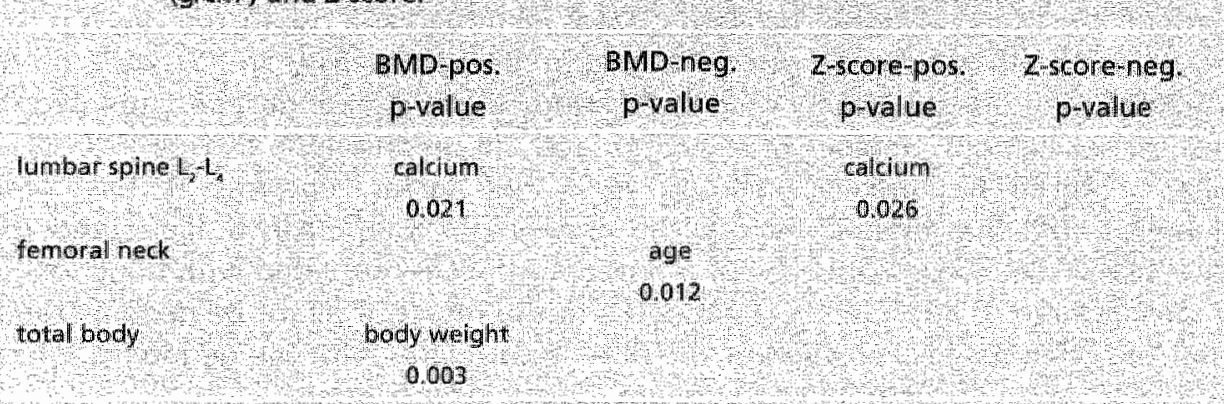

Linear regression analysis:

calcium = serun calcium level in mmollh corrected for albumin level 


\section{Discussion}

In this study we have confirmed the previously identified risk factors for low BMD, namely; age low body weight, gender, postmenopausal status, and steroid use. In addition we have identified some novel risk factors: a history of combined use of azathioprine and corticosteroids was recognized as a significant independent risk factor at the level of the lumbar spine. The corrected serum calcium level was found to be a positive determinant of BMD especially in male patients at the level of the lumbar spine. The serum magnesium level was inversely correlated to the BMD (Z-score) of female CD patients.

The use of prednisolone or equivalent was only a weak negative determinant for BMD in the total body measurement of female patients. Controversies between studies on the effects of corticosteroids on BMD in patients with CD can be explained by: the multifactorial nature of bone 10ss, the difficulties of accurate retrospective calculations of steroid doses used, the heterogeneity and the size of the populations studied, the individual susceptibility of the patients to the damaging effects of corticosteroids, and the confounding effects of disease activity ${ }^{34}$. During disease remissions there might be a reversible component, resulting in a recovery of $\mathrm{BMD}^{35}$.

Regarding the combined use of azathioprine and corticosteroids, disease activity can be an important confounder, since patients using these agents could be considered to be more severely ill. Indications for the administration of azathioprine in this study were as specified in the literature: steroid dependency, recurrent activity of Crohn's disease, and peri-anal disease. The effect of azathioprine on bone mineral density has been mentioned in two studies; both of them were unable to demonstrate a negative effect ${ }^{6,35}$. However, in juvenile patients the use of azathioprine with CD was identified as a risk factor ${ }^{3}$. As it is not possible to retrospectively assess long-term disease activity in $C D$, the proxy parameters of disease activity used in this study were: disease duration, number of hospital admissions, number of resections and life prednisolone dosage. No single one of these parameters emerged as a risk factor. Recently it has been demonstrated that genetic factors, the presence of interleukin 6 allelle, and the absence of the interleukin 1 receptor antagonist allele correlated with bone loss in a mixed group of 86 UC and CD patients ${ }^{38}$. In the future, it might be demonstrated that the phenotypic expression of the disease correlates with the genotype, which would facilitate calculations of treatment /outcome correlations.

Surprisingly, the corrected serum calcium level was found to be a positive determinant of BMD especially in male patients at the levell of the lumbar spine. A possible explanation for this phenomenon is that small fluctuations of the serum calcium and vitamin D level, which might not be compensated by an increased calcium absorption in some patients, influences the secretion of PTH and in the long-term affects BMD. The use of corticosteroids has a negative effect on the calcium and vitamin $D$ absorption. Furthermore, the conversion of vitamin $D$ into its active form is compromised. A high prevalence $(36 \%)$ of vitamin D deficiency was found in this group of CD patients, but no patient had clinical signs of hypovitaminosis D. BMD, expressed in Z-scores, was not different between patients 
with normal serum vitamin D levels and vitamin D deficient patients. The presence of vitamin $D$ deficiency did not correlate significantly with $B M D$, although small minerallisation defects can be missed by DXA. However, addition of this parameter to the linear regression model led to a small improvement in the correlation between the sum of all risk factors and BMD. In a comparable study of $115 \mathrm{CD}$ patients, Andreassen et al. demonstrated a negative correlation between the PTH level and BMD of the femoral neck, distal forearm and total body" "The present study only confirmed a significant negative correlation between the T-score of the femoral neck and serum PTH level.

Almost seventy percent of this population-based cohort of patients with Crohn's disease had used corticosteroids during periods of disease activity, with a mean lifetime dose of 5 grams, but with a large inter-patient variation. Considering the incidence and amount of corticosteroids used in this population, the prevalence of osteoporosis seems relatively low, therefore factors protecting against bone loss might be existing. Possibly, the magnesium metabolism is of importance in this context as the serum magnesium level was found to be a negatively correlated with the Z-score of lumbar spine and femoral neck in female CD patients. This is the first study to bring up the potential role of magnesium as determinant for BMD in CD. Serum magnesium concentrations are no good indicator of body magnesium stores. Lower serum levels can be a consequence of malabsorption and higher levels can be caused by an increased bone resorption. Recently, a large crosssectional study on biochemical markers of bone turnover in $\mathrm{CD}$ demonstrated an increased bone resorption but normal bone formation; this imbalance might explain higher serum magnesium levels as indicator for bone loss ${ }^{4}$. A recent study on bone loss after cardiac transplantation, demonstrated that patients with magnesium deficiency had a lower bone resorption probably due to PTH resistance". The long-term effects of a suboptimall magnesium supply inducing a marginal or moderate deficiency compared to an excessive magnesium supplementation had been investigated in a rat experiment ${ }^{42}$. The results indicated that the long-term suboptimal magnesium supply improved some of the indicators of bone health whereas the long-term supplementation was deleterious. Serum concentrations of 1,25-dihydroxyvitamin D, PTH and IGF-I and the length of the right humeri were not affected by the dietary treatment. An exact explanation of the mechanism was not given in both previous studies. In a population of patients with $C D$ and ileal resections a low urinary magnesium excretion was found in one third of the patients ${ }^{4 \rightrightarrows}$. The prevalence of low serum magnesium levels in this population-based study sample was study $19 \%$.

BMD was found to be independent of disease localisation. Robinson et al. established that jejunal disease localization was a risk factor. In our study the number of patients with only proximal small bowel localised disease was too small for separate analysis.

Although a linear regression model was established, the correlation with the BMD of different localisations was relatively small, and the predictive value therefore seems low.

From this study it can be concluded that patients with $\mathrm{CD}$, who are particularly at risk for low BMD are: the malle and post-menopausal female patients with low body weight and a history of prednisolone use or combined use of prednisolone 
$56 \mid$ Chapter 4

and azathioprine, possibly reflecting the cumulative disease burden. A surprising finding was the inverse correlation between serum magnesium levels and $B M D$. and the correlation with the corrected serum calcium level, findings that need further study. However, clinical risk factors alone are not strong enough predictors of BMD to abandon DXA measurements in patients with Crohn's disease. 


\section{References}

1. Bjamason 1 , Macpherson $A$, Mackintosh $C$. Buxion-Thomas M, Forgacs 1 , Moniz $C$. Reduced bone density in patients with inflammatory bowel disease. Gut 1997:40:228:233.

2. Compston IE, Judd D, Crawley EO, et al, Osteoporosis in patients with inflammatory bowel disease. Gut 1987:28:410-415.

3. Ghosh 5, Cowen 5 , Hannan Wl, Ferguson A. Low bone mineral density in Crohn"s disease, but mot in ulcerative colikis, at diagnosis. Gastroenterology 1994; 107 : 1031-1039.

4. Jahnsen J, Falch JA, Aadland E. Mowinckel P. Bone mineral density is reduced in patients with Crohn"s disease but not in patients with ulcerative colits: a population based study. Gut 1927;40:313-319.

5. Pigot F, Roux $C$, Chaussade $S_{n}$ et al. Low bone mimeral density in patients with inflammatory bowel disease. Dig Dis Sci 1992;37:1396-1403.

6. Robinson RJ al Azzawi F, lqbal sl" et al. Osteoporosis and determinants of bone density in patients with Crohn's disease. Dig Dis Sci 1998;43:2500-2506.

7. Schoon El, van Numen AB, Wouters RS, Stockbrugger RW, Russel MIG. Osteopenta and osteoporosis, in Crohn's disease: prevalience in a Dutch population-based cohont. Scand I Gastroenterol Suppl 2000;35:43-47.

8. Sitvennainen JA, Kartumen $\mathbb{T} J$ Niemela $5 E$, Manelius J), Lehtola لاK. A controlled study of bome mineral density in patients with inflammatory bowel disease. Gut 1995:37:71-76.

9. Bernstein $C N$, Seeger LL, Sayre JW, Antom PA, Artinian L, Shanahan F. Decreased bone density in inflammatory bowel disease is related to corticosteroid use and not disease diagnosis. I Bone Minner Res 1995; 10:250-256.

10. Hyams 15, Wyzga $\mathbb{N}_{r}$ Kreutzer Dh, Justinich CJ, Gronowicz. GA. Alterations in bone metabolism in children with inflammatory bowel disease: an in vitro study. I Pediatr Gastroenterol Nutr $1997: 24: 289-295$.

11. Issenman RM. Bones in Crohn's: Gytokines, a missing link? I Pediatr. Gastroenterol Nutt 1997;24:36月. 362.

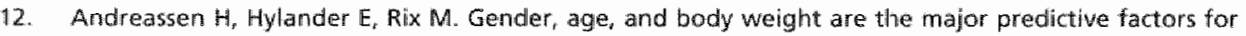
bone mineral density in Crohn"s disease: a case-control cross-sectional study of 113 patients. An J Gastromterol 1999;94:824-828.

13. Vogelsang $H_{*}$ Ferenci $P_{n}$ Woloszzuk $W$, et al. Bone disease in vitamin $D$-defïcient patients with Crohn's disease. Dig Dis 5 ci 1989;34:1094-1099.

14. Silwernoinen JA, Lehtolia $K K$, Niemela SE, smoking is a risk factor for asteoporosis un women with inflammatory bowel disease. Scand I Gastroenterol 1996;31:367-371.

15. Robinson RJ, kqbal SL, al Azzawi F, Abrams KK, Mayberry JF. Sex hormone status and bone metabolism in men with Crohn"s disease. Aliment Pharmacol Ther 1998; 12:21-25.

16. Pollak RD, Karmeli F, Eliakim R, Ackermani $Z$, Tabb K, Rachmilewitz D. Femorall neck osteopenia in patients with inflammatory bowel disease. Am / Gastroenterol 1998;93:1483-1490.

17. The rile M, Horlick M, Bilezikian JP, et al. Osteoporosis an unusual presentation of childhood Crohn's disease. J Cin Endocrinol Metab 2000;85:2122-2126.

18. Dresner-Pollak $R$, Karmeli $F$, Eliakim $R_{x}$ Ackerman $Z_{-}$Rachmilewitz D. hncreased urinary N-telopeptide crosis-linked type 1 collagen predicts bone loss in patients with inflanmatory bowel disease. Am J Gastroenterol 2000;95:699-704.

19. Schoon El, Blok BM, Geerling BU. Russel MG, Stockbrugger RW, Brummar RJ. Bome minerall density in pattents whth recently diagnosed inflammatory bowel disease. Gastroenterology 2000;119:1203-1208.

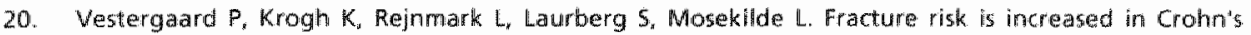
disease, but not in ulcerative collis. Gut 2000;46:176-181. 


\section{8

21. Bernstein CW, Blanchard JF, Leslie W, Wajda $A$, Yu BN. The incidence of fracture among patients whth inflammatory bowel disease. A populationbased cohort study. Ann Intern Med 20100; 133:795-799.

22. Semea El, Stalings WA, Peck SN, Piccoli DA, Vertebral compression fractures in pediatric patients with Crohn's disease, Gastroenterology 1997;112:1710-1713.

23. Russel MG, Donant $E$, Wowics A, al al. High incidence of inflammattory bowel disease in The Netherlands: resulats of a prospective study. The South Limburg 1BD 54 udy Grosp. Dis Colon Rectum $1998 ; 4133 \cdot 40$.

24. Lennard-fones: JE. Gassfication of inflammatory bowel disease. Scand I Gastroenterol suppl $1989 ; 170: 2-6$.

25. Telchmann I. Lange U, stracke H. Doppl W. Klor HU, Federlin K. Rapid spinal trabecular bone loss in famale patients with ileitis terminalis Crohn and additional sacroiliac joint inflammation. Rheumatol Int $1997: 17: 45,48$.

26. Kroger H, Heikkinen J Latinen K, Kotaniami A. Duhlenergy $X$-ray absorptiometry in normal women: a cross-sectlional tudy of 717 Finnish volunteers. Osteoporos int 1992;2:135-140.

27. Mazess PB, Barden HS, Ettinger M, et al, Spine and femul density using dualophoton absorptiometry in US white women. Bone Miner 1987:2:211-219.

28. Stevemson $I C_{\text {. Lees }} \mathrm{B}$, Devenport M. Cust MP. Ganger KF. Determinants of bone density in normal women: risk factors for future osteoponosis? BMII 1989:298:924-928.

29. Assessment of fracture risk and its application to screeming for postmenopausal asteoporosis. Report of a WHO studly Group. World Health Organ Tech Rep Ser 1994;843:1-129.

30. Baecke $J A_{n}$ Burema $J$. Frijters fE. A short questionnaire for the measurement of habitual physical activity in epidemiological studies. Am I Clin Nutr 1982;36:936-942.

31. Beal VA. The nutritional history in langitudimal research. J Am Diet Assoc 1967,51:426-432.

32. Hollis BW, Kamerud IQ Selvaag SR, Lorenz JD, Napoli IL. Defermination of witamin $D$ status by radioimmunoassay with an 1251- labeled tracer. Chin Chem 1993:39:529-533.

33. Roos BA, Lindall AW. Aron DC, et al. Detection and characterization of small midregion parathyroid hormone fragment(s) in nomal and hyperparathyroid glands and sera by immumoextraction and region-specific radiömmunoassays. I Chin Endocrinol Metab 1981:53:709-721.

34. Compston JE. Detection of osteoporosis in patients with inflammatory bownel disease. Eur $J$ Gastroenterol Hepatol 1997;9:931-933.

35. Schulte $C_{r}$ Dignass AU, Mann K, Goebell $H$. Bione loss in patients with inflammatory bowel disease is less than expected: a follow-up study. Scand J Gastroenterol 1999;34:696\%702.

36. Foren $\mathrm{CH}_{4}$ Ahren B, Bengesson M, Bartosilk $J_{n}$ Obrant K. Bone mineral dersity in patients with Crohn's Afisease during long-term treatment with azathioprine. Intern Med 1998;243:423:126.

37. Semeál EJ, Jawad AF, Stouifer NO, Zemel BS, Piccoli DA, Stallings VA. Risk factors for low bone mineral density in children and young adults with Crohn's disease. J Pedatr 1999; 135-593-600.

38. Schule CM, Dignass AU, Goebell $H_{x}$ Roher HD. Schulte KM. Genetic factors determine extent of bone loss in inflammatory bowel disease. Gastroenterology $2000 ; 19,909,920$.

39. Andreassen $H_{4}$. Rix M, Brot C. Eskildsen P. Regulators of calcium homeostasïs and bone mineral density in patients with Crohn's disease. Scand J Gastroenterol 1998; 33:1087-1093.

40. Robinson RJ, lqbal 5., Abrams K, al Azzawi F. Mayberry JF. increased bone resorption in patients with Crohn's disease. Aliment Pharmacol Ther 1998:42:699,705.

41. Boncimino K. MCMahon DJ, Addesso V. Bilezikian JP. Shane E. Magnesium deficiency and bone loss after cardiac transplantation. H Bone Miner Ptes 1999;14:295-303.

42. Riond $J_{w}$, Hartmann $P$. Steiner $P$, et all. Long-term exciessive magnesium supplementation is deleterious whereas suboptimal supply is beneficial for bones in rats. Magnes Res 2000;13:249-264.

43. Hessov 1. Hasselblad C. Fasth S. Huiten L. Magnesin deficiency after ileal resections for Crohn's disease. 5cand 1 Gastroenterol $1983 ; 18: 643 \cdot 649$. 


\section{Bone mineral density in patients with recently diagnosed inflammatory bowel disease}

EJ Schoon, BM Blok, BJ Geerling, MG Russel, RW Stockbrügger, R-JM Brummer 


\section{Abstract}

\section{Background}

A high prevalence of osteoporosis is reported in inflammatory bovel disease and its pathogenesis is not completely resolved. We investigated whether borne mineral density in paxients with inflammatory bowal cisease at diagnosis is lower than ilf population controls, and whether bone mineral density differs between patients with Crohn's disease and those with ulcerative colits:

\section{Methods}

In 68 patients amd 68 , ge, and gender matched population comtrols, bone mineral density of tolal body spine, and fhip was assessed using duallenergy x fay absonotiometry within 6 months after establishing the dagnosis Determ nants for low bone mineral density were assesised

\section{Results}

There were no ignificant differences $1 \mathrm{~m}$ bome minemal density $(\mathrm{g} / \mathrm{cm}$ ) Bartweren patients and controls, and no signiflcant differences in bone

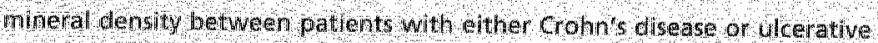

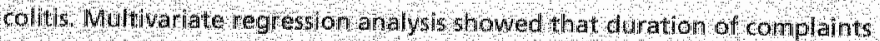
Jonger than 6 months betore diagnosis $(p=0,041$ ) age $(p=0.019)$, and bod, mast ndex lower han $20 \mathrm{~kg} / \mathrm{m}$ lp -0.006 signhicantly correlated with low bone nithoral density.

\section{Conclusions}

Bone Jumenal density in patients with recently daghoosed intlammatory bowel diseaste Wa, not squificart ty cecreased compared with population

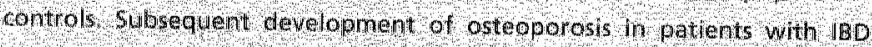
sedns to be a phenomenon related to the disease. brocess andior the

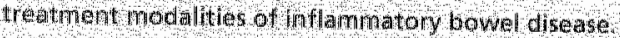




\section{Introduction}

A high prevalence of osteoporosis and osteopenia in inflammatory bovel disease (IBD), especially in Crohn's disease (CD), has been reported in several cross-5ectional and population-based studies". Multiple risk factors such as the systemic use of corticosteroids, disease activity, malnutrition, vitamin D deficiency, smoking, and lack of physical activity are believed to be inwolved in the pathophysiology of IBDassociated osteoporosis ${ }^{\text {a.s }}$ " Osteoporosils may lead to low impact fractures, which are reported already in young children with Crohn's disease ${ }^{36,17}$. Low bone mineral density (BMD) is more often observed in CD than in ulcerative colitis (UC) ${ }^{13}$. Ghosh et al. ${ }^{i g}$ reported that patients with newly diagnosed $C D$ had a significantly lower bone mass than those with newly diagnosed UC. In a large controlled study on long-term $C D$ vs. UC, BMD in patients with $C D$ was significantly reduced at all measured sites compared with patients with UC and healthy subjects ${ }^{18}$. Such findings imply that patients with $C D$ should be screened for osteoporosis at diagnosis, and that systematic preventive treatment should be considered early in the course of the disease.

The aim of this case-control study was to assess whether (1) BMD is lower in patients with newly diagnosed IBD in comparison with matched population controls and (2) BMD differs between CD and UC patients at diagnosis. In addition, determinants of llow BMD in IBD patients at diagnosis were assessed.

\section{Patients and Methods}

\section{Subjects}

All patients with newly diagnosed IBD $(n=76)$ during the study period from June 1995 to December 1997 at the Department of Gastroenterology of the University Hospital Maastricht, the Atrium Medical Center Brunssum, and at the Maasland Hospital sittard (all located in the south of the province of Limburg in The Netherlands) were asked to participate in the study. Sixty-nine patients $(91 \%)$ agreed. The patients were studied within 6 months of diagnosis that was based on findings from endoscopy with histology and/or radiology ${ }^{29}$. One pattient with indeterminate colitis was subsequently excluded. Of the 68 patients with $1 \mathrm{BD}, 24$ had CD ( 8 men and 16 women) and 44 had UC (24 men and 20 women)(Table 5.1). In the patients with $C D$, the disease was localized in the colon in 5 patients, small bowel in 6 patients, and both small bowel and colon in 13 patients. In the UC group, 12 patients had pan-colitis, 26 patients distal colitis, and 6 patients proctitis, respectively. The characteristics of $C D$ and UC patients are shown in Table 5.2. Patient characteristics did not differ significan'tly between $C D$ and $U C$. One $C D$ patient and 2 UC patients were postmenopausal. Thirty-three women with IBD used oral contraceptives $(15 \mathrm{CD}, 18 \mathrm{UC})$. 
Table 5, Age and sex of patients with $1 B D$ and control subjects

\begin{tabular}{|c|c|c|c|c|}
\hline & $\begin{array}{c}C D \text { partents } \\
n=24\end{array}$ & $\begin{array}{c}\text { UC patients } \\
n=44\end{array}$ & $\begin{array}{l}\text { all IBD patients } \\
\qquad n=68\end{array}$ & $\begin{array}{l}\text { controls } \\
\mathrm{n}=6 \mathrm{~s}\end{array}$ \\
\hline age (0) & $297(104)$ & $38.4(14.4)$ & $35.3(13.7)$ & $35.3(13)$ \\
\hline gender (eph) & $16 / 8$ & 20124 & 36132 & $36 / 32$ \\
\hline
\end{tabular}

Table 52 Clinical characteristics of patients with $\mathrm{CD}$ and UC

\begin{tabular}{|c|c|c|}
\hline & $\begin{array}{c}C D \\
n=24\end{array}$ & $\begin{array}{l}4 C^{2} \\
n=44\end{array}$ \\
\hline small bowel involvement $(\%)$ & $17(79)$ & - \\
\hline Tesection $(\%)$ & 407 & 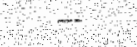 \\
\hline smoking $(\%)$ & 8031 & 15 \\
\hline duration of complaints (months) & $49(73)$ & $34(7)$ \\
\hline number of patients vidh coimplaints & 18 & 12 \\
\hline 56 nenths before diagnosis & & \\
\hline Crohn's d sease activity index & $94=67$ & \\
\hline trutelove \& Witus iladex & + & $96+5.8$ \\
\hline active disease $(\%)$ & $3(12.5)$ & Al \\
\hline predilsolone use $(\%)$ & (8) & $1125)$ \\
\hline Ufe time prednisolonie dose (mg) & $495(845)$ & $301641)$ \\
\hline duration of prednisolone use (itays) & $283(472)$ & $141(28.4)$ \\
\hline
\end{tabular}

Disease activity in CD was assessed using the Crohn's Disease Activity Index (CDAll) and in UC according to the Truelove and Witts index graded numerically from 6 to 19 as being in remission and, when exceeding 19 , as having active disease ${ }^{342}$. Patients with $\mathrm{CD}$ were considered to have active disease when CDAl was $>150$. The total prednisolone dose administered until the date of the dual-energy $x$-ray absorptiometry (DXA) investigation was calculated from medical records.

Sixty-eight volunteers were selected from the patient population database of a general health care center ( 3 general practitioners) located in the same study area. The health care system in The Netherlands is organized with general practitioners as primary health care providers. Nearly every inhabitant $(>95 \%)$, is registered in a family practice. The controls were matched for age and sex with the IBD patients (within 3 years of age). Three postmenopausal patients were matched with postmenopausal controls ( 1 CD control, 2 UC controls). In the control group, 30 female control subjects used oral contraceptives ( 14 CD controls, 16 UC controls). 
The following exclusion criteria were applied for both IBD patients and controls: concomitant diseases predisposing to secondary osteoporosis (thyroid disease, renal disease, diabetes, liver disease or ankylosing spondylitis). Control subjects had no history of IBD or other chronic disease, were not bedridden for an extended period, or were not undergoing long-term medical therapy. Furthermore, patients and controls with a history of medication for the treatment of osteoporosis were not included.

\section{Bone minerall Density}

BMD was measured using DXA (Lunar DPX-L, Lunar software version DPX $L$ 1.3; Lunar Radiation Corp. Madison, WI) of lumbar spine $\left(L_{2}-L_{4}\right)$, nondominant hip, and total body ${ }^{23}$. The coefficients of variation of the lumbar spine and femoral neck were $0.77 \%$ and $1.09 \%$, respectively. BMD was expressed in absolute values $\left(\mathrm{g} / \mathrm{cm}^{2}\right)$. T-score (1 standard deviation (SD) compared with a young adult gender-matched reference population $)$, and Z-score (1 SD compared with an age and sex-matched reference population). Reference data were based on popullations from the United States, United Kingdom, and Northern Europe ${ }^{2426}$. The variation of mean BMD values among geographical areas contributing to normal data was $1.3 \%$.

The number of patients with osteopenia and osteoporosis was assessed according to the World Health Organozation (WHO) classification defining osteopenia as a Tscore between -1 and -2.5 and osteoporosis as T-5core less than $-2.5^{2 \%}$. Body composition (i.e., body fat percentage and fat-free mass) was assessed using DXA of the total body ${ }^{23}$.

\section{Parameters}

The number of wrist, spine and other spontaneous or traumatic fractures in the past was assessed by questionnaire. The cumulative amount of cigarettes smoked during the lifetime was calculated in pack-years (1 pack-year is 1 packet of cigarettes smoked daily during 1 year) from the same questionnaire. Physicall activity was assessed by a habitual physical activity index score according to Baecke et al. ${ }^{25}$ which is an 18-points scale involwing physical activity (sports and daily physical exercise) during childhood (< 12 years), young adulthood (12-18 years) and the previous 6 months, respectively. The body mass index $\left(\mathrm{kg} / \mathrm{m}^{2}\right)$ was assessed. Daily intake of alcohol (g), calcium ( $\mathrm{mg}$ ), and magnesium ( $\mathrm{ng}$ ) were assessed by an experienced dietitian using dietary history ${ }^{30}$. Serum 25-hydroxyvitamin D concentration was measured by a ${ }^{1125}$ I-radioactive immunoassay (RIA Incstarr Corp. Stillwater, MN) with 2 different ranges of reference values (summer (June to December): $70-100 \mathrm{nmol} / \mathrm{l}$, winter (January to May): $25-70 \mathrm{mmol} / \mathrm{/}$ )

\section{Statistical analysis}

Comparisons of parameters and risk factors between patients and controls were performed by using a parametric test (paired Student test) if normal distribution was present; otherwise a nonparametric test (paired Wilcoxon signed-rank test) was used. Comparisons of parameters and risk factors between CD and UC patients were performed using a parametric test (independent $t$ test); otherwise, a non- 
$64 \mid$ Chapter 5

parametric (Manm-Whitney $U$ test or $x^{2}$ test) was performed. The Z-score was used to compare the BMD of CD and UC patients to correct for the age difference between both groups.

Determinants of low bone mass in IBD patients and controls were assessed using a multiple linear regression analysis, after the assessment of potential determinants by an explorative univariate analysis. A backward elimination procedure was performed based on these data. A p-value of $\leq 0.05$ was considered to be statistically significant. The Statistical Package for the Social Sciences (SPSS 8.0.1 for windows package 1998, SPSS Inc, Chicago, IL) was used for the analysis. The study protocol was approved by the Ethics Committee of the University Hospital Maastricht, and all subjects gave their informed consent before the start of the study.

\section{Results}

BMD $\left(g / \mathrm{cm}^{2}\right)$ at total body, lumbar spine, or femoral neck did not differ significantly between IBD patients and controls (Table 5.3 and Figure 5.1). Neither did subgroup analysis (CD vs. controls, UC vs controls, and gender-specific analysis) show any differences. Exclusion of the patients with proctitis $(n=6)$ in the UC group did not change any of the statistical outcomes.

Table 5.3 Mean BMD of total body, lumbar spine, and femoral neck in patients with IBD and control subjects.

\begin{tabular}{|c|c|c|c|c|c|c|}
\hline $\mathrm{BMD}(\mathrm{g} / \mathrm{cm})$ & patierits & controls & patients & controls & patients & controls \\
\hline number & 44 & 44 & 24 & 24 & 68 & 68 \\
\hline \multirow[t]{2}{*}{ total body } & 1,167 & 1,201 & 1.163 & 1164 & 1166 & 1188 \\
\hline & $(0.144)$ & $(0,17)$ & $(0.097)$ & $(0.096)$ & 0,1081 & $(0,10)^{7}$ \\
\hline \multirow[t]{2}{*}{ Lumbar spine } & 1,227 & 1.217 & 1.217 & 1.240 & 1223 & 1226 \\
\hline & $(0.150)$ & $(0.161)$ & $(0 ., 15)$ & $(0.176)$ & $(0.137)$ & $(0,166)^{\mathrm{s}}$ \\
\hline \multirow[t]{2}{*}{ femonal neck } & 1,007 & 1014 & 1031 & 10007 & 1.016 & 1,012 \\
\hline & $(0,183)$ & $0.151)$ & $(0.191)$ & $(0.178)$ & $(0.184)$ & $(0.160)^{\circ}$ \\
\hline
\end{tabular}

All values are expressed as mean (SD)

There were no significant differences be ween groups (paired student's t test)

$p p=0.700, p=0.740, p=0.807, p=0.558, p=0.662, p=0.72, p=0.115, p=0.919, p=0658$.

According to the WHO criteria, 18 patients with IBD and 10 controls had osteopenia (T-score $\leq-1)$ of either total body, lumbar spine, or femoral neck ( $p=$ 0.09). One of the patients was osteoporotic (T-score $\leq-2.5)$ vs. none of the controls (NS). There was no significant difference in number of fractures (all traumatic) between IBD patients and controls ( 48 and 46 , respectively).

Body mass index $(p=0.005)$, vitamin D-levels in winter $(p=0.008)$, magnesium intake $(0.025)$ and alcohol intake $(p=0.002)$ were significantly lower in IBD 
patients than in controls. Percentage body fat, fat free mass, calicium intake, smoking behavior, and physical activity did not differ between the total group of patients and controls (Table 5.4).

BMD did not significantly differ between CD and UC groups at total body. lumbar spine, and femoral neck. Figure 5.2 shows the Z-score of patients with and $C D$ and UC separately, at the different sites of measurement.

Three patients with $C D$ and 4 patients with UC had active disease at the time of bone density measurement. Duration of complaints before IBD diagnosis did not differ significantly between the $C D$ and UC groups, neither did life prednisolone dosage (mg) and duration of prednisolone use before DXA (days)(Table 5.2).

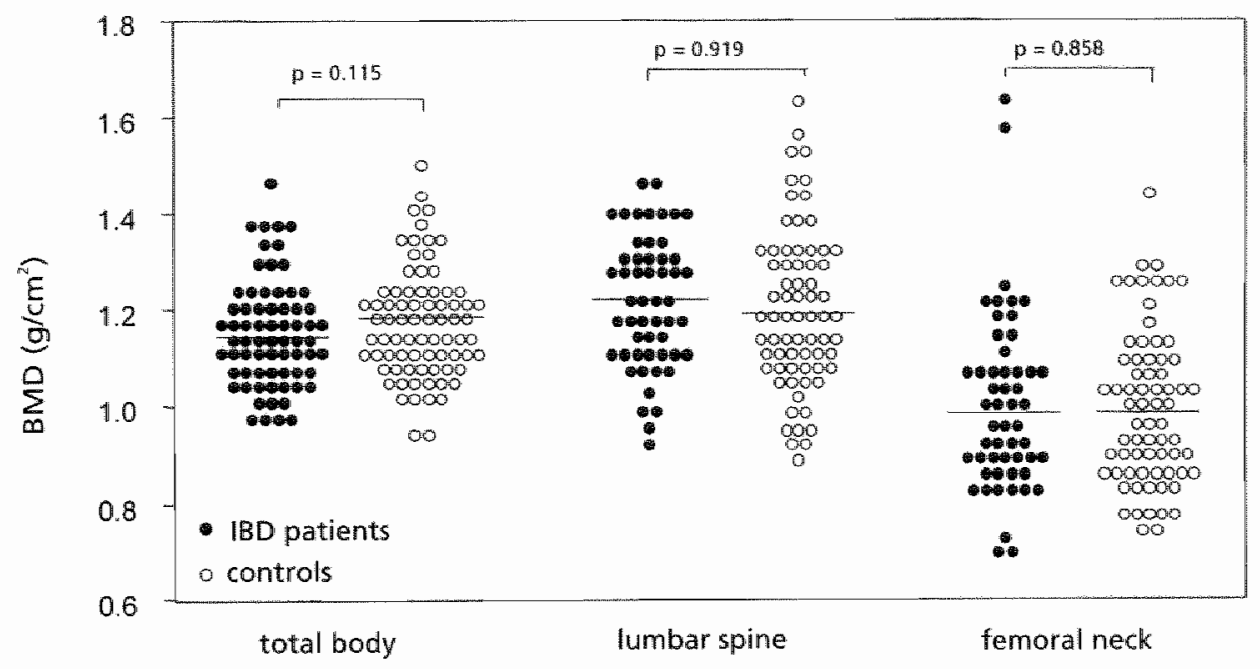

Figure 5.1 BMD $\left(\mathrm{g} / \mathrm{cm}^{2}\right)$ at different sites of measiurement in patients with IBD compared with control subjects. Lines indicate median values. No significant differences were found between IBD patients and controls. Paired differences of mean and $95 \%$ confidence intervals (Cis) of the difference: were calculated. BMD total body: mean $2.25 \times 10^{*}$; SD $0.11,95 \% \mathrm{Cl}:-5.6 \times 10^{-3}$ to $-5.06 \times 10^{*}$; patients ws. controls. BMD at lumbar spine: mean, $-4.4 \times 10^{-3} ;$ SD $0.174,95 \% \mathrm{Cl}:-5.4 \times 10^{-2}$ to $-4.47 \times 10^{2}$; patients vs. controls. BMD at femoral neck. mean 2.65, SD $0.186,95 \% \mathrm{Cl},-4.9 \times$ $10^{2}$ to $5.46 \times 10^{-2}$; pitients vs. controls. 
66 Chapter 5

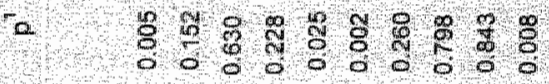

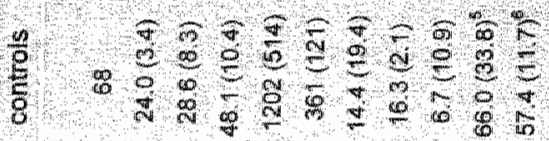

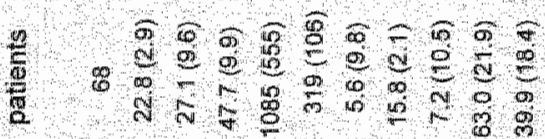

$=$

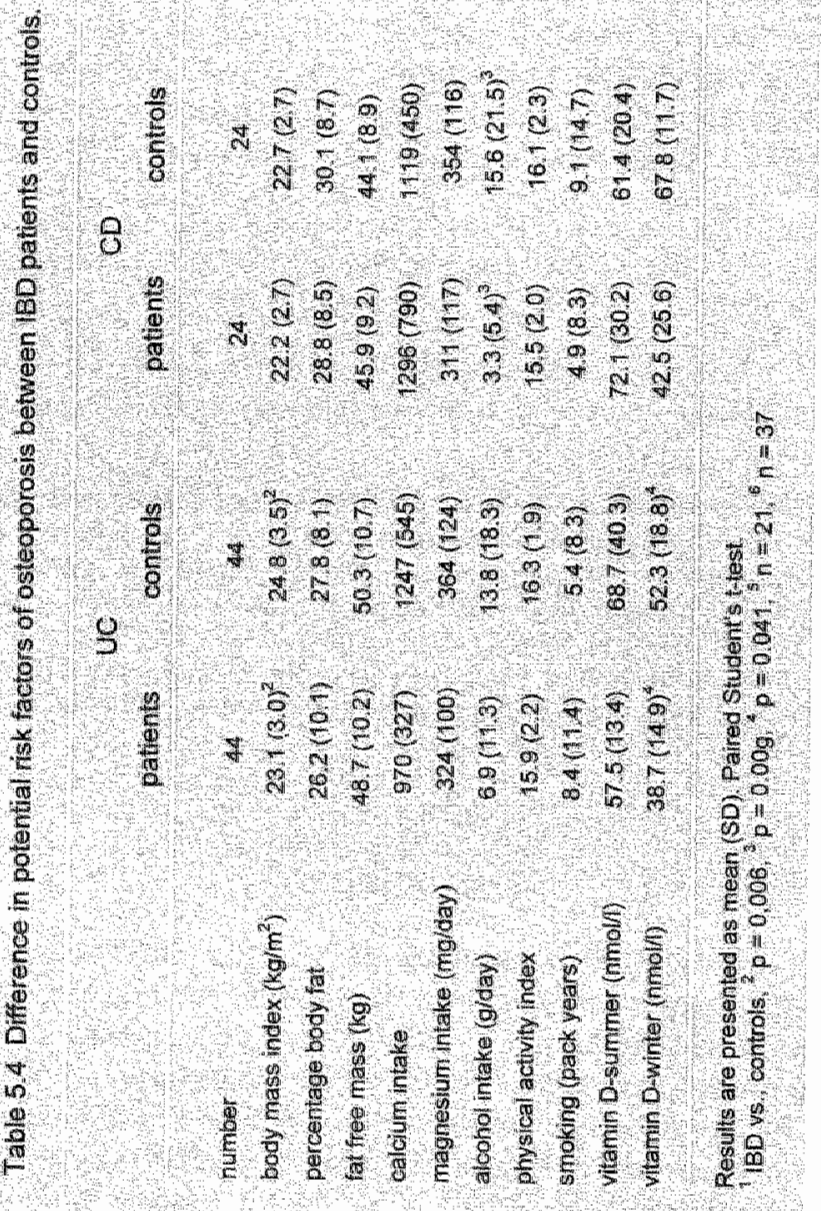




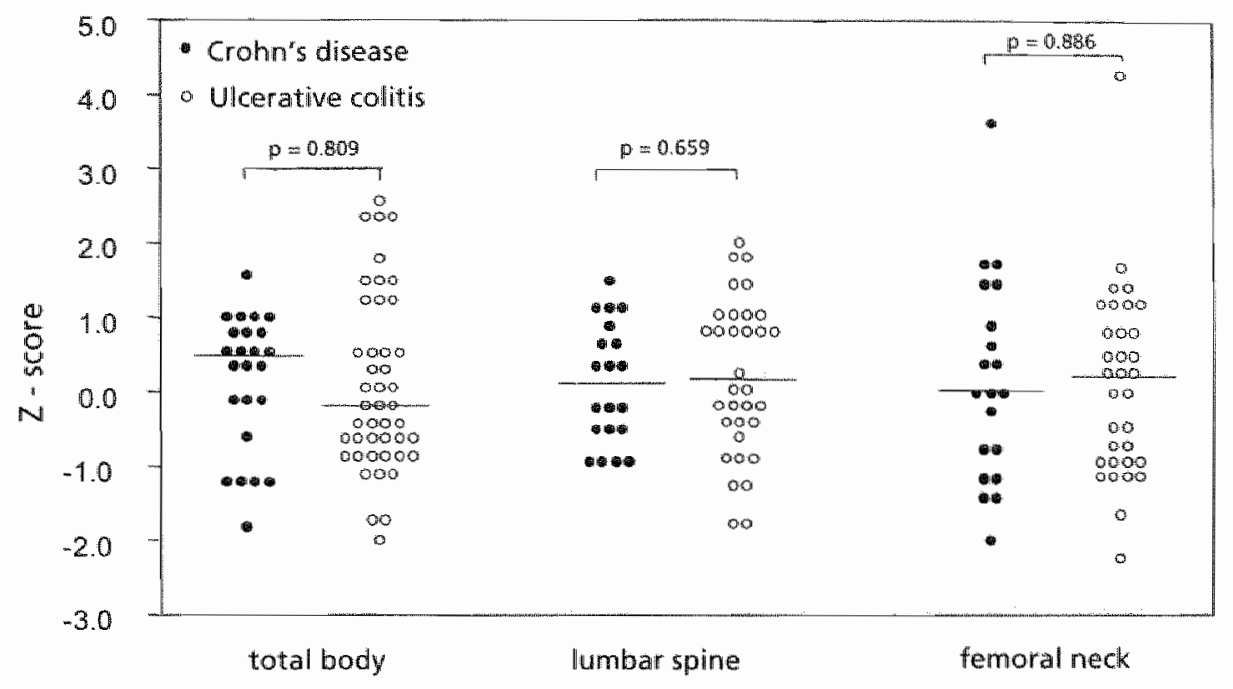

Figure 5.2 BMD (Z-score) at different sites of measurement in patients with CD compared with UC. Lines indicate median values. No significant differences were found between CD and UC patients.

Potential determinants of low bone mass emerging from the explorative univariate analysis in the IBD patients were postmenopausial status in women fonly 3 patients), age, low body mass index $\left(<20 \mathrm{~kg} / \mathrm{m}^{2}\right)$, and duration of complaints ( $>6$ months) before diagnosis. In the multiple linear regression analysis, an independent influence was confirmed with statistical significance for duration of complaints $(\rho=0.041)$, age $(\rho=0.019)$ and body mass index $<20 \mathrm{~kg} / \mathrm{m}^{2}(\rho=0.006)$. Because of the small numbers, the effect of the menopausal status was not included in the multivariate regression analysis. The multivariate analysis model showed that in patients with IBD, cross-sectionally, an increase of age by 1 year resulted in a decrease of $0.27 \%$ of $B M D_{\text {r }}$ which is similar to the expected loss of 3 . $5 \%$ in 10 years for healthy men and premenopausal women. Multivariate regression analysis in the contral population showed that low body mass index ( $p<$ $0.001)$ and increased age $(p<0.001)$ were independent risk factors of low BMD. Alcohol intake was not a significant risk factor in either IBD patients $(p=0.784)$ or the control population $(p=0.489)$.

\section{Discussion}

Because the pathogenesis of asteoporosis in IBD is still not clear, a careful analysis of the metabolic state of the bone in the initial phase of IBD may provide some important clues. Our study showed no significant difference in BMD between patients with recently diagnosed $I B D$ and matched population controlls Furthermore, we found no significant differences in $B M D$ between $C D, U C_{x}$ and 
controls. BMD, corrected for age difference by using Z-scores, did not differ between $C D$ and UC at the time of diagnosis. Although body mass index, alcohol consumption, magnesium intake, and the vitamin D-level in the winter were lower, this was not reflected in a significant difference in BMD in newly diagnosed IBD compared with population controls. Although many of the patients in this study had already been treated with a short course and relatively low dose of corticosteroids before the bone density measurements, we do not think that this influenced the outcome of the study because we found no difference in BMD between CD patients and controls. Also, it seems unreasonable that corticosteroids would improve BMD. In 1994, Ghosh et al. ${ }^{19}$ described that bione mass of patients with newly diagnosed $C D$ was lower than in those with newly diagnosed UC despite the lack of differences in disease activity, body mass index, smoking, gender, physical activity, and biochemical parameters ${ }^{19}$. These data either suggest a genetic predisposition to osteoporosis in $\mathrm{CD}$ or mean that metabolic effects of the disease were already present at diagnosis. If confirmed, such a finding could have major consequences for the management of patients with newly diagnosed IBD, especially for patients with CD. However, several methodological comments can be made regarding the study by Ghosh et al. " only a small patient group with a wide age range (14-83 years) was involved, including 2 prepubertal boys with $C D$ and presumably low BMD. Patients with proctitis (6 of 15 compared with 6 of 44 in the present study) were overrepresented. Also, the menopausal status of the female patients was not mentioned. These factors might have influenced the outcome of the study. To overcome some of these methodological problems we preferred to perform a case-control study. To our knowledge, this study is the second reported so far, but the first controlled study on BMD in patients recently diagnosed with IBD.

In view of the high prevalence of osteoporosis in $1 B D$, the knowledge of a risk factor profile may be beneficial for surveillance of the individual patient. Age, body mass index of $<20 \mathrm{~kg} / \mathrm{m}^{2}$, and duration of complaints $>6$ months before diagnosis are risk factors for low bone mass at the thme of the 180 diagnosis. Therapeutic and secondary preventive measures could be taken, particularly in patients with these risk factors, to avoid deterioration of bone mass.

Body mass index per se is an important determinant of BMD in the general population. Our study confirmed that low body mass index at diagnosis is also a predictive factor for $\mathrm{BMD}$ in $\mathrm{IBD}$. This might be of importance during the course of the disease, especially in $\mathrm{CD}$, because, malabsorption and malnutrition are frequently found in patients with small bowel involvement or small bowel resection.

Disease activity is a confounding factor in the pathophysiology of metabolic bone disease in $1 \mathrm{BD}$. During active disease, circulating pro-inflammatory cytokines have a direct effect on osteoblast and osteoclast function and thereby influence bone turnover ${ }^{k, 3}$, We identified as a risk factor duration of complaints longer than 6 months before diagnosis. Therefore, BMD should be measured at diagnosis in patients with long-term undiagnosed and untreated complaints of IBD type. Although the mean duration of complaints before diagnosis was not significantly longer in patients with $C D$ than in those with $U C$, this did not result in a significant difference in BMD. At the time of BMD measurement, the disease activity, 
especially of $C D$ patients, was relatively mild. The selection of patients was not restricted to the very ill patients with $C D$ because our aim was to explore, whether in general patients with recently diagnosed disease had lower BMD than controls.

We found no difference in physical activity according to the Baecke ${ }^{2 y}$ habitual physical activity questionnaire between patients and controls. Robinson et al ${ }^{3 .}$ recently reported that a simple schedule of regular physical activity is able to increase BMD in patients with CD. For maintenance of bone mass, patients with IBD should be advised to stay physically active if possible.

Although vitamin $\mathrm{D}$, hormone replacement therapy and exercise are able to reduce the rate of bone loss in $C D$, the optimum prevention and therapy for osteoporosis in IBD has yet to be established ${ }^{39}$.

In conclusion, a previous report on low BMD in patients with newly diagnosed IBD, particularly in CD, was not confirmed in our case-control study, and no significant differences in BMD were found between $C D$ and UC patients at diagnosis after adjustment for age. These findings imply that disease-related factors in IBD seem to be mainly responsible for the development of low BMD. Thus, control of disease activity and active, diagnostic and therapeutic management, started early in the course of the disease, may be successful in preventing osteoporosis in IBD. 


\section{References}

1. Abitbol $V$, Roux $\mathbb{C}$, Chausade 5 , Gullemant 5 , Kolta 5 , Dougados: Mouturier D, Amor B. Metabolic bone assesment in patients with inflammatory bowel disease Gastroenterology 1995; 108:417-22.

2. Robinson FU, AlAizzwi F, lqbal SJ, Kryswcki T, Himond L, Abrams K, Mayberry JiF. Osteoporosis and determinamts of bone density in patients with Crohn's disease. Dig Dis 5 ci 1998;43:2500-6.

3. Bjarnason 1, Macpherson A, Mackintosh C, Buxton-Thomas M, Forgacs I, Moriz $C$. Reduced bone densiry in patients with inflammatory bowel disease. Gut 1997; 40:228-33.

4. Compston IE, Judd D, Crawley EO, Evans WD, Evans C, Church HA, Reid EM, Rhodes I. Osteoporosis in patients with inflammatory bowel disease. Gut $1987: 28: 410-5$.

5. Pigot F, Roux $C_{n}$ Chaussade $S$, Hardelin $D_{2}$, Pelleter $O$, Du-Puy MT, Listrat $V$, Dougados M, Couturier $D$, Amor $B$. Low bore mineral density in patients with inflammatory bowel disease. Dig Dis Sci 1992: $37.1396-403$.

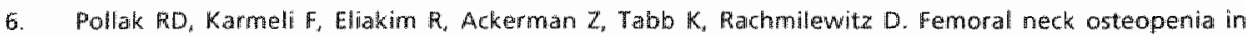
patients with inflammatory bowel disease. Am I of Gastroenterol 1998;931483-90.

7. SHvennoinen JA, Karttunen T, Niemela SE, Manelius J), Lehtolla IK. A controlled study of bone mineral density in patients with inflammatory bowel disease. Gut 1995;37:71-6.

3. Abitbol $V$. The mechanisms underlying osteopenia in chronic inflammatory bowel disease. Semaine des Mopitaux 1998; 74:1090-3.

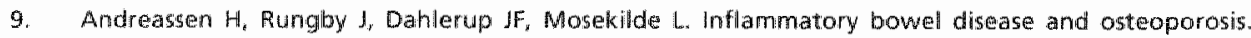
Scand I Gastroenterol $1997 ; 32: 1247-55$.

10. Rernstein CN, Seeger LL, Sayre JW. Anton PA, Artinian L, Shanahan F. Decreased bone density in inflammatory bowel disease is rellated to corticosteroid use and not disease diagnosis. J Bone Miner Res 1995; $10 \div 250 \div 6$.

11. Boot AM, Bouquet J, Krenning EP, de MK. Bone minerall density and nutritional status in children with chronic inflammatory bowel disease. Gut 1998; 42:188-94.

12. Compston JE. Review article: osteoporosis corticosteroids and inflammatory bowel disease. Ahiment Pharmacoll Ther 1995; 9:237-50.

13. Driscoll RH, Meredith $S C$, Sitrin M, Rosenberg $1 H$. Vitamin D deficiency and bone disease in patients with Crohn's disease. Gastroenterology 1982; 83: 1252-8.

14. Sitwennoinery J. Relationsthps between vitamin $D_{n}$ pallathyroin hormone and bone mineral density in inflammatory bowel disease. J Intern hed 1996:239:131\%7.

15. Vogelsang $H$, Klamert $M$, Resch $H$. Ferenci $P$. Dietary witamin $D$ intake in patients with crohn"s disease. Wien Klin Wochenschr 1995; 107:578-81.

16. Cowan Fl, Parker DR, Jenkins HR. Osteppenia in Crohn's disease. Arch Dis Child 1995; 73255-6.

17. Semeao EJ, Stallings VA, Peck $5 N$. Piccoli DA. Vertebral compression fractures in pediatric patients with Crohn's disease. Gastroenterology $1997,112: 1710-3$.

18. Jahnsen I, falch JA, Aadland E, Mowincke! P. Bone mineral density is reduced in patients with Crohn's chiseas but not in patients with wherative colitis: a population based study. Gut 1997; 40:313-9.

19. Ghosh 5 , Cowen $S_{\text {u }}$ Hannan WJ Ferguson A. Low bone mineral density in crohn's disease, but not in ulcerative colitis, at diagnosïs. Gastroenterology 1994: 107:1031-9.

20. Lennard-Jones JE. Classification of inflammatory bowel disease. Scand 1 Gastroemterol suppip.1989: $170.2 \cdot 6$

21. Best WR, Becktel MM. Singleton MW, Kern F. Dewelopment of a Crohn's disease activity index. National Cooperative Crohn's Disease Situdy. Gastroenterology 1976; 70:439-44.

22. Likhtiger $S_{*}$ Present $0 H_{*}$ Kombluth A, Gelernt 1, Bawer J, Galler G, Michelassi F, Hanauer $S$ Cyclosporine in sewere ukerative colitis refractory to steroid therapy. N Engl J Med 1994: 330:1841-5. 
23. Mazes: RB, Barden HS, Bisek JP. Hanson J. Duallenergy x-ray absorptiometry for total-body and regional bone-mineral and soft-tissue composition. Am I Clim Wutr 1990; $51: 1106-12$.

24. Mazess RB, Barden HS, Ettinger M, Johmston C. Dawson HB, Baran D, Powell M, Notelovitz M. Spinte and femur density using dual-photon absorptiometry in US white women. Bone Miner $1987 ; 2: 211-9$.

25. Stewenson $1 C$. Lees $B$, Devenport M. Cust MP. Ganger KF. Determinants of bone density in norma! women: risk factors for future osteoporosis? BMI 1989,298: 924-8.

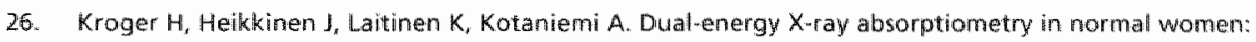
a cross-sectional study of 717 Finmish volunteers. Osteoporos int $1992 ; 2: 135-40$.

27. Assessment of fracture risk and its application to screening for postmenopausal osteoporosis. Report of a WHO Study Group. World Health Organ Tech Rep Ser 1994:843:1-129.

28. Laskey MA. Dual-energy X-ray absorptiometry and body composition. Nutrition 1996; 12(1);45-51.

29. Baecke JA, Burema 1, Frijters JE. A short questionalie for the measurement of habitual physical activity in epidemiological studies. Am J Clin Nutr 1982;36(5):936-42.

30. Beal VA. The nutritional history in longitudinal research. A Am Diet Assoc 1967,51:426-32.

31. Hollis BW, Kamerud JQ. Selwaag SR, Lorenz JD, Napoli JL. Determination of wittamin D status by radioirnmunoassay with an 1251-labeled tracer. Clin Chem 1993;39(3),529,33.

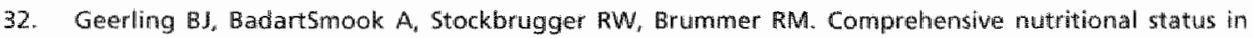
patients with long-standing Crohn disease currently in remission. Am I Clin Nutr 1998:67:919-26.

33. Hyams JS, Wyzga N. Kreutzer DL, Justinieh $C$, Gronowicz GA. Alterations in bone metabolism in children with inflammatory bowel disease: an in vitro studly. J Pediatr Gastroenterol Nutr 1997 ; 24:289-95.

34. Issenman RM. Bones in Crohn's: cytokines, a missing link? J Pediatr Gastroenterol Nutr 1997; 24:361-2.

35. Marcus R. Endogenous and nutritional factors affecting bone. Bone 1996; 18 (Supp):115-35.

36. Nguyen L, Dewhirst FE, Hauschka PV, stashenko P. Interlleukin-1 beta stimullates bone resorption and inhibits bone formation in vivo. Lymphokine Cytokine Res 1991;10:15-21.

37. Wallach S. Aviol: LV, Feiniblatt JD, Carstems-JH J. Cytokines and bone metabolism. Calcif Tissue Int $1993 ; 53: 293-6$.

33. Robinson RJ, Krzywicki T, Alimond L. AlAzzawi F, Abrams K, labal 5J, Mayberry JF. Effect of a lownimpact exercise program on bone mineral density in Crohn's disease: A randomized controlled trial. Gastroenterology 1998;195:36-41.

39. Vogelsang H. Ferenci P. Resch H, Kiss A, Gangl A. Prevention of bone mineral loss in patients with Crohn's disease by long-term oral vitamin D supplementation. Eur I Gastroenterol Hepattol 1995; 7:609-14. 



\section{Low serum and bone vitamin $\mathrm{K}$ status in patients with long-standing Crohn's disease: another pathogenetic factor of osteoporosis in Crohn's disease?}




\section{Abstract}

\section{Background}

A high prevalence of osteoporosis is reponted in Crohn's disease. The pathogenesis is not complexely understood but is probably multifartorial cong standing Crohn s disease in ass to lated whth o deficiency of tat soluble Witamins among ihem witemin $\mathrm{K}$ Whamin $\mathrm{K}$ is a co factor in the Carboxylation of osteoglcin, aratein essential for calcum binding to bones A high level of circulating undercaboxylatsd osteocalcin is a sensituve marker of wiamin K deficlency.

\section{Ailms}

To determine serum and bone vitamin $\mathrm{X}$ staks h patients with crohns dsease and to eliclote ts relationsho with bone hineral density

\section{Methods}

Bone mineral density was ineasurgd in 32 patients with long standing Crohin's disease anid small bowal thwo vement, Gurently in fremission, and

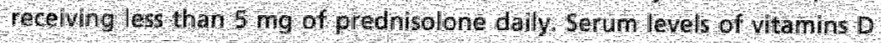
and 1,4 riglycerides, and rotal inmunereactive osteocalch as well as

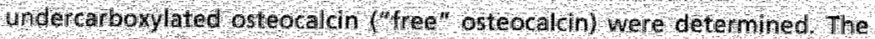
Hiydroxycoatite bunding capaciy of osteocalcin was calculated, oota were compared with an age and gender notched control population.

\section{Results}

Serum vitamin 6 levels of the CO patients were signilicantly decreased

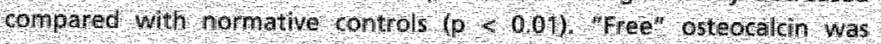
higher and hydroxyapotite binding capaciry of crculating osteocalch was lower than in mathined sontrols $1 \mathrm{p}<0.05$ and $\mathrm{p}, 0.001$, respectlualy) Ghdicating a low bore witamin $\mathrm{K}$ stalus ir grolin's disease. In patients, an Inverse correlavioh was tound between tfreet osteocalch and unibar

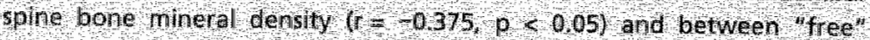
osteocalch and the 2 score of the lumbar spine $(r)-0,38$, $p<0.05)$ Multple linear regression analysis showed that w free' osteocalch was an

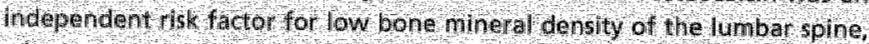
whereas serum valinil 0 was not

\section{Conclusions}

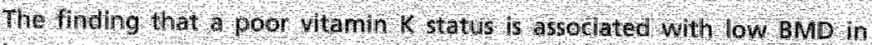
long standing crothin's disease may have implications for the prevention and treatment of osteoporsos is in this disorder 


\section{Introduction}

A high prevalence of osteopenia and osteoporosis is reported in Crohn's disease $(C D)^{1.9}$. The pathogenesis of low bone mineral density (BMD) in CD is multifactorial. Important factors are disease activity, corticosteroid use, hypogonadism and nutritional depletion ${ }^{10: 4}$. The latter includes malabsorption of fat soluble vitamins, especially in patients with ileal involvement and has been proved for vitamin $D^{1213}$. Bone is a living organ with a continuous process of remodelling, consisting of bone resorption by osteoclasts and bone formation by osteoblasts. Osteoblasts need vitamin $K$ as a co-factor for the post-translational carboxylation of protein bound glutamate (Glu) residues into gamma-carboxyglutamate (Gla) (Figure 6.1). During bone formation the osteoblasts produce three Gla-proteins: osteocalcin (OC), matrix-Gla-protein (MGP), and protein S. OC and MGP have a regulatory role in the mineralization and remodelling of bone, whereas the function of protein 5 in bone metabolism remains unclear. Precursors of all three Gla-proteins contain a sequence that serves as a recognition signal for the vitamin $K$ dependent carboxylase. Carboxylation renders the proteins capable of binding to calcium ${ }^{14-6.6}$.

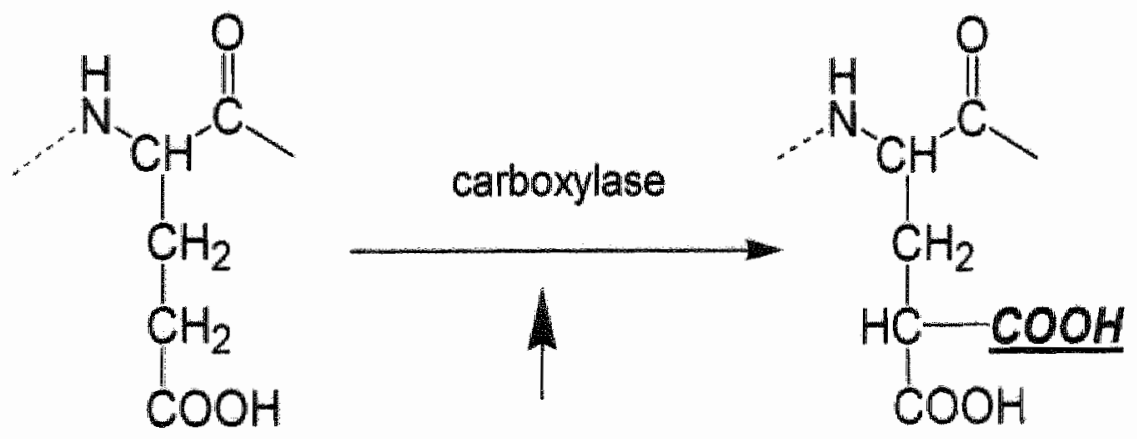

\section{Vitamin K}

\section{Glu}

Gla

Figure 6.1 Schematic representation of the vitamin $K$ dependent carbokylation reaction. Reduced vitamin $K$ acts as a co-factor in the carboxylation of glutamic acid residues (Glu) into gamma-carboxylation acid residues (Gla). These residues render the protein osteocalcin capable of calcium binding to bone. 
Osteocalcin can have three Gla residues, but it is not known how many carboxyl groups are needed for adequate function. Circulating Gla-proteins provide information on vitamin $K$ status of bone. Under conditions of subclinical vitamin $K$ deficiency, $O C$ remains under-carboxylated and is transferred into the circulation. in this chapter undercarboxylated osteocalcin is referred to as "free" osteocalcin $\left(\mathrm{OC}_{\mathrm{reg}}\right)$.

Several studies hawe reported evidence of a relation between vitamin $K$ status and bone mineralization. Low serum concentration of vitamin $K$ has been reported in patients with osteoporatic fractures". Higher concentrations of underarboxylated OC have been shown to be related to advanced age, low BMD and the risk of hip fracture." Loss of bone mass was associated with poor vitamin $K$ status in postmenopausal women" "Oral anticoagulant therapy was associated with an increased firacture ris $k^{\prime \prime}$. Vitamin $k$ supplementation decreases bone loss and calcium excretion ${ }^{14}$.

The aim of this study was to investigate the serum and bone vitamin $K$ status in patients with long-standing $C D$ and to elucidate the relation between vitamin $K$ status and BMD in these patients "Furthermore the relationship of vitamin $K$ status with the serum concentrations of vitamin D and of triglycerides was established.

\section{Methods}

\section{Patients}

Patients were randomly asked to participate in this study while attending the gastroenterology autpatient clinic of the University Hospital of Maastricht. Thirtythree patients with $\mathrm{CD}$ (13 males, 20 females) were included in the study in April and May 1997. Basic characteristics of the patient population are given in Table 6.1. Crohn's disease was diagnosed by clinical findings and a combination of radiology, endascopy and histology for which the Lennard-Jones criteria were applied ${ }^{16}$. At the time of the study, all patients were in clinical remission. Disease activity was measured by the Crohn's disease activity index (COAl) ${ }^{39}$. All patients had small bowel involvement, 13 patients also had inflammation of the colon. In 24 patients an ileall resection had been performed. All patients were using mesalazine (5-ASA). Four patients were taking prednisolone or a steroid equivalent; however for inclusion the prednisolone equivalent dose had to be less than $5 \mathrm{mg} / \mathrm{day}$. Six patients were taking vitamin D supplements (400 IU /day) and four also used calcium supplements ( $500 \mathrm{mg} / \mathrm{day}$ ). Six female patients were postmenopausal, none received hormone replacement therapy. Five other women were taking oral contraceptive medication. At the time of inclusion 14 patients were regular cigarette smokers. Body mass index $\left(\mathrm{kg} / \mathrm{m}^{2}\right)$ was calculated. One female patient, who had been taking vitamin $K$ supplements, was excluded during the course of the study. The study protocal was approved by the ethics committee of the University Hospital of Maastricht and all patients gave informed consent before the start of the study. 
Table 6 , Basic characteristics of the patients with Crohn's disease (n -32 and age and gender matched healthy controls $(n-34)$.

\begin{tabular}{|c|c|c|}
\hline & patients & controls \\
\hline number & 32 & 34 \\
\hline mateffemale & 1319 & $13 / 21$ \\
\hline age (vears) & $42 \geq 1$ & $42=14$ \\
\hline body Mass Index $(\mathrm{kg} / \mathrm{m})$ & $23+4$ & 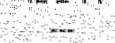 \\
\hline Crothy s disease actwity index & $106 \pm 78$ & - \\
\hline sterod luse (m, (rughday) & $3(2,5)$ & \\
\hline & $11(59)$ & \\
\hline postmenopalisal $(\mathrm{m})$ & 46 & 8 \\
\hline disease duration (years) & $16 \pm 6$ & 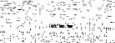 \\
\hline resection (n, th) & $24,65=45$ & $\Rightarrow$ \\
\hline
\end{tabular}

\section{Biochemical measurement}

Total osteocalcin was measured by using the Osteometer test kit (Biotech, Herlev / Denmark). Since carboxylated $O C$ and undercarboxylated $O C$ substantially differ in their affinity for insoluble calcium salts, these fractions can be quantified by measuring serum $O C$ before and after extraction with a standard amount of hydroxyapatite. The fraction that does not bind to hydroxyapatite consists of undercarboxylated "free" osteocalcin $\left(O C_{\text {reft }}\right)$. To measure the $O C_{\text {rREE }}$ fraction, $45 \mathrm{mg}$ of hydroxyapatite were added to $300 \mu$ l of serum. The fraction of carboxylated $O C$ $\left(O C_{s o u n v}\right)$ is calculated from the difference between the total immunoreactive $O C$ $\left(O C_{\text {rotal }}\right)$ and $O C_{\text {rafe }}, O C_{\text {вounsa }}$ expressed as a percentage of total $O C$ is known as the hydroxyapatite binding capacity (HBC) of osteocalcin ${ }^{16}$. The percentage $\mathrm{HBC}$ of the

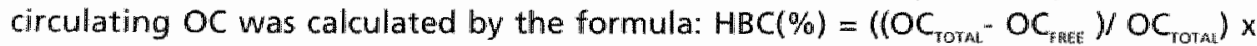
100. The $\mathrm{OC}$ levels and $\mathrm{HBC}(\%)$ were compared to those of an age and gender matched control group of 34 healthy men and women ${ }^{20.21}$.

Vitamin $\mathrm{K}$ was assessed using a HPLC technique with post-column reduction and fluorescence detection as previously described ${ }^{22}$. The serum vitamin $K$ levels of the patients were compared to those of a reference population of 384 healthy men and women. Serum 25 -hydroxyvitamin D concentration was measured using a ${ }^{125} \mathrm{I}$ radioactive immunoassay (Incstarr Corporation-Stillwater, Minnesota, USA) in specimens abtained in April and May for which the winter reference value was applied $(25-70 \mathrm{nmol} /)^{23}$.

\section{Bone Mineral Density}

Bone mineral density (BMD) was measured using dual energy $X$-ray absorptiometry (DXA) (Lunar DPX-L, Lunar software version DPX-L 4.7; Lunar Radiation Corp. Madison, WI, USA $)$ of lumbar spine $\left(L_{2}-L_{4}\right)$, femoral neck and total body ${ }^{22}$. BMD was expressed in absolute values $\left(\mathrm{g} / \mathrm{cm}^{2}\right)$, T-score (one standard deviation of the mean of a young adult gender matched reference population) and Z-score (one standard deviation of the mean of an age and sex matched reference population). 
78 Chapter 6

respectively. Reference data were based on populations from the US, United Kingdom and Northern Europe. There was a 1.3\% SD of the average density values of populations contributing to the normative data in the various geographical areas. The prevalence of osteopenia and osteoporosis was assessed according to the WHO classification in which osteopenia is defined as T-score between -1 and -2.5 and osteoporosis as Twscore $<-2.5^{25}$.

\section{Statistical analysis}

Results are shown as mean and standard deviation (SD). The (unpaired) independent t-test was used for the comparison of $C D$ patients with the reference population regarding serum vitamin $K$ concentration, $O C_{\text {Frief }}$ and $H B C(\%)$. One way ANOVA was used to evaluate the vitamin $K$ status in $C D$ patients with either normal bone mineral density or osteopenia and osteoporosis. Non-parametric tests were used for the remaining statistical evaluations. Correlations between continuous variables were assessed using Pearson's correlation coefficient. Multiple linear regression analysis was performed to identify independent risk factors for bone mineral density and to correct for vitamin $D$ deficiency as a potential confounder. The following independent variables were separately used in this analysis: absolute BMD, T-score and Z-score of fernoral neck, lumbar spine and total body, respectively. Two-tailed tests for significance were used in all statistical analyses. A $P$ value of $<0.05$ was considered to be statistically significant. The Statistical Package for the Social Sciences (SPS5 7.5 for windows package 1996, SPSS inc. Chicago, Illinois/USA) was used for the analysils.

\section{Results}

Mean BMD, expressed as absolute values in $\mathrm{g} / \mathrm{cm}^{2}$, of femoral neck, lumbar spine and total body were $0.89( \pm 0.13), 1.10( \pm 0.16)$ and $1.11( \pm 0.09)$. Mean T-score was $-0.61( \pm 1.29)$ for the total body, $-0.98( \pm 1.16)$ for the femoral neck and -0.66 $( \pm 1.13)$ for the lumbar spine, respectively. Mean Z-score was $-0.49( \pm 1.07)$ for the total body, $-0.45( \pm 1.25)$ for the femoral neck and $-0.28( \pm 1.10)$ for the lumbar spine, respectively. The prevallence of osteopenia and asteoporosis in these patients according to the WHO definition is given in Table 6.2 .

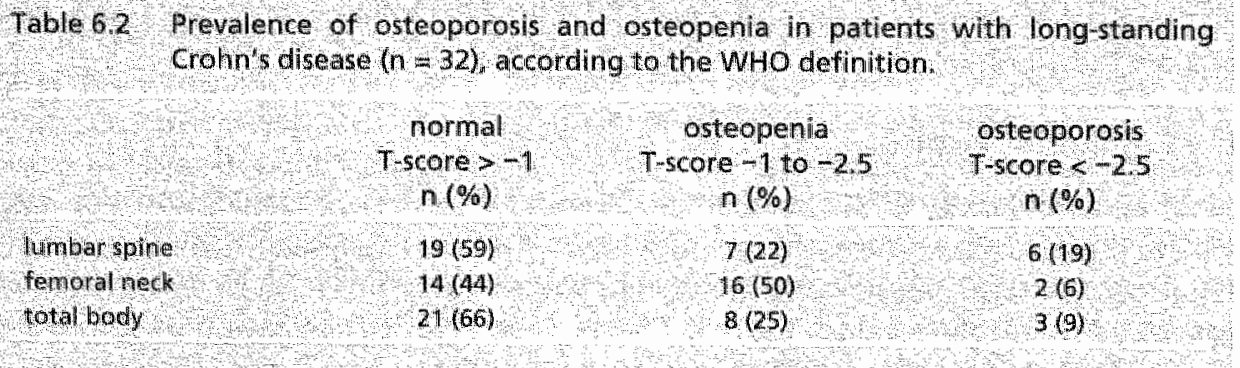


Serum vitamin $K$ concentrations in patients with $C D$ were significantly lower than in a reference population of 384 healthy men and women $(p<0.01)$ (Figure 6.2). Patients with $C D$ had higher serum $O C_{\text {вRE }}(p<0.05)$ and lower HBC values $(p<$ 0.001 ) as compared to the values obtained from the age and gender matched control group of 34 healthy men and women randomly selected from the community registry (Figure 6.3/ Figure 6.4). Serum vitamin $K_{i} O C_{\text {sREE }}$ and $H B C$ did not significantly differ between male and female patients. Although mean $O C_{\text {prize }}$ was generally lower and mean serum vitamin $K$ was higher in patients with normal BMD than in patients with a $T$-score $<-1$ (osteopenia plus osteoporasis), this difference was not statistically significant. In patients a negative correlation was found between lumbar spine BMD and $O C_{\text {raeg }}(r=-0.375, p<0.05)$ (Figure 6.5) and between lumbar spine Z-score and $O C_{\mathrm{rREE}}(r=-0.381, p<0.01)$ (Figure 6.6).

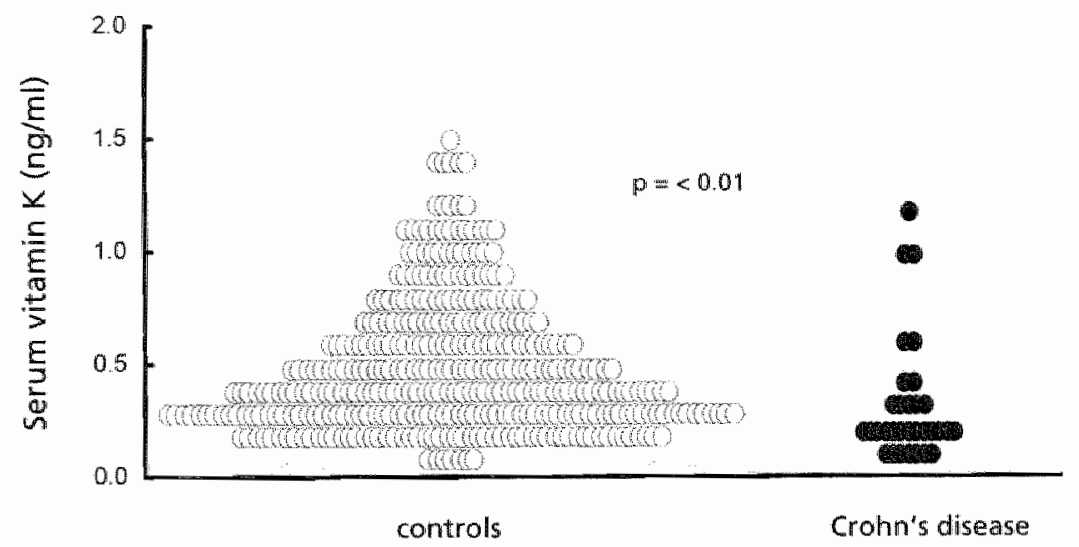

Figure 6.2 Serum witamin K concentrations in patients with long-standing Crohn's disease ( $n=32$ ) compared with healthy contrals $(n=34)$. Wedian for patients with Crohn's disease is 0.402 $(\mathrm{ng} / \mathrm{mll})$; median of healthy controls is $0.610(\mathrm{ng} / \mathrm{ml})$

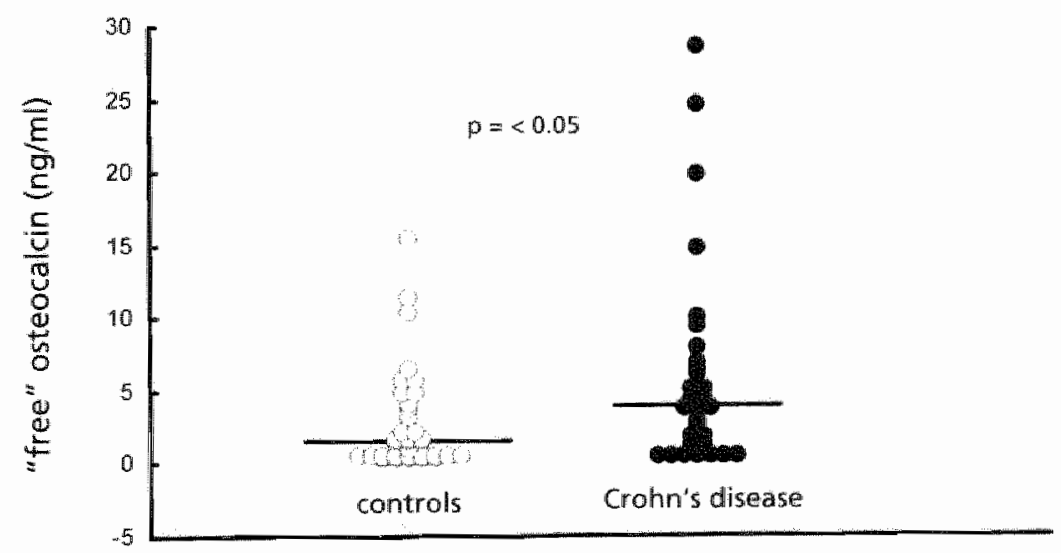

Figure 6.3 Serum concentrations of "free" (undercarboxyated) osteocalcin in patients with longstanding Crohn's disease ( $n=32$ ) compared to age and sex-matched and healthy controls $(n=34)$. Lines indicate median walues. Median of patients with Crohn's disease $=3.89$ $(\mathrm{ng} / \mathrm{m} /)^{2}$, median of healthy controls $=1.51(\mathrm{ng} / \mathrm{ml})$ 
80. Chapter 6

Mean serum level of vitamin $D$ in patients was $28.4( \pm 10.5)$ nmall: 11 patients (34\%) were vitamin D deficient (serum 25 -hydroxy vitamin $\mathrm{D}<25 \mathrm{nmol} / \mathrm{l}$ ). Of the patients taking a vitamin D supplement (400 IU/day for more than 2 months). 3 patients had still serum vitamin D levels $<25 \mathrm{nmol} / 1 \mathrm{l}, 14$ and 23 nmol/l, respectivaly). A significant correlation was found between the serum concentrations of vitamin $D$ and $K(r=0.681, p<0.01)$. No correlation was found between the concentrations of vitamin $D$ and the vitamin $K$ status of bone (either

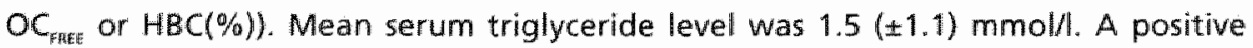
correlation was found between serum concentrations of vitamin $D$ and triglycerides $(r=0.707, p<0.01)$ and vitamin $K$ and triglycerides $(r=0.789, p<0.01)$, respectively.

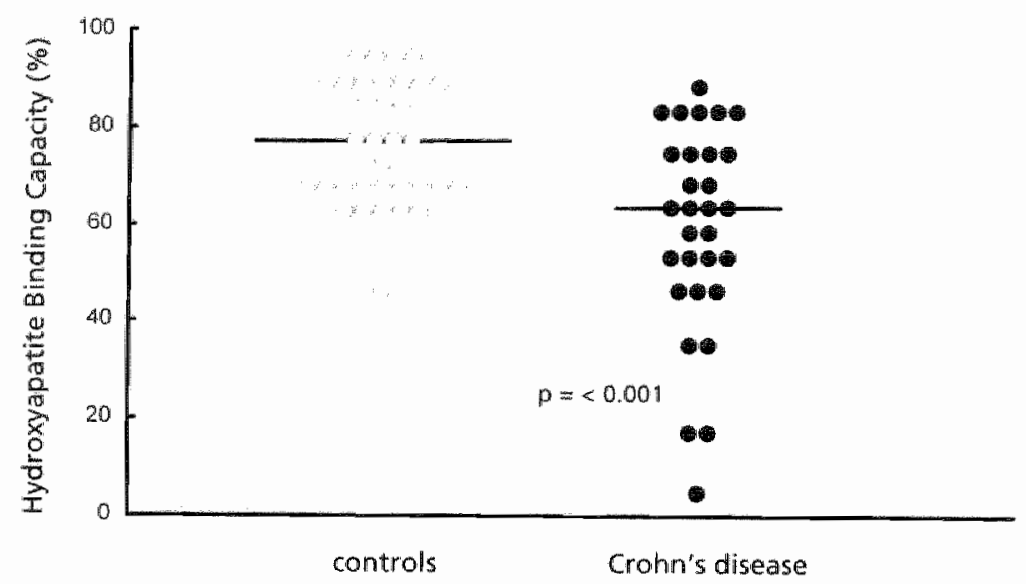

Figure 6.4 Hydroxyapatite binding capacity (HBC) $(\%)$ in patients with long-standing Crohn's disease $(n=32)$ compared to age and sex matched healthy controls $(n=34)$. Lines indicate median values. Median of patients with Crohn's disease $=61.71 \%$; median of healthy controls $=76.84 \%$.

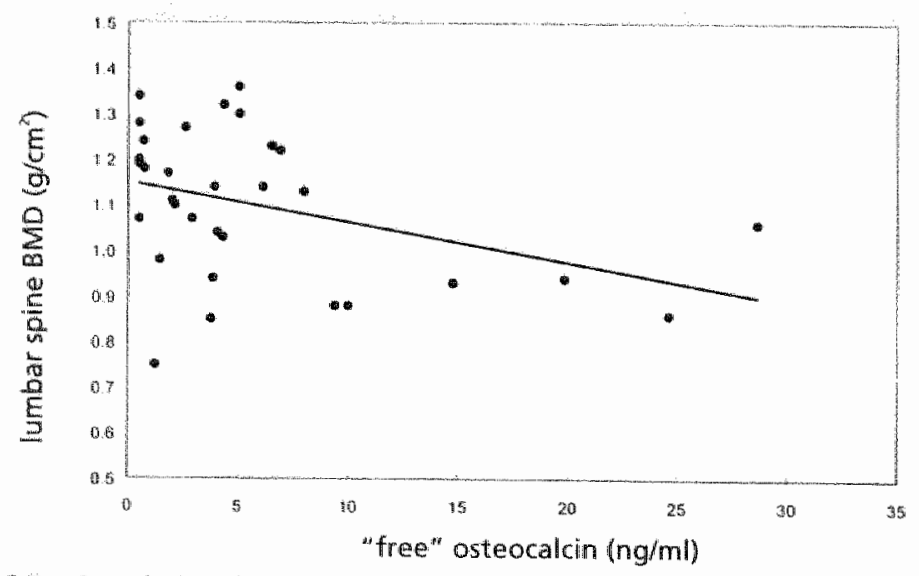

Figure 6.5 Correlation between "free" (undercarboxyated) osteocalcin and bone mineral density (BMD) of the lumbar spine in patients. with long-standing Crohn's disease $(n=32)$, Correlationcoefficient (Pearsons) $r=-0.375, p<0.05$. 


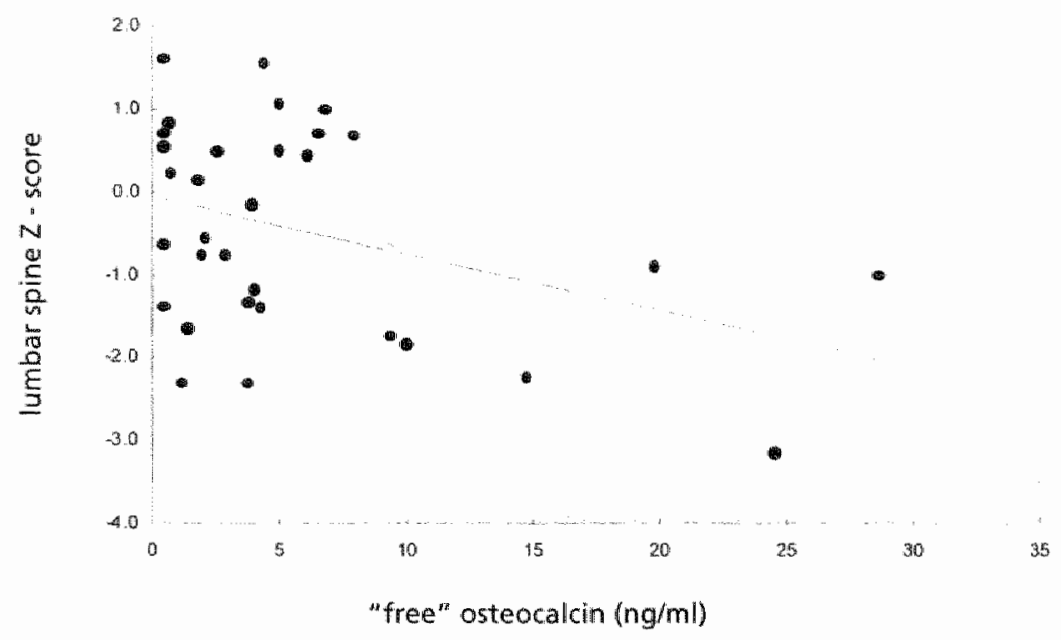

Figure 6.6 Correlation of "free" (undercarboxyated) osteocalcin and bone mineral density Zscore of the lumbar spine in patients with long-standing Crohn's disease ( $n=32$ ). Correlationcoefficient (Pearsons) $r=-0.381, \mathrm{p}<0.01$.

In the patient group the variables sex, age, body mass index, serum vitamin $K$, $O C_{\text {pager }}$ and vitamin $D$ were included in a multiple linear regression. No correlations were found between serum vitamin $K$ levels and $B M D$. $T$ - and Z-scores at any measurement site. We found that $O C_{\text {rRs }}$ correlated significantly with BMD of the lumbar spine $(p=0.05)$ and with the lumbar spine $Z$-score $(p=0.035)$ (Table 6.3). The correlation between $O C_{\text {fREE }}$ and the $T$-score of the lumbar spine did not reach significance $(p=0.091)$. No correlations were found between either BMD, T- and $Z$ score of femoral neck and total body and $O C_{\text {rege }}$. No correlations were found between serum vitamin $D$ levels and BMD, $T$ - and $Z$-scores at any measurement site.

Table 6.3 Results of the multiple linear regression analysis in patients with long-standing CD $(\mathrm{n}=32)$, with absolute BMD and Z-score of the lumbar spine as dependent; and vitamin D and free (undercarboxylated) osteocalicin as independent variables:

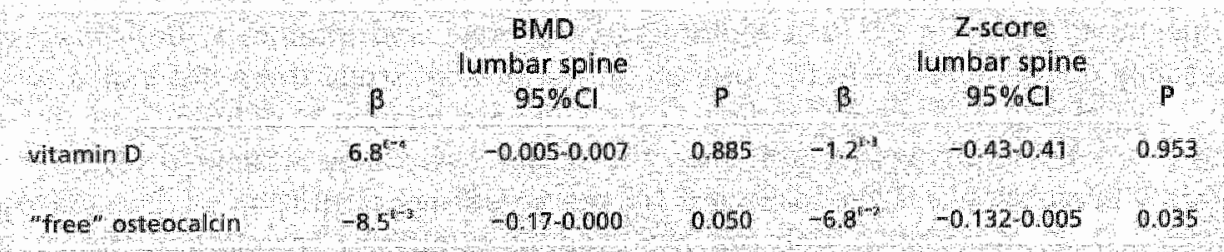

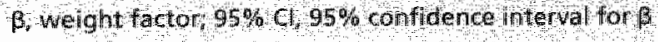




\section{Discussion}

The results of the study reveal low serum vitamin $K$ and low bone vitamin $K$ status (increased $O C_{x g E}$ and lowered $H B C(\%)$ ) in a group of patients with long-standing $C D$ compared with normal controls. Serum $O C_{\text {rate }}$ status, but not the serum vitamin $K$ concentration, correlated with BMD of the lumbar spine.

To exclude the effects of disease activity and corticosteroid use, we investigated a group of patients with inactive $C D$, all with small bowel involvement and/or a previous ileal resection. They were receiving no or very low doses of steroids. In some patients with ileal resection, Crohn's disease activity index scores (CDAI) were relatively high, in spite of clinical remission. The index obviously reflects high frequency of liquid stools in these patients due to illeal resection rather than current intestinal inflammation.

In patients with CD and with ileopathy, caused by either inflammation or previous resection, bille acid and fat malabsorption causes steatorrhoea and malabsorption of fat-soluble vitamins. Serum vitamin $K$ concentrations are influenced by the plasma triglyceride concentrations and reflect recent dietary intalke in healthy subjects $^{16,26}$. While there are several publications on the role of vitamin $D$ in metabolic bone disease in $\mathrm{CD}^{1,3,270}$ only a few data are available with regard to vitamin $K$ status in $C D$. In a study, in which undercarboxylated prothrombin was. used as a marker, vitamin $K$ deficiency was indicated in $46 \%$ of $C D$ patients with "leal invollvement but not in patients with Crohn's colitis". It has also been reported that $O C_{\text {pate: }}$ as used in the present study, is a much more sensitive marker for vitamin $K$ status than prothrombin ${ }^{37}$.

The fact that vitamin $K$ serves as a co-factor for the carboxylation of bone Glaproteins and is of potential importance for bone formation is reflected by an significant independent and inverse correlation between $O C_{\text {FRE }}$ and $B M D$ of the lumbar spine (BMD and Z-score). The trabecular bone of the spine is metabolically more active than the cortical bone of the hip and might thus be more susceptible to vitamin $K$ deficiency. This might explain the lack of correlation between $O C_{\text {gra }}$ and BMD of femoral neck and total body. Surprisingly, no correlation was found between $H B C(\%)$ and $B M D$ at any site. These findings could indicate that the absolute amount of circulating undercarboxylated osteocalcin $\left(O C_{\text {FREE }}\right)$ is more indicative of a low bone vitamin $\mathrm{K}$ status than the fraction of $\mathrm{OC}_{\text {Bouns }}$ expressed by HBC $(\%)$.

Bone mineral loss in $C D$ is a multifactorial process and vitamin $K$ deficiency is certainly only one factor in this process. In the present study there are indications that in patients with long-standing Crohn's disease vitamin $K$ deficiency of bone has a greater influence on BMD than the serum 25-hydroxy vitamin D level. The body vitamin $D$ stores are reflected by the serum concentration of 25 -hydroxy vitamin D. In accordance with our expectations significant correlations between serum vitamin $D$ and $K$ concentrations and triglycerides were found. In the present study, however, patients who were vitamin D-deficient did not have significantly decreased BMD. Published data are equivocal in this respect: significant correlation between vitamin $D$ and the BMD of the forearm was found in one of three large studies on vitamin $D$ deficiency and $B M D$ in patients with $C D^{27-29}$. Vitamin $D$ 
deficiency may cause secondary hyperparathyroidism that predominantly affects cortical bone.

The questions remaining are whether or not bone that is vitamin $K$ deficient is rendered sensitive to other pathogenetic factors of osteoporosis such as the administration of corticosteroids, and whether vitamin $K$ supplementation would improve bone mineralization in CD patients as has been demonstirated in other conditions. In prednisolone-treated rats, vitamin $K$ supplementation inhibited bone $10 s^{33}$. Treatment with vitamin $K$ (menatetrenone) has been reported to increase BMD in disused bones in vitamin $K$ and $D$ deficient hemiplegic patients ${ }^{34}$. In a study in cystic fibrosis patients, a significantly ellevated level of $O C_{\text {FaEF }}$ was found in patients who were not supplemented with vitamin $K$ (phylloquinone) versus supplemented patients ${ }^{35}$. The questions addressed above require further study. It has recently been demonstrated that vitamin $k$ treatment effectively prevents the occurrence of new vertebral fractures in patients with osteoporosis ${ }^{36}$.

In summary, a low serum and bone vitamin $K$ status was found in patients with long-standing $C D$, currently in remission. The poor vitamin $\mathrm{K}$ status correlated with low lumbar spine BMD. Circulating undercarboxylated osteocalcin in particular was found to be an independent risk factor of low BMD of the lumbar spine in these patients, whereas low serum vitamin D was not. Further studies are needed to assess the implications of low serum and bone vitamin $K$ status and the value of vitamin $K$ supplementation for the prevention of osteoporosis in CD. 


\section{References}

1. Abitbol W, Roux $C$. Chaussade $S$, et al. Metabolic bone assessment in patients with inflammatory bovist disiase. Gastroenterology $1995 ; 108.417-22$.

2. Barnason 1, Marpherson $A_{x}$ Mackintosh $C_{\text {, et }}$ al. Reduced bone dersity in patients with inflarmmatory bowel disease. Gut 1997;40:228-33.

3. Compston if, fudd $\mathrm{D}$, Crawley EO, et all. Osteoporosis in patlents with inflammatory bowel disease. Gut 1987:28:410:5.

4. Ghosh 5, Cowen 5 , Hannan W1, et al. Low bone mineral density in Crohn's disease, but mot in ulcerative colitis, at diagnosis. Gastroenterology $1994 ; 107: 1031.9$.

5. Jahnsen 1, Falch JA Aadland $E$, al. Eone mineral density is reduced in patients with Crohn's disease but not in patients with ulcerative colltis: a population based study, Gut $1997 \% 40: 313-9$.

6. Pigot F, Roum C, Chatussade 5 , at al Low bone mineral density in patients with inflammatory bowe: disease. Dig Dis 5 ci $1992 ; 37: 1396-403$.

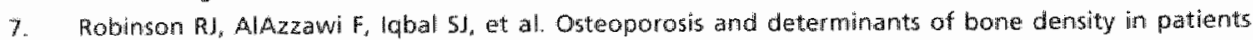
with Crohn's disease. Dig Dis $5 c i 1998^{4} 432500-6$.

8. Silvennoinen IA, Karttunen TI. Niemela SE, et al. A controlled study of bone mineral density in patents with inflammatory bovel disease. Gut 1995;37:7 1-6.

9. Tromm A, Rickels K, Huppe D, et al. Osteopenia ir chronic inflammatory bowel diseases. Results of a cross-sectional study using quantitative computerized tomography. Laber Magen Darm 1994:2423. 30 .

10. Robinson NJ lqbal 5I, A.Azzawi F, et al. Sex hormone status and bone metabolism in men with Crohn's disease. Aliment Pharmacol Ther $1998 ; 12215$.

11. Russell $\mathbb{R}$. Nutrition and inflammatory bowel disease. Current Opinion in Gastroenteralogy 1992; 8.68893 .

12. Geerling BJ, BadartSmook $\mathrm{A}$, Stockbrugger $\mathrm{RW}$, et al Comprehensive nutritional status in patients with long-standing Crohn disease currently in remission. Am J Cllin Nutr 1998;67:919-26.

13. Driscoll RH, Meredith 56 , Sitrin M, et al Rosenberg $\mathbf{H}$. Vitamin $D$ deficiency and bone disease in patients with Crohn's disease. Gastroenterology 1982; 83:1252-8.

14. Binkley NC, Suttie JW. Vitamin K nutition and oskeoporosis. J Nutr 1995;125:1812-21.

15. Verrber C. Gamma-carboxyglutamate-contain ing proteins and the witamin K-dependent carboxylase. Biochem I 1990; 266:625-36.

16. Vermeer C lie KS, Knapen MH. Role of witamin K in Done metabolism. Annu Rew Nutr 1995;15:1-22.

17. Caraballo PJ Heit $J_{A}$, Atkinson EJ, at al. Long-term use of oral anthicoagularts and the risk of fracture. Arch Interr Med 1999; $59: 1750$ -

18. Lenmard-Jones JE. Classification of inflammatory bowel disease. Scand I Gastroenterol Suppl. $1989,170: 2-6$

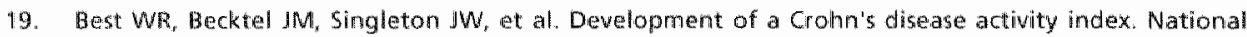
Cooperative Crohn's Disease Study. Gastroenterology 1976; 70:439-44.

20. Knapen MH, Nieuwenhuijzen Kruseman AC, Wouters RS, ef al. Correlation of serum osteocalcin fractions with bone moneral density in women during the first 10 years after menopause. Calcill Tissue Int 1998; $53: 375-9$

21. Knapen MH. Eisenwiener HG, Vermeer $C$. Osteocalcin detection in aging serum and whole blood: stabihity of ellfferent osteocalcin fractions. Clin Chim Acta 1996:256:151-64.

22. Schurgers L, Geleijense J, Grobee D, al. Nutritional intake of vitamins K1 (Phylloquinone)and K2 (Menaquinone) in the Netherlands. Journal of Nutritional \& Enwronmental Medicine 1999;9:115-22.

23. Hollis BW, Kamerud $\$ Q$, Selvaag $S R$, et al. Determination of vitamin $D$ status by radioimmunoassay with an 125llabeled tracer. Clin Chem 1993;39:529-33 
24. Mazess RE, Darden MS, Bäsek JP, et al. Manson I. Dual-energy x-ray absorptiometry for total-body and

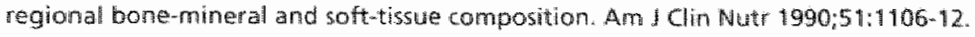

25. Assessment of fracture rusk and te application to screening for postmenopausal osteoporosis. Report. of a WHO Study Group. World Healith Organ Tech Rep Ser $1994843: 1-129$.

26. Ferland $G$, Sadowski JA, OBren ME. Detery induced subclinical vitamin $K$ deficiency in nomal human subiecth. J Clin Invest 1993;91:1761-8.

27. Andreassen $H$, Rix $M_{4}$ Brot $C_{i}$ et al. Regulators of Calcium homeostasis and bone mineral dengity in patients with Crohn's chisease. Scand I Gastroenterol 1998; 33:1087-93.

28. Hessov 1. Masekilde $L$, Melsen $F$ et al. Osteopenia with normal witamin D metabolites after smallbowel resection for Crohn's disease. Scand I Gastroenterol 1984;19;691-6.

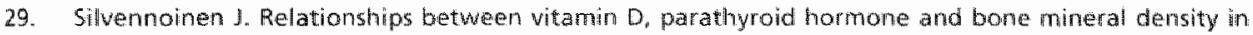
inflammatory bowel disease. $\mathbf{j}$ interm Med $1996 ; 239: 134-7$

30. Vogelsang $H$. Ferenci $P$, Woloszczuk $W$, al. Bone disease in vitamin D-deficient patients with Crohn's discalse. Dig Dis 5ci 1989;34:1094-9.

31. Krasinski 50 , Russell $R M$, Furie $B C$, et al. The prevalence of vitamin $K$ deficiency in chronic gastirointestinal disondars. Am I Clin Nutr 1985;41:639-43.

32. Rucker RB. Improwed functional endpoints for use in vitamin $\mathrm{K}$ assessment: Impontant implications for bone disease. Am $₫$ Clin Nutr 1997;65:883-4.

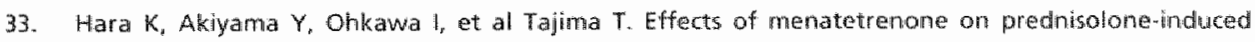
bone loss in rats. Bone 1993:14:813-8.

34. Sato $Y$, Honda $Y$, Kuno $H$, et al. Menatetrenone ameliorates osteopenia in disure-affected limbs of vitamin D-and K-deficient stroke patients Bone 1998;23:291-6.

35. Beker LT, Ahrens RA, Fink Rs, et al. Effect of vitamin K1 supplementation on witamin Katatus in cystic fibrosis patients. J Pediatr Gastroenterol Nutr 1997;24:512-7.

36. Shiraki $M$, Shiraki $Y$, Aoki $C$, et all. Vitamin $K 2$ (menatetrenone) effectiwely prevents fractures and sustains lumbar bone mineral density in osteoporosis. 1 Bone Miner Res 2000;15:515-21. 


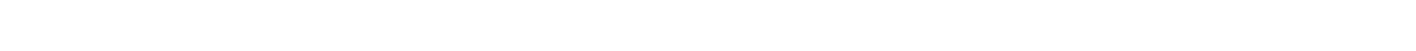




\section{Abnormal bone turnover in long-standing Crohn's disease in remission}

EJ Schoon, BG Geerling, IMA van Dooren, U Schurgers, C Vermeer, R--JM Brummer, RW Stockbrügger

Aliment Pharmacol Ther 2001;15:738-792 
88 $\mid$ Chapter 7

\section{Abstract}

\section{Background}

A high prevalence of osteoporosis is found in patients with Crohn's disease. The pathogenesi of this condition seens to be multiflactorial and its pathophysiology is still not completely understood.

\section{Aim and Methods}

To elucidate the pathophysiology of osteopenia in quiescent Crohin's disease, bone turnover was studied in 26 patients 13 males and 13 (emales) with long-standing quilescent Crohn's disease and small bowel Involvement Bone mineral denisty was assessed by dual energy $x$ ray absorptiometry Blochemkal markers for bone formation (asteacalcin and bone spetific alkaline phosphatase) and for bone resorotion (deoxypuridinoline, and collagen type I (terminal crosslinks) were measured Urinary calcium excretion was determined.

\section{Results}

Markers for bone formation were significantly lowker in patients than in controls (osteocalcin p $=0.027$, bone-specific alkaline phospllatase $\rho$; 0.0011. but both bone resorption markers were not significantly different: Urine calcum excretion was significantly decreased in patients $(\mathrm{p}=0.002)$ compared to contrals. Bone mineral density of the lumbar spine was significantly and inversely correlated with bone-specific alkaline phosphatase and collagen type $1 \mathrm{C}$ terminal crossliniks:

\section{Conclusions}

Bone thrnover in long-standing Crohn's disease la cincal remission is ghitracterked by suppressed bone formation and nornal bene resorption.

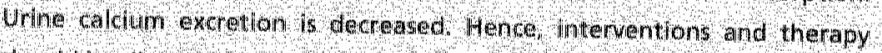
Should be directed towards inprovement of bone formation. 


\section{Introduction}

Patients with Crohn's disease (CD) are at high risk of developing osteopenia and osteoporosis ${ }^{1.5}$. The pathogenesis and pathophysiology of these conditions in CD are still not completely understood. A number of factors are considered to contribute to the reduced bone density. These include: steroid use, malnutrition, vitamin $\mathrm{D}$ and calcium deficiency, immobilisation, smoking, sex hormone deficiency, hyper-parathyroidism, and the inflammatory process itself $f^{\text {. }}$. It has been demonstrated that clinical risk factors are poor diagnostic predictors of actual bone mass?. In a large controlled study, IOW BMD was found in patients with $C$, but not in those with $U C^{B}$.

The pathophysiologic process can be clarified by studying bone turnover by means of biochemical markers that reflect bone turnover in the entire skeleton and have the advantage of being non-invasive, relatively inexpensive and of allowing repeated evaluation". Biochemical markers of bone resorption are: serum osteocalcin, total and bone- specific alkaline phosphatase and procollagen I extension peptides. Markers of bone resorption are: urinary hydroxyproline and hydroxylisine glycosides, urinary pyrinoline and deoxypyriniline and serum tartrateresistant alkaline phosphatase and pyrodinoline peptides. Generally, these markers correllate poorly with current bone mineral density (BMD) . $^{1.12}$ and, therefore, are not appropriate to diagnose low bone mineral density. Published data are conflicting with regard to whether osteopenia in $\mathrm{CD}$ is due to increased bone resorption " suppressed bone formation ${ }^{14}$ or both ${ }^{10.35}$. Some studies have failed to indicate significant changes in biochemical markers in patients compared to controls ${ }^{16-18}$.

In patients with recently diagnosed $\triangle B D$, BMD was not different from that in controls, indicating that the subsequent development of osteoporosis must be related to the disease process and/or the treatment modalities of $1 \mathrm{BD}^{\prime \prime}$. The use of corticosteroids in patients with $C D$ is considered to be an important risk factor for low BMD. In cross-sectional BMD studies in CD patients, the correlation between the cumulative corticosteroids dose and low BMD is not unanimous. One of the pathophysiologic mechanisms of the effect of corticosteroids on bone in $C D$ is the suppression of bone formation ${ }^{13,14}$. Mast of the studies on bone turnover in IBD have been flawed by the inclusion of heterogeneous patient populations regarding the type of disease (CD and UC), the disease activity (active disease and disease in remission), the administration of corticosteroids and the menopausal status of female patients. In two studies, only $C D$ patients were included, in one study including 20 male patients with long-standing quiescent $C D$, no difference in biochemical markers was demonstrated between patients and controls ${ }^{20}$. Another large study, comprising a population of 117 CD patients showed increased bone resorption. However, patients using corticosteroids and postmenopausal female patients were included in this study ${ }^{21}$. To date, the effects of disease activity on bone turnover in Crohn's disease have only been studied in vitro ${ }^{22}$. 
The aim of this study was to evaluate bone turnover using biochemical markers, in longustanding crohn's disease in the absence of active disease, of significant corticosteroid use and of the influence of menopausal status in order to further elucidate the pathophysiology of this condition.

\section{Methods}

\section{Subjects}

Patients were asked to participate in this study while attending the Gastroenterology outpatient clinic of the University Hospital Maastricht. Inclusilon criteria were: Crohn's disease, clinical remission, prednisolone dose $\leq 5 \mathrm{mg} /$ day and duration of disease of 5 years or longer. Exclusion criteria were: postmenopausal status in female patients, past or current active treatment for osteoporosis (bisphosphonates, calcitonine, fluorides, hormone replacement therapy apart from oral contraceptives) and concomitant disease predisposing to secondary osteoporosis (e.g. ankylosing spondylitis, liver disease, renal insufficiency). Twentysix patients with Crohn's disease (13 males, age range 18-68 years and 13 females, age range 22-46 years) with an overall mean age of $38 \pm 12$ years (SD) were included in the study. Basic characteristics of the patient population are given in Table 7.1 . Controls were healthy "age and gender-matched persons (males:20-70 years and pre-menopausal females: $20-50$ years) selected from a community registry.

Crohn's disease was diagnosed by a combination of clinical symptoms and endoscopic, radiological and histological data for which the Lennard-Jones criteria were applied $^{23}$. At the time of the study, all patients were in clinical remission for at least 3 months before inclusion. Disease activity was measured using the Crohn's disease activity index (CDAI) ${ }^{20}$. All patients had small bowel involvement and in 13 patients inflammation also involved the colon. Four patients were taking prednisolone ( $\leq 5 \mathrm{mg} / \mathrm{day}$ ). Steroid doses were kept stable over at least 1 month before inclusion. All patients were using 5-amino sallicylic acid (5-ASA) in a dosage of $2-3 \mathrm{~g} / \mathrm{day}$. Five female patients were taking oral contraceptive medication. Five patients used physiological doses of vitamin D (400 IE/day), and 3 of them were also taking a low-dose calcium supplementation (500 mg/day) which, at the time of the study, was not considered to be active treatment of osteoporosis. Thirteen patients were cigarette smokers; for all patients the number of pack-years was calculated. The patients' lifetime physical activity and their activities during the last 6 months were evaluated according to Baecke ${ }^{25}$. The study protocol was approved by the Ethics Committee of the University Hospital of Maastricht, and all subjects gave their informed consent before the start of the study. 
Table 71 Basic characteristics of 26 patients with long-standing quiescent Crohn's disease.

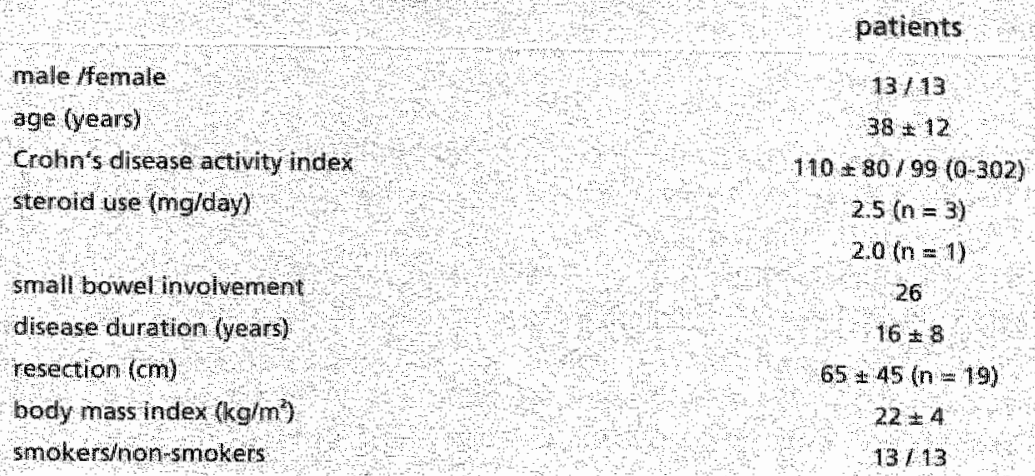

Data are presented as mean (standar d devlation) or as number, exept for cDAl, which is also noted as median (range),

\section{Biochemical Assessment}

Blood samples taken at baseline in the morning after an overnight fast were immediately centrifuged and stored at $-70^{\circ} \mathrm{C}$. The second morning urine portion was collected on the same day and stored at $-70^{\circ} \mathrm{C}$. Two biochemical markers for bone formation and two markers for bone resorption were determined. For the assessment of bone formation, serum osteocalcin (OC) and bone-specific alkaline phosphatase (BAP) were measured. For the assessment of bone resorption, collagen type I C-terminal crosslinks (CTX) and deoxypyridinoline (DPD) were determined in urine.

Serum OC was measured using the Osteometer test kit (Osteometer Bio Tech A/S, Copenhagen/ Denmark). BAP was measured using the IRMA test kit (Hybritech. Liege, Belgium) ${ }^{25}$. The results were compared to those of a group of population controls consisting of 90 healthy men (age range 20-70 years) and women (age range $20-50$ years).

CTX is a product of type I collagen that is degraded during remodelling of the skeleton and is excreted in the urine ${ }^{27}$. CTX was measured using the Crosslabs TM ELISA technique (Osteometer Bio Tech A/S, Copenhagen/ Denmark) ) $^{2}$. DPD was measured using Pyrilinks-D, a competitive enzyme immunoassay for measuring DPD in urine (Metra Biosystems Inc, Mountain View, California/ USA) 29 . Results for both resorption parameters were calculated as the CTX/ creatinine and DPD/ creatinine ratio to correct for small differences in renal function. Data were compared to those of a group of 12 controls, 6 healthy males and 6 healthy females ranging in age from 18 to 28 years.

Calcium-excretion in urine was measured using atom absorption spectrometry and calculated as the calcium/creatinine ratio. The results were compared to the same control population as $O C$ and BAP.

Serum 25-hydroxyvitamin D concentration was measured using a 1251 radioactive immunoassay (Incstar Corporation, Stillwater, Minnesota, USA) in specimens 
$92 \mid$ Chapter 7

obtained in April for which the winter reference value was applied (25-70 nmollis ${ }^{3}$. Routine laboratory parameters were measured including serum creatinine and hematocrit, in order to calculate the CDAI.

\section{Bone Mineral Density}

Bone mineral density (BMD) was measured using dual energy $X$-ray absorptiometry (DXA) (Lunar DPX-L, Lunar software version DPX-L 4.7; Lunar Radiation Corp. Madison, Wi, USA) of the lumbar spine $\left(L_{2}-L_{4}\right)$, femoral neck and total body. BMD was expressed in absolute values $\left(\mathrm{g} / \mathrm{cm}^{2}\right)$. T-score (one standard deviation to the mean of young adult gender-matched reference population) and Z-score (one standard deviation compared to the mean of an age and gender-matched reference population), respectively. Reference data were based on populations from the United States, United Kingdom and Northem Europe ${ }^{32.34}$. There was a $1.3 \%$ SD in the average density values among various geographic areas. The diagnosis of osteopenia and osteoporosis was based on T-scores according to the WHO criteria ${ }^{35}$.

\section{Statistics}

Continuous data were presented as mean $( \pm S D)$ when normally distributed or as median (range) when not. If continuous data were normally distributed, a Student t-test was applied. In other cases, the non-parametric Mann-Whitney $U$ test was used. Correlations between continuous variables were assessed using the Pearson's correlation test or Spearman's rank test, respectively. Two-tailed tests for significance were used in all the statistical analyses and $p \leq 0.05$ was considered statistically significant. The Statistical Package for the Social Sciences (SPSS) was used for the analysis (version 7.5, SPSS Inc. 1998).

\section{Results}

Mean BMD of the lumbar spine, of the femoral neck, and of the total body, as well as the $T$ - and $Z$-scores and the prevalence of osteopenia and osteoporosils are given in Table 7.2.

In the patients, $B A P$ and $O C_{n}$ as biochemical markers of bone formation, were significantly decreased compared to the control population ( $p<0.001$ and $\mathrm{p}=0.027$, respectively), while CTX and DPD as bone resorption markers were not significantly different from those of controls. Urinary calcium excretion was significantly decreased $(p=0.002)$ compared to controls (Table 7.3. Figures 7.1-7.3). 
Table 7.2 Mean bone mineral density, T and Zscores, and prevalence of osteoporasis and osteopenia (according to the WHO criteria') in 26 patients with longstanding Crohn's disease in remission.

\begin{tabular}{|c|c|c|c|c|c|}
\hline & $\begin{array}{l}\text { BND } \\
(\mathrm{g} / \mathrm{cm})\end{array}$ & Tscore & z-score & $\begin{array}{c}\text { osteopenia } \\
\text { Tscore }-1 \mathrm{to}-2 \mathrm{~s} \\
\text { n }(\%)\end{array}$ & $\begin{array}{c}\text { osteoporosis } \\
T_{\text {score }}-2 \\
\text { n }(\%)\end{array}$ \\
\hline dumbar spine & $\begin{array}{l}1411 \\
(50.14)\end{array}$ & $\begin{array}{l}0,71 \\
(1,310)\end{array}$ & $\begin{array}{r}-0.43 \\
(1120)\end{array}$ & $6(23)$ & $4(5)$ \\
\hline femoral neek. & $\begin{array}{c}087 \\
(10,12)\end{array}$ & $\begin{array}{l}-103 \\
( \pm 1,11)\end{array}$ & $\begin{array}{l}0,90 \\
(4098)\end{array}$ & $9(3)$ & 44 \\
\hline tal body & $\begin{array}{c}111 \\
( \pm 0,09)\end{array}$ & $\begin{array}{c}-0,6) \\
(11,23)\end{array}$ & $\begin{array}{l}-0.38 \\
( \pm 1.00)\end{array}$ & $7(27)$ & $2(8)$ \\
\hline
\end{tabular}

Bone mineral density is given as mean ( \pm standard deviation). The prevalence of osteopenia and osteoporosis is given in allsolute numbers, and the proportion of the study population in percentage (10):

Tuscore - one standard cleviation of the mean of a young aduat gender matched reference population. $Z$-sere $=$ one standard deviation to the mean of an age and gender matched control population

Table 73 Results of the biochenical markers of bone turnover in patients with Crohn's disease $(n=26)$ compared to controls.

\begin{tabular}{|c|c|c|c|}
\hline & patients & controls & p value $(95 \% \mathrm{Cl})$ \\
\hline teocalcin (oo) & 142 & 17.3 & 0.027 \\
\hline in & $(05-643)$ & $(8.5-5100)$ & $0,023-0,030$ \\
\hline especific alkalline phosphatase $(\mathrm{BA})$ & 13 & 129 & $<0,001$ \\
\hline WI) & $(1,8-37,9)$ & $(1,3-815)$ & $0000-0.009$ \\
\hline ollagen type a ctermanal crosishlars $(\mathrm{CAX})$ & 135 & 130 & 0.360 \\
\hline reatinume (nmol/umol) & $(50-457)$ & $(50-422)$ & $0,35006,369$ \\
\hline 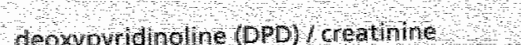 & 30 & 7,5 & 0,055 \\
\hline nmolf(umol) & $(1,5-18,4)$ & $(2,5-1,0)$ & $0051-0,060$ \\
\hline 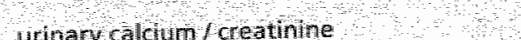 & 0,13 & 0.21 & 0002 \\
\hline (mimol /umpla) & $(0,02-0,44)$ & $(002-0,22)$ & $0001-0,003$ \\
\hline
\end{tabular}

Data are expressed as median (range), for cormparison between pattents and controls, the Manm Whitney U-test was performed $95 \% \mathrm{Cl}=95 \%$ Confidence Interval 
Osteocalcin (ng/m)

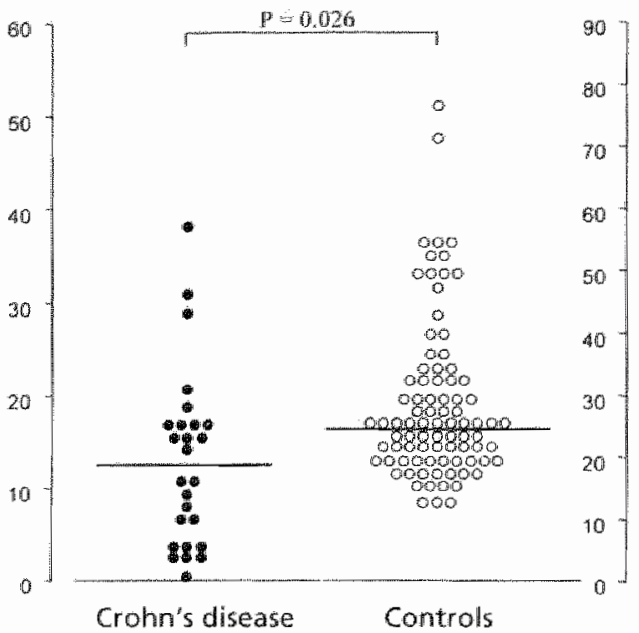

Bone specific alkaline phosphatase (U/1)

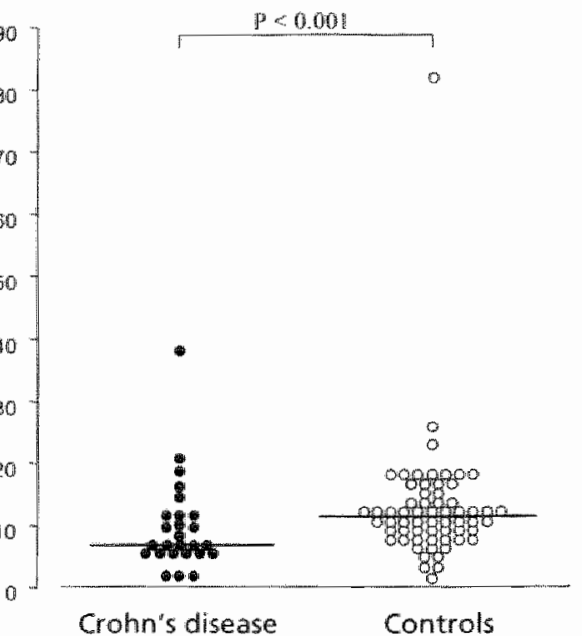

Figure 7.1a Osteocalin (OC) in 26 patients with long-standing quiescent Crohn's disease versus 90 healthy controls. Lines indicate median values. Mann-Whitney U-test.

Figure 7.1 $\mathrm{b}$ Bone-specific alkaline phosphatase (BAP) in 26 patients with long-standing quilescent Crohn's disease versus 90 healthy controls. Lines indicate median values. Mann-Whitney U-test.

CTX/Creatinine (nmol/ $/ \mathrm{mol})$ $p=0.360$

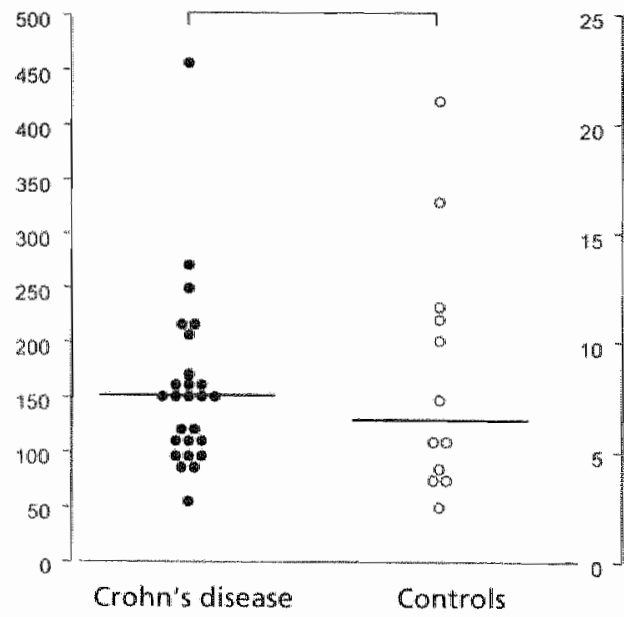

DPD / Creatinine (r.mol/4mol)

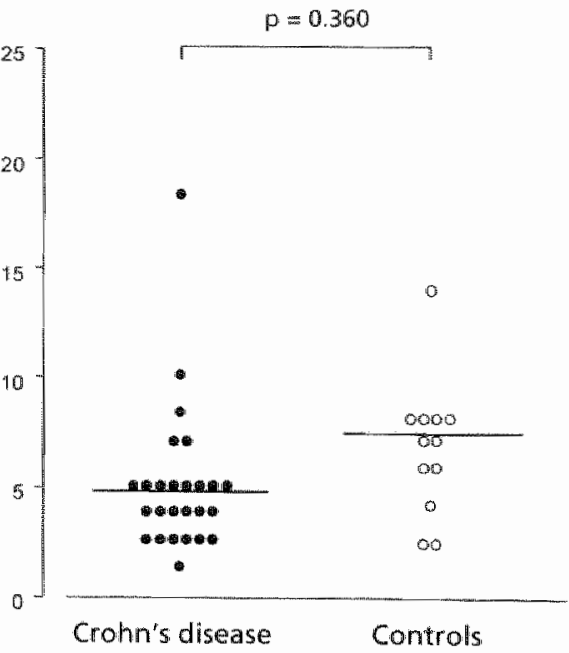

Figure 7.2a Collagen type I C-terminal crosslinks (CTX)icreatinine (nmol/4mol) urinary excretion in 26 patients with long-standing quiescent Crohn's disease versus 12 healthy controls. Lines indicate median values. Mann-Whitney U-test.

Figure 7.2b Deoxypyridinoline (DPD)/creatinine (nmol/umol) urinary excretion in 26 patients with long-standing quiescent Crohn's disease versus 12 healthy controls. Lines indicate median values. Mann-Whitney U-test. 
Urine Calcium $/$ Creatinine

(mmol/umol)

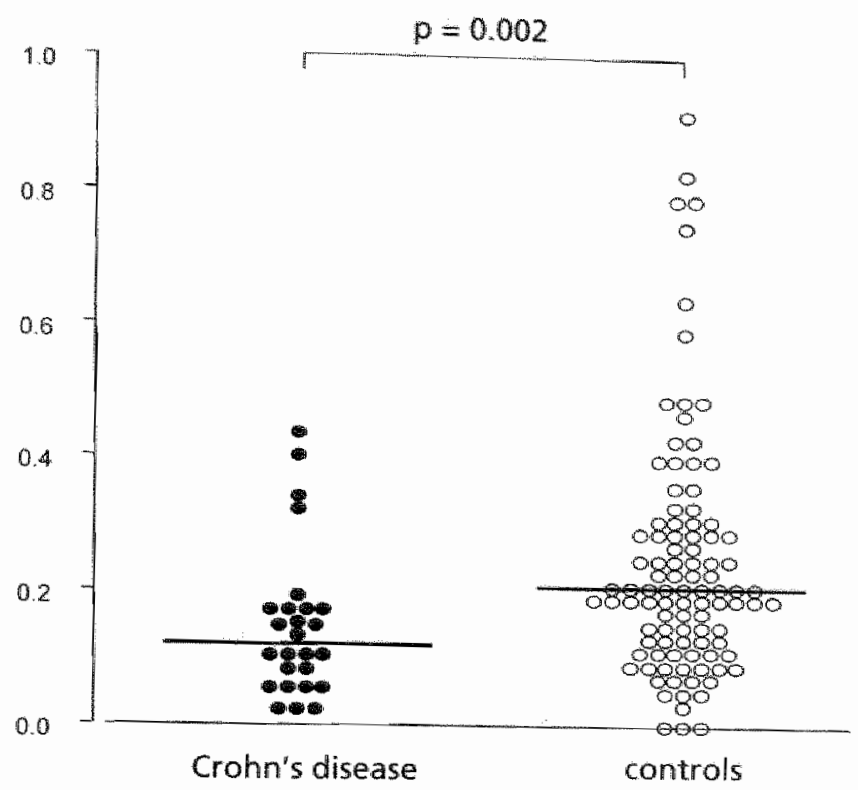

Figure 7.3 Calcium/creatinine urinary excretion in 26 patients with long-standing quiescent Crohn's disease versus 90 healthy controls. Lines indicate median values. Mann-Whitney U-test.

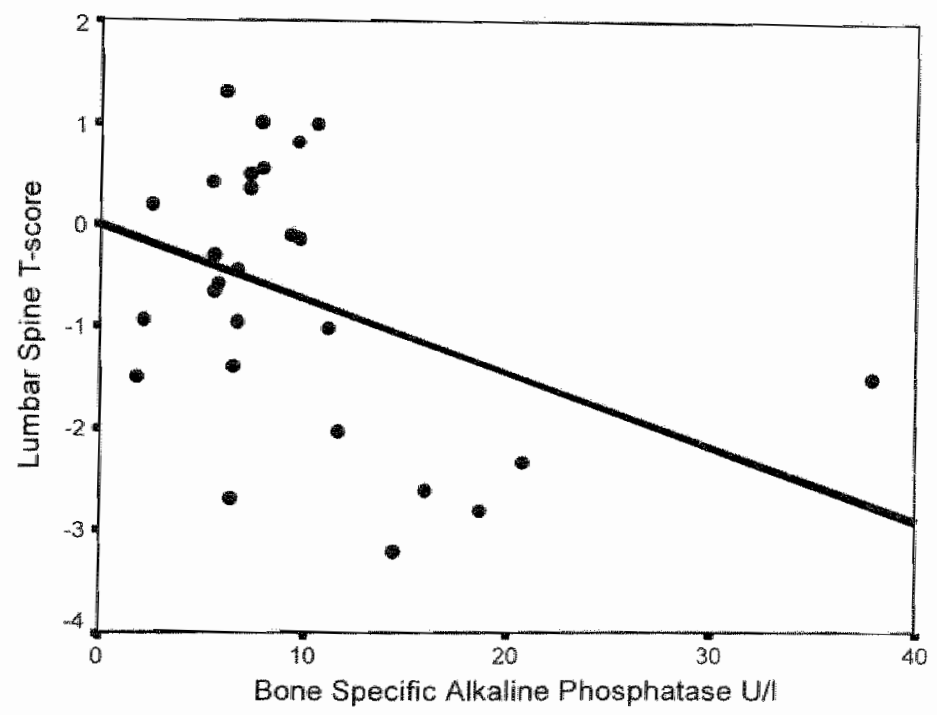

Figure 7.4 Correlation between the lumbar spine T-score and serum bone-specific alkaline phosphatase level (BAP) in 26 patients with long-standing quiescent crohn"s disease. Pearson's coefficient $r=0.408, p=0.035$. 
A significant inverse correlation was found between the serum level of BAP and the lumbar spine BMD $(r=0.386, p=0.047)$, the lumbar spine T-score $(r=0.408$, $p=0.035)$ (Figure 7.4), but not between BAP and the lumbar spine Z-score $(r=0.32 \%, p=0.103)$. The $C T X /$ creatinine ratio also inversely correlated with lumbar spine BMD $(r=0.389, p=0.030)$, llumbar spine T-score $(r=0.390, p=0.049)$ (Figure 7.5) and lumbar spine $Z$-score $(r=0.400, p=0.043)$. A significant inverse correlation was found between the serum level of BAP and the total body T-score $(r=0.421, p=0.029)$ (Figure 7.6). No significant correlations were found between the biochemical markers and femoral neck BMD scores.

Mean serum level of vitamin D was $28( \pm 11) \mathrm{nmol} / \mathrm{l}$, nine patients $(35 \%)$ were considered vitamin $\mathrm{D}$-deficient (serum 25-hydroxyvitamin $\mathrm{D}<25 \mathrm{nmol} / \mathrm{l}$ ), and only one patient had a serum vitamin $\mathrm{D}$ level below $10 \mathrm{nmol} / \mathrm{l}$. Of the patients taking a vitamin D supplement (400 $\mathrm{lU} / \mathrm{day}$ for more than 2 months), three patients still had serum vitamin $D$ levels below $25 \mathrm{nmol} / \mathrm{l}(13,14$ and $23 \mathrm{nmol} / \mathrm{l}$, respectively). No correlation was found between the extent of the small bowel resection $(\mathrm{cm})$ and the vitamin D levels in those patients who did not take vitamin D supplements. Six patients had a CDAl above 150. In these patients, the C-reactive protein CRP, which is a sensitive indicator of disease activity in $I B D$, ranged from 2 to $10 \mathrm{mg} / \mathrm{L}$. The clinical characteristics of these six patients are given in Table 7.4. Exclusion of these patients did not change the results; a significant difference was still found in bone formation (OC and BAP) but not in bone resorption (DPD and CTX).

BMI $(r=0.631, p<0.001)$, percentage body fat $(r=0.569, p=0.002)$ and serum vitamin D level $(r=0.450, p=0.018)$ inversely correlated with CDAl.

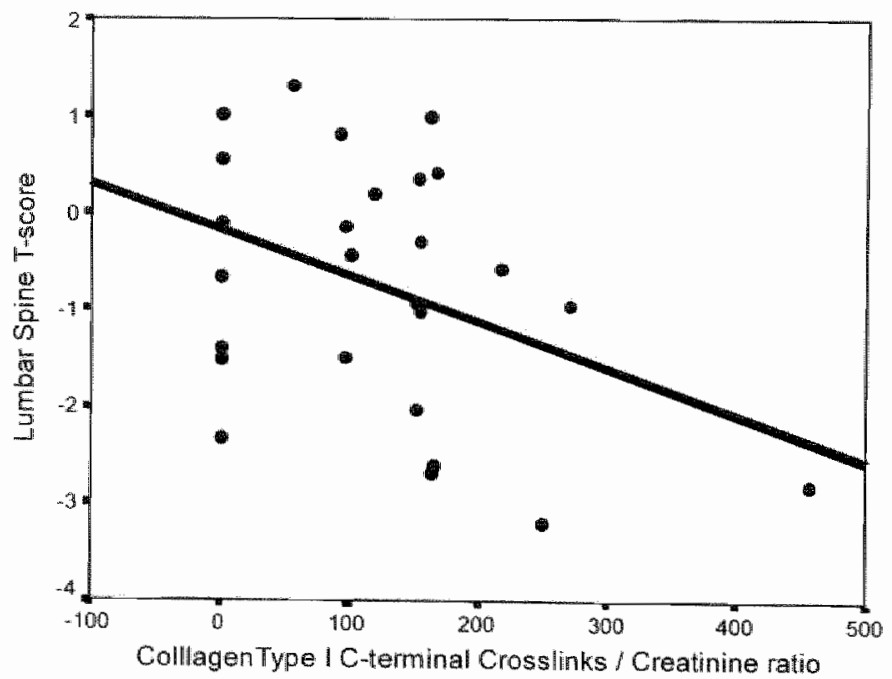

Figure 7.5 Correlation between the lumbar spine T-score and collagen type I C-terminal crosslinks/ creatinine ratio (expressed in nmol/4mol) in 26 patients with long. standing quiescent Crohn"s disease. Pearson's coefficient $r=-0.390, p=0.049$. 


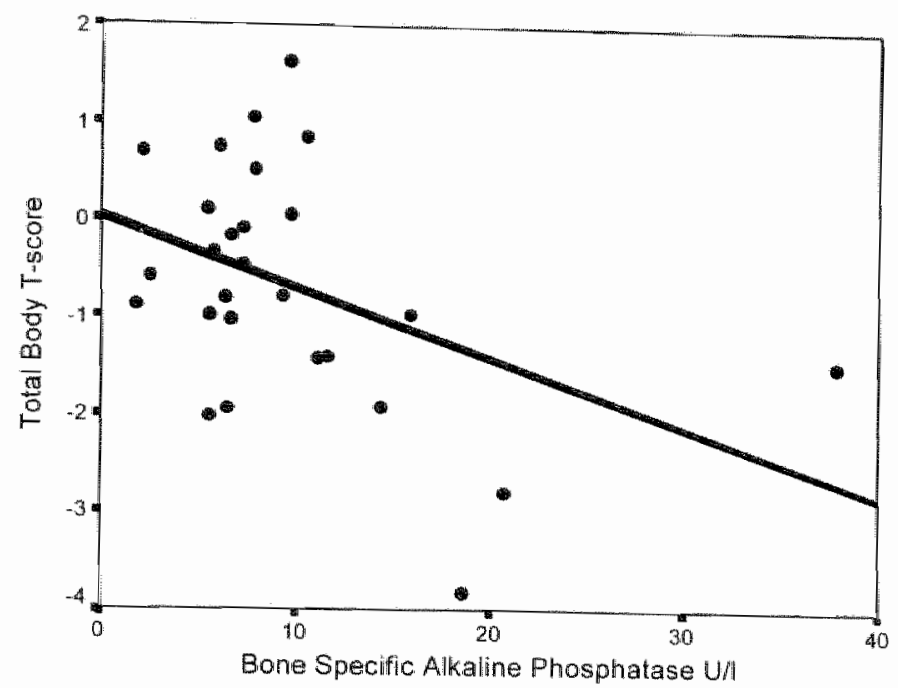

Figure 7.6 Correlation between the total body T-score and serum bone-specific alkaline phosphatase level (BAP) in 26 patients with long-standing quiescent Crohn's disease. Pearson's coefficient $r=0.421, p=0.029$.

Table 7.4 Clinical characteristics of six patients with crohn's disease with a Crohn's diseasse activity index (CDAI) above 150 .

r
age

No significant correlations were found between biochemical markers of bone turnover and physical activity or BMI. No significant differences were found in markers of bone turnover between smokers and non-smokers.

\section{Discussion}

In this study biochemical markers of bone formation (BAP and OC) in patients with long-standing quiescent $C D$ were significantly decreased compared to those in a control population, while bone resorption markers (CTX and DPD) were not 
significantly different from those in controls. An inverse correlation was found between both BMD of the lumbar spine and BAP and BMD of the lumbar spine and CTX creatinine ratio. Urinary calcium excretion was also significantly decreased compared to that in normal controls.

This unbalanced bone metabolism in patients with long-standing $C D$ is pathologic and seems to be an ongoing process, even in the absence of clinical disease activity and significant corticosteroild use. Uncoupling of the bone degradation-formation cycle car be risk factor for progression of bone loss and eventually lead to bone fractures. The inverse correlation between BMD of the lumbar spine and one marker for bone formation (BAP) as well as one marker for bone resorption (CTX) creatinine ratio) indicates that a higher bone turnover level is associated with a llower BMD. If the turnover is unbalanced bone loss occurs even during the "quiescent" phase of the disease process. Just how much the unbalanced bone turnover contributes to bone loss has to be proven in a follow-up study on these patients. The trabecular bone in the lumbar spine is metabolically more active than the cortical bone of the femoral neck and this may explain for the absence of correlation between biochemical markers and BMD of the femoral neck.

The use of corticosteroids and disease activity with high levels of circulating proinflammatory cytokines are supposed to play a pivotal role in the bone metabolism of patients with IBD. To exclude the confounding effects of active disease and corticosteroid use, we investigated a group of patients with inactive $C D$, all with small bowel involvement and/or a previous small bowel resection. They had no or very low stable doses of steroids. In six patients, CDAl scores were higher than 150 , all patients were in clinical remission and had a low CRP.

The results of this study are in agreement with the results of a histomorphometric study performed in 19 patients with IBD and osteoporosis; reduced bone formation was found at cellular level with a negative remodelling balance ${ }^{36}$. Although, in the present study, the biochemical markers for bone turnover BAP and CTX/ creatinine were significant and inversely correlated with the bone BMD of the lumbar spine, these correlations were low. Recently, increased urinary $\mathbb{N}$-telopeptide crosslinked type I collagen (NTx) excretion was found to be predictive of future spinal bone loss in $1 B D$ patients". The value of these markers as a diagnostic tool for osteoporosis for the individual patient with CD needs to be further investigated. given the evidence that the level of bone turnover is as strong a predictor of future fractures as is the level of $B M D$ in conditions other than $\mathrm{BDD}^{37.40}$.

The different results of other studies on bone turnover in CD may be explained by a different bone formation or bone resorption, responsible for bone loss at different phases of the disease process ${ }^{18}$. The patients of the present study were homogeneous according to disease activity, disease duration, steroid use and menopausal status. In only one study a comparable population of 20 male $C D$ patients with quiescent long-standing $C D$ was studied ${ }^{20}$. In this study, normal bone turnover was found. The differences in outcome with the present study can possibly be explained by demography and some clinicall features (only malle patients were involved; patients with more than five bowel movements per day were excluded, fewer patients had been resected (55\% versus $73 \%$ ); and the disease duration was markedly shorter, mean of $10 \mathrm{vs}$. 16 years, respectively). Biochemical markers used were different in both studies, except for osteocalcin. In 
the same study, fractional calcium absorption was not different from that of controls.

In patients with $C D$ and with ileopathy, due either to inflammation or to previous resection, bile acid and fat malabsorption is prevalent, causing steatorrhoea and malabsorption of fat-soluble vitamins. This is suggested in the present study by the inverse correlation between $\mathrm{CDAl}$ and $\mathrm{BMI}_{s}$ body fat and serum vitamin $\mathrm{D}$ level, respectively. A low urinary calcium excretion can be a consequence of vitamin $D$ deficiency, which was prevalent in this group of patients $(35 \%)$. The mean age of the controls for the DPD and CTX measurements was lower than the mean age of the patients. If there had been a significant influence of increasing age, a higher bone resorption would have been expected; however, this was not the case.

It is not possible to determine, on the basis of DXA measurements, whether mineralisation defects also contribute to low bone mineral density. In the present patient group, clinical signs of osteomalacia as bone pain or muscle weakness were absent. Furthermore, the serum BAP level, which is a sensitive indicator of osteomalacia, was generally low. The patient with the highest BAP level had a normal serum 25 -hydroxyvitamin $D$ level.

The low bone formation, but normal bone resorption, found in this study indicates an unbalanced bone turnover, eventually leading to osteopenia and osteoporosis, which is already prevalent in about $40 \%$ of these patients. In CD, therapy should be directed to the prevention of bone loss and/or to the restoration of BMD in patients with low BMD values. Low bone formation points to a lower activity level of osteoblasts. Osteoblast growth and function, cellular life span and eventual apoptosis are influenced in a complex way by several hormones, circulating cytokines and growth factors ${ }^{4,42}$. A pharmacological agent capable of stimulating bone formation through a direct effect on osteoblastic activity is sodium fluoride, which has been extensively investigated in postmenopausal women ${ }^{43}$. Recently, von Tirpitz et al. presented the results of a study that demonstrated a positive effect of a slow release fluoride formulation versus placebo on $\mathrm{BMD}$, also in $\mathrm{CD}^{\text {14. }}$. Therefore, this might be an option for patients with long-standing CD and osteopenia, although the quality of bone after fluoride use is still a subject of debate ${ }^{\text {ss }}$. It has been demomstrated in vitro that other agents, such as bisphosphonates and calcitonine, can prevent asteoblast and osteocyte apoptosis. ${ }^{46}$. Treatment with alendronate significantly improves lumbar spine BMD in patients with Crohn's disease compared to those taking placebo. Furthermore, biochemical markers of bone turnover decreased significantly in the alendronate group compared to those taking placebo ${ }^{47}$.

In summary, the finding of a pathologic bone turnover in patients with longstanding Crohn's disease in remission, in absence of main risk factors for bone loss, i.e. corticosteroids and active disease, may be of importance for future preventive and therapeutic action. In these patients therapy should be directed towards the stimulation of bone formation and the prevention and treatment of vitamin $D$ deficiency. 


\section{References}

Abitbol $V$, Roux $C$, Chassade $S_{*}$ et al. Metabolie bone assessment in patients with inflammatony bowel disease. Gastroenterology $1955 ; 108: 417-422$.

Compston JE, Judd $\mathrm{D}_{n}$ Crawley $\mathrm{O}_{\text {, }}$ et al. Osteoporosis in patients with inflammatony bowel disease. Gut $198728: 410-415$.

Pigot F, Rouk $C$, Chaussade $S$, et al. Low bone mineral density in patients with inflammatory bowe disease big Dis Sil 1992;37:1396-1403.

Wogelsang H, Ferenci $P$, Resch H, Kiss A, Gangl A. Prevention of bone mimeral loss in patients with Crohn's discase by long-term oral witamin D supplementation. Eur I Gastroenterol Hepatol $1995 ; 7: 609-614$

Scharla SH, Minne HW, Lempert JG, Leidig G, Hauber M, Raedsch R et al. Bone mineral density and calcium regulating hormones in patients whinflammatory bowel disease KCrohn's disease and ulcerative colitis). Exp Cilin Endocrinol 1994; $102: 4449 \%$

Andreassen H. Rungby 1, Dahlerup JF, Mosekilde L. Inflammatory bowel disease and osteoporosis. Scand 1 Gastrounterol 1997:32:1247-1255.

Deal CL. Osteoporosis: prevention, diagnosis, and management. Am J Med 1997; 102:355-395.

Jahmsen J, Falch JA, Aadlland E, Mownck $P$. Bone mineral density is reduced in patients with Crohn's disease but not in patients with ulcerative coltis: a population based study. Gut 1997;40:3113-319.

Eastell $R_{x} B$ bumsohn $A$. The value of biochemicat markers of bone turnover in osteoporosis. $I$ Rheumatol $1997: 24: 1215-1217$.

Bischoff SC, Hermann A, Goke M, Manins MP, von-zur MA, Brabant G. Aftered bone metabolism in. inflammatory bowel disease. Am J Gastroenterol 1997; 92:1157\%1163.

Bjarnason 1, Macpherson A, Mackintosh C, Bunton-Thomas M. Forgacs i, Moniz C. Reduced bone density in patients with inflammatory bowel disease. Gut 1997; 40:228-233.

Sivennoinen J, Ristell $L$, Karttunen $\pi$, Risteli J. Increased degradation of type I collagen in patients with inflammatory bowel disease. Gut $1996 ; 38: 223 \times 228$.

Schulte C, Dignasis AU, Mann K, Goebell H. Reduced bone mineral density and unbalanced bone metabolism in patients with inflammazory bowel disease. Inflamm Bowel Dis 1998;4:268-275.

4 DHans G, Verstrate A, Cheyns $K$, Aerden I, Bowillon R. Rutgeerts P. Bone tumover durimg short. term therapy with methytprednisolone or budesomide in Crohn's disease. Aliment Pharmacol Ther $1998 ; 12: 419-424$

5. Dresner-Pollak R. Karmeli F, Eliakim $R$, Ackerman $Z_{A}$ Rachmilewitz $D$. Increased urinary lN-telopeptide cross - linked type 1 collagen predicts bone loss in pattents with inflammatom bowel disease. An I Gastroenterol 2000;95:699m,704

6 Ardizzone S, Bollani 5, Bettica P, Bavilacqua M, Molteni P, Bianchi PG. Altered bone metabolism in inflammatory bowel disease: there is a difference between Crohn's disease and ulcerative colitis. J Intern Med 2000; 247:63-70

7 Dinca $M_{1}$ Fries $W$, Luiseto G, et al. Evolution of osteopenia in inflammatory bowel disease. Am $J$ Gastoenteral 1999;94:1292-1297.

Roux $C$ Abibol $V$, Chausside $S$, et all. Bone loss in patients with inflammatory bowel disease: a prospective situdy. Osteoporos Init 1925:5:156-160

9 Schoon El, Blok BM, Geerling Bl, Russel HG, Stockbrugger RW, Brummer Rl. Bone minetal density in patients with recently diagnosed inflammatory bowel disedse. Gastroenterology 2000;119:1203-1208.

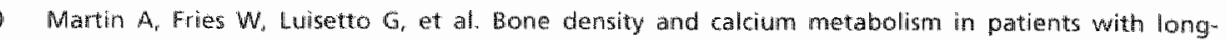
standing quiescent Crohn"s disease. Eur I Gastroenterol Hepatol 1994:6:611-616.

Robinson RJ, Iqual S1, Abrams. K, Al Azzawi F, Mayberry JF, lmcreased bone resorption in patients with Crohn's disease. Aliment Pharmacot Ther 1998;12:699-705. 
Hyams 35, Wyzga No kretzer DL, Justinich G, Gronowicz GA. Alterations in bone motabolism in children with inflammatory bowe disease: an in who study. I Pediatr Gastroenterol Nutr $1997: 24289-295$.

Lennard-Jones JE. Classification of inflammetory bowel disease. Scand I Gastroenterol 5 upp! $1989: 170.2-6$

Best WR, Becktel JM, Singleton WW, Kern F. Development of a Crohn's disease actiwty index. National Cooperative Crohn's Disease Study. Gastroentenology 1976;70:439-444.

Baecke IA. Burema Is Fröjers JE. A short questionnaire for the measurement of habitual physical activity in epidemological studies. An I Clin Nutr 1982; $36.936 \% 942$.

Gamero P. Delmas PD. Assessment of the serum levels of bone alkaline phosphatase whth a mew immunoradiometric assay in patients with metabolic bone disease. I Clin Endocrinol Metab $1993 ; 77 ; 1046-1053$

Bonde M, Qvist P. Fledelius C. Ris B. Christiansen C. Ammunoassay for quantifying type 1 collagen degradation products in urine evaluated. Clin Chem 1994/40:2022-2025.

Bonde $M_{*}$ Qvist P. Fledelius $C_{i}$ Ris BJ, Christiansen C. Applications of an enzyme immunoassay for a new marker of bone resorption (Crosslaps): follow-up on homone replacement therapy and osteoporosis risk assessment.. I Clin Endocrinal Metab 1995:80:864-868.

Rabins SP. Woitge H, Hesley R, Je J. Seyedin S, Seibel MJ. Direct enzyme-linked immunoassay for urinary deoxypyridinoline as a specific marker for measuring bone resorption. I Done Miner Res $1994: 9: 1643 * 1649$

Holis BW, Kamerud JQ. Selvaag SR, Lorenz JD, Napoli JL. Determination of vitamin O status by radioimmunoassay with an 125 Habeled tracer. Chin Chem 1993:39:529.533.

Mazess RB, Barden HS, Bisek IP, Hanson I. Dual-energy xway absomptiometry for totaluody and regional bone-mineral and soft-tissue composition. Am I Clin Nutr 1990;51:1106-1112.

Matess RB, Barden H.S, Ettinger M, Johnston $C_{n}$ Dawson HB, Baran D et al. Spine and famur density using dual photon absorptionetry in US white women. Bone Miner $1987,2: 21: 219$.

Sitevenson IC. Lees B. Devemport M. Cust MP. Ganger KF. Determinants of bone density in normal women: risk factors for future osteoporosis? BMJ $1989 ; 298: 924-928$.

Kroger $H$, Heikkinen J, Laitinen $K_{y}$ Kotaniemi A. Dualenergy Xway absorptiometry in normal women: a cross sectional study of 717 Finnish wolunters. Osteoporos Int 1992;2:135-140.

Assessment of fracture risk and its application to screening for postmenopausal osteoporosis. Report of a WHO Stuidy Group. World Health Organ Tech Rep Ser 1994;843:1-129.

Croucher PH, Vedi S Motley RJ, Garrahan NI. Stanton WR, Compston JE. Reduced bone formation in patients with osteoporosis associated with inflammatory bowel disease. Osteoporos Int 1993;3:236. 241 .

Ganero P. Hausher E, Chapuy MC, et al. Markers of bone resorption predict hip fiacture in elderly women: the EPLDOS Prospective Study. J Bone Miner Res 1996: 11(10):1531-1538.

Metron LI, III, Khosta 5, Atkinsan EJ, et al. Relationship of bone turnover to bone density and fractures. J Bonie Miner Res 1997:12,1083w.109:

Riggs bL, Melton L, III, O'Fallon WW. Drug therapy for wertebral fractures in osteoporosis: evidence that decreases in bone turnover and increases in bone mass both detemine antifracture efficacy. Bone 1996; 18:1975-2015.

Riggs BL. Are biochemical markers for bone wumover clinically useful for monitoring therapy in individual osteoporotic patients Bone 2000,26.551-552

Jilka RL, Weinstein RS, Bellido T, Parfitt AM, Manolagas 5C. Osteoblast programmed cell death (apoptosis): modulation by growth factors and ytokines. Bone Miner Res $1998 ; 13: 793-802$.

Manolagas SC. Weirstein RS. New developments in the pathogenesis and treatment of stercid induced osteoporosis. J Bone Miner Res 1999-14:106, 1 1066.

Teichmann 1, Lange U. Stracke $H_{*}$ Doppl W. Klor HU, Federlin K. Rapid spinal trabecular bone loss in female patients with ileits terminatis Crohn and additonal sacroiliac joint inflammation, Rheumatol Int $1997 \div 17: 45-48$. 
44 von Tirpitz: C, Klaus J. Bruckel J, at al. Increase of bone mineral density whth sodium fluoride in patients wh Crohn's disease In Proces Citation]. Eur I Gastroenterol Hepatol 2000; $2(1): 19.24$.

45 Lips. P. Fuoride in osteoporosis: still an expermental and controversial treatment. Ned Tijdschr Geneeskd 1998;142:1913-1915.

46 Plotkin L. Weinstein RS, Parfitt AM, Roberson PK, Manolagas SC, Bellido T. Prevention of osteocyte and osteoblest apoptosis by bisphosphonates and calcitonif. J Clin Invest 1999:104:4363-1374.

47. Haderslev $K \mathrm{~W}$, Tjellesen L, sorensen HA, staun M. Alendronate increases lumbar spine bone mineral density in patients with Crohn's disease. Gastroenterology 2000; 19:639-646. 


\section{Osteoporosis and spontaneous} vertebral fractures in Crohn's disease: size of the problem and risk factor analysis in a large European study population

RW Stockbrügger, EJ Schoon, S Bollani, PR Mils, E Israeli, L Landgraf, D Felsenberg. S Ljunghall, G Nygard, T Persson, H Graffner. $G$ Bianchi Porro, A Ferguson", on behalf of the MATRIX Study Group

Submitted for publication 


\section{Abstract}

\section{Background}

A high prevalence of orteoporos is has been noted in Crohn's disease (CD). but data about fractures are scaice.

\section{Methods}

Potental als talors for low bone mineral density (BND) and the prevallende ot vertebral frachures were siudiled 273 patients with ileo gecall CD betore randomization into a large furopeandsraell intervantion study one hiundred and eighty fwo sterold ffee patients (STH) with currenty ache $\mathrm{CD}$ and 91 steroid-dependent patients (STD) with gulescent CD were nvest gared wirh $D \times A$ san ot the L L mbar spine and stam dardized ateral $x$ ray of the thoracic and lumbar spine.

\section{Results}

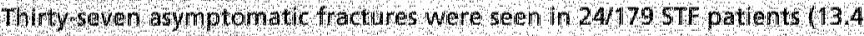

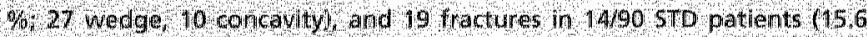
9), 14 wedge, 5 concanity), The averagle $T$-reore and 2 score of patients with fisctures were not significantly different $10 \mathrm{~m}$ those without

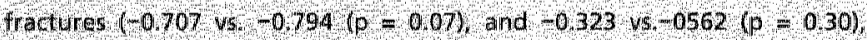

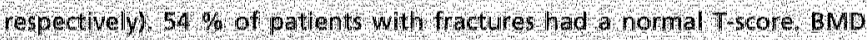

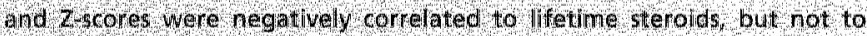
preWous bownel resection, or current disease activity fracture rate was not

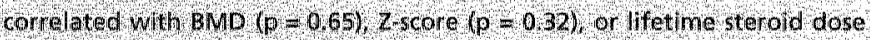
$(0) 085)$

\section{Conclusions}

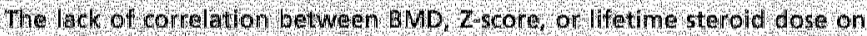
the one hand aird the prevelence of tractures on the other necessitales

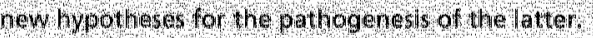




\section{Introduction}

As late as in the early 1990s, inflammatory bowel disease (1BD) did not appear in the list of causes of secondary osteoporosis in authoritative reviews or textbooks. However, in recent years a multitude of articles have been published indicating that osteopenia and osteopenia are frequent in IBD" "more so in Crohn's disease (CD) than in ulcerative colitis (UC) ${ }^{s,}$. In the published literature the prevalence of osteopenia in IBD varies widely between $7 \%$ and $70 \%$. 50 far, only a few studies have assessed the natural history over longer periods of time ${ }^{10.15}$. There are many discordant results regarding the risk factors and pathogemesis of osteoporosis in $\triangle B D$, but most studies agree on the important negative effect of steroid treatment on $\mathrm{BMD}^{2,7-9,5-19}$. The variation between study results can probably be explained by differences in the patient population, disease duration, cumulative disease activity, previous medical and surgical treatment, dietary status, and smoking habits. So far, there are no studies regarding the relationship of BMD and fractures in IBD.

The present study describes the degree of osteopenia and osteoporosis and the prevalence and localization of radiologically established vertebral fractures in $a$ large and well-characterized multi-national group of patients with ileo-cecal CD. either with active disease presently in need of oral steroid medication, or with quiescent disease activity following protracted steroid medication. The bipolar study population reflects frequent management sitwations in Crohn's disease. The data published here represent the baseline of the international MATRIX study ("Effect of long-term treatment with Entocort (budesonide CIR) capsules and prednisolone on bone density, bone metabolism and osteoporosis in patients with Crohn's disease using dual energy X-ray absorptiometry"). In that study the therapeutic effect of both compounds will also be seen in relationship to vertebral fractures.

\section{Patients and Methods}

\section{Study design and patients}

The MATRIX study started in 1996, and is a multicenter Europeam/israeli study with a two-year inclusion period and a maximum two-year follow-up of the individual patient after the start of intervention. Between July 1996 and July 1999, 278 patients were recruited in 34 academic and non-academic centers in nine countries and 273 patients (with at least one intake of study medication) participated in the study. The inclusion and exclusion criteria are described in Table 8.1. 
Table 8. 1 Inclusion and exclusion criteria for MATRUX study

\section{Inclusion criteria}

Age between 20.70 years

Confirmed diagnosis of Crohn's disease by combination of X-ray. endoscopy, histology, and scintigraphyt

Disease confined to the distal lewm, the ileo-cecal region andlor the ascending colon

for the sterold tree (STI) group patients not having received steroids during 6 months before study entry and having an active disease $(\mathrm{COAl}>150)$

For the steroid-dependent (5TD) group patients having received $7-20$ mglday of sterolds for at least 4 out of 5 manths inmediately prior to inclusion in the study and having quiescent disease (CDAl $\leq 200)$ slgned infomed consent

\section{Exclusion criteria}

Pregnancy or breast-feeding

Hypersensitivity to budesonide or other glucocorticosteroids:

Previouls gastric surgery (except for closure of a perforation or selective vagotomy)

Heostomy, colostony or pouch

small bowel resed tion exceeding $100 \mathrm{~cm}$

Any resection cistel to the mid transverse colon

Disease proxinal to the lleum

Adtive crohn's diseage in the rectim (verifted by rectoscopy)

Complicated Crohn's disease (abscess, obstruction, perforation, active fistulas)

Dependence on ether parenteral or enteral nutrition

Thdication for inmediate surgery

Active systemic infection

Clinically releyant renal hepatic cardiowascular or psychiatric disease

Uncontrolled diabetes mellitus

Active peptic disease

Bheumatoid arthritis

Ankylosing spondylitis

Pinary sclerosing cholang tis

Hyperiparathyroidism

History of gastrolntestinal malighancy or high grade dysplasia within the tast 5 years

Alcohol or drug abuse

Use of NSAIDis dhonically ( 3 days consecutively)

stant of therapy with azathioprine, 6 -mercaptopurine or methotrexate less than 3 months prior to visitt 1

Treatment with cyclosporine withn the month pror to visit I

Start of ther apy with cholestyramine during the 2 weeks prior to visit

Start of hormone replacement therapy less than 6 moniths prior to visit 1

Treatment with calcitonin and/or bisphosphonates within the last 6 months

Treatment with fluonide, androgens anabolic sterolds, active metabolites of vitamin 0 within the last 6 montiss

Trearment with oral ketoronazole with in 7 days prior to visit 1

Exposure to I we viruses or live bacterie within 3 mont/as prior to visit 
Demographic and clinical data.

The demographic and clinical data recorded for all patients included gender, age at time of investigation, age at diagnosis of $C D$, extent of $C D$ (including localization and extent of previous operations), current medication for $C D$ and for non-related diseases, cumulative steroid dose, current steroid dose in the STD group, current Crohn"s Disease Activity Index (CDAl) ${ }^{20}$, body mass index (BMI), and a physical activity index. ${ }^{2 \%}$. A smoking history (non-smokers, ex-smokers, and smokers) and a menstrual history (pre-and post-menopausal female, hormone replacement therapy) were also obtained. At the screening visit approximately $20 \mathrm{ml}$ blood was collected and analyzed at each study center: b-hemoglobin, b-hematocrit, bleukocyte concentration, b-platelets, s-alkaline phosphatase, s-albumine, and bESR. A number of markers of bone metabolism, including osteocalcin, pyridinoline cross links, and parathyroid hormone, were assessed in either blood or urine. The preliminary findings of this part of the study have been presented elsewhere ${ }^{22}$.

Radiography of the thoracic and lumbar spine.

An posterior-anterior radiograph of the thoracic and lumbar spine was taken at the patient's clinical center following a study-specific procedure manual applying the EVOS (European Vertebral Osteoporosis Study) recommendations ${ }^{23.24}$. Radiographs were sent with a coded identification to two expert radiologists (L.L., D.F.) who assessed the findings unaware of relevant clinical or laboratory data. In the radiological assessments, vertebrae with an osteoporotic deformation and a height reduction of more than $20 \%$ were considered fractured. In borderline cases morphometric evaluation (6-point-measurement) of the suspected vertebrae was performed using the algorithm of Felsenberg with a threshold of $80 \%$ (Figure 8.1) $)^{23}$. Osteoporotic vertebral fractures were subdivided into wedge, concavity, biconcavity, and crush fractures. Vertebral fractures or deformities with an etiology other than osteoporosis (for example degenerative deformities or traumatic fractures) were not included in the assessment.

\section{Bone Mineral Density}

Bone mineral density (BMD) of the lumbar spine (posterior/anterion), the left femoral neck, and the total body was measured using dual $X$-ray absorptiometry (DXA) (Hologic QDR 1000 W, 1500, 2000, 2000 plus, 4000 (Hologic Inc., Bedford MA, USA); or Lunar DPX, DPX'L, or DPXplus (Lunar Inc., Madison WI, USA). All scans were performed according to the manufacturers instructions. A study-specific Quality Assurance and Procedures manual was distributed by a central quality assurance program provider (Synarc/MDM Hologic, Maynard MA, USA). All DXA scans were stored on floppy discs and sent to SynardMDM Hologic for centralized review and data collection.

DXA results were expressed as BMD in absolute values $\left(\mathrm{g} / \mathrm{cm}^{2}\right)$, as gender-controlled $T$-scores using the WHO criteria definition ("normal" less than 1 standard deviation (SD) below the mean for the reference population, "osteopenia" between 1 SD and 2.5 SD below the mean, and "osteoporosis" more than 2.5 SD below the mean $^{25}$, and as age- and gender-controlled Z-scores. Mean BMD from at least three 
evaluable vertebrae (four when available) from $\mathrm{L} 1$ to $\mathrm{L} 4$ was used. For the purpose of this study only the lumbar spine results are referred to in order to enable correlation with lumbar $X$-ray findings.

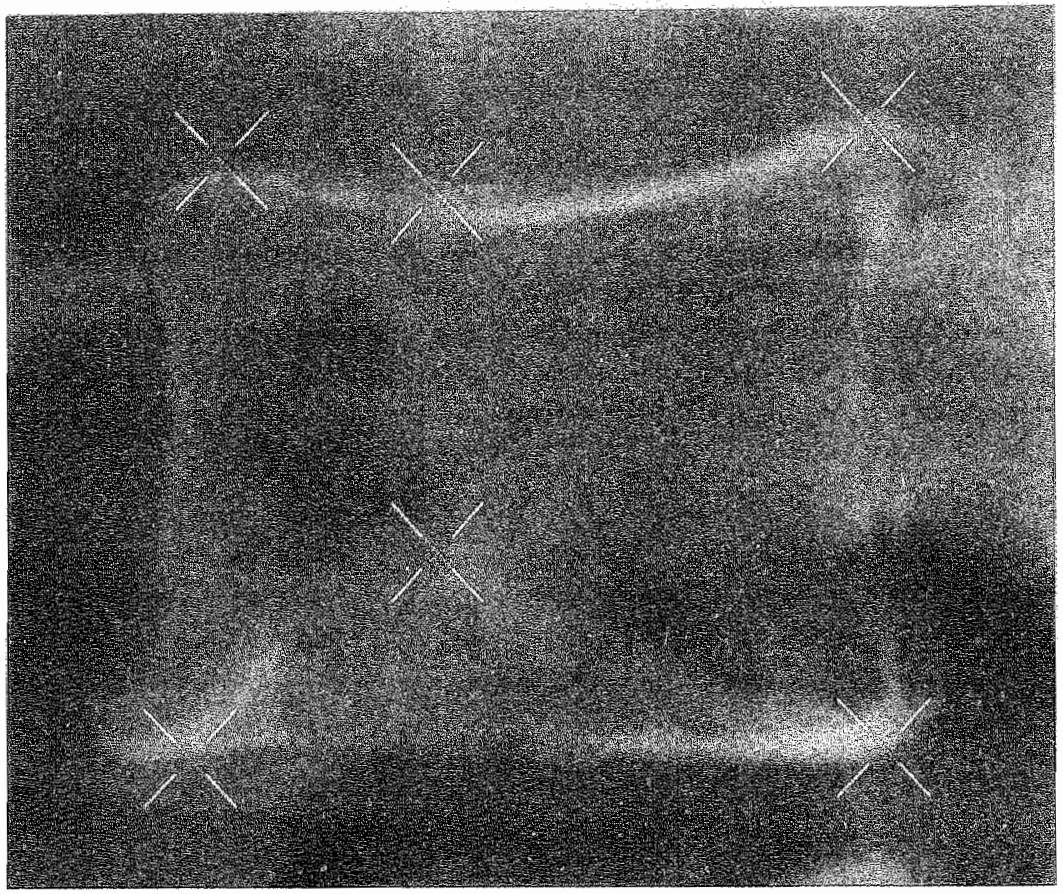

Figure 8.1 Vertebra with fracture of inferior endplate (6-point measurement)

\section{Statistical analysis}

BMD was calculated by dividing the total bone mineral content by total area. Fractured vertebrae as seen on the $X$-ray were excluded (one vertebra for each of 15 patients). For the sake of comparability with Hologic data, Lunar data were transformed using the formula: new $B M D$ value $=0.906 \times$ Lunar value) minus 0.025 . T-scores and $Z$-scores were calculated from BMD values using formulae supplied by Synard MDM Hologic.

Means were compared with Student's t-test, and chi-square test was used for the distribution of T-scores. Correlations were assessed using Spearman rank correlations. Analyses involving several independent variables to explain one dependent variable were done as analysis of covariance and multiple regression with backward selection of varialbles. 


\section{Results}

\section{Demographic and clinical baseline data}

As defined by the study entry criteria, the subgroups of steroid-free (STF) and steroild dependent (STD) patients were significantly different in their clinical presentation (Table 8.2). The STF group had a higher disease activity, a shorter duration of disease, a shorter time since the last exacerbation, and - most importantly - a lower life-time dose of corticosteroid (100 out of the 182 STF patients had never had any corticosteroid treatment for their bowel disease). The groups were similar regarding data such as gender distribution, smoking habits and hormone replacement therapy in female patients. Age was significantly lower in the STF group, and therefore $\dot{Z}$-scores were applied in the evaluation when necessary. Five patients aged 17-19 years were erroneously included as was one patient with 4 fractures. They are all included in the analyses of this paper.

Table 8.2 Demographic and dinical characteristics of 273 treated patients

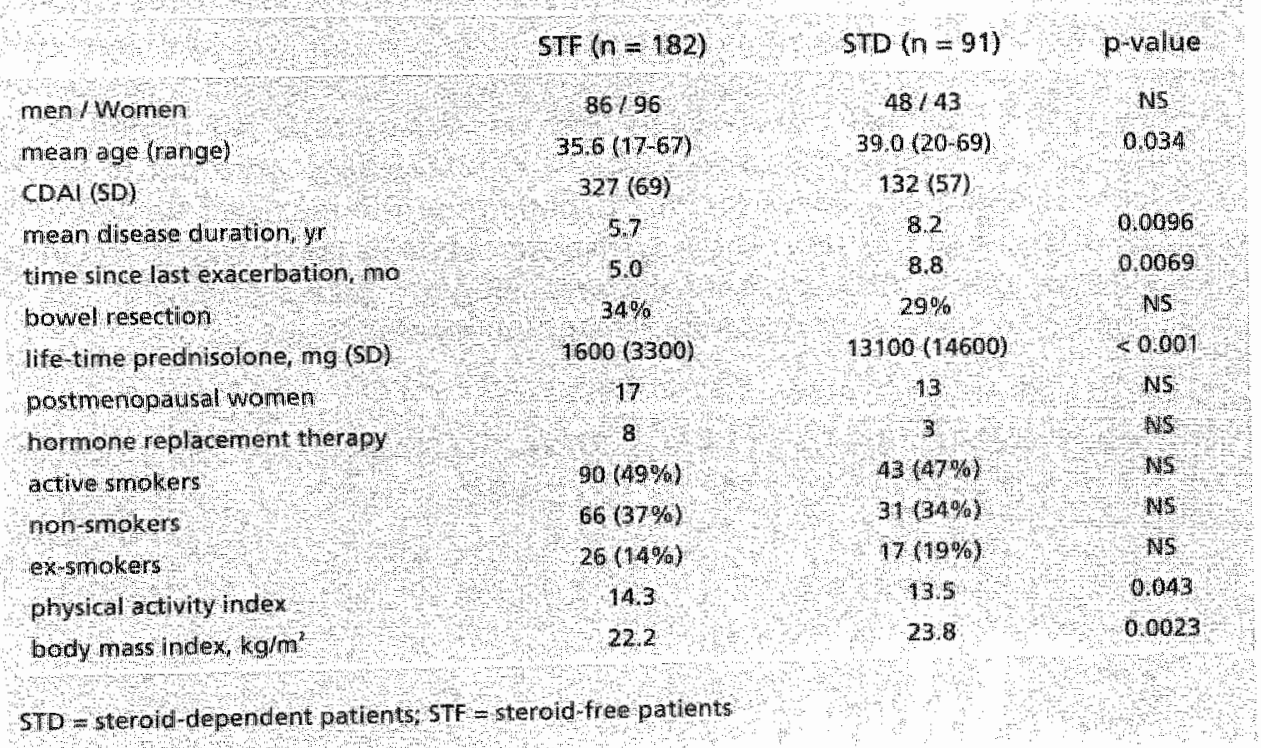

\section{Bone Mineral Density}

BMD, T-scores, and Z-scores are shown in Table 8.3. In absolute values, BMD was about five per cent higher in the STF group than in the STD group, this difference being highly statistically significant. The subgroup difference was also apparent in the distribution of patients with normal BMD, osteopenia and osteoporosis: nearly two thirds of the STF patients had a normal BMD, compared with less tham half of 
the STD patients. Applying a chi-square test, the difference in distribution of $T$ scores was significant $(p=0.0079)$. The age-corrected $Z$-score was also significantly higher in the STF group than in the STD group $(p=0.0032)$.

Table 83 Bone mineral density in 179 sterold-free (STF) and 90 steroid-dependent (STD) patients with Crohn's disease.

\begin{tabular}{|c|c|c|c|}
\hline & $S A F(n=179)$ & $S T O(n=90)$ & $p$-walue \\
\hline BMD values (mean (SD)) & $(0.16)$ & $095(017)$ & 0,0018 \\
\hline Tscore (mean (so)) & $-0.61(1.25)$ & $-13(125)$ & 0,00114 \\
\hline 2 score $($ mean $(s \mathrm{D}))$ & $-0.37(1.23)$ & $-0.86(129)$ & 0,0032 \\
\hline Tscore values & $n(\%)$ & $n(\%)$ & \\
\hline $\mathrm{Tscore}+>-1$ & $190(61)$ & $38(42)$ & 0.0079 \\
\hline Tseore $110-25$ & $56(31)$ & $39(43)$ & \\
\hline Tapore $>-25$ & 130 & $13(15)$ & \\
\hline
\end{tabular}

\section{Thoracic and lumbar fractures of the spine}

A total of 56 fractures were discovered in 38 of $269(14.1 \%)$ evaluable patients (Table 8.4a) without a significant difference regarding prevalence and type between the groups (STF: 27 wedge, 10 concavity; STD; 14 wedge, 5 concavity). Fority-one of the fractures were wedge fractures (Figure 8.1) and fifteen were concavity fractures (Figure 8.2). Biconcavity or crush-fractures were not found in the baseline radiographs. Twelve (of 98) STF patients previously never treated with steroids had vertebral fractures. These twelve steroid naive patients with fractures were not significantly different from the remaining STF patients with respect to any demographic, clinical, or laboratory data including BMD/T-score.

Table 8.4a Prevalence of vertebral fractures ( $\mathrm{x}$ ) in 179 steroid-free (STF) and 90 steroid dependent (STD) patients with Crohn's disease.

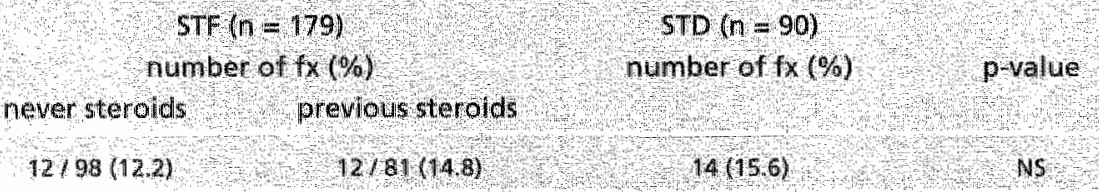

In men the fracture rate tended to be generally higher than in women (Table 8.4b), and was similar in all age groups; in women, a significant increase in fracture rate was observed with increasing age ( $p=0.0037$; linear regression analysis) with a sharp rise in the postmenopausal period (Figure 8.3). Regarding localization of fractures, prevalence peaks were found in the middle thoracic spine and thoraciclumbar junction for wedge fractures, and in the thoracic-lumbar junction and lumbar spine for concavity fractures (Figure 8,4). 


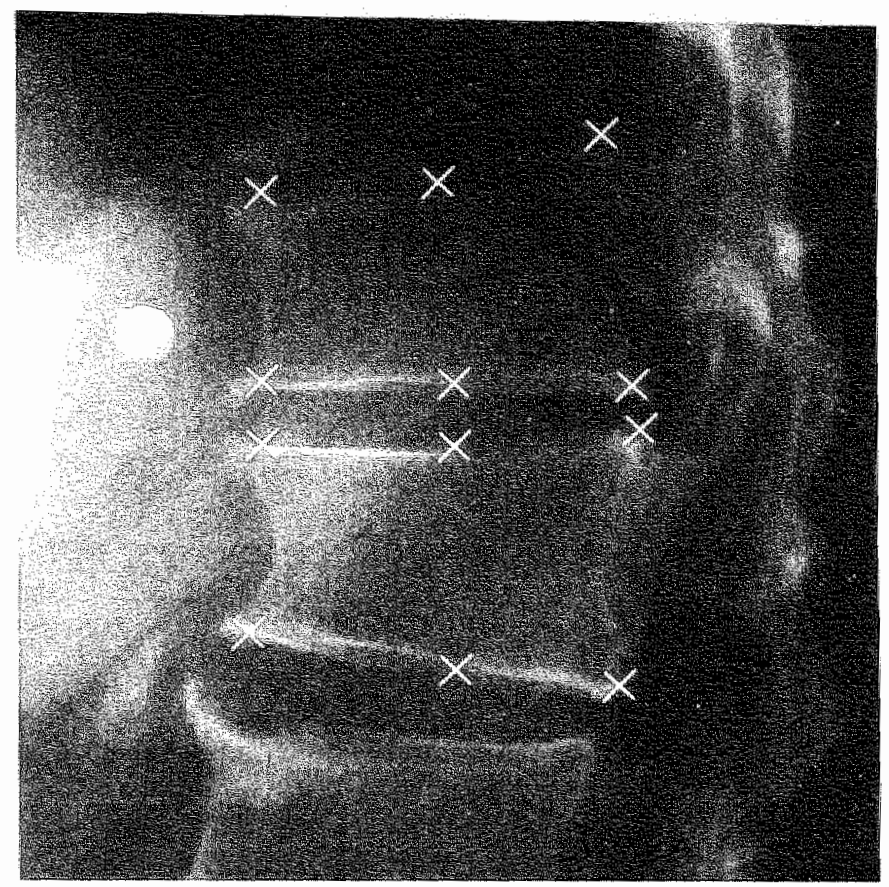

Figure 8.2 Two vertebrae with wedge fracture

Table 8.46 Total number of patients with tactures $(f x)$ and number of patients with fractures (fi) divided by sex and age groups.

\begin{tabular}{|c|c|c|c|c|c|c|}
\hline & total & age 1730 & $31-40$ & 4150 & $51 / 60$ & $61-69$ \\
\hline vatients & 269 & 110 & 63 & 46 & 34 & 16 \\
\hline patrents with fo & $38(14 \%$ & $12(11 \%)$ & $8(13 \%)$ & $7015 \%$ & $6(18 \%)$ & $5(31 \%)$ \\
\hline women & 135 & 99 & 36 & 27 & 16 & 7 \\
\hline women with $\mathrm{t}$. & $17(13 \%)$ & $36 \%$ & $4(1 \%)$ & $4(75 \%)$ & $\pi(19 \%)$ & $3(43 \%)$ \\
\hline nen & 134 & 61 & 27 & 19 & 18 & 9 \\
\hline men with $f x$ & $2116 \% \%$ & $9(15 \%)$ & $4(15 \%)$ & $3(16 \%)$ & $3(17 \%$ & $2(22 \%$ \\
\hline
\end{tabular}

Note. Four patients (all women) had no evaluable $x$-rays 


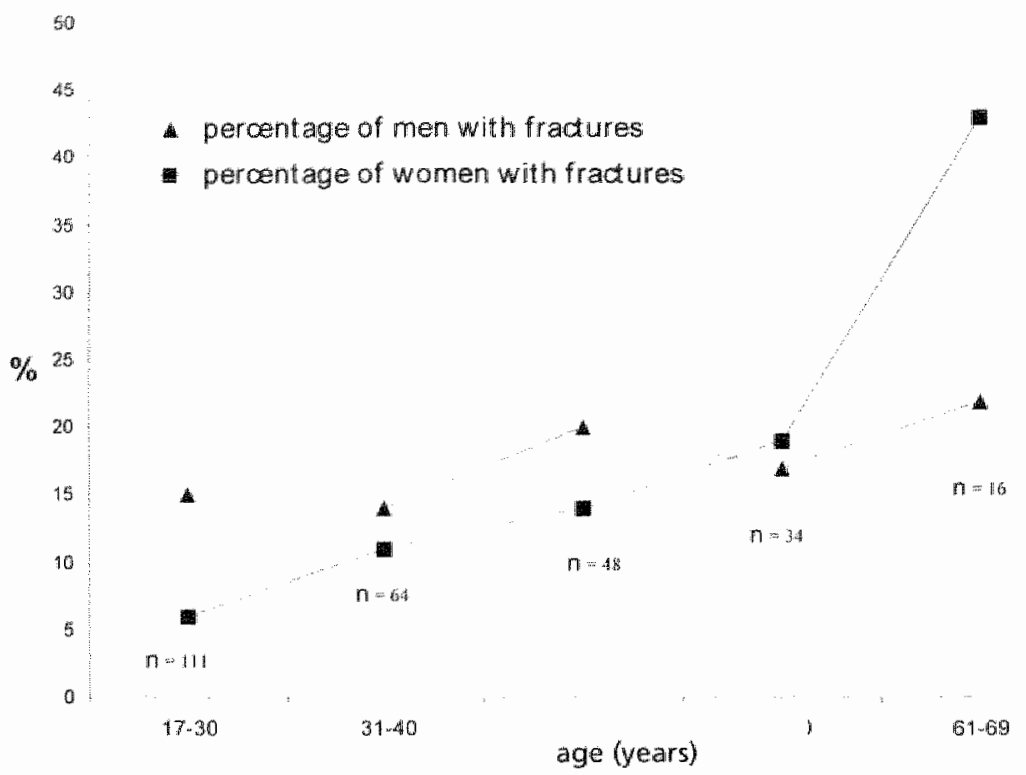

Figure 8.3 Prevalence of vertebral fractures in 269 patients with Crohn's disease by sex and age group.

Correlations between demographic and clinical data, BMD, and spinal fractures

In the study population as a whole, the BMD, T-score, and Z-score were negatively correlated to lifetime steroid dose ( $p<0.001, p<0.001, p=0.0012$, respectively), but not to previous bowel resections or current disease activity. Men had significantly lower $T$-scores $(-4.03$ vs. $-0.54 ; p=0.0013)$ and $Z$-scores $(-0.91$ vs. $-0.18, p<0.001)$ than women.

The fracture rate was not significantly influenced by smoking, bowel resections or current disease activity. Only in women was there a positive association with age: women above the age of 50 years had significantly more fractures than women below that age $(p=0.049)$; however, the fracture rate of women above 50 years was not significantly higher than that of men above 50 years of age.

Fracture rate was not correlated with BMD $(p=0.68)$, T-score $(p=0.80)$, or Z-score $(p=0.32)$ in the patient group as a whole, not even in the subgroup of postmenopausal women ( $p=0.74$ for T-score and $p=0.98$ for Z-score). The mean lumbar T-score of the 38 patients with fractures was $-0.707 \pm 1.393$ and that of the remaining 231 patients without fractures $-0.794 \pm 1.262(p=0.70)$; corresponding figures for $Z$-scores were $-0.323 \pm 1.375$ vs. $-0.562 \pm 1.277(p=0.30)$. Fifty-four per cent of the patients with fractures had a normal T-score.

In multiple regression analysis, none of the following factors was found to independently determine the prevalence of vertebral fractures: gender; age; age at disease onset; previous resection; life-time steroid dlose; current CDAl; STF or STD group. 

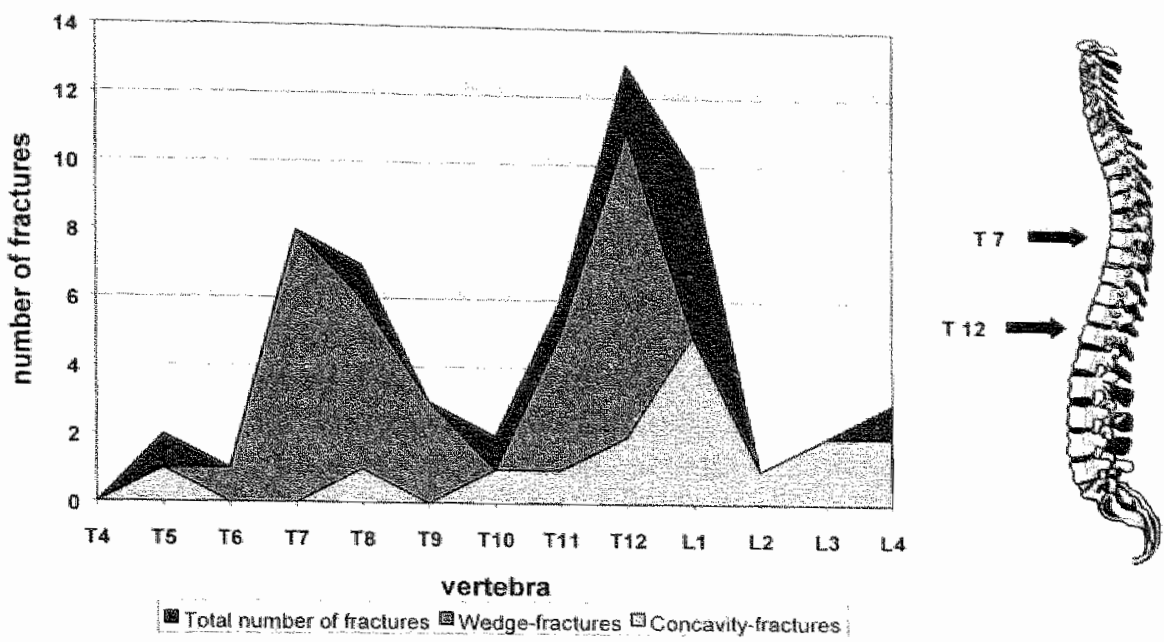

Figure 8.4 Prevalence of vertebral fractures in 269 patients with Crohn's disease by type and localization.

\section{Discussion}

In this study of 273 patients with either currently steroid-free and active or currently steroid-treated and inactive Crohn's disease, the prevalence of osteopenia and osteoporosis has been investigated simultaneously with a radiological assessment of spinal fractures. Overall, a reduced BMD (expressed as T-score $<-1$ ) was seen in about $46 \%$ and vertebral fractures in about $14 \%$ of the patients. BMD was significantly lower in the STD group than in the STF group, and consequently a negative correlation between lifetime steroid dose and BMD emerged. Surprisingly. the fracture rate was similar in both subgroups and was not correlated to the BMD of the lumbar spine.

The entry of patients into this study attempted to match as closely as possible the everyday clinical use of steroids in $C D$, namely either patients who are considered for steroid treatment because of recent exacerbation (STF patients) or protracted treatment of steroids ( $>3$ months) in patients who are currently unable to stop prednisolone. Both patients groups were refifactory to treatment with mesalamine and/or azathioprine only but not under consideration for surgery (STD patients). The multi-center participation in the study allowed a representative population of CD patients to be obtained. At the same time, strict definition of inclusion criteria, uniform collection of demographic and clinicall data, and standardized morphological investigations allowed valid comparisons between such data and the prevalence of low BMD and fractures to be made. For the assessment of possible risk factors for osteopenia/osteoporosis and fractures, it was an advantage that a number of confounding clinical conditions were excluded at study entrance.

The two subgroups had distinct differences: the STF patients were slightly younger. had a shorter history of CD and a lower life-time dose of steroids, although now in 
need of steroid treatment because of a moderate to high disease activity. In this group of patients with active disease at the time of inclusion, the proportion of patients with osteopenia (30\%) was comparable to the prevalence of most crosssectional studies ${ }^{1 \cdot 3,36,3726}$. The combined prevalence of osteopenia and osteoporosis in the STD subgroup $(58 \%)$, however, exceeded the reported prevalence of most comparable studies ${ }^{1-6,5,7,13,8}$.

Lifetime steroid dose emerged as the strongest and possiblly sole causative factor for decreased BMD in the total study group with the exemption of male sex.. Other factors reported in the literature as contributors to osteopenia and osteoporosis in CD and/or ulcerative colitis (UC) were not identified in this large survey: age fin this study corrected for with $Z$-scores), smoking habits ${ }^{23}$, previous bowell resection ${ }^{29}$, or current disease activity ${ }^{17,30}$. Clearly, disease activity is suppressed in the STD subgroup due to steroid treatment, but not even in the STF subgroup a correlation was found between disease activity and BMD. One has to realize that the correlation between disease activity and BMD at any point may not be conclusive. Only a prospective cumulative registration of the CDAl over a longer period could possibly disclose whether increased systemic inflammatory activity, involving proinflammatory cytokines, is a determinant of osteoporosis ${ }^{35.34}$.

To our knowledge, this is the first study using both BMD measurement by DXA and systematic radiological assessment of vertebral fractures in a large group of CD patients. Overall rates of spinal fracture around $14 \%$ from appear high in this generally young patient population. The prevalence of vertebral fractures increases up to $43 \%$ in female patients above 60 years, however, this group was small (7 patients). The present study suffers from a drawback: it cannot compare fracture rate with an age- and gender-matched population from a comparable geographic area. The best comparison for the present study stems from the European Vertebral Osteoporosis Study (EVOS) in which community-based subjects above the age of 50 years were investigated, showing a crude prevalence of low BMD deformities in men and in women of about $10 \%$ in the age of 50 to 65 years $^{35}$. The same radiological method recommended by EVOS was applied in the present study. Fractures were subdivided into wedge fractures and concavity fractures, the former being significantly more frequent than the latter. In a previous study only symptomatic patients had $X$-rays of the spine". In another small cross-sectional study a fracture rate of $7 \%$ was reported, but data of patients with ulcerative colitis and Crohn's disease were not differentiated'. Recently, a large wellcontrolled clinical-epidemiological study, based on hospital records, has shown that the relative risk of $\mathrm{CD}$ patients developing symptomatic vertebral fractures is increased overall by about $50 \%$ compared to the background population ${ }^{35}$. Another study reported an increased risk of low energy fractures in CD compared to controls (15.7\% versus $1.4 \%$, respectively), which was calculated on the basis of a self-administered postal questionnaire and compared to the data of populationbased controls".

The present study describes a simillar prevalence of vertebral fractures in male and in female CD patients. The questionnaire study by Vestergaard et al. ${ }^{37}$ reported a higher frequency in women (relative risk 2.5), but no increased risk in male patients with $C D$. The reason for this gender difference is unclear ${ }^{38}$ : it could hypothetically be caused by environmental factors, such as higher physical activity of men during 
work and leisure activities. In the post-menopausal period, women overtake men with regard to fractures, even if figures are too small to draw any far-reaching conclusions. It is likely that in women in this period of life the effect of diseaseinduced bone damage combined with hormonally induced alterations could be responsible for the disproportionately high fracture rate ${ }^{39}$.

In this large group of CD patients no correlation could be found between degree of osteopenia and vertebral fractures. This correlation has been proven in postmenopausal women ${ }^{\text {and }}$ "and such a correlation has appeared to be evident, but in $C D$ that has rarely been investigated. A potential explanation for the lack of correlation in the present study is that $\mathrm{CD}$ patients are more susceptible to fractures in certain biological phases such as infancy, adolescence, post-menopause, or old age. The report of Semeao et al. ${ }^{\text {An }}$ regarding six children could be interpreted in this way, as could our findings in post-menopausal women. However, in the male patients with fractures no correlation with either disease onset or senescence could be demonstrated. Another possibility is that subclinical fractures occur during phases of active disease - whether treated with high doses of steroids or not and whether with transient osteopenia or not - and that the bone matrix thereafter recovers, obscuring the relationship with the fracture ${ }^{15}$. As a third hypothesis we suggest that there might be more relationships than vertebral fractures and osteopenia alone. The fractures could be occurring on the basis of completely different events changing the matrix structure in the trabecular bone of these patients. The suggested micro-architectural changes in the trabecular bone may weaken the strength of the vertebra. Loss of BMD in CD is partially reversible ${ }^{29}$ but not necessarily the structural changes of the trabecular bone, i.e., cortical thinning and disiruption of trabecular lattice ${ }^{45}$. Ultimately, vertebral fractures may represent a further extra-intestinal manifestation of IBD, comparable to primary sclerosing cholangitis (PSC) or pyoderma gangraenosum, which occur nearly exclusively in patients with IBD but behave surprisingly independently of the natural or treated course of the bowel disorder.

This phenomenon needs further investigation, and it may be necessary to obtain bone biopsies in warious phases of $C D$ activity and treatment to improve our understanding of the vertebral fractures so frequently found.

The interventional study (MATRIX) that followed this baseline investigation will reveal whether budesonide in modified-release capsules is as able to suppress activity in $C D$ and to maintain a prednisolone-induced quiescent disease state without causing further deterioration the bone matrix or leading to additional firactures.

In summary, this study demonstrated a high prevalence of osteopenia and osteoporosis in patients with $\mathrm{CD}$, more in the steroid-dependent than in the steroid-free patients. Lifetime steroid dose was the factor most strongly correlated to a reduced $B M D$, which may be a causative relationship and/or an expression of a high cumulative disease activity. The high frequency of vertebral fractures and the lack of correlation with osteopenia necessitate further investigation. 


\section{References}

1. Ablbol W. Roux C. Chaussade S, Guillemant 5 , Kolta 5 , Dougados MA, Couturier D, Amor B. Metabolic bone assessment in patients whth inflammatory bowel disease. Gastroenterology 1995;108:417-422.

2. Bjarnason I, Macpherson A, Mackintosh $\mathbb{C}$, Euxton-Thomas M. Forgacs 1 , Moniz C. Reduced bone density in patients with inflammatory bowel disease. Gut 1997,40:228-233.

3. Compston JE, Judd D, Crawley EO, Evans wo, wans C, Church HA, Reid EM, Rhodes 1 . Osteoporosis in pattents with inflammatory bowel disease. Gut 1987:28:410-415.

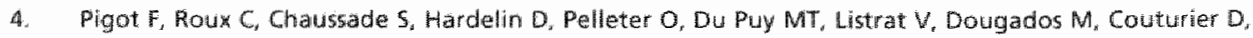
Amor B. Low bone mineral densty in patients with inflammatory bowel disease. Dig Dis 50 $1992,37: 1396-1403$

5. Robinson RJ, al Azzawi F, iqbal SJ, Kryswcki T, Almond $L$, Abrams K, Mayberry fF, Osteoporasis and determinants of bone dencity in patients with Gohn's disease. Dig Dis Sci 1998:43:2500-2506.

6. Schoon EJ, van Nunen AB, Wouters RS, Stockbrugger RW, Russel MG. Osteopenia and osteoporosis in Crohn's disease: prevalence in a Dutch population-basied cohort. Scand I Gastroenterol Suppl $2000: 35 \div 43-47$

7. Silvennoiner $J A_{\text {a }}$ Kartunen TJ Niemela SE, Manelius H, Lehtola JK. A controlled study of bone mineral density in patients with inflammatory bowel disease. Gut 1995;37:71-76.

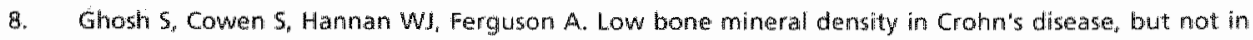
wlcerative colitis, at diagnosis. Gastroenterology 1994; 107:1031-1039.

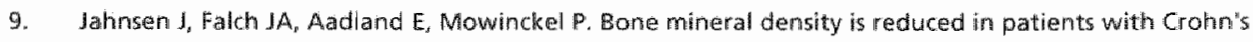
disease but not in pathents with ulcerative colitis: a population based study. Gut 1997:40:313-319.

10. Clements D, Motley RJ, Evans WD, Harries AD, Rhodes J, Coles RJ, Compston $\mathrm{JE}$. Longitudinal study of cortical bone loss in patients with inflammatory bowel disease. Scand J Gastroenterol 1992;27:1055. 1060.

11. Dresner-Pollak R. Karmeli F, Eliakim R, Ackerman Z, Rachmilewitz D. Increased urinary N-thelopeptide cross linked type 1 collagen predicts bone lossi in patients with inflanmaltory bowel disease. Am I Gastroenterol 2000,95:699-704.

12. Motley RJ, Crawley EO, Evans C. Rhodes J, Compston JE. Increased rate of spinal trabecular bone loss in patients with irflammatory bowel disease. Gut 1988,29:1332-1336.

13. Motley RJ, Clements D, Evarys WD, Crawley EO, Evans C. Rhodes 1 , Compston JE. A four year longitudinal study of bone loss in patients with inflammatory bowel disease. Bone Miner 1993;23:915. 104.

14. Roux C. Abitbol V, Chaussade 5, Kolta S, Gullemant S, Dougados M. Amor B, Couturier D. Bone loss in patients with inflammatory bowal disease: a prospective study. Osteoporos int 1995; 5: 156-160.

15. Schulte $C_{\text {. Dignass }} \mathrm{AU}$, Mann $K_{\mathrm{n}}$ Goebell $\mathrm{H}$. Bone loss in patients with intlammatory bowel dissease is lass than expected: follow-up study. Scand J Gastroenterol 1999:34:696-702.

16. Bernstein CN. Seeger LL, Sayre IWW. Anton PA. Artinian $L$, Shanahan $F$. Diecreased bone density in inflammotory bowel disease is related to conticosteroid use and not disease diagnosis. $J$ Bone Miner Res $1995 ; 10: 250-256$.

17. Bischoft SC, Hermann A, Goke M, Manns MP, von zur MA, Brabant G. Altered bone metabolism in inflimmatory bowel disease. Am I Gastroenterol 1997:92:1157-1163.

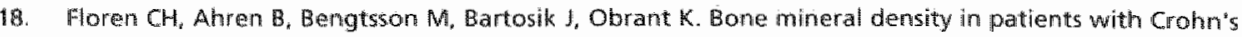
disease during long term treatment with azathioprine. Jintern Med 1998:243:123-126.

19. Pollak RO. Karmeli F, Eliakim $R$. Ackerman Z, Tabb $K$, Rachmilewitz D. Femoral neck osteopenia in patients with intlammatory bowel disease. Am J Gastroenterol 1998,93:1483 1490.

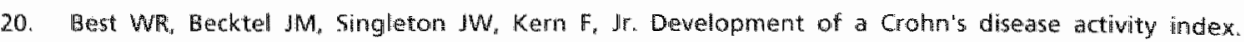
National Cooperative Crohn's Debease Study. Gastroenterology 1976;70:439-444. 
21. Baecke JA, Burema I, Fritters JE. A short questionnaire for the measurement of habitumi physical activity in epidemiological studies. Am I Clin Nutr $1982 ; 36: 936-942$.

22. Bollani S, Schoon EJ, Mills P, Goldin E, Ljunghali S, Vatn M, Persson T, Stackbrugger RW, G.Bianchi Porro. Bone matrix metabolism in ileo-cecal Crohn's disease. Does disease activity matter? Gastroenterology 2001:120:A 626 .

23. Felsenberg $D_{*}$ Wieland $E$, Gowin $W$, Armbreche $G$, Bolze $X_{a}$ Khorassani $A$, Weingarten $U$. Morphometric analysis of roentgen images of the spime for diagnosis of osteoporosis-induced fracture. Med Klin 1998:93: 5 uppl 2:26-30.

24. Kiel D. Assessing vertebral fractures. Nationall Osteoporosis Foundation Working Group on Vertabral Fractures. D Bone Miner Res 1995; 10:518-523.

25. Assessment of fracture risk and its application to screening for postmenopausal osteoporosis. Report of a WHO Study Group. World Health Organ Tech Rep Ser 1994;843:1-129.

26. Tromm A, Rickels $K_{\text {. Hupe }}$, Wiebe $V$. May B. Osteopenia in chronic inflammatony bowel disedses. Results of a cross- sectional study using quantingtive computerized tomography. Leber Magen Dairri: $1994 ; 24: 23 \cdot 30$

27. Andreassen $H_{*}$ Hylander $E_{*}$ Rix M. Gender, age, and body weight are the major predictive factors fior bone mineral density in Crohn's disease: a case-control cross-sectional study of 113 patients. Am I Gastroenterol 1999:94:824:828.

28. Silvennoinen JA, Lehtola $\mathrm{NK}$, Niemela SE. Smoking is a risk factor for osteoporosis in women with inflammatory bowel disease. Scand I Gastroenterol 1996;31:367-371.

29. Compston JE, Ayers AB, Horton LW, Tiglhe JK, Creamer B. Osteomalacia after small-intestinal resection. Lancet $1978 ; 1: 9-12$.

30. Hyams ds. Wyzga $\mathbb{N}_{\text {, Kreutzer }} \mathrm{DL}$, Justinich CJ, Gronowicz GA. Alterations in bome metabolism in children with inflammatory bowel disease: an in vitro study. I Pediatr Gastroenterol Nutr $1997 ; 24: 289-295$

31. Fiocchi C. Production of inflammatory cytokines in the intestinal lamina propria. Immunol Res $1991 ; 10: 239-246$.

32. Issenman RM. Bones in Crohn's: cytokines, a missing link? J Pediatr Gastroenterol Nutr 1997,24:361362.

33. MaCDonald BR, Gowen M. Cytokines and bone. Br J Rheumatol 1992;31:149-155.

34. Raisz LG. Local and systemic factors in the pathogenesis of osteoporosis. N Engl J Med 1988;318:818828.

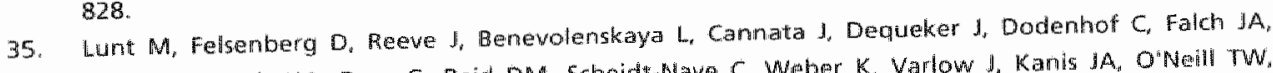
Masaryk P, pols HA, poor G, Reid DMt, Scheidt-Wave $C$. Weber K, Warlow d, Kanis IA, ONeill TW" Silman AJ. Bone dersity warlation and its effects on risk of vertebral deformity in men and women studied in thirteen European centers: the EWOS Study. J Bone Miner fhes 1997; 12:1883-1894.

36. Bernstein $C N$, Elianchard JF, Lesile W, Majdia $A$, Yu BN. The incidence of fracture among patients with inflammatory bowel disease. A population based cohort study. Ann intern Med 2000; 133:79:5-799.

37. Vestergard $P$, Krogh $K$, Rejnmark $L$, Laurberg $S$, Mosekilde L. Fracture risk is increased in Crohn's disease, but not in ulcerative colitis. Gut 2000;46:176-181.

38. Selby PL, Dawies M, Adams JE. Do men and women fracture bones at simälar bone densities? Osteoporos int 2000;11:153-157.

39. Cummings SR, Browner WS, Bauer D. Stone K, Ensrud K, Jamal S, Ettinger B. Endogenous hormones. and the risk of hip and vertebral fractures among older women. Study of Osteoporotic fractures Research Group. N Engl J Med 1998;339:733-738.

40. Hui SL slemenda CW, Johnston CC, Jir. Baseline measurement of bone mass predicts fracture in whitte women. Ann intern Med 1989;111:355,361.

4.1. Marshall $D_{\text {, J }}$ Johnell $O$, Wedel $H$. Meta-analsysis of how well measures of bone mineral density predict occurrence of osteoporotic fractures. BMJ 1996;312:1254-1259.

42. Ross PD, Davis WW. Eptein RS, Wasmich RD. Prewexisting fractures and bone mass predict vertebral fracture incidence in women. Ann intern Med 1991;114:919-923. 
43. Takahashi $M$, Kushida $K$, Naitou $K$. The degree of osteoporosis in patients with vertebral fracture and patients with hip fracture: relationship to incidence of vertebral iracture. J Bone Miner Metab $1999 ; 17: 187 \cdot 194$

44. Semea E\%, SHallings VA, Peck SW, Piccoli DA. Vertebral compression fractures in pediatric patients. with Crohn's disease Gastroenterology 1997;112:1770-1713.

45. Oleksik A, Ott SW, Vedi 5 . Bravenboer W, Compston J, Lips P. Bone structure im patients with low bone minenal density with or whthout vertebral fractures. J Bone Miner Res 2000;15:1368-1375. 


\section{General discussion}





\section{Introduction}

Osteoporosis has become a well-known complication in IBD, and a subject of increasing interest and awareness to dinicians. Osteoporosis is defined as a decreased bone mass, but also indicates changes of architectural structure leading to an increased fragillity of bone". When, in patients with Crohn's disease, the many" potentially contributing factors to low bone mineral density are taken into consideration the term metabolic bone disease seems more appropriate in this context. Osteomalacia is a part of the metabolic bone disease in IBD, but it has only a moderate contribution, even when it is studied by histomorphometric analysis in selected subgroups at risk ${ }^{2 \cdot 4}$.

\section{Prevalence of osteoporosis in IBD}

A high prevalence of osteoporosis and osteopenia was found in the population. based study on BMD in CD described in this thesis ${ }^{5}$ BMD was significantly lower in the hip compared to the lumbar spine, which had also previously been demonstrated in other studies ${ }^{6-3}$ In elderly persons the relatively higher BMD-values of the lumbar spine could have been influenced by artefacts, e.g. of degenerative abnormalities or fractures. This is unlikely in this predominantly young patient population. However, $X$-rays of the lumbar spine were not regularly taken in order to exclude such abnormalities. The lower BMD in the femoral neck compared to the lumbar spine and the slightly higher risk for decreased BMD in male patients with Crohn's disease indicate the presence of a different pathophysiologic mechanism for low BMD to that of senile osteoporosis and purely corticosteroidinduced osteoporosis. The risk of osteoporosis increases in female patients after menopause as expected from the knowledge of the normal population. In our study, an age of onset of CD below 18 years of age was found to be a significant

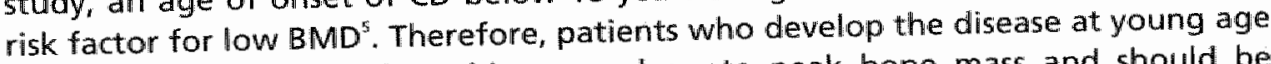
have a lower chance of reaching an adequate peak bone mass and should be monitored $^{9 \cdot 1 !}$.

\section{Risk factors for osteoporosis in IBD}

Patients with IBD have disease and treatment related risk factors for osteoporosis in addition to the risk factors that are present in the general population. In the two largest cross-sectional studies on risk factors of osteoporosis in CD patients, published so far, low body weight, male sex as well as current use and cumulative dose of steroids were reported as independent determinants of low BMD in one ${ }^{12}$, and high age, male sex and low body weight in the other study, respectively. Low body weight, which is the most important clinical risk factor identified so far, contributed to about $20 \%$ of the correlation with BMD. The relatively lower BMD in male patients is not wery well explained so far, when extrapolating from the protective effects of oral contraceptives in young female patients and the low testosterone levels found in male $C D$ patients independent of current corticosteroid use ${ }^{34}$. 
$122 \mid$ Chapter 9

Many other contributing factors have been mentioned, such as smoking. malabsorption, vitamin D deficiency and decreased physical activity, but their contribution is likely to be moderate. Smoking is difficult to study in a mixed population of $\mathrm{CD}$ and $U \mathrm{C}^{15}$, as smoking improves the disease activity in UC but worsens it in $C D^{16}$.

In general, chronic use of corticosteroids is the most important cause of secondary osteoporosis". However, the effect of corticasteroids on BMD in IBD is a subject of debate. Possible arguments in this controversy are given in Table 9.1 . It is evident that $\mathrm{BMD}$ values assessed at one point in time reflect multiple past and present influences. In follow-up studies, the prospective bone loss of patients with wellcontrolled IBD, both $C D$ and $U C_{f}$ is only moderate ${ }^{18 \%}$.

Table 91 Possible explanations of the controversies regarding the effects of corticosteroids on BMD in BBD.

The nultifactorial nafure of the bone los

The difficulties of accurate retrospectlve calculations of steroid doses used

The hadfudual susceptibility of the patients to the damaging effects of conticosteroids

The heterogeneily of he poptlations studied

A reversible component dung remssion

samplestor

Confounding effects of disease activity

The study on determimants of BMD in CD described in this thesis demonstrated that the sum of all significant risk factors contributes only to a maximum of $50 \%$ to the correlation with BMD. Thus, clinical risk factors do not appear to be good predictors of bone mineral density. Therefore, in IBD the threshold for measuring of BMD by means of DXA should be IOW, and the result should be judged in its clinical context.

If it is not possible to test all CD patients for logistic or economic reasons, it is advisable to test the subgroups with a relatively higher risk (e.g. juvenile and postmenopausal patients).

Almost seventy percent of the population-based cohort of patients with Crohn's disease presented in this thesis had used corticosteroids during periods of disease activity. Considering the incidence and amount of corticosteroids used in this population, the prevalence of osteoporosis seems relatively low. This could be caused by protective effects, e.g. genetic or metabolic factors. An example of genetic variability influencing $B M D$ in $I B D$ has been described by Schulte et al ${ }^{20}$. These authors demonstrated that the presence of interleukin 6 allele ${ }_{r}$ and the absence of interleukin 1 receptor antagonist allele correlated with bone loss in a mixed group of 86 UC and CD patients. Another genetic factor influencing bone metabolism could be the vitamin $D$ receptor gene polymorphism, a gene which represents a strong positional candidate susceptibility gene for $18 D^{27}$. It is the cellular receptor for $1,25(\mathrm{OH})_{2}$ vitamin $D^{3}$ (calcitriol) which has a wide range of 
different regulatory effects on the immune system. Other genes influencing the type and course of IBD, are now being vigorously studied ${ }^{12.23}$. In the future, it might be demonstrated that the phenotypic expression of the disease correlates with the genotype, which would facilitate predictions of outcome and may offer the possibility of choosing the appropriate treatment for the disease and facilitate anticipation of possible complications, e.g. osteoporosis.

\section{Recently diagnosed patients with IBD}

In this thesis we demonstrated in a case-control study that BMD in recently diagnosed patients with IBD was not different from controls. $s^{24}$. Furthermore, we found no significant differences in BMD between $C D$ and UC. Our findings conflicted with the data from a previously reported study ${ }^{25}$, but could be explained by methodological differences. Duration of IBD type complaints greater than six months prior to diagnosis was a negative determinant for low BMD in our study. The latter confirms the negative effects of untreated disease on BMD. We concluded that subsequent development of low BMD should be related to the disease activity and/or the treatment of IBD. In another controlled study comparing $C D$ with UC and controls, BMD of CD patients was significantly lower than in both UC and controls ${ }^{26}$. Miedian disease duration in CD was 10 years and in UC 7 years. In rheumatoid arthritis, in which there is another type of "inflammation associated" bone loss, this loss occurs more rapidly early in the course of the disease and correlates well with measures of inflammation and function ${ }^{27}$. Thus, control of the disease activity and active diagnostic and therapeutic management, started early in the course of the disease, may be successful in preventing osteoporosis in IBD.

\section{The role of vitamin $\mathrm{K}$}

The nature and significance of the relationship between vitamin $\mathrm{K}$ status and bone health has been debated for some years. Previously, Vitamin $K$ deficiency was found in 18 of 58 patients $(31 \%)$ with chronic gastrointestinal disease and/or resection ${ }^{z 8}$. All patients with vitamin $K$ deficiency had either Crohn's disease involving the ileum or ulcerative colitis treated with sulfasalazine or antibiotics.

In a study by Szulc et al., the serum levels of undercarboxylated osteocalcin correlated with hip bone mineral density in elderly women ${ }^{25}$. We demonstrated that the vitamin $K$ levels of serum and bone in $C D$ patients were significantly decreased compared with normal controls. Undercarboxylated osteocalcin was found to be an independent risk factor for low bone mineral density of the lumbar spine whereas serum vitamin $D$ was not ${ }^{30}$. The finding that a poor vitamin $\mathrm{K}$ status is associated with low bone mineral density in longstanding Crohn's disease may have implications for the prevention and treatment of osteoporosis in this disorder. The fact that vitamin $K$ inhibited bone loss in prednisolone treated rats is challenging ${ }^{31}$. The findings which are presented in this thesis have been discussed in two articles and require further confirmation as well as assessment of clinical consequences $5^{32.33}$. 


\section{Bone turnover: biochemical assessment}

A key to the solution of the pathophysiology of inflammation associated bone disease might be found at the cellular level of bone turnover. Bone is a living tissue in which there is a constant cycle of degradation (resorption) performed by osteodasts and of bone formation by osteoblasts, replacing old bone with new bone. This bone turnover should be in balance; otherwise, decreased formation, increased resorption or both lead to net bone loss. Osteobllasts and osteoclasts. originate from stem cells in the bone marrow and proliferate under a complex. influence of growth factors, cytokines, and hormones $s^{34}$. It has been demonstrated that cytokines directly affect bone formation and resorption as they influence the osteoblast and osteoclast function. Particularly pro-inflammatory cytokines like TNF, $\|_{-}-1$, and $\mathrm{L}-6$ are thought to have a pivotal role in this process $\mathrm{s}^{25,35}$.

The same cytokines are important in the inflammatory process in IBD ${ }^{3 \%}$. In an experimental study, serum of pediatric patients with active CD was injected into rats $^{38}$. Compared to controls, this serum decreased bone mass, while serum from UC patients had no such effect. These data suggest that pro-inflammatory cytokines. influence bone formation and bone resorption, resulting in bone loss. The abundance of circulating cytokines in Crohn's disease plays ain important role in the inflammation associated bone loss ${ }^{34}$.

Recent studies have shown that pro-inflammatory cytokines stimulate the expression of osteoprotegerin ligand, a transmembrane protein of the tumor necrosis factor ligand superfamily, which is also expressed on activated $T$ cells. Osteoprotegerin ligand stimulates osteoclast formation and activation ${ }^{27}$. The T-cell activation in Crohn's disease may also be involved in the pathways of inflammation induced bone resorption.

We studied bone turnover in patients with longstanding Crohn's disease in remission, currently using no or only very low doses of prednisolone ${ }^{\text {to }}$. Low bone formation was found, which was significantly different from controls. The results were also different from studies on bone turnover in active $C D$, which demonstrate an increased bone resorption ${ }^{\text {s. }}$. . The diverse outcomes of these studies may indicate, that bone turnover is different in different phases of Crohn's disease and may depend on disease activity, corticosteroid use and menopausal status.

\section{Vertebral fractures in Crohn's disease}

In osteoporosis, the whole diagnostic therapeutic and/or preventive interest should be aimed at the prevention of fractures, which is the critical clinical endpoint $t^{\text {as }}$. Especially in Crohn's disease (CD), reports of vertebral fractures in children ${ }^{45}$, or a child presenting with vertebral fractures as first clinical manifestation of CD ${ }^{\text {ith }}$, underline the severity of this complication. Two major epidemiological studies which used questionnaires/ or record studies found a higher relative risk of fractures which was higher than in the background population ${ }^{47,48}$.

This thesis describes the result of the first study that correlates. DXA scores of the lumbar spine with the presence of vertebral fractures. The results of the study indicate a high percentage of vertebral fractures in male as well as in female patients with $C D$. In this large group of $C D$ patients no correlation could be found between degree of osteopenia and vertebral fractures. A potential explanation for 
the lack of correlation in the present study is that CD patients are more susceptible to fractures in certain blological phases of their life. Another possibility is that subclinical fractures occur during phases of active disease, a phenomenon occurring in patients after liver transplantation ${ }^{49}$. A third hypothesis is that the fractures may occur because of completely different events that change the matrix structure in the trabecular bone of these patients. In that way vertebral fractures may represent a further extra-intestinal manifestation of Crohn's disease.

These hypotheses are supported by an experimental study, in which local inflammation provoked by subcutaneous talc powder injections, induced a marked trabecular bone loss in rats within 7 days $5^{50}$.. The pathological findings included local guranulomatosis and distally, a decreased number of trabecular osteoblasts. Neither the appearance and function of osteoblasts in the vicinity of the cortical bone, nor the number of osteoclasts in the metaphysis were found to be altered. The loss of trabecular bone in granulomatosis was caused by a suppression of bone elongation and a fallure of osteoblasts to form normal secondary spongiosa. This study indicates that systemic inflammation can have local effects on a particular type of bone.

For clinicians, the consequence of these findings is that they have to be aware of the potential presence of fractures, e.g. low back pain in young patients with $C D$. The strategy for prevention of osteoporotic complications may be changed to the short periods of the disease course where the patients are at risk of developing a fracture.

\section{Future perspectives}

More evidence is needed on the prevention and treatment of metabolic bone disease in $1 \mathrm{BD}_{4}$ especially in Crohn's disease in which this comorbidity is more apparent than in UC. Nevertheless, bone loss in ulcerative colitis should be treated according to the protocols of corticosteroid-induced bone loss. Data are also lacking on optimal prevention in active Crohn's disease. For example, in ileo-cecal crohn's disease do locally acting steroids such as budsonide (in controlled ileal release formulation), protect bone from further loss in comparison with prednisolone? Studies are now ongoing. Secondly what is the potential role of drugs such as bisphosphonates and SERM's (selective estrogen receptor modifiers) amongst others, and in which formulation? Thirdly what is the effect of using new biological agents (e.g. anti-TNFa antibodies) in the treatment IBD related bone disease? These questions raised should be studied further in randomized controlled trials of adequate sample size, and hopefully the results will shed some further light on nebulous areas concerning the treatment of patients with $I B D$. 


\section{References}

1. Assessment of fracture risk and its application to screening for postmenopausal osteoporosis. Report of a WHO Study Group. World Heatth Organ Tech Rep Sier 1994;843:1-129.

2. Croucher PI, Vedi S, Motley RJ, Garrahan NJ, Stanton MR, Compston JE. Reduced bone formation in patients with osteoporosis associated with inflammatory bowel disease. Osteoporos int 1993;3:236241.

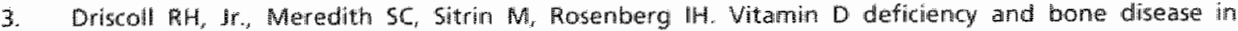
patients with Crohn's disease. Gastroenterology 1982;83:1252"125i8.

4. Hessov I, Masekilde L, Melsen F. Fasth 5 , Hulten L, Lund B, Lund B, Soremsen OH. Osteopenia with normal vitämin D metabolites after small-bovsel resection for Crohn's disease. Scand I Gastroenterol 1984:19:691-696.

5. Schoon EJ, wain Nunen AB, Wouters RS, Stockbrugger RW, Russel MG. Osteopenia and osteoporosis in Crohr's disease: prevalence in a Dutch population-based cohort. Scand I Gastroenterol Suppl 2000:35:43-47.

6. Bjarnason 1, Macpherson A, Mackintosh C. Buxton-Thomas M. Forgacs I, Moniz C. Reduced bone density in patients with inflammatory bowel disease. Gut 1997:40:228-233.

7. Pollak RD, Karmeli F, Eliakim R, Ackerman Z, Tabb K, Rachmilewitz. D. Femoral neck osteopenia in patients with intlammatory bowel disease. Am I Gastroenterol 4998;93:1483-1490.

8. Schulte $C$, Dignass AU, Mann $K_{*}$ Goebell H. Reduced bone mineral density and unbalanced bone metabolism in patients with inflammatory bowel disease. Inflamm Bowel Dis 1998:4:268-275.

9. Boot AM, Bouquet $J$, Krenning $\mathbb{E}$ P, de Muinck Keizer-Schrama SMM. Bone mineral density and nutritional status in children with chronic inflammatory bowel disease. Gut 1998;42:188-194.

10. Issenman RM. Bone mineral metabolism in pediatric inflammatory bowel disease. Imflamm Bowel Dis 1999;5:192-199

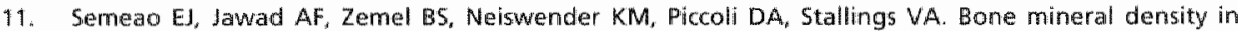
children and youngl aduits with Crohn's disease. Inflamm Bowel Dis 1999;5:161-166.

12. Robinson RJ, al Azzawi F, Iqbal 5J, Kryswcki T, Almond L, Abrams K, Mayberry IF. Osteoporosis and determinants of bone density in patients with Crohn's disease. Dig Dis Sci 1998;43:2500-2506.

13. Andreassen $\mathrm{H}$, Hylander E, Rix M. Gender, age, and body weight are the major predictive factors for bone mineral density in Crohn's disease: a case-control cross-sectional study of 113 patients. Am I Gastroenterall 1999:94:824-828.

14. Robinson RJ, lquall SI, al Azzawi F, Abrams K, Mayberry JF. Sex hormone status and bone metabolism in men with Grohn's disease. Aliment Pharmacol Ther 1998; 12:21-25.

15. Silvennoinen JAA, Lehtola JK. Niemella SE. Smoking is a risk factor for osteoporosis in women with inllammatory bowel disease. Scand I Gastroenterol 1996:31:367-371.

16. Russel $M G_{\text {, }}$ Volovics A, Schoon EJ, wan Wijlick EH, Logan RF, Shivananda S, Stockbrugger RW Inflammatony bowel disease: is there any relation between smoking status and disease presentation? European Collaborative IBD Study Group. Inflamm Bowel Dis 1998;4:182-186.

17. Eastell R, Reid DM, Compston J, Cooper C, Fogelman I Francis RM, Hosking D, Purdie DW, Ralstion SH, Reeve 1. Russell RG, Stevenson JC, Torgerson DI. A UK Consensus Group on management of glucocorticoid-induced osteoporosis: an update. Juntern Med 1998;244:271-292.

18. Schulte C, Dignass AU, Mann $\mathrm{K}$, Goebell $\mathrm{H}$. Bone loss in patients with inflammatory bowel disease is less than expected: a follow-up study. Scand J Gastroenterol 1999;34:696-702.

19. Ulivieri $F M$, Piadi LP. Taioli E, Lisciandrano D, Ranzi T, Vezzoli M, Cermesoni $L$, Bỉanchi P. Bone mineral density and body composition in ulcerative colitis: a six- year follow-up. Osteoparos Int $2001 ; 12: 343-3: 48$ 
20. Schulte CM. Dignass AU, Goebell H, Roher HD, schulte KM. Genetic factor determine extent of bone loss in inflammatory bowel disease. Gastroenterology 2000-119909-920.

21. Simmons 10 . Mulighan C, Welsh Kl, Jewell DP. Vitamin D receptor gene polymorphism: association with Crohn"s disease susceptibility. Gut 2000;47:211-214.

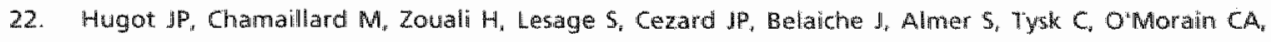

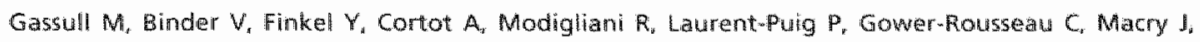
Colombel JF, Sahbatow M. Thomas G. Association of NOD2 leucimeurich repeat watiants with susceptibility to Crohn's disease. Nature 2001/411:599-603.

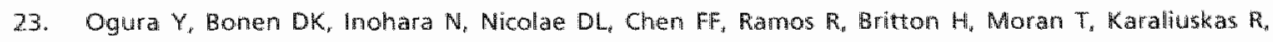
Duerr RH, Achkar JP, Brant SR, Bayless TM, Kirschner BS, Hanauer SB, Nunez G, Cho IH. A frameshifit mutation in NOD2 associated with susceptibility to Crohn's disease. Nature 2001:411:603-606.

24. Schoon EJ, Blok BM, Geerling Od, Russel MG, Stockbrwgger RW, Brummer RJ. Bone mineral density in patients with recently diagnosed inflammatony bowel disease. Gastroenterology $2000 ; 119 ; 1203-1208$.

25. Ghosh 5, Cowen $\$$, Hannan WJ, Ferguson A. Low bone mineral density in Crohn's disease, but not in ukerative collitis, at diagnosis. Gastroenterology 1994; 107:1031-1039.

26. Jahnsen J, Falch JA, Aadland $E$, Mowhinckel $P$. Bone mineral density is reduced in patients with Grohn's disease but not in patients with ulceratiwe colitis: a population based study. Gut 1997,40:313-319.

27. Green M. Deodhar A.A. Bone changes in early rheumatoid arthritis. Bailieres Best Pract Res Clin Rheumatol 2001:15:105-123.

28. Krasinski SD, Russell RM, Furie BC, Kruger SF, lacques PF, Furie B. The prevalence of vitamin $K$ deficiency in chronic gastrointestinal disorders. Am J Clin Nutr 1985;41:639-643.

29. Satc $\mathbb{P}$, Arlot $M$, Chapuy $M C_{*}$ Duboeuf F, Meunier PJ, Delmas PD. Serum undercarboxylated osteocalcin correlates with hip bone mineral density in elderly women.. J Bone Miner Res.1994:9:15911595.

30. Sthoon EJ, Muller MC, Vermeer C, Schurgers L., Brummer Ru, Stockbrugger RW. Low seim and bone vitamin $K$ status in patients with longstainding Crohn's disease: another pathogenetic factor of osteoporosis in Crohn's disease? Gut $2001: 48: 473-477$.

31. Hara K, Akiyama $Y$, Ohkawa I, Tajima T. Effects of menatetirenone on prednisolone-induced bone loss in rats. Bone 1993;14:813-818.

32. Compston JE. Boning up on vitamin $K$. Gut 2001:48:44:8.

33. Szulc $P$, Meunier PJ. Is vitamin $K$ defuciengy a risli factor for osteoporosis in Crohn's disease? Lancett $2001 ; 357 ; 1995-1996$.

34. Manolagas SC, Jika RL. Bome marrow, cytokines, and bone vemodeling. Emerging insigints into the pathophysiology of osteoporosis. N Engl I Med 1995;332;305 31\%.

35. Nguyen L, Dewhirst FE, Hauschka PV. Stashenko P. Interleukin-1 beta stimulates borle resorption and inhibits bone formation in vivo. Lymphokine Cytokine Res 1991:10:15-21.

36. Wallach S, Avioli LV, Feinblatt JD, Carstens IH, Jr. Cytokines and bone metabolism. Calcif Tissue Int $1993 ; 53: 293-296$.

37. Hommes $D W$, wan Dulemen H. Radema $5 A_{\text {. }} T y$ tgat $G N$, wan Deventer 5 J. The role of cytokines in the pathogenesis of inflammatory intestinal diseases. Ned Tijdschr Geneeskd 1994:138:2427-2432.

38. Hyams 15 , Wyzga $N$, Kreutzer DL, Justinich CJ.Gronowicz GA. Alterations in bone metabolism in children with inflammatory bowel disease: an in witro study. I Pediatr Gastroenterol Nutr $1997: 24: 289-295$.

39. Issenman RM. Bones in Crohm's: cytokines, a missing link? I Pediatr Gastroenterol Nultr 1997:24:3613.62 .

40. Schoon EJ, Geerling BG, Van Dooren IM, Schurgers L, Vermeer $C_{\text {w }}$ Erummer RJ. Stokkbrugger RW. Abnormall bone tumover in long-sianding Crom's disease in remission. Aliment Pharmacol Ther 2001:15:783-792.

41. Ballani S, Schoon E. Mills P. Goldir E Ljunghall 5 , Vatn M. Persson T, Stockbrugger RW, G. Bianchi Porro. Bone matrix metabolism in hleo-cecal Crohn's disease. Does disease alctivity matuer? Gestroenterology $2001: 120: A_{0} 626$. 
42. Dresner-Pollak $R$, Karmeli F, Eliakim $R$, Ackerman $Z$, Rachmilewitz $D$. Increased urinary N-telopeptide cross-linked type 1 collagen predicts bone loss in patients with inflamatory bowel disease. Am J Gastroenterol 2000:95:699-704.

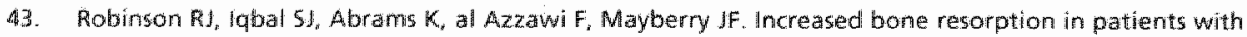
Crohn's disease. Alment Pharmacol Ther 1998,12:699-705.

44. Cranney Aald W. Tugwell P. Wels G, Adachi JD, McGowan J, She B. Responsiveness of endpoints in osteoporosis cinical trialsmon update. I theumatol 1999;26:222-228.

45. Semeao Ei, Stallings VA, Peck 5W, Piccoli DA. Vertebral compression fractures in peditatric patients with Crohn's disease. Gastroenterology $1997 ; 112: 1710-1713$.

46. Thearle M. Hoflick M, Blezilkian JP, Levy J, Gertner JM, Levine LS, Harbison M, Berdon W, Oberfield 5E. Osteoporosis: an unusual presentation of childhood Crohn's disease. I Clin Endocrinol Metab $2000 ; 85: 2122-2126$.

47. Bernstein CH, Blanchard JiF, Lesfle W, Wajda $A_{n}$ Yu BN. The incidence of fracture among patients with inflammatory bowel clisease. A population-based cohort study. Ann Intern Mmed 2000; 133:795-799.

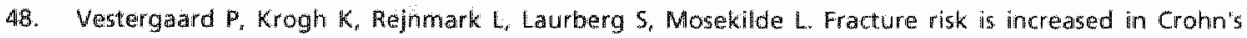
disease, but not in ulcerative colitis. Gut 2000;46:176-181.

49. Ninkovic M, Skingle SJ, Bearcroft PW, Bishop $\mathbb{N}$, Alexander GJ, Compston JE. Incidence of vertebral fractures in the first three months after orthotopic liver transplantation. Eur I Gastroenterol Hepatol $2000 ; 12 \div 931-935$.

50. Kremplen B, Wakicevic 5, Vogel M, Stawljenic A, Buchelle R. Cellular basis of inflammation induced osteopena in growing rats. J Bone Miner Res 1988:3:573-582. 


\section{Summary}




\section{Summary}

This thesis describes the epidemiology, pathophysiologic aspects, and clinical aspects of metabolic bone disease in inflammatory bowel disease (IBD), especially in Crohn's disease. In all the studies bone mineral density (BMD) was measured by dual-X-ray absorptiometry (DXA) of the femoral neck, lumbar spine, and total bodly.

Chapter 2 reviews the current knowledge on the relation between IBD and metabolic bone disease.

In chapter 3 the results are presented regarding the prevalence of osteopenia and osteoporosis and of symptomatic fractures in Crohn's disease of a well-defined population based cohort from the IBD South-Limburg study area. One-hundrednineteen eligible patients were investigated. Osteopenia of lumbar spine and/or femoral neck was found in $45 \%$ of patients. Osteoporosis was found in another 13 $\%$ of patients. Mean BMD (T-score) of femoral neck was significantly lower than of the lumbar spine. Male CD patients and patients aged under 18 at diagnosis are at higher risk of having a low bone mineral density at the lumbar spine and total body. The prevalence of osteoporosis in postmenopausal CD patients $(29 \%)$ was significantly higher than in premenopausal patients (3\%) (Odds ratio: 12). Twentynine of $119(24 \%)$ of patients had a history of symptomatic fractures. We concluded that osteopenia and osteoporosis are frequent in $\mathrm{CD}$ and should have the full attention of the treating physician.

In chapter 4 , clinical determinants of bone mineral density are discussed in a population-based cohort of patients with Crohn's disease. Many potential risk factors for low bone mineral density were taken into consideration and were analysed. Linear regression analysis indicated both body weight and female gender as significant positive determinants of $\mathrm{BMD}_{\text {, }}$ and age as well as a combined use of prednisolone and azathioprine as negative determinants. In females alone, positive determinants of BMD were: body weight and the use of azathioprine. Postmenopausal status, use of prednisolone, serum magnesium level, and the combined use of prednisolone and azathioprine, respectively, were negative determinants. In males, serum calcium level and body weight were significant positive determinants, whereas age was a negative determinant of BMD.

From this study we concluded that patients with $C D$, who are particularly at risk for low BMD are: the male and post-menopausal female patients, with low body weight and a history of combined use of prednisolone and azathioprine, normal or increased serum magnesium levels and a low serum calcium level. However, from the low correlation between the sum of all the risk factors and the BMD measurement in the linear regression model we concluded that clinical risk factors alone are not strong enough predictors of BMD and do not replace DXA measurements in patients with Crohn's disease. 
A study investigating whether bone mineral density in patients with IBD is already low at diagnosis is described in chapter 5. Bone mineral density measurement of recently diagnosed patients with Crohn's disease and ulcerative colitis was measured and compared to age-and gender-matched population controls. No significant differences in bone mineral density $\left(\mathrm{g} / \mathrm{cm}^{2}\right)$ between patients and controls were found. Also, there were no significant differences found in bone mineral density between patients with either Crohn's disease or ulcerative colitis. Multiple linear regression analysis revealed that duration of complaints longer than six months before diagnosis, age, and body mass index lower than $20 \mathrm{~kg} / \mathrm{m}^{2}$ significantly correlated with low bone mineral density.

From this study we concluded that bone mineral density in recently diagnosed patients with inflammatory bowel disease was not significantly decreased compared to population controls. Subsequent development of osteoporosis in IBD patients seems to be a phenomenon related to the disease process and/or the treatment modalities.

In chapter 6, vitamin $K$ status in serum and bone of patients with long-5tanding Crohn's disease in remission is assessed. Long-standing Crohn's disease is associated with deficiency of fat-soluble vitamins, amongst them vitamin $\mathrm{K}$. Vitamin $\mathrm{K}$ is a cofactor in the carboxylation of osteocalcin, a protein essential for calcium binding to bone. A high level of circulating undercarboxylated osteocalcin is a sensitive marker of vitamin $K$ deficiency. Bone mineral density was measured in 32 patients with long-standing Crohn's disease and small-bowel involvement, currently in remission and using less than $5 \mathrm{mg}$ prednisolone daily. Serum levels of vitamins $D$ and $K$, of triglycerides, and of total immunoreactive osteocalcin as well as undercarboxylated osteocalcin ("free" osteocalcin) were determined. The hydroxyapatite binding capacity of osteocalcin was calculated. Data were compared to an age-and gender-matched control population.

Serum vitamin $K$ levels of the CD patients were significantly decreased compared to normative controls. "Free" osteocalcin was higher and hydroxyapatite-binding capacity of circulating osteocalcin was lower than in matched controls, indicating a low bone vitamin $K$ status in Crohn"s disease. In patients, an inverse correlation was found between "free" osteocalcin and lumbar spine bone mineral density and between "free" osteocalin and the Z-score of the lumbar spine. Multiple linear regression analysis showed that "free" osteocalcin was an independent risk factor for low bone mineral density of the lumbar spine, whereas serum vitamin D was not.

From this study we concluded that the finding of a poor vitamim $k$ status, associated with low BMD in long-standing Crohn's disease, could have implications for the prevention and treatment of osteoporosis in this disorder.

In chapter 7, the pathophysiologic process of bone turnover using biochemical markers is described in a homogeneous group of patients with Crohn's disease. Bone turnover was studied in 26 patients with long-standing quiescent Crohn's disease and small bowel involvement. Biochemical markers for bone formation (osteocalcin and bone specific alkaline phosphatase) and for bone resorption 
$132 \mid$ Chapter 10

(deoxypyridinoline -and collagen type I C-terminal crosslinks) were measured. Urinary calcium excretion was determined.

Markers for bone formation were significantly lower in patients than in controls (osteocalcin, bone-specific alkaline phosphatase), but both bone resorption markers were not significantly different. Urine calcium excretion was significantly decreased in patients compared to controls. Bone mineral density of the lumbar spine was significantly and inversely correlated with bone-specific alkaline phosphatase and collagen type I C-terminal crosslinks.

From this study we concluded that bone turnover in long-standing Crohn's disease in clinical remission was characterised by suppressed bone formation and normal bone resorption. Furthermore, urine calcium excretion was decreased. Hence, interventions and therapy should be directed towards improvement of bone formation.

In chapter $B$ the baseline data of an European multi-centre intervention study were described. Potential risk factors for low bone mineral density (BMD) and the prevalence of vertebral fractures were studied in 273 patients with ileo-cecal Crohn's disease. Steroid-free patients (STF) with currently active CD and steroiddependent patients (STD) with quiescent CD were investigated with DXA scan of the lumbar spine and standardized lateral $X$-ray of the thoracic and lumbar spine.

Thirty-seven asymptomatic vertebral fractures were seen in 24 out of 182 STF patients $(13.4 \%)$, and 19 fractures in 14 out of 91 STD patients $(15.6 \%)$. The average T-score and Z-score of patients with fractures were not significantly different from those without fractures. Fifty-four percent of patients with fractures had a normal T-score. BMD and Z-scores were negatively correlated to lifetime steroids, but not to previous bowel resection, current disease activity, or prevalence of vertebral fractures. Fracture rate was not correlated with BMD, Z-score, or lifetime steroid dose.

From this study we concluded that he lack of correlation between BMD, Z-score, or lifetime steroid dose on the one hand and the prevalence of fractures on the other necessitates new lhypotheses for the pathogenesis of the latter. The inflammatory process might cause architectural changes in the trabecular bone leading to bone fragility, or vertebral fractures might be another extra-intestinal manifestation of Crohn's disease.

In chapter 9, the results of above mentioned studies were discussed in the context of current literature. An opinion is given on potential future developments. 


\section{Samenvatting}





\section{Samenvatting}

Dilt proefschrift beschrijft de epidemiologie, pathofysiologische aspecten, als wel klinische aspecten van osteoporose en/af metabole botziekten die optreden bij chronische inflammatoire darmziekten (IBD), met name bij de ziekte van crohn. In alle onderzoeken die in dit proefschrift beschreven worden, is de botdichtheid van de lumbale wervelkolom, femurhals en het totale lichaam gemeten met behulp van dual-energy $X$-ray absorptiometry (DXA).

In hoofdstuk $\mathbf{2}$ wordt een overzicht gegeven van de literatuur en wordt de huidige kennis omtrent het verband tussen $I B D$ en metabole botziekten beschreven.

in hoofdstuk 3 wordt de prevalentie getoond van osteopenie en osteoporose evenals de prevalentie van symptomatische fracturen bij een goed gedefinieerde en op populatiegegevens gebaseerde groep patiënten met de ziekte van Crohn. De patiënten zijn geselecteerd uit de registratie van IBD patiënten (IBD Zuid-Limburg). In totaal werden er 119 patiënten met een gemiddelde leeftijd van 42 jaar onderzocht. Osteopenie van de lumbale wervelkolom en/of van de femurhals werd bij $45 \%$ van de patiënten gevonden. Osteoporose werd bij $13 \%$ van de patienten vastgesteld. De gemiddelde botdichtheid van de femurhals was significant lager dan die van de lumbale wervelkolom. Mannelijke patiënten en patiënten waarbij de ziekte van Crohn voor het achttiende levensjaar werd vastgesteld hadden een hoger risico op een verlaagde botdichtheid van de lumbale wervelkolom en het totale lichaam. De prevalentie van osteoporose in post-menopauzale vrouwen met de ziekte van Crohn (29\%) was significant hoger dan die in pre-menopauzale patiënten ( $3 \%$, relatief risico 12). Negenentwintig van de 119 (24\%) patiënten hadden symptomatische fracturen in de voorgeschiedenis. Concluderend wordt gesteld dat osteopenie en osteoporose frequent voorkomen bij de ziekte van Crohn en dat preventie en behandeling van deze complicatie de aandacht van de behandelend arts behoeven.

In hoofdstuk 4 worden de klinische determinanten van de botmineraaldichtheid beschreven in een populatie gebaseerd cohort van patienten met de ziekte van Crohn. Er worden veel verschillende potentiéle risicofactoren voor het krijgen van een lage botmassa onderzocht, zoals algemene en voor de ziekte specifieke risicofactoren. Lineaire regressie analyse toonde aan dat zowel lichaamsgewicht als het vrouwelijke geslacht significante positieve determinanten van botmineraaldichtheid zijn en dat leeftijd zowel als het gecombineerd gebruik van corticosteroiden en azathioprine als negatieve determinanten zijn gevonden. Bij vrouwelijke Crohn patiënten waren lichaamsgewicht en het gebruilk van azathioprine positieve determinanten. De postmenopauzale status en het gebruik van prednisolon, het gecombineerde gebruik van prednisolon en azathioprine en de serum magnesiumspiegel waren negatieve determinanten. Bij mannen waren 
de serum calciumspiegel en het lichaamsgewicht significante positieve determinanten en de leeftijd een negatieve determinant van de botmineraaldichtheid. Uit dit onderzoek worden de volgende conclusies getrokken. Patiënten met de ziekte van Crohn die met name een verhoogd risico hebben op de aanwezigheid van een lage botmineraaldichtheid zijn: mannelijke en postmenopauzale vrouwelijke patienten die een laag lichaamsgewicht en een voorgeschiedenis met een gecombineerd gebruik van zowel prednisollon als azathioprine, nomale of hoge serum magnesium-spiegels en een lage serum calciumspiegel hebben. De lage correlatie die wordt gevonden tussen de som van alle risicofactoren en de gemeten botmineraaldichtheid in het lineaire regressiemodel laat zien dat de klinische risicofactoren een onvoldoende voorspellende waarde hebben om de DXA-meting te vervangen bij patiënten met de ziekte van Crohn.

In hoofdstuk 5 is een onderzoek beschreven waarbij wordt onderzocht of de botmineraaldichtheid bij patienten met IBD reeds verlaagd is bij het stellen van de diagnose. De botmineraaldichtheid van patiënten die recent zijn gediagnostiseerd met de ziekte wan Crohn of colitis ulcerosa worden vergeleken met op leeftijd en geslacht uitgekozen controle personen uit dezelfde populatie (case-control).

Er werden geen significante verschillen tussen patiënten en gezonde controle personen gevonden. Ook werden er geen verschillen gevonden in botmineraaldichtheid tussen patiênten met de ziekte van Crohn en colitis ulcerosa indien het leeftijdswerschill tussen beide groepen werd gecorrigeerd door gebruik te maken van de Z-score. Multipele lineaire regressie analyse toonde aan dat de aanwezigheid van bij IBD passende buikklachten, die langer dan 6 maanden voor het stellen wan de diagnose aanwezig waren, de leeftijd en een body mass index (BMI = gewicht / lengte ${ }^{2}$ ) lager dan $20 \mathrm{~kg} / \mathrm{m}^{2}$, significante determinanten waren voor een lage botmineraaldichtheid.

Uit dit onderzoek concludeerden we dat de botmineraaldichtheid van patiënten waarbij recentelijk de diagnose IBD gesteld werd, niet lager was dan van op leeftijd en geslacht gecontroleerde controle personen. Het ontstaan van osteoporose bij IBD patiēnten moet daarom een verschijnsel zijn, dat gerelateerd is aan het ziekteproces en/of de behandeling van de ziekte.

In hoodstuk 6 wordt de vitamine K status van het serum en het bot beschreven bij een groep patiënten met langbestaande ziekte van Crohn in remissie. Langbestaande ziekte van Crohn is geassocieerd met een deficiẻntie van vet oplosbare vitamines, waarvan vitamine $K$ er één is. Vitamine $K$ is een co-factor die noodzakelijk is voor de carboxylering van osteocalcine, een eiwit dat essentieel is bij de binding van calcium in het bot. Een hoge spiegel van ondergecarboxyleerd osteocalcine is een zeer gevoeligle maat voor vitamine $K$ deficiéntie. De botmineraallidichtheid werd gemeten bij 32 patiënten. Bij alle patiënten was de dunne-darm in het ziekteproces betrokken en de meeste patiënten hadden één of meerdere dunne-darmresecties ondergaan. Alle patiënten waren in remissie en gebruikten minder dan $5 \mathrm{mg}$ prednisolon per dag. Serum spiegels van vitamine D, $K$ en van triglyceriden, het total immunoreactieve osteocalcine en het ondergecarboxyleerd osteocalcine ("vrije osteocalcine") werden gemeten. Ook 
werd de capaciteit om hydroxyapatiet te binden berekend. De gevonden waarden werden vergeleken met een naar leeftijd en geslacht gematchte controle groep. Serum vitamine $K$ spiegels van de patiënten met de ziekte van Crohn waren significant lager dan die van de gezonde controles. Het "vrije" osteocalcine was hoger en de hydroxyapatiet bindingscapaciteit van het circulerende osteocalcine was lager dan in gematchte controles, hetgeen eem lage vitamine $K$ status bij de patiënten met de ziekte van Crohn indiceert. Bij patiênten werd een inverse correlatie gevonden tussen de serumspiegels van het "vrije" osteocalcine en de botmineraaldichtheid van de lumbale wervelkolom en tussen het "vrije" osteocalcine en de Z-score van de lumbale wervelkolom. Multipele lineaire regressie analyse toonde aan dat het "vrije" osteocalcine een onafhankelijke risicofactor is voor een lage botmineraaldichtheid van de lumbale wervelkolom. Voor de serum vitamine D-spiegel werd dit niet gevonden.

Uit de gegevens van dit onderzoek concludeerden we dat een vitamine $k$ deficientie in serum en bot en de associatie met de botmineraaldichtheid van de lumbale wervelkolom implicaties zouden kunnen hebben voor de preventie en de behandeling van osteoporose bij de ziekte van Crohn.

In hoofdstuk 7 wordt het pathofysiologische proces van de botombouw beschreven van een homogene groep van patiënten met de ziekte van Crohn. Er werd gebruik gemaakt van meerdere biochemische merkstoffen.

Botombouw werd onderzocht bij 26 patiënten met een langdurig bestaande ziekte van Crohn en een ziekte lokalisatie in de dunne darm. De volgende biochemische merkstoffen van botombouw werden hierbij bepaald: voor botaanmaak (= formatie) osteocalcine en bot specifieke alkalische fosfatase en voor botafbraak (= resorptie) deoxypyridinoline en collageen type / C-terminale crosslinks. Tevens werd de calcium-excretie in de urine bepaald.

Merkstoffen voor botaanmaak waren significant lager bij patiënten met de ziekte van Crohn vergeleken met controlepersonen. Merkstoffen voor botresorptie waren echter niet verschillend ten opzichte van controlepersonen. De calcium excretie was significant lager bij patiënten vergeleken met de controlepersonen. De botmineralal-dichtheid van de lumbale wervelkolom was bij patienten ongekeerd en significant gecorreleerd met het bot specifieke alkalische fosfatase en collageen type IC-terminale crosslinks.

Uit dit onderzoek werden de volgende conclusies getrokken: botombouw bij langdurige bestaande ziekte van Crohn in remissie kenmerkt zich door een verminderde botaanmaak en een normale botafbraak. De calcium-uitscheiding bij deze patiënten was verlaagd. Interventies en therapieën moeten erop gericht zijn om de botaanmaak te verbeteren.

In hoofdstuk $\mathbf{8}$ worden de demografische gegevens, bij de aanvang vastgesteld, van een groot Europees multi-center interventie onderzoek beschreven.

Botmineraaldichtheid, potentiele risicofactoren voor het hebben van een lage botdichtheid en de aanwezigheid van wervelfracturen werden bestudeerd in een groep van 273 patiënten met ileo-coecal gelokaliseerde ziekte van Crohn.

Patiënten die geen steroiden gebruikten met een actieve ziekte en steroildenafhankelijke patiẻnten in een rustige fase van de ziekte van Crohn werden 
onderzocht met behulp van een DXA en een gestandaardiseerde röntgenfoto van de thoracale en lumbale wervelkolom.

Er werden zevenendertig asymptomatische wervelfracturen gevonden bij 24 van de 179 patiënten zonder steroïden (13:4\%) en 19 fracturen bij 14 van de 90 steroiden afhankelijke patiènten (15.6\%). De gemiddelde $T$. en Z-score van patienten met fracturen was niet significant verschillend ten opzichte van diegenen zonder fracturen. Vierenviftig procent van de patiénten met wervelfracturen had een normale T-score. Botmineraaldichtheid en Z-score waren negatief gecorreleerd met de cumulatieve doses steroiden die een patiënt tijdens zijn leven gebruikt heeft. Er was geen correlatie tussen de botmineraaldichtheid en vroegere darmresectie, actuele ziekteactiviteit, of de prevalentie van wervelfracturen.

Fracturen waren niet gecorreleerd met botmineraaldichtheid, Z-score of de cumulatieve dosering steroïden.

Uit dit onderzoek concludeerden wij dat het ontbreken van de correlatie tussen botmineraaldichtheid, Z-score en de cumulatieve dosering steroiden die een patiënt tijdens zijn leven gebruikt heeft en de hoge prevalentie van fracturen, de noodzaak aantoont om nieuwe hypothesen op te stellen voor de pathogenese van de fracturen. Ofwel het ontstekingsproces zelf veroorzaakt mogelijk microarchitecturale veranderingen in het bot thetgeen leidt tot een verminderde botsterkte, of wervelfracturen zijn een extra-intestinale complicatie van de ziekte van Crohn.

In hoofdstuk 9 worden de resultaten van bovenbeschreven onderzoeken besproken in de context van de huidige literatuur. Tenslotte wordt tevens een opinie gegeven over mogelijk toekomstige ontwikkelingen. 


\section{Metabole botziekten bij chronische inflammatoire darmziekten}




\section{Samenvatting}

Ostegporose is eer bekende complicatie bil patenten met een ohroniseh nnammatoire darmziekte (Inflammatony Bowel disease, $1 \mathrm{BD}$, De gerapponterde prevalentie is afhankelik wan de selectie van patenten. wan de meetme thoden en van de dethities van verlaagde botmassa die gebrukl 2 in in het hetreffende onderoek De pathogenese van botwelles

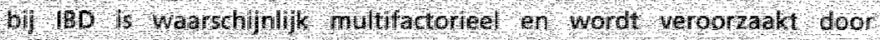
malnurrte, nalabsorptie met wtamine $\mathrm{Qten}$ callium deficentie, thypogronadismo, roken, ziekteacilitelt en hel gebruilk yan conticosterotom

Hicen aental ondarzoeken is de botm nerabldichtheld (BMDJbi) patienten

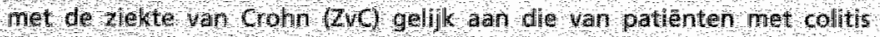
Ulerosa (CU), maar anderen vinden een lage botdhohtheid alleen bij de

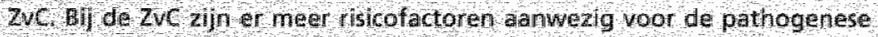
van osteopente dan by CU, waar het in hiet alghemenen het gebrutk van rortiosterolden als belangurikste factor wordt beschouwd wet behulp wan bionemische pherkstoffen word en vertoorde botombouw Beschreven door een verminderde botaanmala, verlioogde afbraak, of beide, afhankellk var de selectie van de pathenten, Recentelikk is de eerste serie beschreven van wervelfracturen bi k hideren met de ZuG De drempel tot het meter wan de botdichtheid aroul bi] pat enten met $1 \mathrm{BD}$ laag moeten Ulin Er 2 in lechts enkele onderzogken over preventie en beliandeling van osteoporose bil BD beschkbaar 


\section{De prevalentie van osteoporose bij IBD}

De associatie tussen osteoporose en chronisch inflammatoire darmziekten (Inflammatory Bowel Disease, IBD) werd voor het eerst beschreven in 1964: Osteoporose werd in die tijd gediagnosticeerd met relatief onnauwkeurige methoden zoals radiologische tekenen van verminderde botdichtheid en de aanwezigheid wan fracturen. Osteopenie en groeiretardatie bij adolescenten met IBD werd beschreven door Genant in $1976^{*}$.

Sinds 1987 zijn er verschillende onderzoeken gepubliceerd over de prevalentie van osteoporose en osteopenie bij IBD ${ }^{3.10}$. Met name sinds de introductie van dual energy X-ray absorptiometry (DEXA) is het aantal onderzoeken toegenomen. De gerapporteerde prevalentie van verminderde botmassa varieert zeer sterk van 4.4 tot $77 \%$, en is hoger bij de ZVC dan bij CU. Er is geen algemeen gebruikte definitie van osteoporose uitgedrukt in Z-score (één standaard deviatie ten opzichte van een leeftijd en geslacht gematchte controle groep) en daardoor kan het vergelijken van de bestaande gegevens over de prevalentie vam osteoporose bij IBD nogal verwarrend zljn. Ondanks het gebrek aan uniformiteit van de aanwezige onderzoeken lijkt het duidelijk dat er een hoge prevalentie is van osteoporose en osteopenie bij IBD. Opvallend genoeg hebben mannen een hoger risico op botverlies dan vrouwen en is de botmassa van de heup in het algemeen lager dan die van de lumbale wervelkolom. Zoals in de gezonde populatie neemt ook bij IBD de kans op osteoporose significant toe na de menopauze.

De prevalentie van fracturen Bij IBD is vastgesteld in vijf onderzoeken. In een studie van Compston hadden 6 van de 23 patiènten met osteoporose (26\%) (in dit geval gedefinieerd als een $z$-score $<-2$ ) radiologisch aarwijzingen van een of meer vertebrale compressie fracturen'. In twee andere onderzoeken werden 5 en $7 \%$ van de patiexinten wervelfracturen gevonden ${ }^{3,7}$. Jahnsen vond $3.3 \%$ symptomatische fracturen bij de ZvC en $1.6 \%$ bij $\mathrm{CU}^{\prime \prime}$. Recentelijk werd een onderzoek gepubliceerd waarbij de prevalentie van symptomatische fracturen bij patienten met IBD en controles werd onderzocht met behulp van een enquête. Het aantal fracturen bij vrouwen met de $Z$ WC was verhoogd ten opzichte van controles (relatief risico 2.5 ), maar er werd geen verschil gevonden bij mannen niet de $Z V C$ noch tussen CU patiënten en controles ${ }^{92}$.

\section{De pathofysiologie van botverlies bij IBD}

Bot is een levend argaan waarin er een constante cyclus van botafbraak door osteoclasten en botaanmaak door osteoblasten aanwezig is. Een verminderde botaanmaak, een verhoogde afbraak, of beide kan botverlies veroorzaken. Deze onbalans kan leiden tot osteopenie en osteoporose. Voor het stellen van de diagnose osteomalacie is een botbiopsie noodzakelijk waarbij omgemineraliseerde botmatrix of osteoid wordt gevonden. 


\section{Histomorfometrie}

De histomorfometrische veranderingen zaals die in het bot van 19 osteoporotische patienten met BDD werden gevonden, toonden een verminderde botaanmaak. Tevens waren er aanwijzingen voor een mild mineralisatiedefect, die echter niet voldeden aan de criteria die gelden voor osteomalacie ${ }^{13}$. Bij 36 ongeselecteerde patienten met de $Z v C$ en dunne-darm resecties, werd een verlaagde trabeculaire botmassa gevonden. Er waren slechts aanwijzingen voor osteomalacie bij 2 patienten in dit onderzoek ${ }^{1 / 4}$. Een onderzoek met patiënten na een dunne darmresectie (voornamelijk patiënten met de ZvC) toonde bij 9 van de 25 veranderingen in het bot passend bij osteomalacie. Bij 9 patienten, geselecteerd als hoog risicopatient voor een metabole botziekte, was er osteomalacie bij 6 en bijkomende osteopenie bij 4 patiënten ${ }^{15}$.

\section{Biochemische merkstoffen}

Osteoblast and osteoclast functies kunnen worden gemeten door middel van biochemische merkstoffen ${ }^{16}$. Deze biochemische merkstoffen geven informatie over de botombouw die plaatsvindt in het gehele skelet. Ze zijn echter niet geschikt om de actuele botmassa te voorspellen". Met behulp van deze merkstofen, vinden sommige onderzoeken een verhoogde botafbraak ${ }^{A, 38,19}$, verminderde botaanmaak ${ }^{20}$, of beide ${ }^{20,22}$. In een aantal onderzoeken wordt geen verschil gevonden met controles $^{2325}$. De verschillen in de uitkomst van deze onderzoeken kan voor een deel worden verklaard door verschillen in patiënten selectie, ziekteactiviteit, gebruik van corticosteroïden en het includeren van post-menopauzale vrouwen ${ }^{3,4,432,25}$. In een vergelijkend onderzoek naar de effecten van prednisolon en budesonide CIR ("controlled ileal release") bij actieve ZVC op osteoblastfunctie, gemeten met serum asteocalcine, werd een suppressie van het osteocalcine gezien door $40 \mathrm{mg}$ prednisolon. Bij een equivalente dosering van $9 \mathrm{mg}$ budesonide $\mathrm{CIR}$ trad dit fenomeen niet $o p^{20}$. Er werd geen verschil gevonden in botafbraak gemeten met behulp van urine pyridinoline en deoxypyridinoline. Rectaal toegediende prednisolon (2 maal daags $20 \mathrm{mg}$ ) veroorzaakte een suppressie van de botaanmaak bij patienten met een distale $\mathrm{Cu}^{37}$. Een longitudinaal onderzoek over 2 jaar bij 36 patienten toonde dat het $N$-telopeptide cross-linked type-l collageen een voorspellende waarde heeft ten aanzien van het botverlies van de lumbale wervelkolom ${ }^{2}$. Een ander longitudinaal onderzoek vond geen voorspellende waarde van biochemische merkstoffen op het botverlies in 80 IBD patiënten ${ }^{29}$.

\section{Risicofactoren voor osteoporose bij IBD}

Risicofactoren die bijdragen aan het ontstaan van een lage botmassa bij IBD zijn in het algemeen niet verschillend van risicofactoren bij andere aandoeningen die leiden tot secundaire osteoporose. Er zijn echter een aantall specifieke risicofactoren, die gerelateerd zijn aan de onderliggende ziekte en de behandeling daarvan. De belangrijkste risicofactoren zijn schematisch weergegeven in Figuur 12.1. 


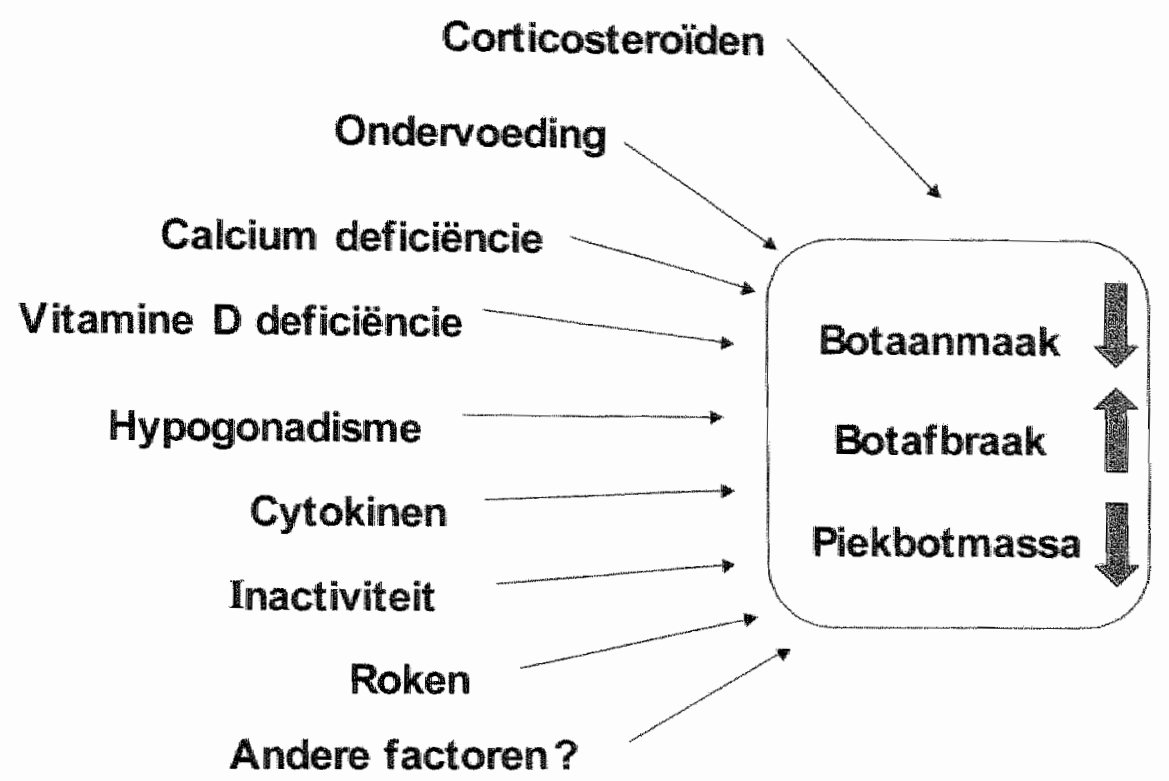

Figure 12.1 Schematisch overzicht van risicofactoren die een rol spelen bij de pathogenese van osteoporose bij IBD.

\section{Corticosteroïden}

Behandeling met corticosteroilden is in het algemeen de belangrijkste oorzaak van secundaire osteoporose. Corticosteroïden zijn effectief in de behandeling van actieve IBD, maar er zijn bij deze ziekten ook nadelige effecten op het bot. Corticosteroiden veroorzaken een negatieve calcium balans door verminderde resorptie van calcium uit de darm, verminderde vitamine $\mathrm{D}$ resorptie, verhogen de renale calcium excretie en veroorzaken suppressie van de geslachtshormoonproductie ${ }^{29.30}$. Tevens hebben ze een supprimerend effect op de botaanmaak en veroorzaken ze een toename van de botafbraak.

In een aantal onderzoeken wordt een negatief effect van corticosteroiden op de botdichtheid van IBD patienten gerapporteerd ${ }^{3,5,7,10,1 \%}$, analoog aan het effect van corticosteroilden bij andere chronische ziekten". Bij de meerderheid van deze onderzoeken wordt deze hypothese ondersteund, maar zijin er ook tegenstrijdige gegevens. Bjarnasson vond in een populatie gebaseerd onderzoek geen correlatie tussen de BMD en het corticosteroid gebruik. Een magelijke verklaring voor deze bevinding is het uitsluiten van groepen met een hoog risico: patienten die recentelijk (6 weken voor de DXA) nog $10 \mathrm{mg}$ per dag of meer gebruikten, patiënten met een cumulatieve dosering van meer dan 25 gram en postmenopauzale vrouwen. In een populatie gebaseerd onderzoek van silvennoinen werd een lage prevalentie van osteoporose gevonden ${ }^{q}$. De onderzoekers wonden wel een significante correlatie met de cumulatieve hoeveelheid corticosteroilden. In een gecontroleerd onderzoek van de BMD bij 60 patiénten met de ZVC, 60 met CU en 60 gezonde controle personen was de BMD significant lager bij patiënten met 
de ZVC dan bij CU en controles. De cumulatieve hoeveetheid corticosteroiden bij patienten met de ZvC was in dit onderzoek significant hoger". Resecties, lokalisatie en duur van de ziekte hadden geen significante invloed op de BMD. In een multivariate analyse werden body mass index en het gebruik van steroiden als belangrijkste determinanten gevonden van BMD bij de ZVC. In een longitudinaal 2 jaar durend onderzoek bij kinderen met CD werd geen verschill gevonden in BMD/ body mass (index) ratio tussen patiennten met het gebruik van lage dosis prednison om de dag, in vergelijking met patienten zonder sterölen ${ }^{32}$.

\section{Ziekteactiviteit}

Verondersteld wordt dat ziekteactiviteit zelf een belangrijke rol speelt bij de ontwikkeling van metabole botziekten bij IBD, met name bij de ZVC. Reeds bij het. stellen van de diagnose bij patiênten die nooit met corticosteroïden zijn behandeld kan een significant verlaagde botmassa gevonden worden in vergelijking met patiënten met $\mathrm{CU}^{6}$. Het is aangetoond dat cytokinen een direct effect kunnen uitoefenen op botaanmaak en botafbraak doordat zij de osteoblast- en osteoclastfuncties kunnen beïnloeden. Met name pro-inflammatoire cytokinen zoals TNF, IL-1 en IL-6 worden verondersteld hier een centrale roll in te vervullen ${ }^{33,34}$. Deze cytokinen spelen een ook belangrijke rol in het ontstekingsproces bij IBD $^{35}$.

In een proefdierexperiment, waarbij ratten geinjecteerd werden met serum van jeugdige patiënten met de ZvC, bleek dat er een sterk verminderd droog botgewicht en verminderde hoeveetheid calcium werd gevonden in vergelijking met de botten van ratten geïnjecteerd met serum van controles of CU patiënten ${ }^{35}$. De exacte factoren die van belang zijn voor dit fenomeen worden verder onderzocht ${ }^{37}$.

\section{Roken}

Slechts één onderzoek heeft het effect van roken op de botmassa bij IBD beschreven $^{39}$. Er werd een significant negatief effect van roken gevonden, met name bij vrouwelijke patienten. Bij mannen werd geen effect van roken op de botmassa gevonden, dit was echter niet verwonderlijk omdat vrijwel alle mannen in dit onderzoek rookten.

\section{Hypogonadisme}

Hoevel het bekend is dat corticosteroilden de productie van geslachthormoon onderdrukken, werden bij mannelijke patiënten met de ZwC lage testosteronsplegels gevonden als onafhankelijke risicofactor voor een lage botmassa. In dit onderzoek werd er een significante correlatie gevonden tussen de serum testosteron en osteocalcine spiegels. Deze correlatie was onafhankelijk van de leeftijd en het actuele gebruik van corticosteroïden ${ }^{39}$. Bij vrouwelijke patiënten kan een secundaire amenorroe optreden bij het gebruik van hoge doses steroïden. Als de oestrogeen protectie na de menopauze stopt, neemt de botresorptie en daarmee de snelheid van het botverlies toe, met name in de eerste jaren. 


\section{Lichaamsgewicht}

Een laag lichaamsgewicht is een risicofactor voor osteoporose in het algemeen. Bij de ZvC kan dit met name optreden door malnutritie, anorexie en door malabsorptie als gevolg van ziekteactiviteit in de dunne-darm en/of na resecties van dunne-darm met het extreme geval van een "short-bowel"syndroom. Meerdere onderzoeken bij IBD hebben aangetoond dat patiënten met een laag lichaamsgewicht of lage body mass index $\left(\mathrm{kg} / \mathrm{m}^{2}\right)$ een grotere $\mathrm{kans}$ hebben op een lage botmassa ${ }^{40,4 !}$.

\section{Vitamine $D$ deficiëntie}

Er is een hoge prevalentie van vitamine D deficièntie bij patienten met de ZvC. De oorzaken zijn dunne-darmziekte, diarree, vetarm dieet, resecties en het gebruik van medicatie zoals cholestyramine. Dit kan leiden tot een verminderde calcium absorptie en veroorzaakt een negatieve calcium balans. Vitamine $D$ status wordt gemeten door middel van de serumspiegel van het 25 -hydroxy vitamine $D$, hetgeen de vitamine D status in het lichaam weergeeft. Ofschoon 25 -OH vitamine D spiegels. laag waren bij $56 \%$ van de ZvC patiënten in een populatie gecontroleerd onderzoek, was de actieve metaboliet, het 1,25-hydroxy vitamine $D$ niet verschillend van controles ${ }^{41,12}$. Uit dit onderzoek bleek de vitamine $D$ status onathankelijk van voedingstatus, ziektelocalisatie en voorafgaande resecties.

Door vitamine $\mathrm{D}$ deficiëntie kan osteomalacie ontstaan. Als gevolg van hypocalciaemie kunnen, in ernstige gevallen, botpijnen, botdeformaties bij kinderen, fracturen, spierzwakte en tetanie optreden. Er zijn typische radiologische veranderingen van het bot beschreven. Bij biochemische afwijkingen zoals een verhoogd parathyroid hormoon, een verhoogd (botspecifiek) alkalische fosfatase en hele lage 25-hydroxy vitamine D spiegels $(<10 \mathrm{nmol} / \mathrm{l})$ zou er sprake kunnen zijn van osteomalacie en kan een botbiopsie worden overwogen. DEXA kan niet. differentiëren tussen osteoporose en osteomallacie. Klinische symptomen van osteomalacie zijn echter zeer zeldzaam bij 1 BD $^{15}$. In een onderzoek waarbij de relatie tussen vitamine $\mathrm{D}$, PTH en BMD bij IBD werd onderzocht, toonden IBD patienten lagere vitamine D spiegels dan gezonde controle personen. Vitamine D intake en PTH spiegells waren niet verschillend ${ }^{4 i}$. Zowel serum vitamine $D$ als vitamine D-inname en PTH waren niet geassocieerd met BMD.

\section{Ziekteduur}

In longitudinale onderzoeken bij IBD patienten werd een verschillende mate wan jaarlijks botverlies gezien. Motley beschreef de mate van BMD verlies in een jaar van de ruggenwervels met behulp van kwantitatieve computer tomografie (QCT) in 70 IBD patienten ${ }^{4 .}$. Hij vond een gemiddeld verlies van $3 \%$ per jaar. BMD van de radius werd vervolgd bij 39 IBD patiënten, met een gemiddelde follow-up van ongeveer 8 jaar ${ }^{45}$. Het gemiddelde botverlies bedroeg minder dan $1 \%$ per jaar bif zowel mannen als vrouwer. In een kleiner onderzoek met 23 IBD patiënten met 1 jaar follow-up werd met behulp van DXA geen verschil gevonden, ondanks corticosteroid gebruik in 20 van deze patiënten ${ }^{6}$. Roux bestudeerde prospectief 35 patiënten met IBD met behulp van DXA gedurende een gemiddelde follow-Lip 
periode van 19 maanden en werd een gemiddeld jaarlijks verlies van $6.2 \%$ and $0.9 \%$ gevonden, respectievelijk bij patiẻnten met en zonder het gebruik van steroiden, hetgeen significant verschillend was. Na colectomie bij patiênten met cu trad conform de verwachting geen botverlies meer op. Een ander longitudinaal onderzoek bij 109 ZvC patiënten en een gemiddelde follow-up van 5.5 jaar, liet slechts botverlies zien in de femurhals, die niet gerelateerd was aan corticosteroid gebruik, de duur van de ziekte, of de lengte van het gereserceerde dunne-darm segment ${ }^{46}$. Schulte beschrift een laag gemiddeld verlies van BMD (maximaal $-1.1 \%$ ter hoogte van de Wards triangle) in een follow-up wan gemiddeld 18 maanden, maar met een groot verschil tussen patiënten onderling ${ }^{2}$.

\section{Jeugdige patiënten}

Jeugdige patiënten met de ZvC hebben een hoger risico op het ontwikkelen van osteoporose dan patienten met $\mathrm{CU}^{47}$. Behandeling met corticosteroiden en vaedingsstatus zijn belangrijke determinanten van BMD bij deze patiënten ${ }^{48}$. Behandeling van de onderliggende ziekte kan resulteren in een aanmerkelijke verbetering in botmineralisatie. Echter veel adolescente IBD patiënten bereiken een lagere piekbotmassa dan gezonde personen. In de normale populatie wordt de piekbotmassa bereikt op een leeftijd tussen 20 en 30 jaar. IBD patienten met het begin van de ziekte op jeugdige leeftijd kunnen, indien er botverllies op gaat treden op latere leeftijd, eerder de fractuurdrempel bereiken.

Recentelijk is de eerste serie beschreven wan vijf pediatrische patiennten met de ZVC en compressiefracturen van de ruggenwervels als complicatie van osteoporose ${ }^{\text {A }}$. Ook zijn wervelfracturen als presenterend symptoom beschreven bij een kind met de $Z v^{5}$

\section{Extra-intestinale ziekte}

Vrouwelijke patiënten met de ZvC gelokaliseerd in het terminale illeum en bijkomende ontsteking van de sacro-iliacale gewrichten hadden een significant lagere botmassa dan patiënten met alleen ileitis terminalis ondanks dat deze laatste controlegroep een langere gemiddelde ziekteduur had ${ }^{51}$. Bif mannen is dit niet onderzocht.

Bijkomende leverziekten, zoals met IBD-geassocieerde primair scleroserende cholangitis (PSC), moeten als een sterke risicofactor voor osteoporose beschouwd worden.

\section{Preventie en behandeling van osteoporose bij IBD}

Behandelingen die het totale botverlies van jaren herstellen zijn niet beschikbaar. Om deze reden zouden er -indien mogelijk-preventieve maatregelen getroffen moeten worden. In het algemeen moet het dieet voldoende calcium en vitamine D bewatten, wordt geadviseerd het roken en excessief gebruik van alcohol te staken en voldoende lichaamsbeweging te nemen. De dagjelijkse hoeveelheid elementair calcium die de voeding moet bevatten is ongeveer $1.200 \mathrm{mg}$ voor adolescenten en volwassenen en $1500 \mathrm{mg}$ voor post-menopauzale vrouwen. 
Er is slechts een zestal onderzoeken over de preventie en behandeling van osteoporose bij IBD beschreven. Botverlies werd in een groep van 75 patienten met de $Z V C$ voorkomen door substitutie met vitamine D (1000 IE) gedurende een Jaar. Bif met placebo behandelde controle patiènten trad een significant botverlies op van mediaan $7 \%$. Een niet gecontroleerd onderzoek toonde dat oestrogeen substitutie effectief is in het voorkomen van botwerlies bij post-menopauzale IBD patienten". Een prospectief gerandomiseerd onderzoek met calcium en lage dosis vitamine $D$ versus placebo in corticosteroid behandelde IBD patiënten kon geen verschil aantonen na een jaar behandeling ${ }^{54}$. Recentelijk werd er, ondanks het kleine aantal patiënten in het onderzoek, een significant verschil gevonden in BMD verandering tussen de patienten met een chronisch actieve ZvC behandeld met ("slow release") fluoride versus placebo ${ }^{55}$. Alle patiënten in dit onderzoek kregen als basistherapie calcium (1000 $\mathrm{mg} / \mathrm{dag}$ ) en vitamine D (1000 / E/dag). Bij patiènten met de ZvC die gedurende een jaar lichaamsbeweging met lage intensiteit beoefenden en therapietrouw waren, was er een $3-4 \%$ toename in BMD ten opzichte van de uitgangswaarde ${ }^{56}$. Bovengenoemde interventies zijn samengevat in Tabel 12.1.

Tabel 12,1 interventies met geneesmiddelen en lichaamsbevieging ter preventie en behandeling van osteoporose bij chronische inflammatoire darmziekten (BBD).

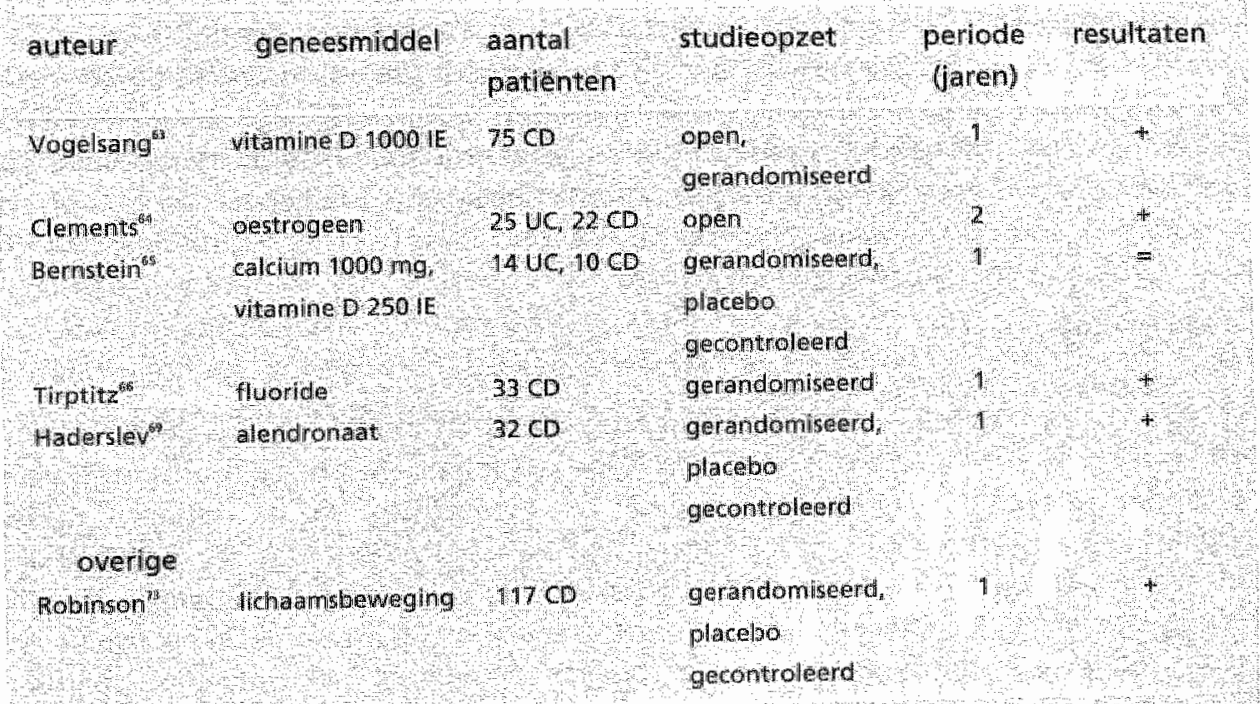

Gebruikmakend van de nu bekende beperkte gegevens zou liedere patiênt dieet advies moeten krijgen ten aanzien van calcium en vitamine D inname: deze zouden gesuppleerd moeten worden in het geval van vitamine $D$ deficientie, het gebruik van corticosteroilden, na uitgebreide resectie van de dunne-darm of bij het chronisch gebruikk van cholestyramine.

Er zijn nog geen onderzoeken gepubliceerd over behandeling met bisfosfonaten bij IBD, behoudens een onderzoek waar alendromaat werd gegeven ter preventie van osteoporose bij met corticosteroïden behandelde patiënten en een diversiteit aan onderliggende ziekten ${ }^{5 *}$. Vijf procent van deze populatie betrof patiënten met 
IBD. Na 48 weken therapie was er in de met 5 en $10 \mathrm{mg}$ alendronaat behandelde patienten groepen een significante toename in BMD. De onderliggende ziekte had geen effect op de respons in de subgroepanalyse, echter deze gegevens worden in het artikel niet verstrekt. De eerste onderzoeken met oraal en intraveneus toegediende bisfosfonaten bij patienten met de ziekte van Crohn zijn recentelijk als abstract verschenen en de resultaten lijken goed.

Op basis van deze gegevens en op basis wan eerder onderzoek bij postmenopauzale en corticosteroilden geinduceerde osteoporose zouden bisfosfonaten kunnen worden overwogen bij ieder IBD patiënt die langdurig met corticosteroiden moet worden behandeld met name degenen die bij de start van de therapie reeds een lage botmassa hebben, fracturen in de voorgeschiedenis, post-menopauzaal zijn, of bij wie de botmassa snel daalt bij opeenvolgende DEXA metingen, of een hoge botturnover met behullp van biochemische merkstoffen geidentificeerd wordt. Preventieve behaindeling bij iedere patiënt is op dit moment echter controversieel omdat er een verschillende individuele gevoelighelid is voor corticosteroilden bij patiënten met IBD. Echter osteoporose (T-score $\leq-2.5)$ van de heup of de lumbale wervelkolom of een laagenergetische fractuur zijn indicaties voor actieve behandeling. Bij osteopenie (T-score tussen -1 tot -2.5 ) zouden tenminste preventieve maatregelen genomen moeten worden. Het resultaat van de interventie moet worden vervolgd met BMD metingen in intervallen van 2-3 jaar. Tegelijkertijd is het van primair belang om de onderliggende ziekte optimaal te behandelen en indien nodig corticosteroïden te geven zo laag en zo kort mogelijk. Bij patiënten die van corticosteroïden afhankelijk zijin moet worden overwogen om steroilden-sparende en geneesmiddelen om recidieven te voorkomen, zoals azathioprine, aan de behandeling toe te voegen.

\section{Bespreking}

Bij IBD is er ondanks de verschillende meetmethoden een definities van osteoporose voldoende bewijs voor een hoge prevalentie en hoge morbiditeit van metabole botziekten zoals osteoporose en osteopenie en in mindere mate osteomalacie. Hierbij moet het gegeven worden betrokken dat de gemiddelde leeftijd van de patiënten in de onderzochte populaties ongeveer 40 jaar is. Er zijn weinig beschikbare gegevens over symptomatische en asymptomatische fracturen en er zijn nog er geen lange termijn onderzoeken naar het optreden daarvan beschikbaar. Bij post-menopauzale vrouwen is er een goede correlatie tussen BMD en het optreden van fracturen, en deze gegevens kunnen misschien geëxtrapoleerd worden naar IBD patiënten ${ }^{\text {s. }}$.

Als methode van screenen voor een lage BMD, werd de relatie tussen de huidplooidikte van de hand en gesuggereerd bij patienten met de ZvC $C^{59}$. De gemiddelde huidplooidikte van de hand was significant lager bij patiënten met osteoporose in vergelijking met controle $Z$ VC patiënten met een normale botmassia, echter de associatie was niet sterk genoeg om deze methode voor selectie van patiënten aan te bevelen. 
Breedband ultrageluid metingen van de calcaneus bij een grote groep ZvC patiënten en leeftijd-en geslacht-gematchte gezonde controles toonde minder verzwakking van het ultrageluid in de patientengroep. Er was een significante associatie tussen de ultrageluid metingen en de BMD van de heup en wervelkolom, maar ook deze correlatie leek onvoldoende ${ }^{6 i}$. Een ander onderzoek met ultrageluid toonde met name een goed correlatie met de DEXA metingen van de lumballe wervelkolom, hoewel de botdichtheid onderschat werd bij vrouwelijke patienten met de ZvC $C^{6}$. Het belang van ultrageluid als methode van screenen bij IBD in de dagelijkse praktijk en de voorspellende waarde ten aanzien van het optreden van fracturen moet nog nader worden bepaald.

Tegenstrijdige uitkomsten van de effecten van corticosteroiden op het bot kunnen verklaard warden door de vele verschillende factoren die bijdragen aan het botverlies, de heterogene populaties die zijn onderzocht, de individuele gevoeligheid voor de nadelige effecten van conticosteroiden de relatief onnauwkeurige retrospectieve berekening van cumulatief gegeven medicatie en tevens de ziekteactviteit als confounder. Patiënten met IBD worden vaak initieel behandeld met hoge doses corticosteroüden die daarna zo snel mogelijk worden afgebouwd, met als doel een remissie te bereiken. Bij het gebruik van corticosteroiden treedt het meeste botverlies op in de eerste drie maanden van de behandeling en is er mogelijk een reversibele component na het stoppen van de therapie. Controle van de ziekteactiviteit met daarvoor geschikte middelen zou een verbetering van de botmineralisatie kunnen bewerkstelligen.

Er is behoefte aan meer kennis over de belangrijkste risicofactoren en hun interacties. Deze gegevens kunnen verkregen worden door grote, bij voorkeur op populatie gebaseerde onderzoeken. In deze context is van belang om te weten of locaal werkende steroilden zoals budesonide een minder negatief effect hebben op bot dan prednisolon. Dit laatste word op dit moment onderzocht in een groot gerandomiseerd Europees onderzoek.

Omdat een lage botdichtheid bij ZvC reeds bij het stellen van de diagnose bij kan worden gevonden, er een hogere prevalentie en er een ander risicoprofiel is dan bij CU, moeten deze ziekten als een aparte entiteit worden beschouwd in het onderzoek, preventie en behandeling van osteoporose bij IBD.

Omdat patienten met $I B D$ een verhoogd risico hebben op osteoporose, zou de BMD moeten worden vervolgd om patienten te identificeren die behandeling behoeven, or interventies te monitoren die bedoeld zijn om botverlies te voorkomen dan wel osteoporose te behandelen. Echter het hebben van een of meerdere doorgemaakte fracturen is een sterke risicofactor voor een toekomstige fractuur en moet beschouwd worden als een indicatie voor behandeling onafhankelijk van BMD. In het geval dat de mogelijkheid niet aanwezig is om botdichtheid te meten zou de patient voor behandeling geselecteerd moeten worden op basis van sterke risicofactoren zoals behandeling met corticosteroiden, hypogonadisme en malnutritie 6 .

Alle patiënten met de ZVC moeten dieetadvies krijgen ten aanzien van calcium en vitamine $D$ inname. Vitamine $D$ deficiëntie moet worden gecorrigeerd, zonodig preventief worden gesuppleerd. Een eventueel tekort aan geslachtshormoon moet worden gesuppleerd. Lïchaambeweging moet worden gestimuleerd. 


\section{Literatuur}

1 Edwards F, Truelowes. The course and prognosis of ulcerative colitis. Giut 1964; 5: 1-22.

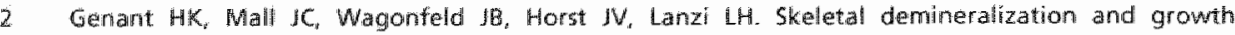
retardation in inflammatory bowel disfase. Invest Radiol 1976; 11:541-5;49.

Abitbol V, Roux C. Chausade S. Guillemant 5 , Kolta 5, Dougados M et al. Metabolic bone assesment in patfents with inflammatory bowel disease. Gastroenterology $1995 ; 108 ; 417-422$. Bjarnason I, Macpherson A, Mackintosh C, Buxton-Thomas M, Forgacs 1, Moniz C. Reduced bone density in patients with inthammatory bowel disease. Gut 1997; 40:228-233.

5 Compston JE Judd D, Crawley EO, Ewans WD. Evans C, Church HA al asteoporosis in patients with inflammatory bowel disease. Gut 1987, 28:410-49.15.

Ghosh 5, Cowen S, Hannar WJ, Ferguson A. Low bone mineral density in Crohm's disease, but not in wicerative colitis, at diagnosis. Gastroenterology 1994; 107:1031-1039

Pigot F, Rouk C, Chassade 5 . Hardelin D. Pelleter 0 , Du-Puy MT et al. Low bone mineral density in patients with imflammatory bowel disease. Dig Dis $5 c i$ 1992; 37:1396-1403.

\$ Pollak RD, Karmeli F, Elialkim R, Ackeman Z, Tabb K, Rachmilewitz D. Femoral neck osteopenia in patients with inflammatory bowel disease. Am. J. Gastroenterol 1998; 931483-1490

9 Silwennoinen JA, Kartunen TJ, Niemeha SE, Manelius IH, Lehtala JK. A controlled study of bone mineral density in patients with inflammatory bowel disease. Gut 1995; 37:71-76.

10 Tromm $A$, Pickels $K_{x}$ Huppe $D_{t}$ Wiebe $W$, May $B$. Osteopenie bei chronisch entzundichen Darmerkrankungen, Ergebnisse einer Querschnittsuntersuchung mittels quantitativer Computertomographie. Lelber Magen Darm 1994; 24: 23-30.

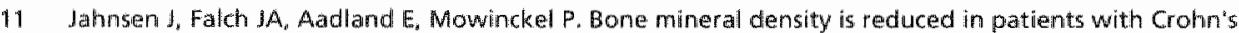
disease but not in patients whth ulcerative colits: a popullation based study. Gut 1997; 40:313 319.

\#2 Vestergaard $P$, Krogh $K_{n}$ Rejnmark L, Laurberg 5 , Moselkillde L. Fracture risk is increased in Crohn's disease, but not in ulcerative collitis. Gut 2000; 46:176-18\#.

13 Crovcher PI, Vedi $s_{3}$ Motley RJ, Garrahan NJ, Stanton MR, Compston JE. Reduced bone fomation in patients with osteoporosis associated with inflammatory bowel disease. Osteoporos Int $1993 ; 3: 236$. 241.

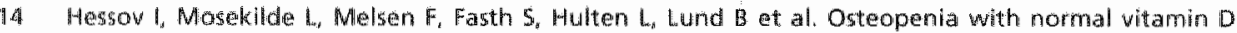
metabolites after smallwowel resection for Crohn's disease. Scand J Gastroenterol 1984; 19: 691696.

15 Driscall RH, Meredith $3 \mathrm{C}$, Sitrin M, Posenberg IH. Witamin D deficiency and bone disease in pathents with Crohn's disease. Gastoenterology 1982; 83: 1252-1258.

16 Eastell $\mathbb{R}$, Bhumsonm A. The value of biochemical markers of bone turnover in osteoporosis. 1. Rhentomatol 1997; 24:1215;1217.

17 Marcus R. Biochemical assessment of bone resorption and formation. Bone 1996; 18:155-165.

18 Silvennomen d, Risteli $L$, Kartunen $T$, Risteli J. Increased degradation of type 1 collagen in patients with infllammatory bowel disease. Gut 1996; 38: 223-228.

19 Schulte C. Dignass AU, Mann K, Goebell H. Reduced bone mimeral density and unbalanced bone metabolism in patientswith inflammatory bowel disease. Inflammatory Bowel Diseases 1998; 4: 268275.

20 DHaens $G$, Verstraete $A$, Cheyns $K$, Aerden $I_{\text {"Bollon }}$ Butgeents $P$. Bone turnover during shortterm therapy with methylorednisolone or budesonide in Crohin"s disease Aliment Pharmacol Ther 1998 s $12: 419-424$

2. Bischoff SC, Hermann A, Gioke M, Manns MP, von-zur MA, Brabant G. Altered bone metabolisim in inflammatory bowel disease. Am J Gastroenterol 1997; 92:1157\%1163.. 
22. Dresner-Pollak R, Karmeli F, Eliakim R, Ackerman Z, Rachmilewitz D. Increased urinary N-telopeptide cross-linked type 1 collagen predicts bone loss in patients with inflammatory bowel disease. Am I Gastroenteroll 2000; 95:699-704.

23 Abitbol $V$. The mechanisms underlying osteopenia in chronic inflammatory bowel disease. Semaine des Hopitaux 1998; 74:1090-1093.

24 Dinca $M$, Fries $W$, Lusetto $G$, Peccolo $F$, Bottega $F$, Leone $\mathbb{L}$ at all. Evolution of osteopenia in inflammatory bowel disease. An $₫$ Gastroenterol 1999; $94: 1292-1297$.

25 Roux C. Abitbol V, Chaussade 5, Kolta 5, Gullemant 5, Douglados M et all. Bone loss ho patients with inflammatory bowel disease: a prospectiwe study. Osteoporos int. 1995, 5:156-160.

26. Ardizzone 5, Bollani 5, Bettica P. Bevilacqua M. Molteni P, Bianchi PG. Altered bone metabolism in inflammatory bowel disease: there is a difference between Crohm's disease and ulceratiwe colitis. I. intern. Med. $2000 ; 247: 63-70$.

27 Robinson R., lqbal 5J, Whitaker RP, Abrams K, Mayberry JF. Rectal steroids suppress bone formation in patients with colitis. Aliment Pharmacol Ther $1997 ; 11201 \% 204$.

28 Schulte $C$, Dignass AU, Mann $K$, Goebell $H$. Sone loss in patients with inflammatory bownel disease is less than expected: a follow-up study. Scand J Gastroenterol 1999; 34: 696-702.

Camalis. E. Clinical review: Mechanisms of glucocorticoid action in bone: implications to glucocorticoid-induced osteoporosis. J Clin Endocrinol Metab 1996; 81:3441-3447.

Eastell R. Maryagment of corticosteroid-inducad osteoporosis. UK Consensus Group Meeting on Osteoporosis. Ilintern Med 1995; 237;439-447.

Adinoff AD, Hollister JR. Steroid-induced fractures and bone loss in patients with asthma. Nangl I Med 1983; 309:265m268.

Issenman RM, Atkinson SA, Radoja C, Fraher L. Longitudimal assessment of growth. mineral metabolism, and bone mass in pediatric Crohn's disease. J Pediatr Gastroenterol Nutr 1993; 17:401. 406 .

Nguyen L, Dewhirst FE, Hauschka PV, 5tashemko P. Interleukin-1 beta stimulates bone resorption and inhibits bone formation in vivo. Lymphokine Cytokine Res 1991; 10:15-21.

Wallach 5, Avioli LV, Feinblatt 1D, Carstens..JH J. Cytokines and bone metabolism. Calcif Tissue Int 1993: $53: 293-296$

35. Hommes DW, van Duliemen $H_{*}$ Radema SA, Tytgat GN, van Deventer SJ. SDe rol wan cytokinen in de pathogenese wan inflammatoire darmziekten. Ned Tijdschir Geneeskd 1994; 138:2427-2432.

Hyams JS, Wyzga $N$, Kreutzer DL, Justinich C, Gronowicz GA. Atterations in bone mevabolism in children with inflammatory bowel disease; an in vitro study. I Pediatr Gastroenterol Nutr 1997: $24: 289 \cdot 295$.

Issenman RM. Bones in Crohn's; cytokines, a missing link? J Pediatr Gastroenterol Nutr 1997; 24:361362.

Silvennoiner JA, Lehtol JK. Niemela SE. Smoking is a risk factor for osteoporosis in women with inflammatory bowel disease. Scand $J$ Gastroenterol 1996: 31:367-371.

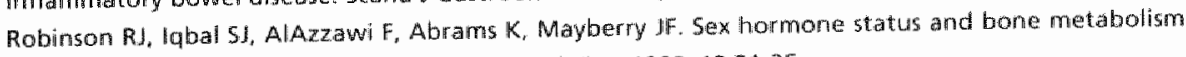
in men with Crohn's disease. Aliment Phamacol Ther 1998; 12:21-25.

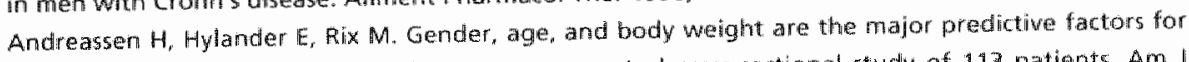
bone mineral density in Crohn's disease: a cace-control cross-sectional study of 193 patients. Am J Gastroenterol 1999:94: 824-828. deficient patients with Crohn's disease. Dig Dis Sci 1989; 34:1094-1099. Silwennoinen J. Relationships between witamin D, parathyroid hammatory bowel disease. IIntern Med 1996; 239:131-137. 
45 Clements D, Motley RI. Evans WD. Harries AD, Rhodes $/$, Colles RI et al. Longitudinal study of cortical bone loss in patients with intiammatory bowel disease. Scand 1 Gastroenter ol 1992: 27:1055 1060 .

Staun M, Tjellesen $L_{*}$ Thate M. Shadit 0 , Jarnum 5 . Bone minerall content in pathents wh Crohn"s disease. A longitudinal study in patients, with bowel resections. Scand I Gastroenterol 1997, 32:226232.

47 Boot AM, Bouquet J! Krenning EP, de MK. Bone mineral density and nutritional status in chitdren with chronic inflammatosy bovel disease. Gut 1998; 42:188-194.

46 Gokhalc R, Fawus M. Karison T, Sutton MM, Rich B, Kirshner BS. Bone mimeral density assesment in chiddren with inflammatory towel disease. Gastroenterology 1998; 114:902-911.

49 Semeao El. Stallings WA, Peck SW, Piccoli DA. Vertebral compression fractures in pediatric patients with Crohn's disease. Castroenterology 1997; 112:1710-1713.

50 Thearle M. Horlick M, Bilezikian JP, Lewy J, Gertmer JM, Levine LS et al. Osteoporosig: an unusual presentation of childhood Crotn's disease. J Clin Endocrimol Metab 2000; 85:2122-2126.

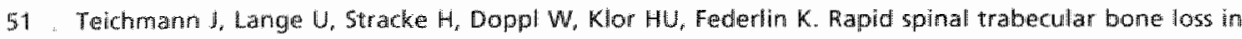
female patients with lleitis terminalis Crohn and additonal sacroiliac joint inflammation. Rheumatol Int 1997; 17:45-48.

52 Vogelsang $H_{n}$ Ferendi P, Resch $H$, Kiss A, Gangl A. Prevention of bone mineral loss in patients with Croinn's disease by long-term aral witamin D supplementation. Eur I Gastroenterol Hepatol 1995: $7.609-614$

53 Clements D, Compstom JE, Evans MD, Rhodes J. Hormone replacement therapy prevents bone loss in patients with infllammatory bowel disease. Gut 1993; 34:1543\% 1546.

54 Bernstein CN, Seeger Lu, Anton PA, Artinian L, Geftrey S, Goodman W et al. A randomized, placebocontrolled trial of calcium supplementation for decreased bone densty in corticosteroid-using patients with inflammatory bowel disease: a pillot study. Aliment Pharmacol Ther 1996; 10:777-786. won Tirpitz $C_{n}$ Klaus J, Bruckel I, Rieber A, Scholer A, Adler G at al Increase of bone mineral density with sodium fluoride in patients with Crohn's disease. Eur 1 Gastroenterol Hepatol 2000; 12:19-24.

Robinson BJ, Krzywick: T, Almond L, AlAzzawi F, Abrams K, labal SI et al. Effect of a low-impact exercise program on bone mineral density in Crohn's disease: A randomized controlled trial. Gastroenterology 1998; 115:36-41.

57 Saag KG, Emkey $R$, Schmitzer $T J$, at Alendronate for the prevention and treatment of glucocorticaid induced osteoporosis. N Engll Med 1998; 339:292 299.

58 Marshall $\mathrm{D}$, Johnell $\mathrm{O}$. Wedel $\mathrm{H}$. MMeta-analysis of how well measures of bone mineral density predict occurrence of osteoporotic fractures. BMJ 1996; 312:1254-1259.

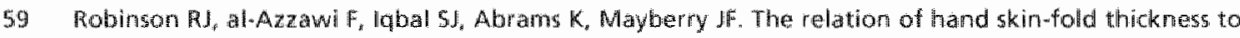
bone mineral density in patient's with Crohn's disease. Eur I Gastroenterol Hepatol 1997; 9:945-949.

60 Robinson R. Carr I, lqbal st, Al Azzawi F, Abrams K, Mayberry JF. Screening for asteoporosis in Crohn's disease. A detailed evaluation of calcaneal wltrasound. Eur \& Gastroenterol Hepatol 1998; 10 : H37-140.

b) Fries W, Dinca M. Luisetto G. Peccolo Fy bottega F. Martin A. Calcaneal ultrasound bone densitometry in inflammatory bowel disease-wa comparison with dowble way densitometry of the lumbar spime. Am J Gastroenterol 1998; $93: 2339-2344$.

62 Compston JE. Detection of osteoporosis in patients with inflammatory bowell disease. Eur 1 Gastroenterol Hepatol 1997; 9.931-933. 


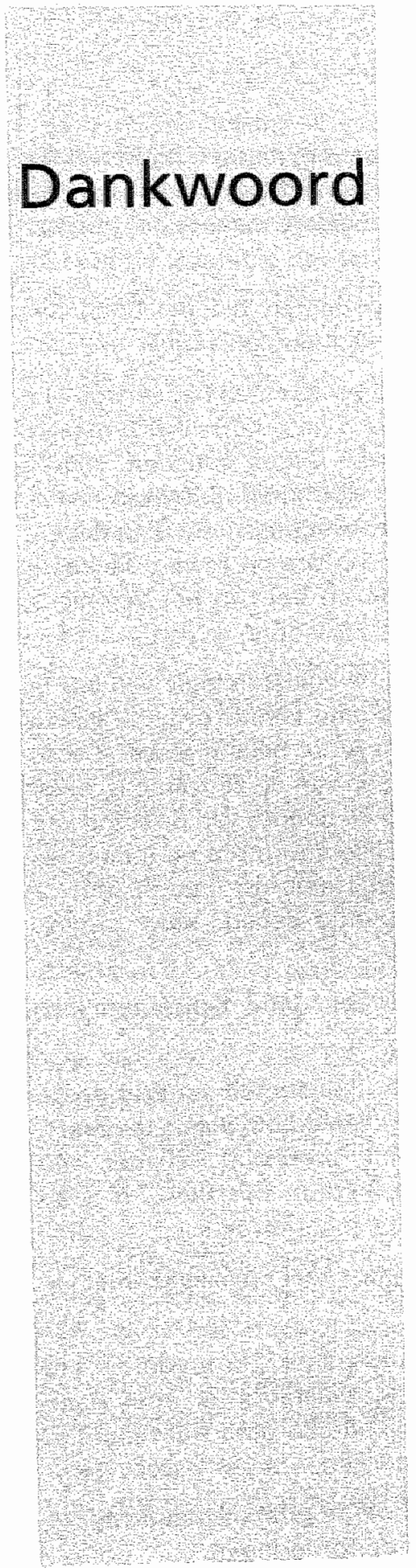




\section{Dankwoord}

Het maken van een proefschrift, is een werk waar zeer veel mensen bij betrokken zijn. Niet iedereen die een steentje heeft bijgedragen aan het tot stand komen van dit proefschrift kan ik dan ook in dit dankwoord vermelden, maar ik zal trachten de belangrijkste hiervan te noemen.

Allereerst will ik mijn respect uitspreken voor de patiënten die meedoen aan onderzorek waar voor henzelf de voordelen niet altijd even duidelijk zijn.

Reinhold Stockbrügger. Mede door jouw stimulerende krachten en het vertrouwen dat je mij schonk, je analytische denkwijze en werklust is dit proefschrift ontstaan. Alle manuscripten werden minitieus van opbouwende kritiek voorzien. Hierbij werd het gebruik diverse communicatiemiddelen niet geschuwd. Ik ben je tevens erkentelijk voor de gastroenterologie opleiding en de vaste plaats die ik in de staf kreeg. Eén van de hoogtepunten vind ik het diner in Ferrara en ik ben dankbaar voor die gastwrijheid. Ik vind dat jij de enige Europeaan bent in het verenigde Europa die het predikaat Europeaan verdient.

Maurice Russel. Jouw pionierswerk op het gebied van de epidemiologie van IBD in Limburg en de daarbijbehorende registratie en opgedane kennis over de ziekte van Crohn en colitis ulcerosa in het allgemeen, zijn van groot belang geweest voor dit onderzoek. Ondanks dat het "botten"-onderzoek een van de zijstraten is, bleef je enthousiast over de ideeën en stelde je wekelijks op de hoogte van de stand van zaken. Als vrienden hebben we vele gemeenschappelijke interessen en indien we wat meer tijd hadden om samen te fietsen door het Limburgse heuvelland (of elders) dan hadden we tenminste... een betere conditie gehad. Jouw organisatietalent belooft een goede toekomst.

Robert-Jan Brummer wil ik graag bedanken voor het begeleiden en becommentarieren van de "metabiole" stukken.

Beoordelingscommissie. Prof.dr. E.M. Wouters, Prof.dr. P.B. Soeters en Prof.dr. Sj. van der Linden dank ik woor hun werk en hun bereidwilligheid om plaats te nemen in de beoordelingscommissie. I would like to thank professor Hanauer and professor Bianchi Porro for their willingness to participate in this thesis. It is an honor for me to have you in the board

Professor H.F.P. Hillen, beste Harry, ik heb 12 jaar zeer plezierig met je samengewerkt.

Bertine Geerling zag het voordeel om het voedingsonderzoek "in brede zin" te verrichten en verzamelde een schat aan gegevens, waarvoor ik veel dank verschuldigd ben. Mijn promotie werd reeds in je bekende kordate stijl tijdens je verdediging aangekondigd.

Rene Wouters liet voor mij een fantastisch onderwerp om te promoveren achter in Maastricht en bleef van een afstand interesse tonen in de vorderingen. 
Bruce Wolfenbuttel will ik bedanken voor de adviezen met name in de beginfase van het onderzoek en ook zeker het advies om eens contact op te nemen met cees vermeer.

Cees Vermeer bedank ik voor zijn expertise en de mogelijkheden om samen te werken met de afdeling biochemie van de Universiteit Maastricht. Leon Schurgers voor de buitengewoon plezierige samenwerking en de interesse voor het patiëntgebonden onderzoek. Met onze gemeenschappelijke theorieën zaten we zeker in de frontlinie van het bottenonderzoek en verder.... Succes met de laatste loodjes van jouw proefschrift.

Afdeling Nucleaire geneeskunde. Ing-ham Liem zag tijdens een voor hem zeer drukke periode nog kans om te helpen om vele DEXA's te re-analyseren met behulp van de nieuwste software. De DEXA laboranten en met name Lia van lersel wil ik bedanken voor de betrokkenheid bij dit onderzoek.

Piet Geusens voor het delen van het enthousiasme voor botten en het daaraan gerelateerde onderzoek.

Petra Koken en Reini Bretveld voor de onmisbare hulp bij de statistische analyses.

Het Maastrichtse onderwijssysteem biedt studenten al vroeg de mogelijkheid om in het onderzoek te participeren, hieraan heb ik veel plezier beleefd. Vrijwel alle onze project-aanvragen werden in eerste instantie door de stagecommissie van de faculteit afgewezen. De studenten raakten hierdoor gelukkig nog meer gemotiveerd. Annick van Nunen maakte de eerste database, verrichtte veel werk aan hoofdstuk 3 en 4 en is nu ook zelf bijna gepromoveerd. Barbara Blok heeft de Parke-Davis studentenprijs gewonnen op de Nederlandse vereniging voor Gastroenterologie voor haar werk aan hoofdstuk 5. Marcella Müller won de tweede prijs in het internationale Maastrichtse wetenschappelijk symposium woor studenten met haar werk aan hoofdstuk 6 . Verder wil ik graag Ivo van Dooren bedanken woor het werk aan hoofdstuk 7. Froukje Verstraeten dank ik voor het werk aan de follow-up data.

René van Oerle. Door het verfraaien van de grafieken gingen meerdere editors direct overstag.

Pamela Falger en Barbara Ryan. Dank voor de sympathieke correctie van de Engelse taal.

Collega's gastroenterologen. Wim Hameeteman, Peter Houben, Boudewijn Loffeld, Rob Adang, Ton Vrij en Ger Koek will ik bedanken voor de uitermate plezlierige samenwerking en de collegialiteit. Voor Anmemarie Wensing, Frank Wolters en Marc de Bièvre verwacht ik een goede toekomst

IBD researchstaf. Martine van der Kruijs, Ingrid van der Eijk en Daisy Jonkers wil ik bedanken voor de goede spirit in het IBD-team.

Tiny Wouters heeft een hoofdrol gespeeld in de laatste fase van het proefschrift. Jouw inzet hiervoor is dan ook niet te beschrijven; zelfs in het weekend werd 
zonodig doorgewerkt. De planning werd zorgvuldig bewaakt. Tiny, we zullen het op z'n Limburgs eens goed gaan vieren!

Paranimfen Bas Oldenburg en Cees Mosch voor hun vriendschap en de bereidheid deze taak op zich te nemen. Beste Bas, de gelijkenis tussen onze medische carrières moet op zuiver toeval berusten! Cees kwam ik op dag 1 van de studie Geneeskunde tegen op het faculteitsbureau aan de Catharijnesingel in Utrecht. We hebben toen dezelfde middag "onze eerste patiênt" bezocht. Deze patient had toevallig de ziekte van Crohn.

Pieter Blaauw, mijn schoonvader, voor het minutieus doornemen van het gehele proefschrift en de goede adviezen.

Mijn ouders wil ik bedanken voor alle liefde, het vertrouwen en de mogelijkheden om mij verder te kunnen ontwikkelen.

Lieve Gabrielle, het is voor elkaar. Dit boek is uit. Ik hoop dat er ons nog vele hoofdstukken gegeven zijn. Jouw rol achter de schermen is groots. Folkert en Veerle, danzij jullie leer ik iedere avond naast liedjes, versjes en "Mestreechs" ook over dinosauriërs, apen en krokodillen. Karlijn, jouw vrolijkheid is ontroerend. Ik ben trots op jullie! 


\section{Curriculum Vitae}




\section{Curriculum Vitae}

De auteur van dit proefschrift werd geboren in 1960 in Dordrecht. In 1989 behaalde hij zijn WWO diploma aan het Titus Brandsma College in Dordrecht. Door uitlotingen voor de studie geneeskunde studeerde hij eerst twee jaar scheikunde aan de rijksuniversiteit van Utrecht. In 1981 begon hij met de studie geneeskunde te Utrecht. In 1988 werd het artsexamen afgelegd. Na een korte periode als agnio op de afdeling interne geneeskunde in het academisch ziekenhuis te Maastricht en in het Catharina ziekenhuis te Eindhoven, startte hij in 1990 in Eindhoven met de specialisatie interne geneeskunde (opleider dr. H.F.P. Hillen). In 1993 werd deze opleiding in het academisch ziekenhuis te Maastricht vervolgd (opleiders: prof.dr. J.A. Flendrig", prof.dr. A. Nieuwenhuizen Kruseman en prof.dr. H.F.P. Hillen). De registratie tot internist volgde op 1 januari 1996 waarna direct aangevangen werd met de opleiding tot gastroenteroloog in het academisch ziekenhuis te Maastricht (opleider: prof.dr. R.W. Stockbrügger) en registratie volgde op 1 januari 1999. Tijdens de opleiding gastroenterologie werd gestart met de voorbereidingen van het wetenschappelijk onderzoek beschreven in dit proefschrift. In 1998 werd hij aangesteld als staflid bij de werkgroep maag/darm en leverziekten van het academisch ziekenhuis te Maastricht (hoofd: prof.dr. R.W. Stackbrügger). Vanaf oktober $2001 \mathrm{zal}$ de loopbaan verwolgd worden als maag/darm- en leverarts in het Catharina ziekenhuis te Eindhoven.

In 1992 is hij gehuwd met Gabrielle Blaauw. Samen hebben ze drie kinderen: Folkert (1995), Veerle (1996) en Karlijn (1999). 